Modelling of

Ammonila V/olati,ilisati,ion in Fertilised and Flooded Rice Systems
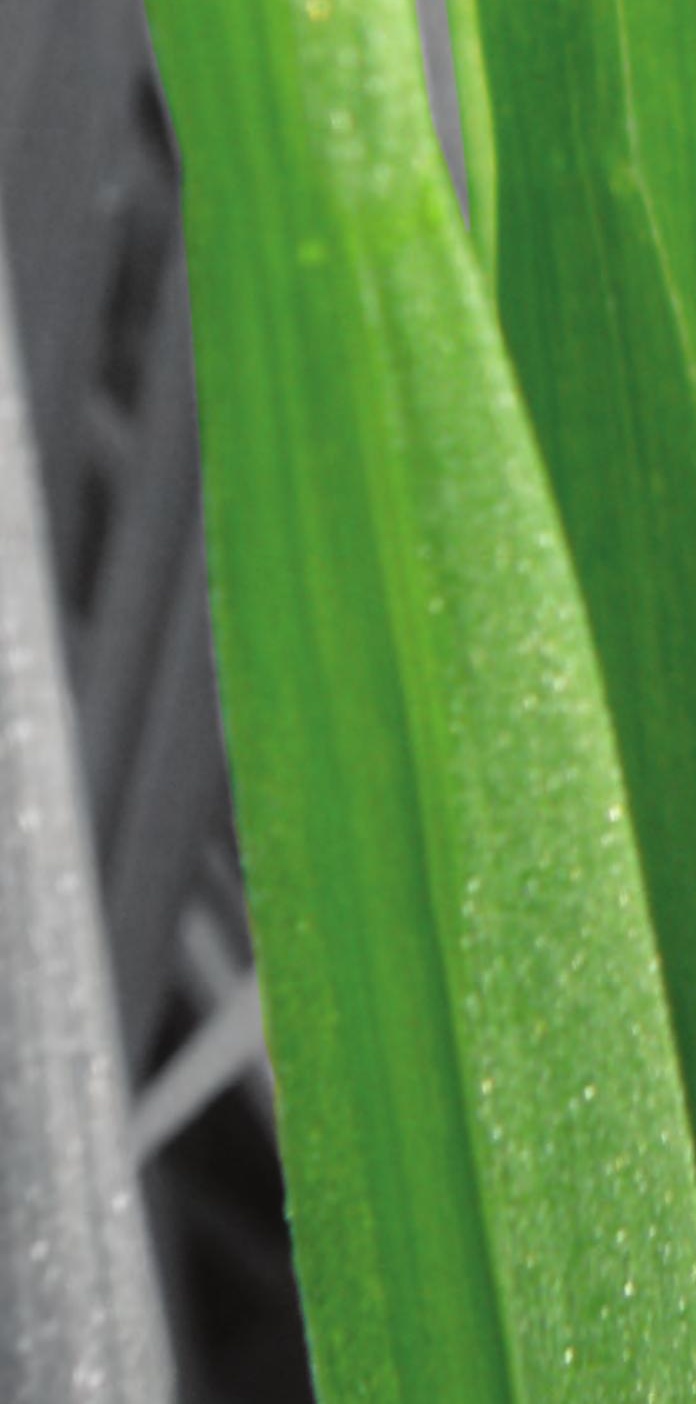



\section{Modelling of ammonia volatilisation in fertilised and flooded rice systems}




\section{Thesis committee}

\section{Promotor}

Prof. Dr P.C. Struik

Professor of Crop Physiology

Wageningen University \& Research

\section{Co-promotors}

Dr K.J. Keesman

Associate professor, Biobased Chemistry and Technology

Wageningen University \& Research

Prof. Dr Mohamad Pauzi Zakaria

Associate member, Institute of Ocean and Earth Sciences

University of Malaya, Malaysia

\section{Other members}

Prof. Dr O. Oenema, Wageningen University \& Research

Prof. Dr J.W. Erisman, VU University Amsterdam

Prof. Dr J. Molenaar, Wageningen University \& Research

Prof. Dr E. Hoffland, Wageningen University \& Research

This research was conducted under the auspices of the Graduate School SENSE (SocioEconomic and Natural Sciences of the Environment) 


\section{Modelling of ammonia volatilisation in fertilised and flooded rice systems}

\section{Nurulhuda Khairudin}

Thesis

submitted in fulfillment of the requirements for the degree of doctor

at Wageningen University

by the authority of the Rector Magnificus,

Prof. Dr A.P.J. Mol,

in the presence of the

Thesis Committee appointed by the Academic Board

to be defended in public

on Wednesday 15 March 2017

at 4 p.m. in the Aula. 
Nurulhuda Khairudin

Modelling of ammonia volatilisation in fertilised and flooded rice systems, 209 pages.

PhD thesis, Wageningen University, Wageningen, the Netherlands (2017)

With references, with summary in English

ISBN: 978-94-6257-669-8

DOI: http://dx.doi.org/10.18174/402053 


\section{Abstract \\ Modelling of ammonia volatilisation in fertilised and flooded rice systems}

In flooded rice systems that are broadcast with urea, significant amounts of nitrogen $(\mathrm{N})$ may be lost to the atmosphere in the form of ammonia $\left(\mathrm{NH}_{3}\right)$. Many models with different complexities with regards to describing the process of $\mathrm{NH}_{3}$ volatilisation and the overall $\mathrm{N}$ dynamics in the systems are available. However, given the differences in local conditions, both too simple and too complex models may not be able to predict $\mathrm{NH}_{3}$ volatilisation correctly or may lead to large prediction uncertainties. Therefore, the main objective of this thesis is to provide a framework to determine an appropriate process-based model with corresponding uncertainty characteristics for estimating $\mathrm{NH}_{3}$ volatilisation in fertilised and flooded rice systems.

As a first step in the selection of a model for a specific application, an overview on the modelling concepts and the performance of 14 models developed to simulate $\mathrm{N}$ dynamics in flooded soil systems is given. Next, in order to understand differences in modelling concepts for a specific process, co-validation was conducted at single process level: urea hydrolysis, $\mathrm{NH}_{3}$ volatilisation, and floodwater $\mathrm{pH}$. Then, a new process-based model for estimating $\mathrm{NH}_{3}$ volatilisation in fertilised and flooded rice systems, which is of a complexity appropriate for scarce soil $\mathrm{N}$ data, is presented and evaluated with field observations. For the flooded rice systems in the Philippines, conceptualisation of the two-step urea hydrolysis, partitioning between ammonium and $\mathrm{NH}_{3}$, and a time-varying rate coefficient of $\mathrm{NH}_{3}$ volatilisation in the proposed model improved the prediction of the net $\mathrm{NH}_{3}$ loss. Subsequently, a set-membership parameter estimation approach with soft-error-bounds was used to characterise the uncertainty in the parameter estimates in the proposed model. The set-membership approach is appropriate for poor quality data sets as it allows simultaneous consideration of the different sources of uncertainty affecting the model prediction, such as uncertainty in the model structure, parameters, and observations. Findings of this study can be used as criteria for stakeholders to make an informed selection of models, to modify the existing models for a specific purpose, and to interpret model-output responses critically.

Keywords: ammonia volatilisation, nitrogen, flooded soil, flooded rice, dynamic modelling, parameter estimation, set-membership 



\section{Nomenclature}

\begin{tabular}{|c|c|}
\hline $\mathrm{C}$ & Carbon \\
\hline CEC & Cation exchange capacity \\
\hline $\mathrm{CO}_{2}$ & Carbon dioxide \\
\hline DAT & Days after transplanting \\
\hline FPS & Feasible parameter-vector set \\
\hline $\mathrm{N}$ & Nitrogen \\
\hline $\mathrm{N}_{2}$ & Dinitrogen \\
\hline $\mathrm{NH}_{3}$ & Ammonia \\
\hline $\mathrm{NH}_{4}^{+}$ & Ammonium \\
\hline $\mathrm{NO}_{2}^{-}$ & Nitrite \\
\hline $\mathrm{NO}_{3}^{-}$ & Nitrate \\
\hline NO & Nitric oxide \\
\hline $\mathrm{N}_{2} \mathrm{O}$ & Nitrous oxide \\
\hline $\mathrm{O}_{2}$ & Oxygen \\
\hline $\mathrm{P}$ & Phosphorus \\
\hline
\end{tabular}

PAB Photosynthetic aquatic biomass (i.e., algae) 



\section{Table of contents}

Chapter 1

Chapter 2

Chapter 3

Chapter 4

Chapter 5

Chapter 6

Summary

Glossary

Acknowledgements

General discussion volatilisation systems overview of concepts and performance of models

A model study of urea hydrolysis and ammonia

Process-based dynamic model for predicting ammonia 109 volatilisation in fertilised and flooded rice systems

Set-membership estimation from poor quality data sets: Modelling ammonia volatilisation in flooded rice

About the author

List of publications

SENSE diploma 207

Funding 209 

CHAPTER 1

General Introduction

K. Nurulhuda 


\subsection{General Introduction}

Rice is staple food for more than half of the world's population (Redfern et al., 2012). In 2012, about 156 million ha of rice were harvested worldwide, and about $88 \%$ and $31 \%$ of the global harvested area were in Asia and South East Asia, respectively (FAO, 2013). About $95 \%$ of global rice production occurs on soil that is flooded during at least part of the rice-cropping period (Buresh et al., 2008).

In South East Asia, rice is mainly cultivated by smallholder farmers, on harvested area of typically less than 4 ha per farmer (Hossain and Fischer, 1995, Molle and Srijantr, 2000, Estudillo and Otsuka, 2006, Aimrun et al., 2011, Kamaruddin et al., 2013). Rice cultivation is one of the central subjects of the economic policy and factors in national objectives in South East Asia (Redfern et al., 2012, Kamaruddin et al., 2013).

Nitrogen $(\mathrm{N})$ deficiency results in severe yield losses, hence, $\mathrm{N}$ is considered as one of the most important nutrients for rice crops (De Datta, 1986, Sinclair and Jamieson, 2006, Makino, 2011). Although $78 \%$ of the atmosphere is composed of dinitrogen $\left(\mathrm{N}_{2}\right)$, it is neither in a chemically nor a biologically usable form, because of the strong triple bond (Galloway et al., 2004). Unlike the non-reactive $\mathrm{N}_{2}, \mathrm{~N}$ in the form of ammonia $\left(\mathrm{NH}_{3}\right)$ is reactive and can be utilised as a source of $\mathrm{N}$ fertiliser.

In the early 20th century, Fritz Haber invented the Haber-Bosch process to produce $\mathrm{NH}_{3}$ by reacting atmospheric $\mathrm{N}_{2}$ with hydrogen in the presence of iron at high pressure, approximately $20 \mathrm{MPa}$, and high temperature, between $400{ }^{\circ} \mathrm{C}$ and $500{ }^{\circ} \mathrm{C}$ (Erisman et al., 2008, Zuberer, 2005). This process consumes a lot of energy: about 875 cubic meters of natural gas is used to fix one metric tonne of $\mathrm{NH}_{3}$ (Zuberer, 2005). About $80 \%$ of the total $\mathrm{N}$ manufactured via the Haber-Bosch process is used for producing agricultural fertilisers (Erisman et al., 2008). Of the total agricultural fertilisers produced, it is estimated that $14 \%$ is used for rice production in the year 2010/11, comparable to the amount required for wheat (Heffer, 2013).

\subsection{Characteristics of flooded rice systems}

In Asia, flooded rice systems may have three distinct soil layers: plough, hard pan, and subsoil layers (Fig. 1). Hard pan is developed between the plough and subsoil layers, and is 
found between $0.10 \mathrm{~m}$ to $0.30 \mathrm{~m}$ from the ground surface (Kundu and Ladha, 1999, Chen and Liu, 2002, Aimrun and Amin, 2009).

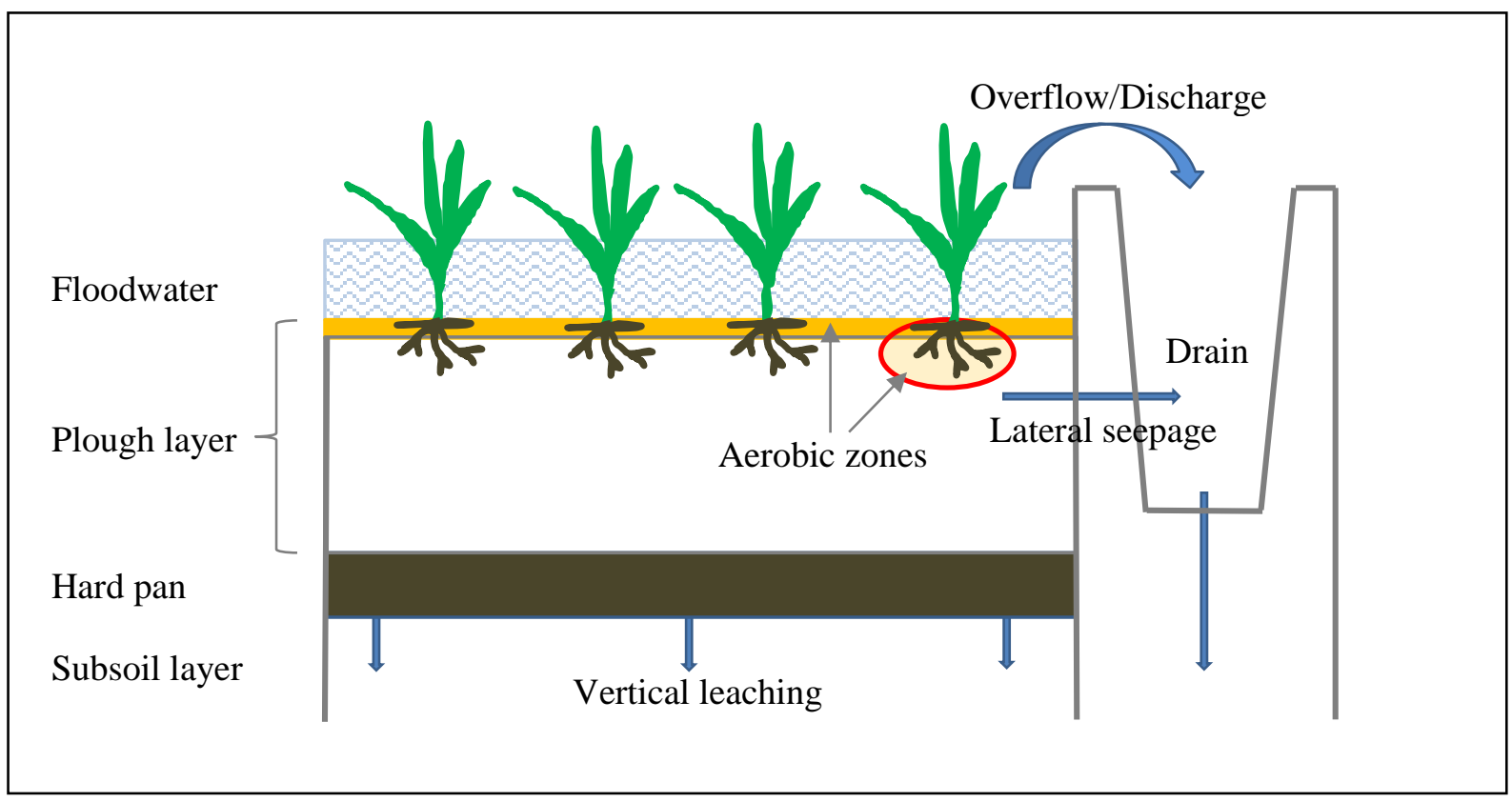

Fig. 1 General characteristic of flooded rice systems

The hard pan is formed in two ways; physical compaction due to repeated puddling of the plough layer, which is then followed by use of heavy machineries, or chemical precipitation of ferum, manganese, and silica (Sharma and De Datta, 1986). The hard pan has the lowest permeability compared to the other two layers, and, therefore, regulates the percolation rates in flooded rice systems (Aimrun and Amin, 2009). The hard pan may also restrict growth of rice roots beyond the layer (Aimrun and Amin, 2009).

The overall percolation rate in flooded rice systems is site specific, ranging from $1 \mathrm{~mm}$ day $^{-1}$ to as high as $30 \mathrm{~mm} \mathrm{day}^{-1}$ (Sharma and De Datta, 1986, Nakasone et al., 2004, Tsubo et al., 2005, Aimrun et al., 2010). Additionally, lateral seepage through the adjacent bund in flooded rice systems is also reported (Liang et al., 2014).

In flooded rice systems, penetration of oxygen $\left(\mathrm{O}_{2}\right)$ is reported only in the upper $1 \mathrm{~mm}$ to 6 $\mathrm{mm}$ of the plough layer (Liesack et al., 2000, Nicolaisen et al., 2004). The limited $\mathrm{O}_{2}$ penetration creates the thin aerobic layer at the surface of the plough layer (Patrick and Reddy, 1976, Reddy, 1982, Liesack et al., 2000). The plough layer is mainly anaerobic as $\mathrm{O}_{2}$ in the layer rapidly depletes due to greater consumption of $\mathrm{O}_{2}$ by the crop and microbial activity compared to the renewal rate of $\mathrm{O}_{2}$ through the floodwater (Reddy, 1982, Liesack et 
al., 2000). Additionally, micro aerobic zones are formed within the rhizosphere in the plough layer, due to active release of $\mathrm{O}_{2}$ by rice roots (Patrick and Reddy, 1976, Liesack et al., 2000, Nicolaisen et al., 2004, Kirk and Kronzucker, 2005). The characteristics of flooded rice systems described in this section affect the $\mathrm{N}$ pathways in the system.

\subsection{Nitrogen cycles in fertilised and flooded rice systems}

In addition to applied synthetic $\mathrm{N}$, rice crops may obtain $\mathrm{N}$ via $\mathrm{N}_{2}$ biological fixation and organic $\mathrm{N}$ mineralisation (Ladha and Reddy, 2003). The rice crop absorbs $\mathrm{N}$ in the form of dissolved ammonium $\left(\mathrm{NH}_{4}{ }^{+}\right)$or nitrate $\left(\mathrm{NO}_{3}{ }^{-}\right)$that are present within the rice crop root zone (Kirk and Kronzucker, 2005, Brady and Weil, 2008). In addition, the $\mathrm{NH}_{4}{ }^{+}$or $\mathrm{NO}_{3}{ }^{-}$may undergo other pathways such as $\mathrm{NH}_{3}$ volatilisation, simultaneous nitrification and denitrification, leaching, dissimilatory $\mathrm{NO}_{3}{ }^{-}$reduction to $\mathrm{NH}_{4}{ }^{+}$, and immobilisation of $\mathrm{N}$ (Patrick and Reddy, 1976, Reddy, 1982) (Fig. 2).

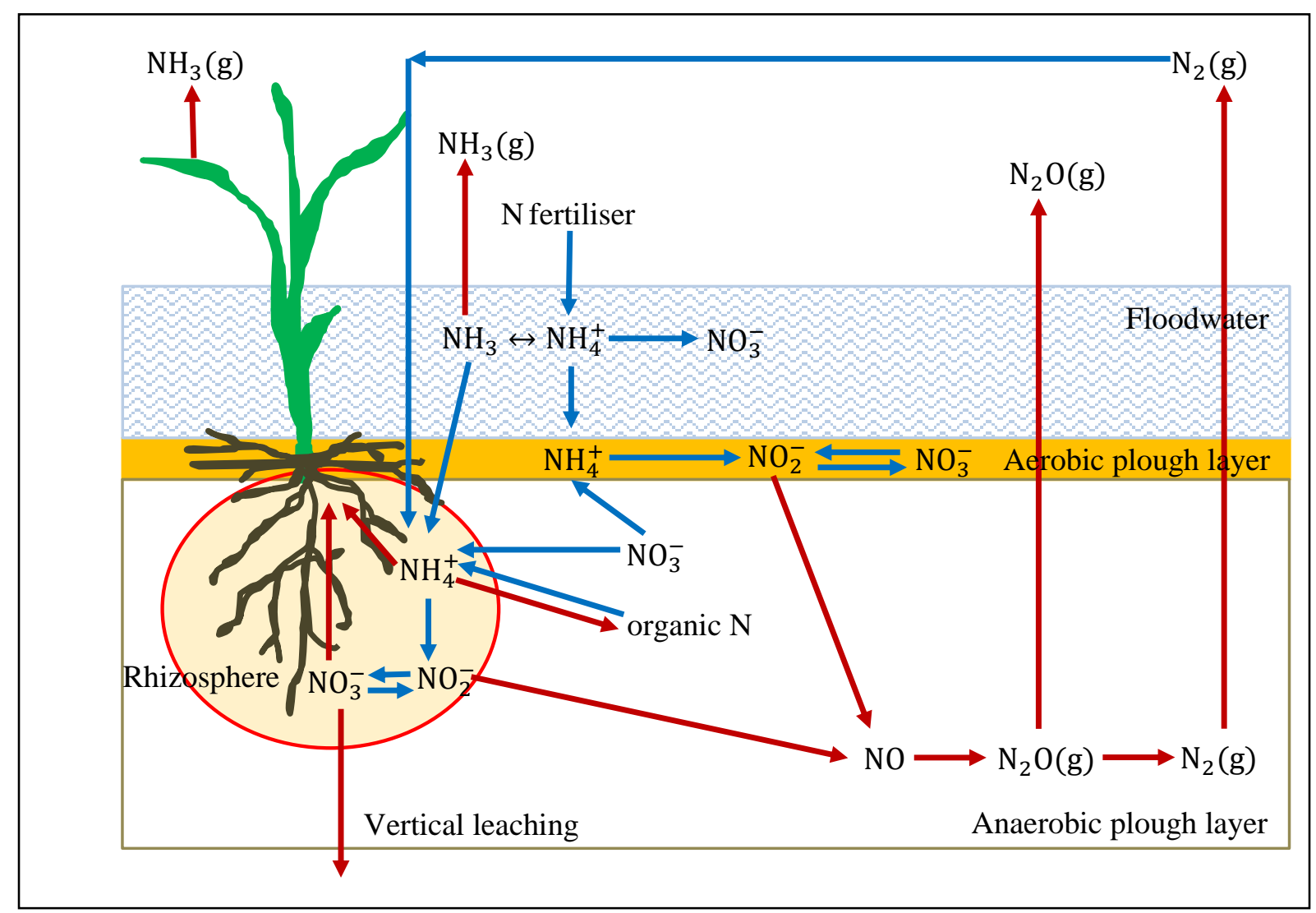

Fig. 2 Diagrammatic representation of possible $\mathrm{N}$ pathways in fertilised and flooded rice systems. Adapted from Reddy (1982), Jetten (2008), and Ward (2012). Red arrows indicate pathways of $\mathrm{N}$ sinks in the systems 
In flooded rice systems, $\mathrm{NH}_{3}$ volatilisation is, in general, claimed to occur from the floodwater surface (Section 1.6). Nitrification is oxidation of $\mathrm{NH}_{4}{ }^{+}$to $\mathrm{NO}_{3}{ }^{-}$, and, therefore it occurs in any of the three aerobic zones: the floodwater, the thin aerobic plough layer, or the rhizosphere (Reddy, 1982, Rao et al., 1984). Denitrification is reduction of $\mathrm{NO}_{3}{ }^{-}$that results in $\mathrm{N}_{2} \mathrm{O}$ as the intermediate product, and $\mathrm{N}_{2}$ as the final product, and therefore takes place within the anaerobic plough layer (Reddy, 1982). Dissimilatory $\mathrm{NO}_{3}{ }^{-}$reduction to $\mathrm{NH}_{4}{ }^{+}$also occurs in the anaerobic plough layer, and this process may limit the amount of $\mathrm{NO}_{3}{ }^{-}$available for denitrification (Buresh and Patrick, 1978, Yin et al., 2002). In addition, anaerobic $\mathrm{NH}_{4}{ }^{+}$ oxidation (Anammox), where $\mathrm{NO}_{2}{ }^{-}$and $\mathrm{NH}_{4}{ }^{+}$are directly converted into $\mathrm{N}_{2}$, was recently reported in flooded rice soil systems (Zhu et al., 2011).

The transport of $\mathrm{NH}_{4}{ }^{+}$and $\mathrm{NO}_{3}{ }^{-}$between the floodwater and soil occurs by either diffusion or mass transfer with percolated water (Reddy, 1982). Unlike the positively charged $\mathrm{NH}_{4}^{+}$, which may bind with the negatively charged clay particles, the negatively charged $\mathrm{NO}_{3}{ }^{-}$is susceptible to leaching (Reddy, 1982).

\subsection{Synthetic nitrogen fertiliser types and application methods in flooded rice systems}

Synthetic $\mathrm{N}$ fertilisers can be of several forms: urea, $\mathrm{NO}_{3}{ }^{-}, \mathrm{NH}_{4}{ }^{+}$, or a combination of $\mathrm{NO}_{3}{ }^{-}$ and $\mathrm{NH}_{4}{ }^{+}$(e.g., potassium nitrate, ammonium sulphate, and ammonium nitrate). Due to pricy ammonium sulphate in the current market and potential use of ammonium nitrate as explosive, urea $\left(\mathrm{CO}\left(\mathrm{NH}_{2}\right)_{2} ; 460 \mathrm{~g} \mathrm{~N} \mathrm{~kg}^{-1}\right)$ remains the primary source of $\mathrm{N}$ fertiliser in the market (Soares et al., 2012).

$\mathrm{NO}_{3}{ }^{-}$based fertilisers are not recommended in flooded rice systems due to potential $\mathrm{N}$ loss through denitrification in the anaerobic plough layer (Reddy, 1982). In flooded rice systems, urea continues to be the primary source of synthetic $\mathrm{N}$. The conventional method for application is via broadcast of granular urea on the floodwater. Once urea is broadcast on the floodwater, urea is hydrolysed into $\mathrm{NH}_{4}{ }^{+}$, and the chemical equations are as follows (Palanivell et al., 2015):

$$
\begin{aligned}
& \left(\mathrm{NH}_{2}\right)_{2} \mathrm{CO}+2 \mathrm{H}_{2} \mathrm{O} \stackrel{\text { urease }}{\longrightarrow}\left(\mathrm{NH}_{4}\right)_{2} \mathrm{CO}_{3} \\
& \left(\mathrm{NH}_{4}\right)_{2} \mathrm{CO}_{3}+2 \mathrm{H}^{+} \rightarrow 2 \mathrm{NH}_{4}^{+}+\mathrm{CO}_{2}+\mathrm{H}_{2} \mathrm{O}
\end{aligned}
$$


However, global estimates indicated that fertiliser $\mathrm{N}$ recovery by rice crop averages $46 \%$ in rice systems (Ladha et al., 2005). In order to minimise loss of $\mathrm{N}$ to the environment (Section 1.5), different fertiliser technologies were developed and tested in order to increase retention time of $\mathrm{N}$ in the rice systems, which allow the rice crop to absorb the released N. Among the technologies tested were split $\mathrm{N}$ fertiliser application, use of coated $\mathrm{N}$ fertilisers, use of specific enzyme inhibitors, deep placement of $\mathrm{N}$ fertiliser, and incorporation of $\mathrm{N}$ fertiliser into the soil via puddling (Vlek et al., 1980a, Vlek et al., 1980b, Craswell et al., 1981, Cao et al., 1984, Buresh et al., 1988, De Datta et al., 1988, Yang et al., 2013, Peng et al., 2015, Liu et al., 2015).

\subsection{Overall nitrogen losses in fertilised and flooded rice systems}

Table 1 shows the percentages of $\mathrm{N}$ loss via three major pathways in fertilised and flooded rice systems. The table demonstrates that $\mathrm{N}$ loss via $\mathrm{NH}_{3}$ volatilisation, denitrification and $\mathrm{NO}_{3}{ }^{-}$ leaching in fertilised and flooded rice systems are equally important ranging from negligible to about $50 \%$ or $60 \%$ of total $\mathrm{N}$ applied.

Table 1 Pathways of $\mathrm{N}$ in fertilised and flooded rice systems

\begin{tabular}{ll}
\hline $\mathbf{N}$ pathway & N loss of total N applied \\
\hline $\mathrm{NH}_{3}$ volatilisation & Negligible to $60 \%$ (Fillery et al., 1984, Fillery et al., 1986, Hayashi et al., \\
& 2006, Lin et al., 2007, Liang et al., 2014, Chen et al., 2015) \\
Denitrification & Negligible to $50 \%$ (Buresh and De Datta, 1990, Freney et al., 1990) \\
$\mathrm{NO}_{3}^{-}$leaching & Negligible to $60 \%$ (Peng et al., 2015) \\
$\mathrm{N}$ uptake by rice crop & 35 to 50\% (De Datta et al., 1991, Liang et al., 2014, Fageria et al., 2014) \\
\hline
\end{tabular}

In the following, each of the pathways is discussed in more detail. Firstly, ammonia $\left(\mathrm{NH}_{3}\right)$ volatilisation from the floodwater is claimed as one of the major pathways of $\mathrm{N}$ losses in fertilised and flooded rice systems, when urea is broadcast on the floodwater and not followed with incorporation of the urea into the soil (Fillery et al., 1984, Fillery et al., 1986, Freney et al., 1990, Buresh et al., 2008). In the year 1995, about $20 \%$ of the 11.8 million tons of synthetic $\mathrm{N}$ yearly applied in flooded rice fields globally was estimated to be lost via $\mathrm{NH}_{3}$ volatilisation (Bouwman et al., 2002). In addition to economic losses, $\mathrm{NH}_{3}$ volatilisation from fertilised and flooded rice systems has negative effects on the environment, for instance acid rain and global warming (Sommer et al., 2004), and was also recently reported a potential concern in public health as $\mathrm{NH}_{3}$ reacts with other air pollutants to create tiny particles that can lodge in the lungs (Stokstad, 2014). In Sections 1.6 and 1.7, details on mechanisms of $\mathrm{NH}_{3}$ gas exchange in 
crop systems and sources of variation in observations of $\mathrm{NH}_{3}$ flux, respectively, are further discussed.

Secondly, the rate of denitrification is limited by the rate of nitrification (Section 1.3). The rates of these processes are likely to be site specific and depend on the population of microbes and irrigation practice. Accurate measurement of denitrification in the field is difficult because the final product is $\mathrm{N}_{2}$, and, thus, cannot be easily distinguished from the $\mathrm{N}_{2}$ that is naturally present in the atmosphere (De Datta et al., 1991, Groffman et al., 2006). Moreover, $\mathrm{N}_{2}$ may also be released via Anammox (Zhu et al., 2011). Nevertheless, high rate of $\mathrm{N}$ loss via denitrification is observed to occur in rice systems with intermittent flooding management (Akiyama et al., 2005, Zhao et al., 2011, Linquist et al., 2012). In continuously flooded soil, $\mathrm{N}$ loss via denitrification may be assumed negligible as nitrification may be limited. However, by running a semiphysical model, Kirk and Kronzucker (2005) suggested that nitrification occurs in the rhizosphere under flooded condition, but the $\mathrm{NO}_{3}{ }^{-}$resulting from the nitrification is quickly absorbed by rice roots.

Thirdly, leaching is suggested to be limited to $\mathrm{N}$ in the form of $\mathrm{NO}_{3}{ }^{-}$(Section 1.3). In flooded soils, $\mathrm{NO}_{3}{ }^{-}$leaching is regulated by saturated hydraulic conductivity, which is dependent on the soil type and texture, and may range from $1 \mathrm{~mm} \mathrm{day}^{-1}$ to $20 \mathrm{~mm} \mathrm{day}^{-1}$ (Aimrun et al., 2007).

Which of the three $\mathrm{N}$ pathways contributes to $\mathrm{N}$ losses appears to be dependent on physical and chemical properties of floodwater and soil, and the practised $\mathrm{N}$ and irrigation managements. Trade-off between these major pathways was also observed. For instance, Freney et al. (1990) demonstrated that when the rate of $\mathrm{NH}_{3}$ volatilisation was reduced by incorporating urea into the soil, the rate of nitrification increased. A low hydraulic saturated conductivity may cause accumulation of total ammoniacal- $\mathrm{N}$ in the floodwater after $\mathrm{N}$ application, which may be susceptible to $\mathrm{NH}_{3}$ volatilisation. These trade-off mechanisms may contribute to variation of $\mathrm{N}$ loss for all three $\mathrm{N}$ processes (Table 1). Other factors that could contribute to the large variations of $\mathrm{N}$ losses include the types of $\mathrm{N}$ fertiliser applied, rates, timing and methods of $\mathrm{N}$ fertiliser application, irrigation practices, methods of rice crop planting, or methods of measurements.

\subsection{Mechanisms of ammonia gas exchange in crop systems}

In order to infer the sinks and sources of $\mathrm{NH}_{3}$ in arable crop systems, the models that describe 
the process of canopy gas exchange and the inverse Lagrangian analysis were proposed. The models of canopy gas exchange are often based on analogy to electrical resistances where the network of fluxes are described by resistances in series or parallel, resulting in several types of canopy resistance and canopy compensation point models (Erisman et al., 1994, Nemitz et al., 2000b, Denmead et al., 2008, Wichink Kruit et al., 2010, Massad et al., 2010).

The single-layer canopy compensation point resistance model allows for bi-directional $\mathrm{NH}_{3}$ flux through a stomatal pathway and a uni-directional or a bi-directional non-stomatal leaf pathway. The stomatal pathway is regulated by the stomatal resistance $R_{s}$ and the stomatal compensation point $\chi_{s}$. The $\chi_{s}$ is the $\mathrm{NH}_{3}$ gas concentration in the sub-stomatal cavity. Assuming a scenario where the stomatal exchange is the only pathway, the $\mathrm{NH}_{3}$ is emitted through the stomata if the $\chi_{s}$ is greater than the canopy compensation point $\chi_{c}$, and $\mathrm{NH}_{3}$ is absorbed through the stomatal pathway when $\chi_{s}<\chi_{c}$. The $R_{s}$ is dependent on leaf morphology, leaf area index, photosynthetically active radiation, temperature, $\mathrm{pH}$, and water status, whereas the $\chi_{s}$ is dependent on $\mathrm{pH}$ and concentration of $\mathrm{NH}_{4}{ }^{+}$in the apoplast of a leaf, and the leaf surface temperature. The deposition of $\mathrm{NH}_{3}$ to leaf cuticles is regulated by the cuticular resistance $R_{w}$, which is dependent on leaf wetness, atmospheric $\mathrm{NH}_{3}$ concentration and temperature (Farquhar et al., 1980, Nemitz et al., 2000b, Massad et al., 2010, Wichink Kruit et al., 2010, Schrader et al., 2016).

The multi-layer resistance models are needed if additional sinks and sources occur at different heights of the canopy or from sources other than canopy-like litters on the soil surface. In order to conceptualise the additional sinks and sources, more parameters were introduced in the multi-layer models. For instance, three additional parameters were conceptualised in order to describe bi-directional $\mathrm{NH}_{3}$ flux from the leaf litters on the soil surface (Nemitz et al., 2000b), and more parameters were needed to describe $\mathrm{NH}_{3}$ flux from the soil surface (Pleim et al., 2013).

Estimation of some of the parameters in the resistance models is highly uncertain and requires extensive sets of observations. For instance, Nemitz et al. (2000b) estimated the dimensionless $\mathrm{NH}_{3}$ emission potential of litter $\left(\Gamma_{1}=\left[\mathrm{NH}_{4}^{+}\right] /[\mathrm{H}]^{+}\right.$in the leaf litter $)$on three occasions and $\Gamma_{1}$ had values ranging from 3000 to 13000 , and the value was suspected to vary between day and night time. Wichink Kruit et al. (2010) reported that the dimensionless potential $\mathrm{NH}_{3}$ emission of stomata $\left(\Gamma_{\mathrm{s}}=\left[\mathrm{NH}_{4}^{+}\right] /[\mathrm{H}]^{+}\right.$in the leaf apoplast), which regulates 
the $\chi_{s}$, appears to be affected by crop physiology which is dependent on many factors such as crop growth stages, climate conditions and $\mathrm{N}$ fertiliser and irrigation practices, but dependencies of $\Gamma_{\mathrm{S}}$ on these factors have not been distinguished. Moreover, there is uncertainty in the estimated $\Gamma_{\mathrm{s}}$ due to the use of different measurement methods (Massad et al., 2010). It should also be noted that the results obtained through simulation of resistance models of crop gas canopy exchange could also contradict with the results obtained from inverse Lagrangian analysis as shown in Nemitz et al. (2000b).

Nevertheless, by coupling the inverse Lagrangian analysis to models of crop gas exchange, insights in $\mathrm{NH}_{3}$ cycling in arable crop systems were obtained. For instance, Harper et al. (2000) reported that $79 \%$ of the net $\mathrm{NH}_{3}$ loss was emitted from the surface of the corn leaves, and not through a stomatal pathway, most likely from residues that remained on the surface of the leaves following overhead sprinkler application of dairy effluent, and $21 \%$ of net $\mathrm{NH}_{3}$ loss was emitted from the soil surface. Nemitz et al. (2000a) reported that the net $\mathrm{NH}_{3}$ loss in a field with a mature oilseed rape canopy $(L A I=5.3)$ was most likely due to $\mathrm{NH}_{3}$ emitted by the siliques and not by the leaves. Nemitz et al. (2000a) also showed that the volatilised $\mathrm{NH}_{3}$ from the ground surface possibly from the decomposition of the leaf litters was recaptured by the lower half of the oilseed rape crop. Denmead et al. (2008) reported that $20 \%$ of total $\mathrm{NH}_{3}$ volatilised from the soil surface that was fertilised with urea was recaptured by the leaves of sugarcane $(L A I=2.0)$, and the amount of $\mathrm{NH}_{3}$ recaptured by the leaves increased when $L A I$ increased, up to $L A I=2.0$. Ferrara et al. (2014) identified the soil in a sorghum field as the main emitter of $\mathrm{NH}_{3}$ after urea application as the soil compensation point is about 6 times greater than the canopy compensation point. These studies suggest non-stomatal pathways in arable crop systems.

In contrast, for fertilised and flooded rice systems, Hayashi et al. (2008) suggested that the stomatal pathway contributed to the net $\mathrm{NH}_{3}$ loss, in addition to $\mathrm{NH}_{3}$ volatilisation from the floodwater surface. Hayashi et al. (2008) estimated the bi-directional $\mathrm{NH}_{3}$ mission or absorption through the stomata by subtracting the net $\mathrm{NH}_{3}$ loss measured using the wind tunnel approach from the $\mathrm{NH}_{3}$ volatilisation from the floodwater surface estimated using the Jayaweera and Mikkelsen (1990) model. Based on laboratory experiments, Kumagai et al. (2011) reported that the rate of $\mathrm{NH}_{3}$ emission through a stomatal pathway varied among different rice cultivars due to differences in concentrations of $\mathrm{NH}_{4}^{+}$in the leaves of the cultivars, which were partially dependent on glutamine synthetase activity. However, 
compared to arable crop systems, little is known about the details of $\mathrm{NH}_{3}$ cycling within a rice crop canopy. In fertilised and flooded rice systems, the net $\mathrm{NH}_{3}$ loss, in general, is suggested to occur from the floodwater surface after an $\mathrm{N}$ fertiliser application (Fillery et al., 1984, Chen et al., 2015).

$\mathrm{NH}_{3}$ volatilisation from the floodwater surface is regulated by five factors: concentration of total ammoniacal- $\mathrm{N}$ in the floodwater, wind speed, floodwater $\mathrm{pH}$, temperature, and depth (Jayaweera and Mikkelsen, 1990). The floodwater $\mathrm{pH}$ governs partitioning of total ammoniacal- $\mathrm{N}$ into $\mathrm{NH}_{3}$ or $\mathrm{NH}_{4}^{+}$(Reddy, 1982). At $\mathrm{pH}$ value greater than $8, \mathrm{~N}$ is predominantly present in the form $\mathrm{NH}_{3}$, and, thus, $\mathrm{NH}_{3}$ volatilisation is found to be substantial under this condition, provided concentrations of total ammoniacal-N in the medium are high (Reddy, 1982). The concentration of ammoniacal-N in the floodwater is directly affected by the floodwater depth (Jayaweera and Mikkelsen, 1990). At a higher wind speed and higher floodwater temperature, $\mathrm{NH}_{3}$ is stripped from the floodwater at a faster rate (Fillery et al., 1984, Fillery et al., 1986). However, the effect of wind speed on $\mathrm{NH}_{3}$ volatilisation from the floodwater surface is reduced with increasing crop canopy cover (Fillery et al., 1984, Fillery et al., 1986).

\subsection{Measurements of $\mathrm{NH}_{3}$ loss from fertilised and flooded rice systems}

Two common types of methods for the measurement of $\mathrm{NH}_{3}$ fluxes are the micrometeorological and enclosure methods. The micrometeorological methods are advantageous because the methods minimise the external disturbance during sampling and integrate across heterogeneities in the experimental area (Freney et al., 1983, Sommer et al., 2004). Therefore, the measurements obtained using micrometeorological methods can be regarded as the net $\mathrm{NH}_{3}$ loss. Several micrometeorological methods such as the mass balance, ZINST, aerodynamic gradient, and eddy co-variance techniques have been discussed in Sommer et al. (2004) and Harper et al. (2005). The eddy covariance technique, which is one of the most direct and least error-prone micrometeorological methods, requires measurements of $\mathrm{NH}_{3}$ at high time resolution. This was recently made possible with substantial progress in the development of tunable laser absorption spectrometers and quantum cascade lasers (Ferrara et al., 2012).

The enclosure methods can be categorised into three: static chambers, dynamic chambers, and wind tunnels. A static chamber is placed on the soil surface and without air flow through the 
head-space (Sommer et al., 2004), whereas a dynamic chamber is typically with lids that can be removed through which air can be pumped out (Kissel et al., 1977). A basic design of a wind tunnel can be found in Lockyer (1984). These enclosure methods are developed to allow comparison of rates of $\mathrm{NH}_{3}$ volatilisation across treatments and locations, and only require a small area for implementation, e.g., $1 \mathrm{~m}^{2}$ area or less (Smith et al., 2007).

The extraction air speed of a dynamic chamber is typically lower than the natural wind speeds observed in rice systems. The extraction of $\mathrm{NH}_{3}$ through the outlet of a dynamic chamber was reported to reach maximum at 15 exchange volume $\min ^{-1}$, which approximated to wind speed less than $0.2 \mathrm{~m} \mathrm{~s}^{-1}$ (Kissel et al., 1977, Hayashi et al., 2008). Meanwhile, Fillery et al. (1984) reported wind speeds ranging from about $1 \mathrm{~m} \mathrm{~s}^{-1}$ to $8 \mathrm{~m} \mathrm{~s}^{-1}$ at $1.2 \mathrm{~m}$ above the floodwater. It may be possible to modify the chambers to match the external wind speed (Cabrera et al., 2001), but Miola et al. (2015) expressed concern that the air flow dynamics and micro-climate within the static and dynamic chambers may significantly differ from natural field conditions. Meanwhile, good agreement was observed between the $\mathrm{NH}_{3}$ fluxes measured using the wind tunnel and the $\mathrm{NH}_{3}$ fluxes measured using the micrometeorological methods when wind speed in the wind tunnel was adjusted to match the ambient wind speed (Ryden and Lockyer, 1985, Smith et al., 2007, Sommer and Misselbrook, 2016).

Unlike the micrometeorological methods, measurements obtained using static and dynamic chambers may be least representative of the net $\mathrm{NH}_{3}$ loss when the observed value based on small area is scaled up ( $\mathrm{Ni}$ et al., 2015), and may represent only the rates of $\mathrm{NH}_{3}$ volatilisation from floodwater surface as it is unlikely that these chambers would contain rice seedlings due to their small volumes. Meanwhile, a wind tunnel was modified by Hayashi et al. (2008) to contain eight rice seedlings in the wind tunnel in order to measure the net $\mathrm{NH}_{3}$ loss in a flooded rice system.

Table 2 presents the percentage of $\mathrm{NH}_{3}$ loss of the total $\mathrm{N}$ applied measured using micrometeorological and enclosure methods in rice systems with the following characteristics: 1) urea was the source of $\mathrm{N}$ fertiliser, 2) urea was broadcast on the floodwater and without subsequent incorporation into the soil, and 3) the rice systems were flooded for several days after urea application. These conditions were claimed conducive to $\mathrm{NH}_{3}$ volatilisation in fertilised and flooded rice systems (Section 1.6). Additionally, rate and time of urea- $\mathrm{N}$ application, and the regulating factors of $\mathrm{NH}_{3}$ volatilisation are also included in 
Table 2.

Although information in Table 2 is restricted to rice systems with conditions that are claimed conducive to $\mathrm{NH}_{3}$ volatilisation from the floodwater, still large variations in percentage of $\mathrm{NH}_{3}$ loss were observed. The large variation may be attributed to rates of urea-N application relative to rice crop growth stages, and physical and chemical properties of floodwater and soil. Other plausible causes are the different time, duration, and frequency of sampling, and resolution of $\mathrm{NH}_{3}$ concentration (Harper, 2005).

Miola et al. (2015) expressed concern that the rates of $\mathrm{NH}_{3}$ volatilisation may be underestimated due to lack of air movement in the chambers, but Liu et al. (2015) reported both low and high $\mathrm{NH}_{3}$ loss at a late crop growth stage using static chambers, i.e., $24 \%$ of total urea-N applied on 67 DAT and $50 \%$ of total urea-N applied on 63 DAT (Table 2). Although extraction air speeds of the dynamic chambers are lower than natural wind speed observed in rice systems, high rates of $\mathrm{NH}_{3}$ volatilisation (greater than $40 \%$ of $\mathrm{N}$ applied) were observed by Li et al. (2008) using the dynamic chamber methods (Table 2). Meanwhile, $\mathrm{NH}_{3}$ loss measured using the micrometeorological methods ranges from $3 \%$ to $54 \%$ of total $\mathrm{N}$ applied. Lower $\mathrm{NH}_{3}$ volatilisation in Griffith was possibly due to lower wind speed following urea application and high denitrification rate which is site specific (Freney et al., 1988, Humphreys et al., 1988).

Despite the variation in measurements of $\mathrm{NH}_{3}$ volatilisation rates and regardless of methods of measurements, some data in Table 2 suggest substantial $\mathrm{N}$ loss via $\mathrm{NH}_{3}$ volatilisation in flooded soil systems with a young rice crop when high rate of urea is broadcast onto the floodwater and without subsequent incorporation into the soil, provided the environments are conducive to $\mathrm{NH}_{3}$ volatilisation and there is no competing $\mathrm{N}$ loss pathways (see Section 1.6). In addition, the percentages of $\mathrm{NH}_{3}$ volatilisation with respect to the total $\mathrm{N}$ applied appear dependent on the rate of urea application relative to the stage of rice crop growth.

\subsection{Mitigation of $\mathrm{NH}_{3}$ loss in fertilised and flooded rice systems}

As far as $\mathrm{NH}_{3}$ volatilisation is concerned, deep placement of urea between $0.07 \mathrm{~m}$ to $0.10 \mathrm{~m}$ from the flooded soil surface was recommended to substantially reduce $\mathrm{NH}_{3}$ volatilisation (Craswell et al., 1981, Cao et al., 1984, Liu et al., 2015). 


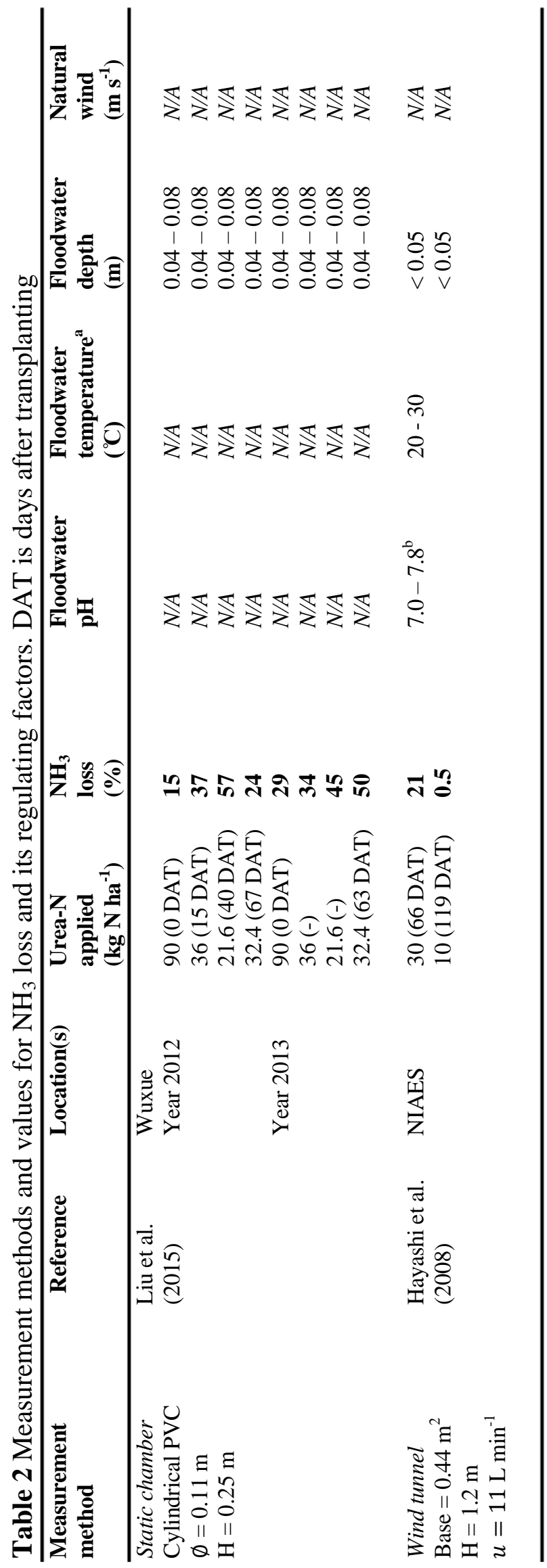




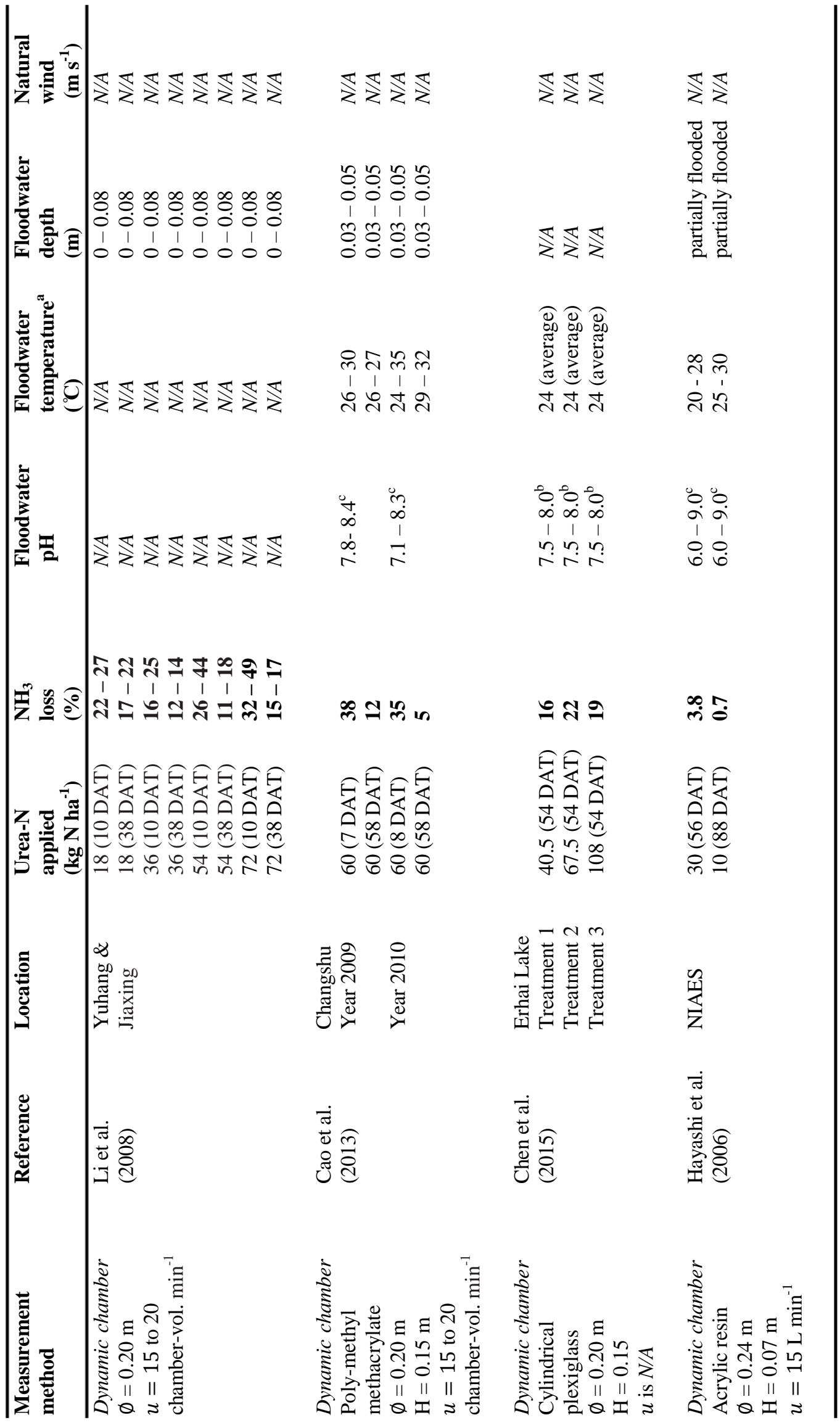




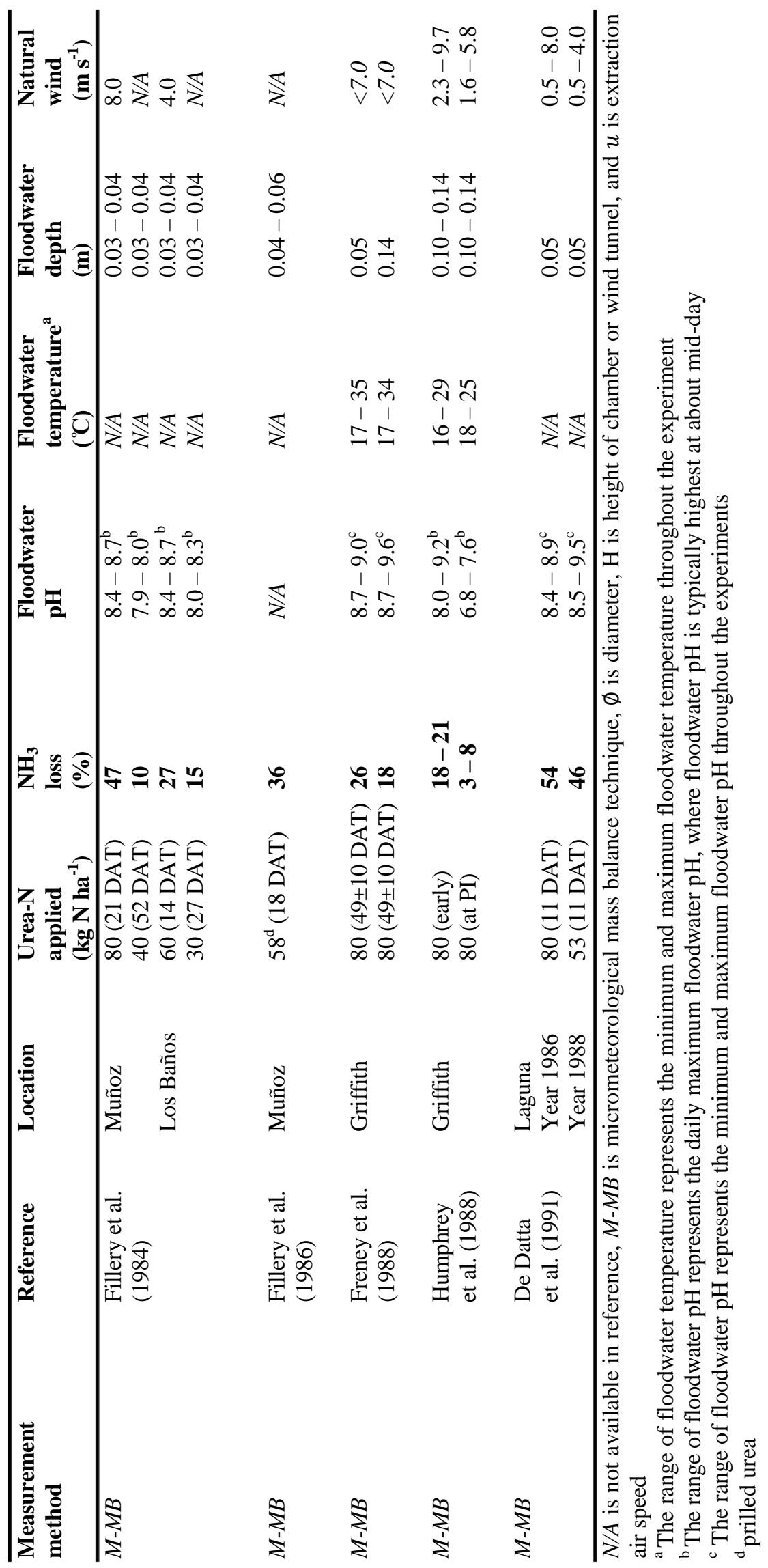


Deep placement of urea reduced total ammoniacal-N in the floodwater, and, consequently, less $\mathrm{NH}_{3}$ is susceptible to volatilisation from the floodwater. Use of coated urea also reduces the risk of $\mathrm{N}$ leaching in soil with high permeability (light textured soil) (Vlek et al., 1980a, Peng et al., 2015).

However, the advantages of $\mathrm{N}$ fertiliser technologies that were pointed out in research studies are often not enough to motivate smallholder rice farmers in developing countries to adopt the recommended technology (Fujisaka, 1994). For instance, in Peninsular Malaysia and possibly in other countries in Southeast Asia as well, the conventional broadcast of urea on the floodwater without incorporation into the soil is still widely adopted, regardless of the alternative application methods that were introduced since the 1980's. The immediately incurring cost and the delayed and risky benefits possibly hinder technology adoption (Fujisaka, 1994).

Without technical and financial support from local authorities of developing countries, and actual field demonstration where farmers can actively participate to learn and apply the recommended technology, local smallholder rice farmers are not likely convinced of the energy efficiency and other benefits of the recommended methods (Fujisaka, 1994, Corales et al., 2015). Adoption of technology has to be on a significant scale to be economically and environmentally advantageous. Until then, $\mathrm{NH}_{3}$ volatilisation may remain significant in fertilised and flooded rice systems.

\subsection{Research challenges}

Earlier, we have deduced that the $\mathrm{NH}_{3}$ volatilisation from the floodwater is one of the major $\mathrm{N}$ loss pathways in fertilised and flooded rice systems that are broadcast with urea (Sections 1.6 and 1.7). The importance of this process prompted the development of mathematical models to estimate $\mathrm{NH}_{3}$ volatilisation from the floodwater in flooded soil systems with or without a rice crop.

Since the 1980's, models for the estimation of $\mathrm{NH}_{3}$ volatilisation from the floodwater surface were developed either for scientific insights into the $\mathrm{N}$ dynamics of fertilised and flooded rice systems or as alternatives to tedious field and lab experiments (Rao et al., 1984, Jayaweera and Mikkelsen, 1990, Singh and Kirk, 1993, Chen et al., 2015). $\mathrm{NH}_{3}$ volatilisation is also conceptualised into $\mathrm{N}$ dynamics models that were developed for scenario studies in fertilised and flooded rice fields to make recommendations on management practices (Godwin and Singh, 
1998, Li et al., 2004, Jing et al., 2010, Gaydon et al., 2012b), or to estimate the seasonal N balances (Chowdary et al., 2004, Antonopoulos, 2010).

These models have varying complexities with regards to describing the process of $\mathrm{NH}_{3}$ volatilisation. For instance, the process of $\mathrm{NH}_{3}$ volatilisation from the floodwater surface is merely approximated by a first-order process in the lumped-parameter model of Chowdary et al. (2004). In contrast, the $\mathrm{NH}_{3}$ volatilisation is detailed as a function of ambient wind speed, floodwater depth, $\mathrm{pH}$, and temperature in models of Jayaweera and Mikkelsen (1990) and Gaydon et al. (2012b) (i.e., APSIM-Oryza).

Some of these models also have varying complexities with regard to describing the overall $\mathrm{N}$ dynamics in the fertilised and flooded soil systems with or without a rice crop. For instance, NFLOOD by Rao et al. (1984) divided the floodwater and soil compartments into several vertical layers where solute transport between these layers is governed by diffusion. Meanwhile, Chowdary et al. (2004), Liang et al. (2007) and Antonopoulos (2010) assumed homogeneous compartments of floodwater and soil. Models by Jayaweera and Mikkelsen (1990) and Rao et al. (1984) did not conceptualise the effect of a rice crop. Rao et al. (1984) and Chowdary et al. (2004) assumed an additional $\mathrm{N}$ sink in the floodwater, i.e., nitrification, whereas in APSIM-Oryza nitrification is assumed negligible in flooded soil (Gaydon et al., 2012b).

With progress in the development of the models for simulating $\mathrm{N}$ dynamics in flooded soil systems, with and without a rice crop, the present challenges are, therefore, i) to evaluate which of the existing models have the appropriate model structure for estimating $\mathrm{NH}_{3}$ volatilisation in fertilised and flooded rice systems that was broadcast with urea, ii) to propose modifications that will improve the model's performance, and iii) to characterise the uncertainty in the model given poor quality field observational data sets and model structure inadequacy. Poor quality data refers to small number of observations or large errors in the observations, or both.

Simpler process-based models are easy to understand and simulate, but these models may treat important mechanisms lightly. Meanwhile, complex process-based models detail out the systems, but these models may be over-parameterised to such an extent that some of the parameters cannot be estimated from the limited observational data sets available. Fig. 3 summarises the trade-off between prediction error and model complexity, where an increase 
in model prediction error is expected when a model is too simple or too complex. The art of modelling is to find the optimal complexity for a given modelling purpose.

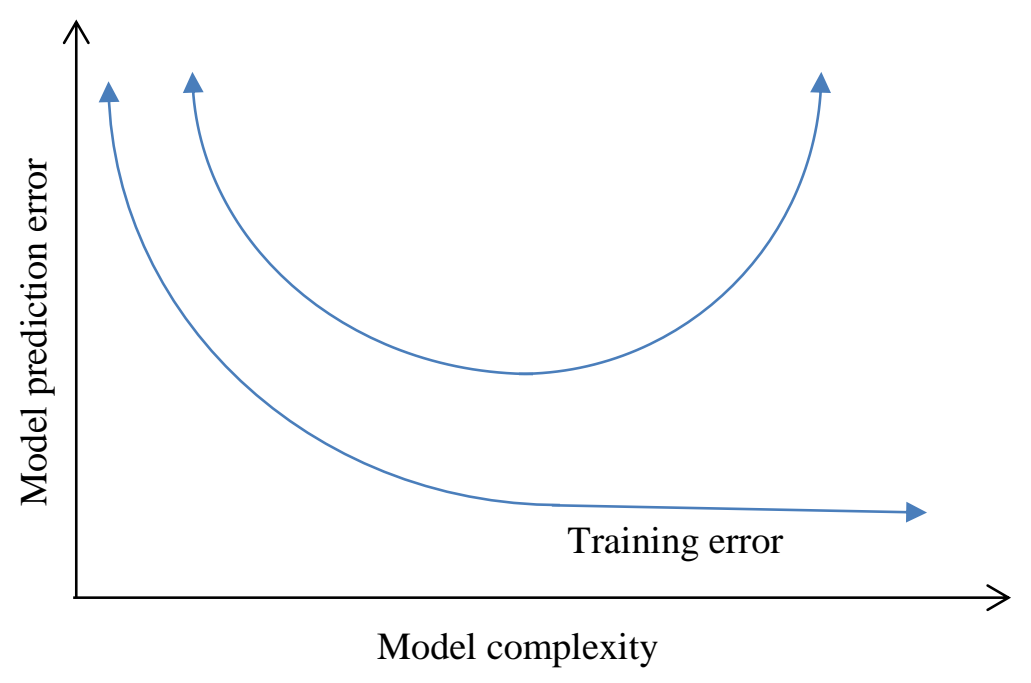

Fig. 3 Training and prediction error for new observational data set (adapted from Dieterle (2003), after Martens and Naes (1989))

Selection of models should be based on users' research objectives, concepts and structures of the models with respect to prior knowledge of the physical systems, and performances of the models (Norton, 1986, Jakeman et al., 2006, Bellocchi et al., 2010, Keesman, 2011, Bennett et al., 2013). To the best of our knowledge, many of the models that can simulate the $\mathrm{NH}_{3}$ volatilisation from the floodwater have never been co-validated with one another. Covalidation is the assessment of proximity of one model to alternative models by comparing the prediction of the models' common outputs (Bellocchi et al., 2010). Therefore, evaluation criteria for selection of models for estimating $\mathrm{NH}_{3}$ volatilisation in fertilised and flooded rice systems are currently limited to the objectives of the models defined by the modellers, and performances of the models with respect to observational data sets. Although confidence in models can be increased by performing extensive evaluation against observational data sets (Bellocchi et al., 2010), this approach may be difficult when reliable observational data sets for thorough evaluation of models are limited.

Ill-defined systems are characterised by unrepresentative (poor quality) observational data sets (Young et al., 1978), often attributed to measurement difficulties, and lack of physical $a$ priori knowledge. As such, the fertilised and flooded rice systems can be characterised as ill- 
defined systems. The systems are complex with many interactive processes that vary with time and differ between locations. For instance, in the case of $\mathrm{NH}_{3}$ gas exchange in fertilised and flooded rice systems, the dominant pathways of $\mathrm{NH}_{3}$ loss, either from the floodwater surface or through the stomata of the rice crop, are not entirely known. The $\mathrm{NH}_{3}$ volatilisation from the floodwater surface is regulated by time-varying process variables (Section 1.6), but some of these variables were either reported at poor time resolution or not available at all. Also, Section 1.7 gives an overview on the sources of variation in observation of $\mathrm{NH}_{3}$ loss.

Calibration of soil $\mathrm{N}$ parameters in models are reported to be hindered by scarcity of soil $\mathrm{N}$ data as reported by Gaydon et al. (2012a), Katayanagi et al. (2013) and Liang et al. (2014). Earlier, Cassman et al. (2002) have already suggested that realistic prediction of soil $\mathrm{N}$ dynamics using models is difficult due to complexity of the interactive $\mathrm{N}$ processes. In field experiment, not all of the sinks of applied $\mathrm{N}$ would be measured simultaneously. For instance, an experiment that aims quantify crop production would measure the grain production and crop properties, but not the rate of denitrification and $\mathrm{NH}_{3}$ volatilisation. These limitations indicate that complex models cannot be easily evaluated for ill-defined systems, such as the fertilised and flooded rice systems. Furthermore, with limited data set, two models with different underlying fundamentals may easily fit the same data as demonstrated by Kircher et al. (1996) using two relatively simple environmental models.

Given existing models that can simulate $\mathrm{NH}_{3}$ volatilisation in fertilised and flooded rice systems and that have different complexity, it is of interest to determine which of the models has the adequate model structure for a specific purpose. Complex models may be more 'correct', but more data is needed to evaluate the models (Gupta et al., 2012).

The overall objective of this thesis is, therefore, to determine an appropriate model structure with corresponding uncertainty characterisation for the estimation of $\mathrm{NH}_{3}$ volatilisation in fertilised and flooded rice systems.

\subsection{Research questions, approach, and outline}

To achieve the objective of this thesis, four relevant research questions were formulated, and answered in each technical chapter. 
1) What are the modelling concepts in existing models developed to simulate $\mathrm{N}$ dynamics in flooded soil systems with or without a rice crop, and how were the performances of these models evaluated?

Many models with the capability to estimate $\mathrm{NH}_{3}$ volatilisation from fertilised and flooded soil systems have been developed. In systems and control theory, a priori knowledge is gained through deduction, and not through empirical evidence (Keesman, 2011). Therefore, in Chapter 2, the first step starts with a critical evaluation of the a priori knowledge in terms of concepts and structures of 14 existing models for simulation of $\mathrm{N}$ dynamics in fertilised and flooded soil systems, with or without a rice crop. In this step, the aim is to understand how the overall $\mathrm{N}$ dynamics and transport in the systems were conceptualised. The 14 models are NFLOOD v.1 (Rao et al., 1984), NFLOOD v.2 (Reddy et al., 1990), J-M's (Jayaweera and Mikkelsen, 1990), S-K's (Singh and Kirk, 1993), CERES-Rice (Godwin and Singh, 1998), Chowdary's (Chowdary et al., 2004), Nakasone's (Nakasone et al., 2004), Yoshinaga's (Yoshinaga et al., 2004), DNDC-Rice (Li et al., 2004), K-K's (Kirk and Kronzucker, 2005), Liang's (Liang et al., 2007), RIWER (Jing et al., 2010), RICEWNB (Antonopoulos, 2010), and APSIM-Oryza (Gaydon et al., 2012a, Gaydon et al., 2012b). Similarities and differences in concepts underlying these models were identified, and motivations (hypotheses or theories) underlying the concepts were recognised. Also, an overview on the model performance with respect to relevant $\mathrm{N}$ dynamics components was given based on published reports (Chapter 2).

However, independent data sets used for the evaluation of each model do not allow direct comparison of the model outcomes. Therefore, the next step is to investigate whether the differences in modelling concepts and structures would lead to substantial differences in model-output responses, which led to the next research question.

2) How do the different concepts of mathematical models of urea hydrolysis and $\mathrm{NH}_{3}$ volatilisation affect the model-output responses?

Equifinality is defined as the capability of mathematical models to produce similar model-output responses (Bellocchi et al., 2010). Equifinality may also be one of the information criteria to aid model selection. However, equifinality of existing models 
for the estimation of $\mathrm{NH}_{3}$ volatilisation has neither been evaluated at single process level nor at full model level.

Co-validation of models may unravel equifinality among mathematical models and can be performed at two levels: at full (field) model level or at a single process level (Bellocchi et al., 2010). Co-validation at full model level is able to reveal equifinality of the full models with respect to common outputs that resulted from the integrated $\mathrm{N}$ processes, but two limitations of this approach are anticipated.

First, the effects of different modelling concepts of an individual process may not be apparent due to interactive $\mathrm{N}$ processes. For instance, the amount of total ammoniacal- $\mathrm{N}$ in the floodwater is an input to mathematical models of $\mathrm{NH}_{3}$ volatilisation. At full model level, the total ammoniacal-N may be regulated by different processes or process variables in different models. Second, co-validation at full model level is ideal for comparing models that are developed for the same objective as stated in Bellocchi et al. (2010). Consequently, not all models can be co-validated at full model level. For instance, it is not appropriate to co-validate the model by Chowdary et al. (2004) with the model by Jayaweera and Mikkelsen (1990). The former is developed for flooded soil systems with $\mathrm{N}$ uptake by the rice crop, while the latter was developed for flooded soil systems without a rice crop.

Due to possible limited insights from co-validation at full model level, the first step is to perform co-validation at process level. Therefore, the mathematical models of urea hydrolysis and $\mathrm{NH}_{3}$ volatilisation from floodwater surface were extracted from the full models and co-validated at single process level in Chapter 3 with the aim to investigate equifinality between simple and complex process models. Urea hydrolysis was selected as the process that influences the rate of $\mathrm{NH}_{3}$ volatilisation via input of total ammoniacal-N in the floodwater following a urea application. Insights obtained from Chapters 2 and 3 are used to answer the next research question.

3) Is a simple process-based model adequate for estimating $\mathrm{NH}_{3}$ volatilisation in fertilised and flooded rice systems?

In-line with Einstein's quote "Everything should be made as simple as possible, but 
not simpler", Young (1976) and Gaydon et al. (2012a) state that details should only be added when data allows validation of the extended model. Thus, simple process-based models tend to be appropriate for ill-defined systems because of the limited observational data sets for calibration and cross-validation of the models. However, one of the questions relevant prior to selection of models as posed by Bennett et al. (2013) is whether a simple model can substitute its complex counterpart, and if not, to what extent should the model be detailed? Therefore, in Chapter 4, the objective is to determine whether the simple process-based model has adequate model structure for the estimation of $\mathrm{NH}_{3}$ volatilisation in fertilised and flooded rice systems.

Based on insights from Chapters 2 and 3, a new and relatively simple model for the estimation of $\mathrm{NH}_{3}$ volatilisation from fertilised and flooded rice systems was developed. The proposed model was calibrated and cross-validated with data sets from two locations in the Philippines and three locations in China. The performance of the proposed model was also co-validated with the lumped-parameter model by Chowdary et al. (2004). Limitations and advantages of the proposed model are discussed.

However, an appropriate characterisation of the estimation uncertainties from a calibration step is still lacking. Hence, the last research question is formulated as follows:

4) What are the uncertainties in the parameter estimates and what is an appropriate way to characterise these uncertainties under poor quality data? The poor quality data refer to either small number of observations, or large errors in the observations, or both.

Applying an appropriate parameter estimation technique is important in developing models (Fig. 4). Probabilistic parameter estimation approaches are not adequate for small data sets, as these do not allow a detailed error characterisation in terms of probability density functions and correlations (Keesman, 1990, Walter and PietLahanier, 1990). Unlike the probabilistic parameter estimation approaches, the setmembership (bounded-error) approach avoids any assumption beyond the structure of the model and the output error-bounds, and thus, is appropriate for ill-defined systems. Thus, in Chapter 5, we demonstrated how six parameters in the proposed model of Chapter 4, can be estimated based on two data sets from the Philippines, using a sampling-based set-membership approach. The estimates obtained from the approach 
are compared with estimates obtained using conventional non-linear least-squares methods.

The research approach is graphically summarised in Figure 4. In Chapter 6, a general discussion of this thesis and perspectives for further research are given.

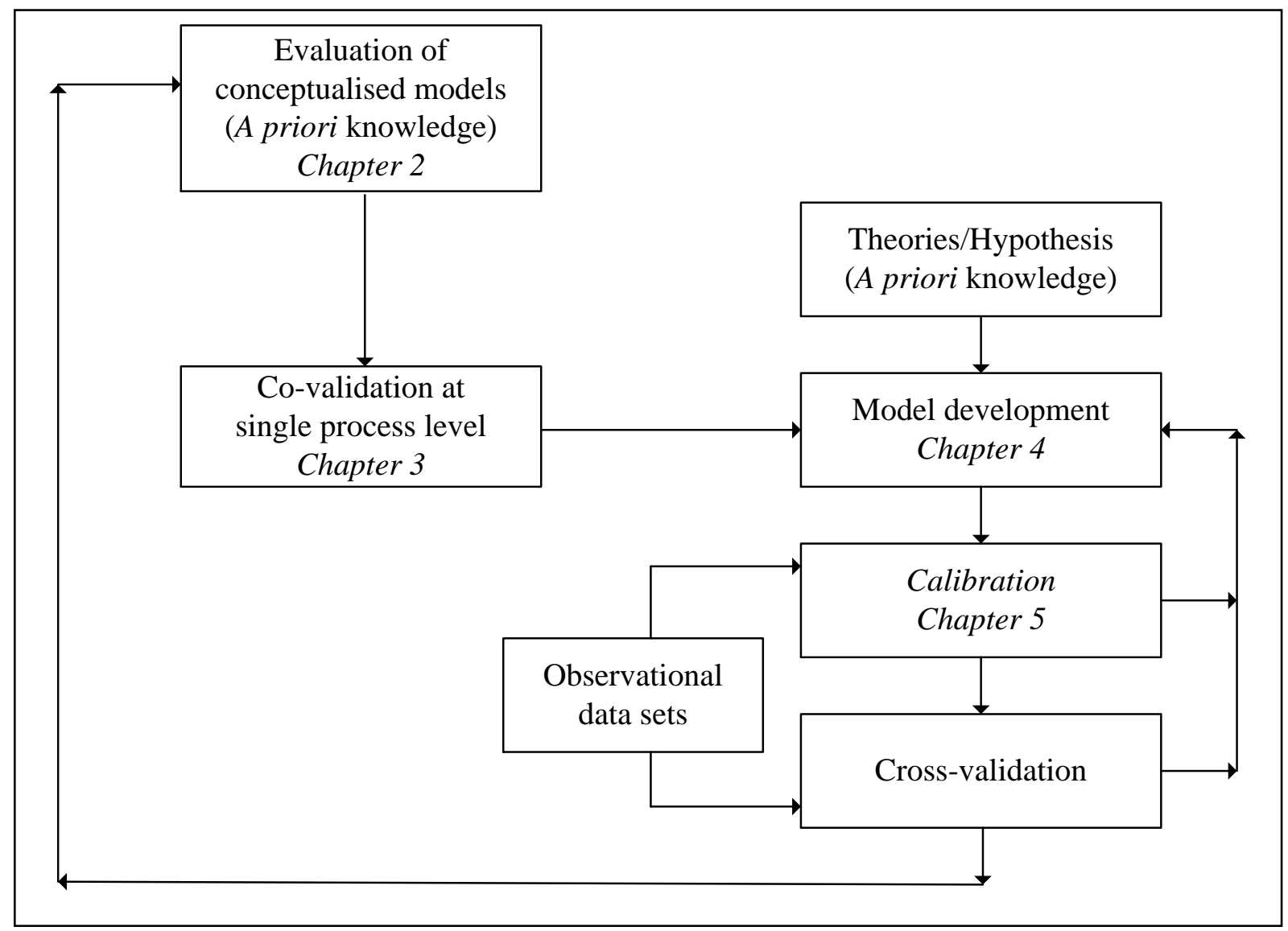

Fig. 4 Research approach of this thesis

\section{References}

Aimrun, W. \& Amin, M. S. M. 2009. Pedo-transfer function for saturated hydraulic conductivity of lowland paddy soils. Paddy Water Environ, 7, pp. 217-225.

Aimrun, W., Amin, M. S. M., Desa, A., Hanafi, M. M. \& Chan, C. S. 2007. Spatial variability of bulk soil electrical conductivity in a Malaysian paddy field: key to soi management. Paddy Water Environ, 5, pp. 113-121.

Aimrun, W., Amin, M. S. M. \& Gholizadeh, A. 2010. Spatial variability of irrigation water percolation rates and its relation to rice productivity. Am J Appl Sci, 7, pp. 51-55.

Aimrun, W., Amin, M. S. M. \& Nouri, H. 2011. Paddy field zone characterization using apparent electrical conductivity for rice precision farming. Int J Agric Res, 6, pp. 1028.

Akiyama, H., Yagi, K. \& Yan, X. 2005. Direct $\mathrm{N}_{2} \mathrm{O}$ emissions from rice paddy fields: Summary of available data. Glob Biogeochem Cycl, 19, pp. 
Antonopoulos, V. Z. 2010. Modelling of water and nitrogen balances in the ponded water and soil profile of rice fields in Northern Greece. Agric Water Manag, 98, pp. 321-330

Bellocchi, G., Rivington, M., Donatelli, M. \& Matthews, K. 2010. Validation of biophysical models: Issues and methodologies. A review. Agron Sustain Dev, 30, pp. 109-130.

Bennett, N. D., Croke, B. F. W., Guariso, G., Guillaume, J. H. A., Hamilton, S. H., Jakeman, A. J., Marsili-Libelli, S., Newham, L. T. H., Norton, J. P., Perrin, C., Pierce, S. A., Robson, B., Seppelt, R., Voinov, A. A., Fath, B. D. \& Andreassian, V. 2013. Characterising performance of environmental models. Environ Model Softw, 40, pp. 120.

Bouwman, A. F., Boumans, L. J. M. \& Batjes, N. H. 2002. Estimation of global $\mathrm{NH}_{3}$ volatilization loss from synethetic fertilizers and animal manure applied to arable lands and grasslands. Glob Biogeochem Cycl, 16, pp. 8-1 - 8-14.

Brady, N. C. \& Weil, R. R. 2008. The Nature and Properties of Soils. New Jersey: Pearson Prentice Hall.

Buresh, R. J. \& De Datta, S. K. 1990. Denitrification losses from puddled rice soils in the tropics. Biol Fertil Soils, 9, pp. 1-13.

Buresh, R. J., De Datta, S. K., Padilla, J. L. \& Samson, M. I. 1988. Effect of two urease inhibitors on floodwater ammonia following urea application to lowland rice. Soil Sci Soc Am J, 52, pp. 856-861.

Buresh, R. J. \& Patrick, W. H. 1978. Nitrate reduction to ammonium in anaerobic soil. Soil Sci Soc Am J, 42, pp. 913-918.

Buresh, R. J., Reddy, K. R. \& Van Kessel, C. 2008. Nitrogen transformations in submerged soils. In: Schepers, J. S. \& Raun, W. R. (eds.) Nitrogen in Agricultural Systems. Madison: American Society of Agronomy, Crop Science Society of America, and Soil Science Society of America, pp. 401-436.

Cabrera, M. L., Kissel, D. E., Davis, R. C., Qafoku, N. P. \& Segars, W. I. 2001. Design and ammonia-recovery evaluation of a wind speed-sensitive chamber system. Soil Sci Soc Am J, 65, pp. 1302-1306.

Cao, Y., Tian, Y., Yin, B. \& Zhu, Z. 2013. Assessment of ammonia volatilization from paddy fields under crop management practices aimed to increase grain yield and $\mathrm{N}$ efficiency. Field Crop Res, 147, pp. 23-31.

Cao, Z.-H., De Datta, S. K. \& Fillery, I. R. P. 1984. Nitrogen-15 balance and residual effects of urea-N in wetland rice fields as affected by deep placement techniques. Soil Sci Soc Am J, 48, pp. 203-208.

Cassman, K. G., Dobermann, A. \& Walters, D. T. 2002. Agroecosystems, nitrogen-use efficiency and nitrogen management. AMBIO: J Hum Environ, 31, pp. 132-140.

Chen, A., Lei, B., Hu, W., Lu, Y., Mao, Y., Duan, Z. \& Shi, Z. 2015. Characteristics of ammonia volatilization on rice grown under different nitrogen application rates and its quantitative predictions in Erhai Lake Watershed, China. Nutr Cycl Agroecosyst, 101, pp. 139-152.

Chen, S.-K. \& Liu, C. W. 2002. Analysis of water movement in paddy rice fields (I) experimental studies. J Hydrol, 260, pp. 206-215.

Chowdary, V. M., Rao, N. H. \& Sarma, P. B. S. 2004. A coupled soil water and nitrogen balance model for flooded rice fields in India. Agric Ecosyst Environ, 103, pp. 425441.

Corales, A. M., Sibayan, E. B. \& Palis, F. G. 2015. Dissemination of natural resource management technology for irrigated rice in the Philippines: On-farm validation to national extension. Pertanika J Trop Agric Sci, 38, pp. 219-233.

Craswell, E. T., De Datta, S. K., Obcemea, W. N. \& Hartantyo, M. 1981. Time and mode of nitrogen fertilizer application to tropical wetland rice. Fert Res, 2, pp. 247-259. 
De Datta, S. K. 1986. Improving nitrogen fertilizer efficiency in lowland rice in tropical Asia. Fert Res, 9, pp. 171-186.

De Datta, S. K., Samson, M. I., Obcemea, W. N., Real, J. G. \& Buresh, R. J. 1991. Direct measurement of ammonia and denitrification fluxes from urea applied to rice. Soil Sci Soc Am J, 55, pp. 543-548.

De Datta, S. K., Samson, M. I., Wang, K.-R. \& Buresh, R. J. 1988. Nitrogen use efficiency and nitrogen-15 balances in broadcast-seeded flooded and transplanted rice. Soil Sci Soc Am J, 52, pp. 849-855.

Denmead, O. T., Freney, J. R. \& Dunin, F. X. 2008. Gas exchange between plant canopies and the atmosphere: Case-studies for ammonia. Atmos Environ, 42, pp. 3394-3406.

Dieterle, F. J. 2003. Multianalyte Quantifications by Means of Integration of Artificial Neural Networks, Genetic Algorithms and Chemometrics for Time-Resolved Analytical Data. PhD. Der Eberhard-Karls-Universität Tübingen.

Erisman, J. W., Sutton, M. A., Galloway, J., Klimont, Z. \& Winiwarter, W. 2008. How a century of ammonia synthesis changed the world. Nat Geosci, 1, pp. 636-639.

Erisman, J. W., Van Pul, A. \& Wyers, P. 1994. Parametrization of surface resistance for the quantification of atmospheric deposition of acidifying pollutants and ozone. Atmos Environ, 28, pp. 2595-2607.

Estudillo, J. P. \& Otsuka, K. 2006. Lesson from three decades of green revolution in the Philippines. Dev Econ, 44, pp. 123-148.

Fageria, N. K., Moreira, A., Moraes, L. a. C. \& Moraes, M. F. 2014. Nitrogen uptake and use efficiency in upland rice under two nitrogen sources. Commun Soil Sci Plant Anal, 45, pp. 461-469.

FAO. 2013. Rice Market Monitor Vol. XVI. [online]. Available at: http://www.fao.org/economic/est/publications/rice-publications/rice-market-monitorrmm/en/ [Accessed 28 Nov. 2016].

Farquhar, G. D., Firth, P. M., Wetselaar, R. \& Weir, B. 1980. On the gaseous exchange of ammonia between leaves and the environment: Determination of the ammonia compensation point. Plant Physiol, 66, pp. 710-714.

Ferrara, R. M., Loubet, B., Decuq, C., Palumbo, A. D., Di Tommasi, P., Magliulo, V., Masson, S., Personne, E., Cellier, P. \& Rana, G. 2014. Ammonia volatilisation following urea fertilisation in an irrigated sorghum crop in Italy. Agric For Meteorol, 195-196, pp. 179-191.

Ferrara, R. M., Loubet, B., Di Tommasi, P., Bertolini, T., Magliulo, V., Cellier, P., Eugster, W. \& Rana, G. 2012. Eddy covariance measurement of ammonia fluxes: Comparison of high frequency correction methodologies. Agric For Meteorol, 158-159, pp. 30-42.

Fillery, I. R. P., Roger, P. A. \& De Datta, S. K. 1986. Ammonia volatilization from nitrogen sources applied to rice fields: II. Floodwater properties and submerged photosynthetic biomass. Soil Sci Soc Am J, 50, pp. 86-91.

Fillery, I. R. P., Simpson, J. R. \& De Datta, S. K. 1984. Influence of field environment and fertilizer management on ammonia loss from flooded rice. Soil Sci Soc Am J, 48, pp. 914-920.

Freney, J. R., Simpson, J. R. \& Denmead, O. T. 1983. Volatilization of ammonia. In: Freney, J. R. \& Simpson, J. R. (eds.) Gaseous Loss of Nitrogen from Plant-Soil Systems. Dordrecht: Springer-Science + Business Media, B.V., pp. 1-32.

Freney, J. R., Trevitt, A. C. F., De Datta, S. K., Obcemea, W. N. \& Real, J. G. 1990. The interdependence of ammonia volatilization and denitrification as nitrogen loss processes in flooded rice fields in the Philippines. Biol Fertil Soils, 9, pp. 31-36. 
Freney, J. R., Trevitt, A. C. F., Muirhead, W. A., Denmead, O. T., Simpson, J. R. \& Obcemea, W. N. 1988. Effect of water depth on ammonia loss from lowland rice. Fert Res, 16, pp. 97-107.

Fujisaka, S. 1994. Learning from six reasons why farmers do not adopt innovations intended to improve sustainability of upland agriculture. Agric Syst, 46, pp. 409-425.

Galloway, J. N., Dentener, F. J., Capone, D. G., Boyer, E. W., Howarth, R. W., Seitzinger, S. P., Asner, G. P., Cleveland, C. C., Green, P. A., Holland, E. A., Karl, D. M., Micheals, A. F., Porter, J. H., Townsend, A. R. \& Vöosmarty, C. J. 2004. Nitrogen cycles: Past, present and future. Biogeochem, 70, pp. 153-226.

Gaydon, D. S., Probert, M. E., Buresh, R. J., Meinke, H., Suriadi, A., Dobermann, A., Bouman, B. \& Timsina, J. 2012a. Rice in cropping systems - Modelling transition between flooded and non-flooded soil environments. Eur J Agron, 39, pp. 9-24.

Gaydon, D. S., Probert, M. E., Buresh, R. J., Meinke, H. \& Timsina, J. 2012b. Modelling the role of algae in rice crop nutrition and soil organic carbon maintenance. Eur J Agron, 39, pp. 35-43.

Godwin, D. C. \& Singh, U. 1998. Nitrogen balance and crop response to nitrogen in upland and lowland cropping systems. In: Tsuji, G. Y., Hoogenboom, G. \& Thornton, P. K. (eds.) Understanding Options for Agricultural Production. Springer Netherlands, pp. 55-77.

Groffman, P. E., Altabet, M. A., Böhlke, J. K., Butterbach-Bahl, K., David, M. B., Firestone, M. K., Giblin, A. E., Kana, T. M., Nielsen, L. P. \& Voytek, M. A. 2006. Methods for measuring denitrification: Diverse approaches to a difficult problem. Ecol Model, 16, pp. 2091-2122.

Gupta, H. V., Clark, M. P., Vrugt, J. A., Abramowitz, G. \& Ye, M. 2012. Towards a comprehensive assessment of model structural adequacy. Water Resour Res, 48, pp.

Harper, L. A. 2005. Ammonia: Measurement issues. In: Hatfield, J. L. \& Baker, J. M. (eds.) Micrometeorology in Agricultural Systems. Madison: American Society of Agronomy, Crop Science Society of America, and Soil Science Society of America, pp. 345-379.

Harper, L. A., Denmead, O. T. \& Sharpe, R. R. 2000. Identifying sources and sinks of scalars in a corn canopy with inverse Lagrangian dispersion analysis: II. Ammonia. Agric For Meteorol, 104, pp. 75-83.

Hayashi, K., Nishimura, S. \& Yagi, K. 2006. Ammonia volatilization from the surface of a Japanese paddy field during rice cultivation Soil Sci Plant Nutr, 52, pp. 545-555.

Hayashi, K., Nishimura, S. \& Yagi, K. 2008. Ammonia volatilization from a paddy field following applications of urea: Rice plants are both an absorber and an emitter for atmospheric ammonia. Sci Total Environ, 390, pp. 485-494.

Heffer, P. 2013. Assessment of Fertilizer Use by Crop at the Global Level 2010-2010/11. [online]. Available

at: http://www.fertilizer.org/ItemDetail?iProductCode=9592Pdf\&Category=STAT\&Web siteKey [Accessed 28 Nov. 2016].

Hossain, M. \& Fischer, K. S. 1995. Rice research for food security and sustainable agricultural development in Asia: Achievements and future challenges. GeoJournal, 35, pp. 286-298.

Humphreys, E., Freney, J. R., Muirhead, W. A., Denmead, O. T., Simpson, J. R., Leuning, R., Trevitt, A. C. F., Obcemea, W. N., Wetselaar, R. \& Cai, G.-X. 1988. Loss of ammonia after application of urea at different times to dry-seeded, irrigated rice. Fert Res, 16, pp. 47-57.

Jakeman, A. J., Letcher, R. A. \& Norton, J. P. 2006. Ten iterative steps in development and evaluation of environmental models. Environ Model Softw, 21, pp. 602-614. 
Jayaweera, G. R. \& Mikkelsen, D. S. 1990. Ammonia volatilization from flooded soil systems: A computer model. I. Theoretical aspects. Soil Sci Soc Am J, 54, pp. 14471455.

Jetten, M. S. M. 2008. The microbial nitrogen cycle. Environ Microbiol, 10, pp. 2903-2909.

Jing, Q., Van Keulen, H. \& Hengsdijk, H. 2010. Modeling biomass, nitrogen and water dynamics in rice-wheat rotations. Agric Syst, 103, pp. 433-443

Kamaruddin, R., Ali, J. \& Mohd. Saad, N. 2013. Happiness and its influencing factors among paddy farmers in granary area of MADA. World Appl Sci J, 28, pp.

Katayanagi, N., Ono, K., Fumoto, T., Mano, M., Miyata, A. \& Hayashi, K. 2013. Validation of the DNDC-Rice model to discover problems in evaluating the nitrogen balance at a paddy-field scale for single-cropping of rice. Nutr Cycl Agroecosyst, 95, pp. 255-268.

Keesman, K. J. 1990. Membership-set estimation using random scanning and principal component analysis. Math Comput Simul, 32, pp. 535-543.

Keesman, K. J. 2011. System Identification: An Introduction. Springer UK.

Kirchner, J. W., Hooper, R. P., Kendall, C., Neal, C. \& Leavesley, G. 1996. Testing and validating environmental models. Sci Total Environ, 183, pp. 33-47.

Kirk, G. J. D. \& Kronzucker, H. J. 2005. The potential for nitrification and nitrate uptake in the rhizosphere of wetland plants: A modelling study. Ann Bot, 96, pp. 639-646.

Kissel, D. E., Brewer, H. L. \& Arkin, G. F. 1977. Design and test of a field sampler for ammonia volatilization. Soil Sci Soc Am J, 41, pp. 1133 - 1138.

Kumagai, E., Araki, T. \& Ueno, O. 2011. Ammonia emission from leaves of different rice (Oryza sativa L.) cultivars. Plant Prod Sci, 14, pp. 249-253.

Kundu, D. K. \& Ladha, J. K. 1999. Sustaining productivity of lowland rice soils: Issues and options related to N availability. In: Balasubramanian, V., Ladha, J. K. \& Denning, G. L. (eds.) Resource Management in Rice Systems: Nutrients. Kluwer Academic Publishers, pp. 27-44.

Ladha, J. K., Pathak, H., Krupnik, J. T., Six, J. \& Van Kessel, C. 2005. Efficiency of fertilizer nitrogen in cereal production: Retrospects and prospects. Advances in Agronomy. Academic Press, pp. 85-156.

Ladha, J. K. \& Reddy, P. M. 2003. Nitrogen fixation in rice systems: State of knowledge and future prospects. Plant Soil, 252, pp. 151-167.

Li, C., Mosier, A., Wassman, R., Cai, Z., Zheng, X., Huang, Y., Tsuruta, H., Boonjawat, J. \& Lantin, R. 2004. Modeling greenhouse gas emissions from rice-based production systems: Sensitivity and scaling. Glob Biogeochem Cycl, 18 pp. 1-19.

Li, H., Liang, X., Chen, Y., Tian, G. \& Zhang, Z. 2008. Ammonia volatilization from urea in rice fields with zero-drainage water management. Agric Water Manag, 95, pp. 887894.

Liang, X., Yuan, J., He, M., Li, H., Liang, L. \& Tian, G. 2014. Modeling the fate of fertilizer $\mathrm{N}$ in paddy rice systems receiving manure and urea. Geoderma, 228-229, pp. 54-61.

Liang, X. Q., Chen, Y. X., Li, H., Tian, G. M., Ni, W. Z., He, M. M. \& Zhang, Z. J. 2007. Modelling transport and fate of nitrogen from urea applied to a near-trench paddy field. Environ Pollut, 150, pp. 313-320.

Liesack, W., Schnell, S. \& Revsbech, N. P. 2000. Microbiology of flooded rice paddies. FEMS Microbiol Rev, 24, pp. 625-645.

Lin, D.-X., Fan, X.-H., Hu, F., Zhao, H.-T. \& Luo, J.-F. 2007. Ammonia volatilization and nitrogen utilization efficiency in response to urea application in rice fields of the Taihu lake region, China. Pedosphere, 17, pp. 639-645.

Linquist, B., Van Groenigen, K. J., Adviento-Borbe, M. A., Pittelkow, C. \& Van Kessel, C. 2012. An agronomic assessment of greenhouse gas emissions from major cereal crops. Glob Change Biol, 18, pp. 194-209. 
Liu, T. Q., Fan, D. J., Zhang, X. X., Chen, J., Li, C. F. \& Cao, C. G. 2015. Deep placement of nitrogen fertilizers reduces ammonia volatilization and increases nitrogen utilization efficiency in no-tillage paddy fields in central China. Field Crop Res, 184, pp. 80-90.

Lockyer, D. R. 1984. A system for the measurement in the field of losses of ammonia through volatilisation. J Sci Food Agr, 35, pp. 837-848.

Makino, A. 2011. Photosynthesis, grain yield, and nitrogen utilization in rice and wheat. Am Soc Plant Biol, 155, pp. 125-129.

Martens, H. \& Naes, T. 1989. Multivariate Calibration. New York: John Wiley \& Sons Inc.

Massad, R. S., Nemitz, E. \& Sutton, M. A. 2010. Review and parameterisation of bidirectional ammonia exchange between vegetation and the atmosphere. Atmos Chem Phys, 10, pp. 10359-10386.

Miola, E. C. C., Aita, C., Rochette, P., Chantigny, M. H., Angers, D. A., Bertrand, N. \& Gasser, M.-O. 2015. Static chamber measurements of ammonia volatilization from manured soils: Impact of deployment duration and manure characteristics. Soil Sci Soc Am J, 79, pp. 305-313.

Molle, F. \& Srijantr, T. 2000. Access to land resources in the Chao Phraya delta: Land tenure issues revisited. In: The Chao Phraya Delta: Historical Development, Dynamics and Challenges of Thailand's Rice Bowl, 12-15 December. Bangkok: Kasetsart University, 175-209.

Nakasone, H., Abbas, M. A. \& Kuroda, H. 2004. Nitrogen transport and transformation in packed soil columns from paddy fields. Paddy Water Environ, 2, pp. 115-124.

Nemitz, E., Sutton, M. A., Gut, A., San José, R., Husted, S. \& Schjoerring, J. K. 2000a. Sources and sinks of ammonia within an oilseed rape canopy. Agric For Meteorol, 105, pp. 385-404.

Nemitz, E., Sutton, M. A., Schjoerring, J. K., Husted, S. \& Paul Wyers, G. 2000b. Resistance modelling of ammonia exchange over oilseed rape. Agric For Meteorol, 105, pp. 405425.

Ni, K., Köster, J. R., Seidel, A. \& Pacholski, A. 2015. Field measurement of ammonia emissions after nitrogen fertilization - A comparison between micrometeorological and chamber methods. Eur J Agron, 71, pp. 115-122.

Nicolaisen, M. H., Risgaard-Petersen, N., Revsbech, N. P., Reichardt, W. \& Ramsing, N. B. 2004. Nitrification-denitrification dynamics and community structure of ammonia oxidizing bacteria in a high yield irrigated Philippine rice field. FEMS Microbiol Ecol, 49, pp. 359-369.

Norton, J. P. 1986. An Introduction to Identification. London: Academic Press.

Palanivell, P., Ahmed, O. H. \& Ab Majid, N. M. 2015. Minimizing ammonia volatilization from urea, improving lowland rice (cv. MR219) seed germination, plant growth variables, nutrient uptake, and nutrient recovery using clinoptilolite zeolite. Arch Agron Soil Sci, pp. 1-17.

Patrick, W. H. \& Reddy, K. R. 1976. Nitrification-denitrification reactions in flooded soils and water bottoms: Dependence on oxygen supply and ammonium diffusion. $J$ Environ Qual, 5, pp. 469-472.

Peng, X., Maharjan, B., Yu, C., Su, A., Jin, V. \& Ferguson, R. B. 2015. A laboratory evaluation of ammonia volatilisation and nitrate leaching following nitrogen fertiliser application on a coarse-textured soil. J Agron, 107, pp. 871-879.

Pleim, J. E., Bash, J. O., Walker, J. T. \& Cooter, E. J. 2013. Development and evaluation of an ammonia bidirectional flux parameterization for air quality models. J Geophys Res: Atmos, 118, pp. 3794-3806.

Rao, P. S. C., Jessup, R. E. \& Reddy, K. R. 1984. Simulation of nitrogen dynamics in flooded soils. Soil Sci, 138, pp. 54-62. 
Reddy, K. R. 1982. Nitrogen cycling in a flooded-soil ecosystem planted to rice (Oryza sativa L.). Plant Soil, 67, pp. 209-220.

Reddy, K. R., Rao, P. S. C. \& Jessup, R. E. 1990. Transformation and transport of ammonium nitrogen in a flooded organic soil. Ecol Model, 51, pp. 205-216.

Redfern, S. K., Azzu, N. \& Binamira, J. S. 2012. Rice in Southeast Asia: Facing risks and vulnerabilities to respond to climate change. In: Meybeck, A., Lankoski, J., Redfern, S., Azzu, N. \& Gitz, V., eds. Building Resilience for Adaptation to Climate Change in the Agriculture Sector, 23-24 April. Rome: FAO, pp. 295.

Ryden, J. C. \& Lockyer, D. R. 1985. Evaluation of a system of wind tunnels for field studies of ammonia loss from grassland through volatilisation. J Sci Food Agric, 36, pp. 781788.

Schrader, F., Brümmer, C., Flechard, C. R., Wichink Kruit, R. J., Van Zanten, M. C., Richter, U., Hensen, A. \& Erisman, J. W. 2016. Non-stomatal exchange in ammonia dry deposition models: Comparison of two state-of-the-art approaches. Atmos Chem Phys Discuss, 2016, pp. 1-23.

Sharma, P. K. \& De Datta, S. K. 1986. Physical properties and processes of puddled rice soils. In: Stewart, B. A. (ed.) Advances in Soil Science. New York: Springer, pp. 139-178.

Sinclair, T. R. \& Jamieson, P. D. 2006. Grain number, wheat yield, and bottling beer: An analysis. Field Crop Res, 98, pp. 60-67.

Singh, R. \& Kirk, G. J. D. 1993. A model for predicting the fate of nitrogen fertilizer in lowland ricefields. I. Theory. J Soil Sci, 44, pp. 271-283.

Smith, E., Gordon, R., Bourque, C. \& Campbell, A. 2007. Comparison of three simple field methods for ammonia volatilization from manure. Can J Soil Sci, pp. 469-477.

Soares, J. R., Cantarella, H. \& Menegale, M. L. D. C. 2012. Ammonia volatilization losses from surface-applied urea with urease and nitrification inhibitors. Soil Biol Biochem, 52, pp. 82-89.

Sommer, S. G. \& Misselbrook, T. H. 2016. A review of ammonia emission measured using wind tunnels compared with micrometeorological techniques. Soil Use Manag, 32, pp. 101-108.

Sommer, S. G., Schjoerring, J. K. \& Denmead, O. T. 2004. Ammonia emission from mineral fertilizers and fertilized crops. Advances in Agronomy. Academic Press, pp. 557-622.

Stokstad, E. 2014. Ammonia pollution from farming may exact hefty health costs. Science, 343, pp. 238.

Tsubo, M., Fukai, S., Basnayake, J., Tuong, T. P., Bouman, B. \& Harnpichitvitaya, D. 2005. Estimating percolation and lateral water flow on sloping land in rainfed lowland rice ecosystem. Plant Prod Sci, 8, pp. 354-357.

Vlek, P. L. G., Byrnes, B. H. \& Craswell, E. T. 1980a. Effect of urea placement on leaching losses of nitrogen from flooded rice soils. Plant Soil, 54, pp. 441-449.

Vlek, P. L. G., Stumpe, J. M. \& Byrnes, B. H. 1980b. Urease activity and inhibition in flooded soil systems. Fertil Res, 1, pp. 191-202.

Walter, E. \& Piet-Lahanier, H. 1990. Estimation of parameter bounds from bounded-error data: A survey. Math Comput Simul, 32, pp. 449-468.

Ward, B. 2012. The global nitrogen cycle. In: Knoll, A. H., Canfield, D. E. \& Konhauser, K. O. (eds.) Fundamentals of Geobiology. Chichester: John Wiley \& Sons, Ltd, pp. 3648.

Wichink Kruit, R. J., Van Pul, W. a. J., Slauter, F. J., Van Den Broek, M., Nemitz, E., Sutton, M. A., Krol, M. C. \& Holtslag, A. a. M. 2010. Modeling the surface-atmosphere exchange of ammonia. Atmos Environ, 44, pp. 945-957. 
Yang, Y., Zhang, M., Li, Y., Fan, X. \& Geng, Y. 2013. Controlled-release urea commingled with rice seeds reduced emission of ammonia and nitrous oxide in rice paddy soil. $J$ Environ Qual, 42, pp. 1661-1673.

Yin, S. X., Chen, D., Chen, L. M. \& Edis, R. 2002. Dissimilatory nitrate reduction to ammonium and responsible microorganisms in two Chinese and Australian paddy soils. Soil Biol Biochem, 34, pp. 1131-1137.

Yoshinaga, I., Feng, Y., Singh, R. K. \& Shiratani, E. 2004. Dissolved nitrogen model for paddy field ponded water during irrigation period. Paddy Water Environ, 2, pp. 145152.

Young, P. 1976. Some observations on instrumental variable methods of time-series analysis. Int J Control, 23, pp. 593-612.

Young, P. C., Hornberger, G. M. \& Spear, R. C. 1978. Modelling badly defined systems: Some further thoughts. In: Proceedings of SIMSIG Simulation Conference, September, Canberra, Australia. Australian National University, 24-32.

Zhao, X., Min, J., Wang, S., Shi, W. \& Xing, G. 2011. Further understanding of nitrous oxide emission from paddy fields under rice/wheat rotation in south China. $J$ Geophys Res: Biogeoscience, 116, pp.

Zhu, G., Wang, S., Wang, Y., Wang, C., Risgaard-Petersen, N., Jetten, M. S. M. \& Yin, C. 2011. Anaerobic ammonia oxidation in a fertilized paddy soil. ISME J, 5, pp. 19051912.

Zuberer, D. A. 2005. Biological dinitrogen fixation: Introduction and nonsymbiotic. In: Sylvia, D. M., Fuhrmann, J. J., Hartel, P. G. \& Zuberer, D. A. (eds.) Principles and Applications of Soil Microbiology. 2nd ed. New Jersey: Pearson Prentice Hall, pp. 376. 
CHAPTER 2

Nitrogen dynamics in flooded soil systems: An overview on concepts and performance of models

K. Nurulhuda ${ }^{1,2}$, D.S. Gaydon ${ }^{3}$, Q. Jing ${ }^{4}$, M.P. Zakaria ${ }^{5}$, P.C. Struik ${ }^{6}$, and K.J. Keesman ${ }^{2}$ ${ }^{1}$ Biological and Agricultural Engineering, Universiti Putra Malaysia, Malaysia ${ }^{2}$ Biobased Chemistry and Technology, Wageningen University, The Netherlands ${ }^{3}$ CSIRO Agriculture and Food, Brisbane, Australia

${ }^{4}$ Ottawa Research and Development Centre, Agriculture and Agri-Food Canada, Canada ${ }^{5}$ Institute of Ocean and Earth Sciences, University of Malaya, Malaysia

${ }^{6}$ Centre for Crop Systems Analysis, Wageningen University, The Netherlands

A modified version of this chapter was submitted to the Journal of the Science of Food and Agriculture 


\begin{abstract}
Extensive modelling studies on nitrogen $(\mathrm{N})$ dynamics in flooded soil systems have been published. Consequently, many $\mathrm{N}$ dynamics models are available for users to select from. With the current research trend, inclined towards multi-disciplinary research, and with substantial progress in understanding of $\mathrm{N}$ dynamics in flooded soil systems, the objective of this chapter is to provide an overview of the modelling concepts and performance of 14 models developed to simulate $\mathrm{N}$ dynamics in flooded soil systems. This overview provides breadth of knowledge on the models, and, therefore, is valuable as a first step in the selection of an appropriate model for a specific application.
\end{abstract}

Keywords: Nitrogen model, nitrogen dynamics, flooded rice, flooded soil 


\subsection{Introduction}

Nitrogen $(\mathrm{N})$ fertiliser is applied in flooded rice systems to increase grain production, but not all applied $\mathrm{N}$ will be absorbed by the rice crop (Fageria et al., 2014). Therefore, to limit costs and negative environmental outcomes, $\mathrm{N}$ losses from fertilised and flooded rice systems must be minimised. As an alternative to a conventional experimental approach, many semi-physical $\mathrm{N}$ dynamics models for simulating $\mathrm{N}$ dynamics in flooded soil systems have been developed over the last 30 years (Rao et al., 1984, Jayaweera and Mikkelsen, 1990, Reddy et al., 1990, Godwin and Singh, 1998, Chowdary et al., 2004, Li et al., 2004, Liang et al., 2007, Antonopoulos, 2010, Jing et al., 2010, Gaydon et al., 2012b). Simulations of system behaviour of these models under different conditions provide insights into the underlying mechanisms, and are useful in evaluating which management practices reduce $\mathrm{N}$ losses and increase grain production best.

However, the interactive, non-linear and time-varying $\mathrm{N}$ processes in flooded soil systems resulted in models of different complexities. Consequently, model selection for a specific application is challenging. Fig. 1 shows the key ingredients with corresponding links required for the model selection procedure, and also illustrates that model selection commonly occurs in a loop.

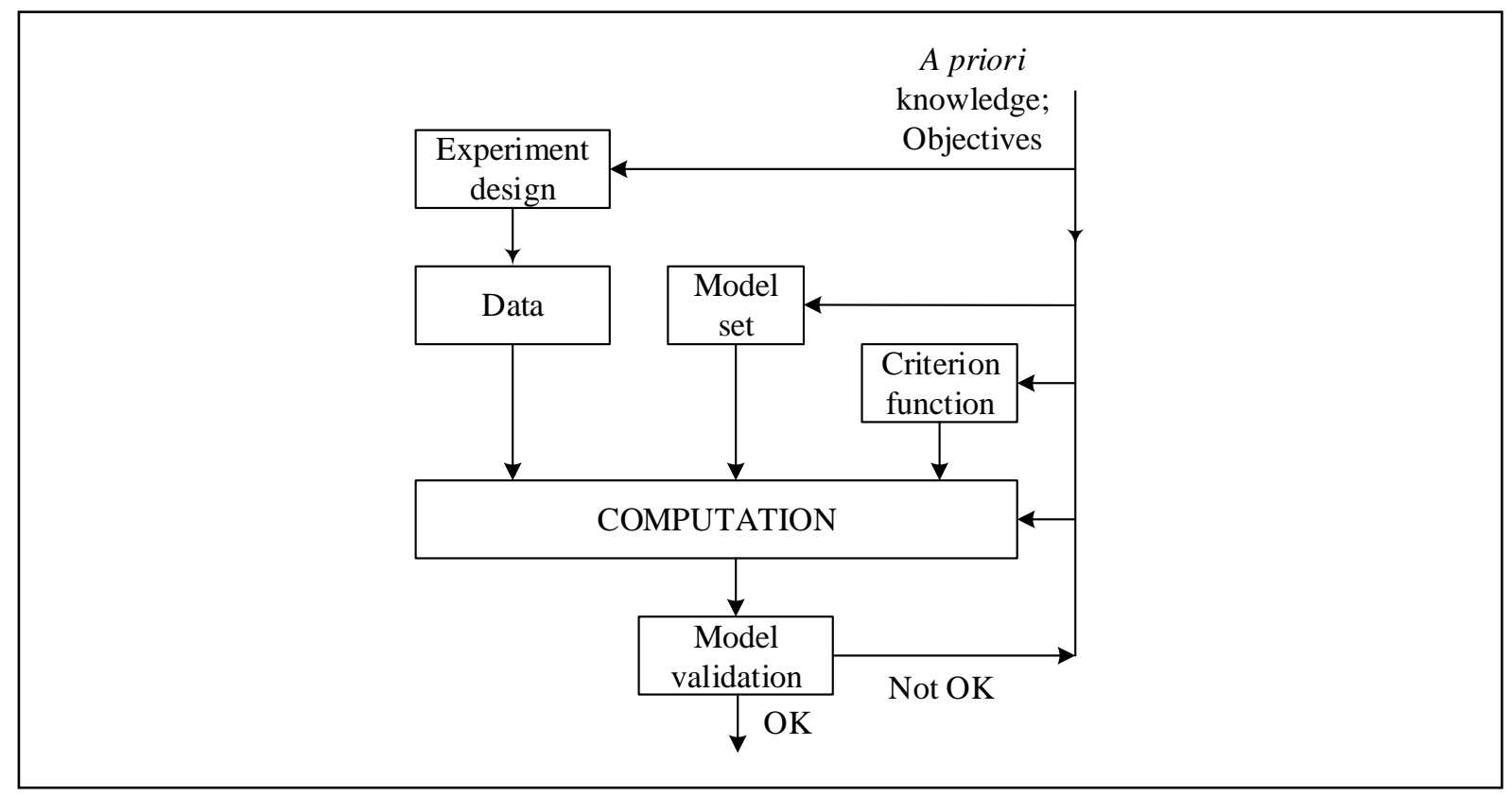

Fig. 1 The model selection loop adopted from Keesman (2011) 
Jayaweera and Mikkelsen (1991) reviewed the concepts and performances of physicallybased models developed for the estimation of $\mathrm{NH}_{3}$ volatilisation in flooded soil systems without a rice crop and in absence of other $\mathrm{N}$ processes, as e.g. included in the models of Bouwmeester and Vlek (1981), Moeller and Vlek (1982), and Jayaweera and Mikkelsen (1990). Benbi and Richter (2003) reviewed the objectives and capabilities of about 20 soil $\mathrm{N}$ dynamics models, but none of the reviewed models were applied to simulate the $\mathrm{N}$ dynamics in flooded rice systems. Nieder and Benbi (2008) reviewed models of carbon (C) and N dynamics in a soil-plant-atmosphere system, but few models were selected to illustrate different modelling concepts. Giltrap et al. (2010) and Gilhespy et al. (2014) specifically reviewed the development and performances of DeNitrification-DeComposition (DNDC) variants.

Current reviews either focus on $\mathrm{N}$ dynamics models not specific for understanding behaviour of flooded soil systems, or dedicated in understanding only one specific $\mathrm{N}$ process, or in demonstrating the capability of only one model, and, therefore, did not include comparison with alternative models. Therefore, an overview is needed that summarises key modelling concepts of models developed for simulating $\mathrm{N}$ dynamics in flooded soil systems, and provides insights to performances of these models with respect to observed data.

The objective of this chapter is, therefore, to provide an overview of modelling concepts and performance of 14 models developed to simulate $\mathrm{N}$ dynamics in flooded soil systems. The 14 models are NFLOOD v.1 (Rao et al., 1984), NFLOOD v.2 (Reddy et al., 1990), J-M's (Jayaweera and Mikkelsen, 1990), S-K's (Singh and Kirk, 1993a), CERES-Rice (Godwin and Singh, 1998), Chowdary's (Chowdary et al., 2004), Nakasone's (Nakasone et al., 2004), Yoshinaga's (Yoshinaga et al., 2004), DNDC-Rice (Li et al., 2004), K-K's (Kirk and Kronzucker, 2005), Liang's (Liang et al., 2007), RIWER (Jing et al., 2010), RICEWNB (Antonopoulos, 2010), and APSIM-Oryza (Gaydon et al., 2012a, Gaydon et al., 2012b). With substantial progress in modelling of $\mathrm{N}$ dynamics in flooded soil systems since previously published multi-model reviews, this overview provides breadth of knowledge on available models for simulating $\mathrm{N}$ dynamics in flooded soil systems, and, therefore, is valuable as a first step in the selection of an appropriate model for a specific application.

Some of these $\mathrm{N}$ dynamics models were integrated with a rice plant growth and development model, and a water balance model (Godwin and Singh, 1991, Li et al., 2004, Gaydon et al., 
2012a). However, the conceptualisation of the rice plant growth and development models is not discussed in this chapter, which may require an extensive review on its own.

In the following sections, backgrounds of the 14 models are given, followed by an overview of the key modelling concepts on $\mathrm{N}$ processes in flooded soil systems and the performance of the models. The chapter concludes with a discussion and conclusions section.

\subsection{Background of the models}

The general information on the 14 models and their acronyms, used throughout this chapter, are shown in Table A.1 in Appendix A. DNDC (Li et al., 1992), CERES (Jones and Kiniry, 1986), and APSIM (Holzworth et al., 2014) were originally developed to simulate $\mathrm{N}$ dynamics in upland agro-ecosystems. These models underwent continuous development over time, and eventually were adapted to simulate $\mathrm{N}$ dynamics in rice systems, and are referred to as DNDC-Rice (Li et al., 2004), CERES-Rice (Godwin and Singh, 1998), and APSIM-Oryza (Gaydon et al., 2012a, Gaydon et al., 2012b). RIWER (Jing et al., 2010) was developed to simulate $\mathrm{N}$ dynamics for rice-wheat cropping systems, but only components relevant to the rice system are discussed in this chapter. The remaining models presented in this chapter were developed specifically for flooded soil systems with or without rice crop.

The minimum user input that is required to run the models is summarised in Table A.2. Additional input may be needed in order to simulate rice crop growth and development models with respect to $\mathrm{N}$ uptake, but detailing of this information is not within the scope of this chapter. The $\mathrm{N}$ transport and transformations conceptualised in all 14 models is summarised in Table A.3.

\subsection{Compartmental modelling}

A compartmental modelling approach is typically used to approximate a floodwater-soil continuum in a flooded rice field. In simpler models such as Chowdary's, Liang's, RIWER, and RICEWNB, the floodwater-soil continuum is divided only into two compartments, which are a floodwater compartment and a bulk reduced soil compartment. In these models, both compartments are assumed homogeneous (Table A.1), and the thin aerobic soil layer at the floodwater-soil interface is neglected, because of its relatively small thickness (Chowdary et al., 2004). 
The floodwater is typically treated as a homogeneous compartment in all models discussed in this chapter, except in NFLOOD v.1 and v.2, and S-K's, where the floodwater was discretised vertically into smaller compartments. The floodwater depth is derived on a daily basis from the mass balance of water fluxes in a rice field, or assumed to be constant when meteorological data is not available.

In more complex models such as NFLOOD v.1 and v.2, S-K's, CERES-Rice, and APSIMOryza, the soil compartment is discretised vertically into several smaller compartments. In these models, each discretised soil compartment is assumed to be ideally mixed, and is categorised as either aerobic or anaerobic, at a given time, typically based on the calculated soil moisture content. Alternatively, the DNDC-Rice simulates the volume of aerobic and anaerobic microsites within each discretised soil compartment based on the soil redox potential. The soil redox potential was calculated using the Nernst equation on the basis of dominant oxidant and reductant concentrations in the soil (Li et al., 2004).

\subsection{Sources of nitrogen in flooded soil systems with rice crop}

Urea $\left(\mathrm{CO}\left(\mathrm{NH}_{2}\right)_{2} ; 460 \mathrm{~g} \mathrm{~N} \mathrm{~kg}^{-1}\right)$ remains the primary source of $\mathrm{N}$ in the market (Soares et al., 2012). Therefore, conceptualisation of hydrolysis of urea is relevant in models for simulating $\mathrm{N}$ dynamics in fertilised and flooded rice systems (Table A.4). Hydrolysis of urea is most often described by first-order kinetics, either with a constant rate coefficient (i.e., Chowdary's, Liang's, RIWER), or a time-varying rate coefficient that is governed by subdaily $\mathrm{pH}$ and temperature (i.e., CERES-Rice, APSIM-Oryza). Urea is either conceptualised to be fully hydrolysed in the floodwater (i.e., Chowdary's, Liang's, CERES-Rice, APSIMOryza), or to be incorporated directly into the soil (i.e., CERES-Rice, APSIM-Oryza). Vlek and Craswell (1981) reported that, unless deep placement of urea is undertaken, still $50 \%$ to $60 \%$ of applied urea entered the floodwater, despite incorporation into the soil. Thus, model simulations may substantially deviate from reality if the model assumes that all urea incorporated into the soil does not diffuse into the floodwater.

The amounts of additional $\mathrm{N}$ supply from biological $\mathrm{N}_{2}$ fixation, rainfall or irrigation water are site specific. Biological $\mathrm{N}_{2}$ fixation, however, was considered only in DNDC-Rice, merely as a rate constant that was estimated from experiments. 
In APSIM-Oryza, the dead photosynthetic aquatic biomass (PAB, i.e., algae) at the end of a rice crop was conceptualised as a source of $\mathrm{C}$ and $\mathrm{N}$ for the next cropping season. It was demonstrated that this conceptualisation was essential in simulating the performance of the International Rice Research Institute long-term continuous cropping experiment, and allows APSIM-Oryza to self-initialise the values of $\mathrm{C}$ and $\mathrm{N}$ at the beginning of each cropping season during long-term simulations (Gaydon et al., 2012a, Gaydon et al., 2012b). In order to estimate $\mathrm{N}$ obtained from dead PAB, growth of the PAB needs to be estimated. Currently, there are only two mathematical models that approximate the growth of PAB in fertilised and flooded rice systems (Gaydon et al., 2012b, Aschonitis et al., 2013).

\subsection{Inorganic nitrogen transport}

Transport of dissolved inorganic $\mathrm{N}\left(\mathrm{NH}_{4}{ }^{+}, \mathrm{NO}_{3}{ }^{-}\right.$, and urea) across the floodwater and soil compartments occurs via $\mathrm{N}$ percolation and/or $\mathrm{N}$ diffusion. $\mathrm{In}$ this chapter, $\mathrm{N}$ percolation refers to movement of dissolved $\mathrm{N}$ along with the soil water flow. As a result of compartmental modelling (Section 2.3), the $\mathrm{N}$ percolates out from one compartment to the compartment below. Diffusion, on the other hand, is driven by concentration gradients of dissolved inorganic N, which is described by Fick's law, and can be either in the upward or downward direction. Table A.3 shows the conceptualised transport of dissolved inorganic $\mathrm{N}$ in the models discussed in this chapter.

Leaching of $\mathrm{N}$ is conceptualised in CERES-Rice, Chowdary's, Nakasone's, Liang's, RICEWNB, RIWER, and APSIM-Oryza, and applies only to $\mathrm{NO}_{3}$. The $\mathrm{NH}_{4}{ }^{+}$is assumed to be bound to clay particles, whereas urea is assumed to be completely hydrolysed within the floodwater or soil compartment.

\subsection{Ammonia volatilisation}

Theoretically, only $\mathrm{NH}_{3}$ in the floodwater is susceptible to volatilisation, and the partitioning between $\mathrm{NH}_{4}{ }^{+}$and $\mathrm{NH}_{3}$ is regulated by the floodwater properties, such as $\mathrm{pH}$ and temperature. However, in Chowdary's, Liang's, and RICEWNB, the $\mathrm{NH}_{3}$ volatilisation is described in terms of first-order kinetics with a constant rate coefficient, independent of the floodwater properties. In NFLOOD v.1, the $\mathrm{NH}_{3}$ volatilisation is also described in terms of first-order kinetics, but the partitioning between $\mathrm{NH}_{4}{ }^{+}$and $\mathrm{NH}_{3}$ is approximated by a function of total ammoniacal-N concentration and floodwater $\mathrm{pH}$. 
In J-M's, the $\mathrm{NH}_{3}$ volatilisation is also described in terms of first-order kinetics, but the volatilisation rate coefficient is expressed as the ratio of an overall mass transfer coefficient and floodwater depth. A function of the overall mass transfer coefficient is further derived on the basis of the two-film theory (i.e., a thin gas film and a thin liquid film), where the movement of $\mathrm{NH}_{3}$ through the thin films is assumed to occur via molecular diffusion. Consequently, the volatilisation rate coefficient is a function of floodwater depth and temperature, and wind speed (Jayaweera and Mikkelsen, 1990). In the J-M's, the partitioning between $\mathrm{NH}_{4}{ }^{+}$and $\mathrm{NH}_{3}$ is approximated by total ammoniacal-N concentration, and floodwater $\mathrm{pH}$ and temperature. What distinguishes J-M's from other models is that the floodwater depth has a two-fold effect, one through the dilution of floodwater $\mathrm{NH}_{4}{ }^{+}-\mathrm{N}$ concentration, and the other directly through the volatilisation rate coefficient (Jayaweera and Mikkelsen, 1991).

In CERES-Rice and APSIM-Oryza, $\mathrm{NH}_{3}$ volatilisation is described by regression equations which are functions of partial pressure of $\mathrm{NH}_{3}$ in floodwater, floodwater depth, and wind speed effect. The partial pressure of $\mathrm{NH}_{3}$ in floodwater is described as a function of $\mathrm{NH}_{3}$ concentration in the floodwater and floodwater temperature (Denmead et al., 1982). Due to lack of measured wind speed, in CERES-Rice the wind speed effect is related to pan evaporation rate and leaf area index (Godwin and Singh, 1991), whereas in APSIM-Oryza, the wind speed effect is represented by a calibrated rate coefficient and pan evaporation rate (Gaydon et al., 2012b).

In DNDC-Rice, the floodwater $\mathrm{N}$ dynamics is not conceptualised. Instead, $\mathrm{NH}_{3}$ volatilisation is described as a function of $\mathrm{NH}_{3}$ concentration in the soil water, soil temperature and soil water content ( $\mathrm{Li}$ et al., 1994). Despite up to $60 \%$ of total $\mathrm{N}$ applied is susceptible to $\mathrm{NH}_{3}$ volatilisation (Fillery et al., 1984, De Datta et al., 1991), this process was not conceptualised in RIWER.

\subsubsection{Floodwater pH}

The diurnal trend of floodwater $\mathrm{pH}$, where the floodwater $\mathrm{pH}$ typically peaks at about midday, was observed by Fillery et al. (1984). The trend was hypothesised to be a result of consumption of $\mathrm{CO}_{2}$ through $\mathrm{PAB}$ photosynthesis during the day, and release of $\mathrm{CO}_{2}$ during respiration during the night. This phenomenon is conceptualised in S-K's, CERES-Rice, and APSIM-Oryza to estimate the sub-daily floodwater $\mathrm{pH}$ value. 
In CERES-Rice and APSIM-Oryza, the floodwater $\mathrm{pH}$ is approximated by a function that follows an absolute sine curve, and the $\mathrm{pH}$ magnitude is driven by PAB activity (Godwin and Singh, 1998, Gaydon et al., 2012b). The sub-daily PAB activity is defined by the most limiting among four factors: available light as a function of solar radiation and rice leaf area index (shading of floodwater), floodwater temperature, and inorganic $\mathrm{N}$ concentration and $\mathrm{P}$ presence in the floodwater. Each of these factors ranges from zero (no activity) to unity (most active). Additionally, the effect of urea hydrolysis on floodwater $\mathrm{pH}$ is included (Gaydon et al., 2012b).

In S-K's, the sub-daily floodwater $\mathrm{pH}$ was calculated from the number of protons added or consumed when there was a net change of $\mathrm{HCO}_{3}{ }^{-}$or $\mathrm{NH}_{4}{ }^{+}$, due to processes like urea hydrolysis, $\mathrm{NH}_{3}$ and $\mathrm{CO}_{2}$ volatilisation, $\mathrm{CO}_{2}$ consumption by $\mathrm{PAB}$, soil $\mathrm{CO}_{2}$ production, and transfer of protons between soil and floodwater (Singh and Kirk, 1993a).

The ranges of floodwater $\mathrm{pH}$ simulated with CERES-Rice and APSIM-Oryza are between $\mathrm{pH}$ 7.0 and 9.5 (Gaydon et al., 2012b). Singh and Kirk (1993b) assumed a soil pH of 7.0 for their simulation, which resulted in a floodwater $\mathrm{pH}$ that ranges between 7.5 and 9.0. However, this $\mathrm{pH}$ range is not always observed at other locations. For instance, floodwater $\mathrm{pH}$ on acid

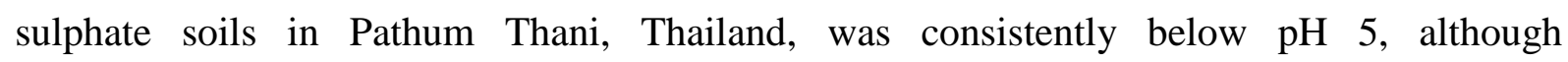
measurements were made at mid-day, when the $\mathrm{pH}$ is typically at maximum (Snitwongse et al., 1988). Nevertheless, at $\mathrm{pH}$ lower than 6.5 , the $\mathrm{NH}_{3}$ volatilisation is assumed negligible. The limitation of these models at low $\mathrm{pH}$ can be easily overcome by setting $\mathrm{NH}_{3}$ volatilisation to nil when floodwater $\mathrm{pH}$ is less than 6.5. What is important is that users must realise that the underlying concepts limit the application of the model to specific condition, i.e., rice systems with PAB growth.

\subsection{Mineralisation and immobilisation of nitrogen}

During decomposition of organic matter, inorganic $\mathrm{N}$ is released (mineralisation), and simultaneously a fraction of the available inorganic $\mathrm{N}$ is used for growth of microbial biomass (immobilisation).

In simpler models, like NFLOOD v.1 and v.2, Yoshinaga's, Chowdary's, and RICEWNB, the net mineralisation and immobilisation of $\mathrm{N}$ are described by first-order kinetics and are 
assumed to be one-step processes. In these models, the decomposition of organic matter was not detailed.

However, in DNDC-Rice, CERES-Rice, RIWER, and APSIM-Oryza, the main assumption is that not all of the fresh organic matter is prone to decomposition, and, therefore, the fresh organic matter is, in general, categorised into three pools. Decomposition of each fresh organic matter pool occurs at different rate, and results in formation of soil microbial biomass, which creates the $\mathrm{N}$ immobilisation demand. Due to death of microbes, the soil microbial biomass can further decompose into a stable pool in either one (e.g., APSIM-Oryza) or several steps (e.g., DNDC-Rice). Typically, slower potential rates of decomposition are defined under flooded soil systems compared to non-flooded soil systems (Jing et al., 2010, Gaydon et al., 2012a). Details and flow diagram of the concepts for DNDC-Rice are given in Li et al. (1992), for RIWER in Jing et al. (2010), for CERES-Rice in Godwin and Singh (1998), and for APSIM in Keating et al. (2003). The net $\mathrm{N}$ mineralised or immobilised is calculated from the mass balance of $\mathrm{N}$ that resulted from the decomposition. Factors that regulate the rate of decomposition in these models are summarised in Table A.5.

The decomposition of organic matter is assumed to take place below ground surface in DNDC-Rice (Li et al., 2004), RIWER (Jing et al., 2010), and CERES-Rice (Godwin and Singh, 1998). Alternatively, APSIM-Oryza conceptualised decomposition of fresh organic materials either on the soil surface (simulated by APSIM-SurfaceOM module), and if however the fresh organic materials are subsequently tilled into the soil, the materials decompose below ground surface (simulated by APSIM-SoilN module) (Gaydon et al., 2012a, Gaydon et al., 2012b). The concepts used in the CERES group of models for simulating mineralisation and immobilisation of N, were adapted in APSIM (Keating et al., 2003). The immobilisation $\mathrm{N}$ demand created is satisfied from inorganic $\mathrm{N}$ pool below ground surface under aerobic conditions, which is similar to the approach in CERES-Rice, or from inorganic $\mathrm{N}$ in the floodwater (simulated by APSIM-Pond module) under flooded soil conditions (Probert et al., 1998, Gaydon et al., 2012a, Gaydon et al., 2012b).

\subsection{Simultaneous nitrification and denitrification}

Nitrification and denitrification are described by first-order kinetics in NFLOOD v.1 and v.2, Chowdary's, Yoshinaga's, Nakasone's, Liang's, RICEWNB, RIWER, and CERES-Rice, whereas these processes are described by Michaelis-Menten kinetics in DNDC-Rice, K-K's, 
and APSIM-Oryza. These processes are further limited by additional factors in some of the models (Table A.6). For simplification, the limiting factors in RIWER, CERES-Rice and APSIM-Oryza are described as an index-factor, ranging between zero (no activity) and unity (most active). The growth and death of nitrifiers and denitrifiers are neglected in all of the discussed models, except in DNDC-Rice.

In the different models, nitrification and denitrification are assumed to occur at different locations in the floodwater-soil profile (Table A.6). Chowdary's assumed that the thin aerobic layer is insignificant, and therefore, they conceptualised the nitrification in the floodwater. In Yoshinaga's, denitrification is conceptualised to occur at the floodwater-soil interface. This contradicts with the common perception that denitrification does not occur at the floodwatersoil interface, where typically an aerobic layer at the floodwater-soil interface may form. The influence of rhizosphere on nitrification is excluded from all of the presented models, except in $\mathrm{K}-\mathrm{K}$ 's.

Both nitrification and denitrification are conceptualised in CERES-Rice and APSIM-Oryza. In APSIM-Oryza, under flooded condition, nitrification is halted under the assumption that $\mathrm{O}_{2}$ is immediately lost from the soil profile, but denitrification continues (Gaydon et al., 2012a).

\subsection{Nitrogen uptake by rice crop}

Inorganic $\mathrm{N}$ uptake by rice is conceptualised in all models discussed in this chapter, except in NFLOOD v.1 and v.2, J-M's, Nakasone's, and Yoshinaga's (Table A.3). Models that were developed to estimate grain production are coupled to a comprehensive rice plant growth and development model. For instance, DNDC-Rice is coupled to a generic crop growth and development model, MACROS (Penning De Vries et al., 1989), whereas RIWER and APSIM-Oryza are coupled to ORYZA2000 (Bouman et al., 2001), which is specifically developed for rice systems. CERES-Rice incorporates its own rice production model. However, details of these integrated models are out of the scope of this chapter.

Models that were developed to estimate the overall $\mathrm{N}$ balances used a simpler approximation of $\mathrm{N}$ uptake by rice crop. For instance, the $\mathrm{N}$ uptake by rice crop in Chowdary's and Liang's is described as a function of established rice crop coefficient and daily evapotranspiration. In RICEWNB and K-K's, the $\mathrm{N}$ uptake is described by Michaelis-Menten kinetics. In RICEWNB, the maximum rate of $\mathrm{N}$ uptake is limited by leaf area index, root distribution, and 
temperature, where each of these limiting factors is expressed as an index-factor.

Singh and Kirk (1993b) simulated that the urea and ammoniacal-N spread from the soil surface to $0.03 \mathrm{~m}$ below the soil surface in 7 days. Based on this calculation, Kirk and Solivas (1997) hypothesised that most of the broadcast $\mathrm{N}$ were absorbed by the dense root mat at the floodwater-soil interface.

\subsection{Ammonium adsorption and desorption in soil}

The $\mathrm{NH}_{4}{ }^{+}$may reside in soil solution or be absorbed to clay particles. Several models conceptualised the adsorption and desorption (Table A.3). $\mathrm{NH}_{4}{ }^{+}$adsorption and desorption are complex and site-specific processes, and measurement method to discriminate between native (non-available) and recently absorbed (plant-available) $\mathrm{NH}_{4}{ }^{+}$needs further research (Nieder et al., 2011). Detailing $\mathrm{NH}_{4}{ }^{+}$adsorption and desorption in a field-scale model that already has many parameters (calibrated rate coefficients) will most likely lead to unidentifiable parameters (Keesman, 2011). From a systems theory point of view, an unidentifiable parameter does not have a unique value in a parameter estimation (calibration) step, and thus cannot be estimated uniquely.

\subsection{Performance of nitrogen dynamics models}

In this section, an overview of performance of each model with respect to observational data sets shown in Table A.7 is given. Only data sets relevant to $\mathrm{N}$ dynamics in flooded soil systems that are either continuously flooded or flooded during at least part of the rice cropping period are listed in the table as this chapter focuses on modelling of $\mathrm{N}$ dynamics in flooded soil systems. In addition to Table A.7, a comprehensive review on the performance of CERES-Rice for simulating rice crop grain production, aboveground biomass, and phenological variables based on 26 studies is already provided by Basso et al. (2016).

Out of the 14 models presented in this chapter, only Chowdary's, Liang's, RICEWNB, DNDC-Rice, RIWER, CERES-Rice, and APSIM-Oryza are ready for simulation of $\mathrm{N}$ dynamics in fertilised and flooded rice systems, as $\mathrm{N}$ fertiliser as input and plant uptake by the rice crop are conceptualised in these models.

Chowdary's, Liang's, and RICEWNB could be categorised as lumped-parameter models because all of the $\mathrm{N}$ processes in these models, except for $\mathrm{N}$ uptake by the rice crop, are 
described by a first-order kinetics, independent of the environmental variables, such as $\mathrm{pH}$ and temperature. These lumped-parameter models are suitable for the estimation of the seasonal $\mathrm{N}$ balances in fertilised and flooded rice systems at the end of a cropping season, such as seasonal $\mathrm{N}$ uptake by rice crop, $\mathrm{NH}_{3}$ volatilisation, denitrification, mineralisation, immobilisation or $\mathrm{NO}_{3}{ }^{-}$leaching (Table A.7). However, differences in the modelling concepts in each of these models must be evaluated for conditions at a study site. For instance, mineralisation and immobilisation are included in Chowdary's, but not in Liang's. N loss via surface runoff and lateral seepage are included in Liang's, but not in Chowdary's. In these models, the estimates of seasonal $\mathrm{N}$ balances are largely determined by the calibrated constant rate coefficients, which may change over time and location. Nevertheless, these models are appealing and comprehensible because of their simplicity, and given small data sets, these models are advantageous.

For flooded soil systems without a rice crop, the J-M's is valuable for simulating temporal (daily or sub-daily) $\mathrm{NH}_{3}$ volatilisation. This model has been evaluated for estimating temporal $\mathrm{NH}_{3}$ volatilisation from total ammoniacal-N solution (Table A.7). The regulators of $\mathrm{NH}_{3}$ volatilisation, such as wind speed, floodwater temperature, $\mathrm{pH}$, and depth are conceptualised in this model (Section 2.6), and, therefore, the model is appropriate for studying the mechanisms of $\mathrm{NH}_{3}$ volatilisation from the floodwater surface of a flooded soil system. The trade-off, however, is that the operation of the model requires several measured input data such as sub-daily concentrations of total ammoniacal-N in the floodwater, wind speed, floodwater $\mathrm{pH}$, temperature, and depth which may not always be available, and, therefore, this may hinder simulation of J-M's. A significant assumption underlying this model is that the rate of $\mathrm{NH}_{3}$ volatilisation equates to the change in total ammoniacal- $\mathrm{N}$ in the floodwater. Consequently, estimation of $\mathrm{NH}_{3}$ volatilisation from the floodwater using this model is currently limited to flooded soil systems without rice crops.

The NFLOOD v.1, NFLOOD v.2, and S-K's, were developed to simulate temporal $\mathrm{N}$ dynamics in both the floodwater and soil. NFLOOD v.2 was evaluated with temporal concentrations of $\mathrm{NH}_{4}{ }^{+}$in the soil profile, but NFLOOD v.2 did not include $\mathrm{NH}_{3}$ volatilisation unlike NFLOOD v.1 (Table A.7). S-K's has not been evaluated with observational data sets, but an advantage of the S-K's model compared to all other models is its ability to simulate the diurnal floodwater $\mathrm{pH}$ based on the total ammoniacal-N and organic $\mathrm{C}$ balances in the floodwater and soil. 
CERES-Rice, RIWER, and APSIM-Oryza offer estimation of temporal $\mathrm{N}$ content in the floodwater and soil, temporal $\mathrm{N}$ uptake by a rice crop, and the crop biomass (root, stem, leaf, grain). In order to operate these models, detailed input on rice varietal crop stages (phenology) is required. CERES-Rice and APSIM-Oryza have been rigorously evaluated for grain production (Table A.7 and Basso et al. (2016)). Unlike CERES-Rice and APSIM-Oryza, application of RIWER is currently limited to conditions where $\mathrm{NH}_{3}$ volatilisation is negligible. Of the three models, APSIM-Oryza can self-initialise the soil $\mathrm{C}$ and $\mathrm{N}$ values because it accounts for $\mathrm{C}$ and $\mathrm{N}$ inputs from $\mathrm{PAB}$, and, therefore, the model can continuously simulate the $\mathrm{N}$ dynamics and the crop biomass for several cropping seasons without reset (Gaydon et al., 2012b).

DNDC-Rice was developed mainly to predict greenhouse gas emissions $\left(\mathrm{N}_{2} \mathrm{O}\right.$ and $\left.\mathrm{NO}\right)$ and $\mathrm{NH}_{3}$ loss in fertilised and flooded rice systems. In comparison to other models, the DNDCRice has been rigorously evaluated with $\mathrm{N}_{2} \mathrm{O}$ emissions from fertilised and flooded rice systems (Table A.7), but not for $\mathrm{NH}_{3}$ volatilisation. Overall, DNDC-Rice is able to produce good estimates of seasonal $\mathrm{N}_{2} \mathrm{O}$ emissions, but at times, poor performance in simulating the temporal trends of $\mathrm{N}_{2} \mathrm{O}$ was observed (Table A.7). The model does not simulate the $\mathrm{N}$ dynamics in the floodwater, which in theory is a vital component for estimating $\mathrm{NH}_{3}$ volatilisation in a flooded soil system. The extent to which neglecting of the floodwater $\mathrm{N}$ dynamics affects the estimation of $\mathrm{NH}_{3}$ volatilisation has not been quantified nor compared against experimental data. Therefore, the performance of DNDC-Rice for estimating $\mathrm{NH}_{3}$ volatilisation is a subject for further assessment.

Nakasone's and Yoshinaga's are limited to simulating temporal concentrations of inorganic $\mathrm{N}$ in the soil and floodwater, respectively (Table A.7). The total $\mathrm{N}$ uptake by a rice crop was not conceptualised in Yoshinaga's. Despite this debatable modelling concept, simulation of the model for flooded soil systems with a young rice crop resulted in a good fit between observed and simulated inorganic $\mathrm{N}$ concentration in the floodwater. It is most plausible that the conceptualised phytoplankton $\mathrm{N}$ uptake from the floodwater compensated for the absence of rice crop $\mathrm{N}$ uptake.

\subsection{Discussion and conclusions}

Each model presented in this chapter produces multiple outputs, but Table A.7 shows that not all of the outputs were evaluated with observational data sets. Furthermore, each model was 
evaluated with observational data sets obtained from different experiments, conducted at different location and time. Consequently, outcomes of evaluation of these models cannot be directly compared with each other. Furthermore, model evaluation based on data fitting alone is not always ideal, because two models of different fundamentals can fit the same data set as demonstrated in Kirchner et al. (1996), especially if the model is over-parameterised and data is scarce. Co-validation is the assessment of the difference between models with respect to the values of their common output, and may provide insights on behaviour of models (Bellocchi et al., 2010, Bennett et al., 2013), and, thus, is the next step in order to quantify discrepancies of simulated outputs by models with different fundamentals, and limitation of each model, preferably under range of site conditions. Under scarce data conditions, evaluating output trends and systems behaviour using synthetic data sets that mimic typical site conditions could be an alternative.

Detailed modelling of soil $\mathrm{N}$ dynamics easily results in complex models, but the model component related to the soil $\mathrm{N}$ dynamics is also the component least evaluated against measurement. Table A.7 shows that, except for NFLOOD v.2, RICEWNB, and RIWER, the temporal soil inorganic $\mathrm{N}$ simulated by other models are not evaluated with measured soil $\mathrm{N}$ data, mainly due to scarcity of data. Notice also from Table A.7 that for the evaluation of RICEWNB, the measured soil $\mathrm{N}$ data set is small; only three measurements of soil total inorganic $\mathrm{N}$ were recorded after the first $\mathrm{N}$ fertiliser application, and another three measurements following the second application.

To the best of our knowledge, detailed spatial and temporal soil inorganic $\mathrm{N}$ variation was published only in two papers (Makarim et al., 1991, Dobermann et al., 1994). In Dobermann et al. (1994), the experimental plot received a total of $200 \mathrm{~kg} \mathrm{~N} \mathrm{ha}^{-1} ; 80 \mathrm{~kg} \mathrm{~N}^{-1}$ was incorporated into the soil for basal application and $120 \mathrm{~kg} \mathrm{~N} \mathrm{ha}^{-1}$ was broadcasted into the floodwater in three equal splits. Dobermann et al. (1994) observed low concentration of $\mathrm{NH}_{4}{ }^{+}-\mathrm{N}$, ranging from $0 \mathrm{mg} \mathrm{N} \mathrm{L}^{-1}$ to $3 \mathrm{mg} \mathrm{N} \mathrm{L}^{-1}$, in soil solutions that were extracted using three techniques: soil solution extracted using a rhizon soil solution sampler (diameter of 2.3 $\mathrm{mm}$ and a pore size of $0.1 \mu \mathrm{m})$, soil solution extracted by centrifuging field-moist soil (9000 rpm for 15 minutes), and solution obtained with a standard cation displacement technique (3 $\mathrm{g}$ of field moist soil in $30 \mathrm{~mL}$ of $2 \mathrm{M} \mathrm{KCl}$ ). Similarly, low concentrations of $\mathrm{NH}_{4}{ }^{+}-\mathrm{N}$, ranging from $0 \mathrm{mg} \mathrm{N} \mathrm{L}^{-1}$ to $3 \mathrm{mg} \mathrm{N} \mathrm{L}^{-1}$, were observed by Makarim et al. (1991). 
At low concentrations of $\mathrm{NH}_{4}{ }^{+}-\mathrm{N}$, the temporal dynamics may be masked by the spatial variation (Dobermann et al., 1994). Based on this setback, in combination with interactive soil $\mathrm{N}$ processes (e.g., mineralisation, immobilisation, nitrification, denitrification, and $\mathrm{NH}_{4}{ }^{+}$ adsorption and desorption), we infer that validation of field scale models for simulating $\mathrm{N}$ dynamics in fertilised and flooded rice systems against measured temporal inorganic soil $\mathrm{N}$ content may not be informative with respect to the model structure adequacy. Although soil N processes contribute to the overall $\mathrm{N}$ dynamic in the systems, due to lack of relevant data for evaluation of these processes, it is debatable whether these processes should be detailed in existing field-scale models. It was already suggested by Cassman et al. (2002) that a realistic prediction of soil $\mathrm{N}$ dynamics using models is difficult due to complexity of the interactive soil $\mathrm{N}$ processes.

Other potential processes such as anaerobic ammonium oxidation (Zhu et al., 2011), dissimilatory reduction of $\mathrm{NO}_{3}{ }^{-}$, or biological $\mathrm{N}_{2}$ fixation, were as yet not conceptualised in any of the 14 models. Regardless of this, notice that some of the outputs of the models have been successfully validated against observational data sets (Section 2.11). Conceptualising these neglected processes may emulate the actual system, but the model may become overparameterised. Consequently, parameters may become unidentifiable, and experimental (parameter) values may not be representative for all sites.

There is a traditional trade-off between simple and complex models. The rate coefficients in simpler models may be identifiable, i.e., will lead to a unique set of parameter estimates in a calibration step, but the model may not accurately predict the changing future behaviour (Beck, 1981). Meanwhile, the model can be used for a wide range of applications and future predictions, but estimation of the rate coefficients may require more data sets (Beck, 1981). Observational data sets from flooded rice systems are typically small - not all of the process variables are measured in a particular experiment, because experiments, in general, were not specifically designed for evaluation of a model. The observations are seldom true values due to measurement errors. Confalonieri et al. (2016) state the need for conceptual and mathematical frameworks that considers multiple sources of uncertainty in the prediction, such as uncertainty in the model structure, parameters, and observations that are used as input to the model or calibration data set. For small data sets, a probabilistic estimation is not adequate because detail error characterisation in terms of probability density function is hindered (Keesman and Van Straten, 1990). Alternatively, a set-membership (bounded-error) 
parameter estimation can be used to evaluate a model (Walter, 1990, Norton, 1994, Norton, 1995, Milanese et al., 1996, Nurulhuda et al., 2015).

$\mathrm{NH}_{3}$ volatilisation is claimed as one of the major pathways for $\mathrm{N}$ loss, but may range from 2 $\%$ through $60 \%$ of total $\mathrm{N}$ applied (Fillery et al., 1984, Fillery et al., 1986). $\mathrm{NH}_{3}$ volatilisation is conceptualised in 9 out of 14 models presented. We observed that the conceptualisations of $\mathrm{NH}_{3}$ volatilisation in these models vary (Section 2.6). Therefore, to increase confidence in existing models, future research should investigate whether these different concepts would result in different model outputs, and under what conditions. The floodwater $\mathrm{pH}$ is one the key regulators of $\mathrm{NH}_{3}$ volatilisation, and can be estimated by several models (Section 2.6.1). Therefore, the accuracy of the floodwater $\mathrm{pH}$ prediction, and to what extent the accuracy does affect the predicted $\mathrm{NH}_{3}$ volatilisation by each model, is subject to further research.

Interest in the roles of $\mathrm{PAB}$ is recently rekindled with modelling work progressing towards understanding of the contribution of PAB in nutrient cycles in flooded rice systems (Gaydon et al., 2012b, Aschonitis et al., 2013). Therefore, a better understanding of how potential PAB growth rates vary with location and environment will increase the confidence in models that had already included a sub-model of PAB activity, such as CERES-Rice and APSIM-Oryza.

Given the set of $\mathrm{N}$ dynamics models considered with their different concepts, it is challenging for the researcher to choose a model for evaluating static and dynamic management strategies in rice farming to support farmers, producers and researchers, in their decision making. In this chapter, however, we have provided a basis to assist the researcher in choosing based on definition of key focal processes

\section{References}

Antonopoulos, V. Z. 2010. Modelling of water and nitrogen balances in the ponded water and soil profile of rice fields in Northern Greece. Agric Water Manag, 98, pp. 321-330

Aschonitis, V. G., Lekakis, E. H., Petridou, N. C., Koukouli, S. G. \& Pavlatou-Ve, A. 2013. Nutrients fixation by algae and limiting factors of algal growth in flooded rice fields under semi-arid Mediterranean conditions: case study in Thessaloniki plain in Greece. Nutr Cycl Agroecosyst, 96, pp. 1-13.

Babu, Y. J., Li, C., Frolking, S., Nayak, D. R. \& Adhya, T. K. 2006. Field validation of DNDC model for methane and nitrous oxide emissions from rice-based production systems of India. Nutr Cycl Agroecosyst, 74, pp. 157-174.

Basso, B., Liu, L. \& Ritchie, J. T. 2016. A comprehensive review of the CERES-Wheat, Maize and -Rice models' performances. In: Donald, L. S. (ed.) Advances in Agronomy. Academic Press, pp. 27-132. 
Beck, M. B. 1981. Hard or soft environmental systems? Ecol Model, 11, pp. 233-251.

Bellocchi, G., Rivington, M., Donatelli, M. \& Matthews, K. 2010. Validation of biophysical models: Issues and methodologies. A review. Agron Sustain Dev, 30, pp. 109-130.

Benbi, D. K. \& Richter, J. 2003. Nitrogen dynamics. In: Benbi, D. K. \& Nieder, R. (eds.) Handbook of Processes and Modeling in the Soil-Plant System. New York, London, Oxford: Food Products Press and The Harworth Reference Press, pp. pp. 409-482.

Bennett, N. D., Croke, B. F. W., Guariso, G., Guillaume, J. H. A., Hamilton, S. H., Jakeman, A. J., Marsili-Libelli, S., Newham, L. T. H., Norton, J. P., Perrin, C., Pierce, S. A., Robson, B., Seppelt, R., Voinov, A. A., Fath, B. D. \& Andreassian, V. 2013. Characterising performance of environmental models. Environ Model Softw, 40, pp. 120.

Bouman, B. a. M., Kropff, M. J., Tuong, T. P., Wopereis, M. C. S., Ten Berge, H. F. M. \& Van Laar, H. H. 2001. ORYZA2000: Modelling Lowland Rice. Wageningen: International Rice Research Institute, Los Banos and Wageningen University and Research Centre.

Bouwmeester, R. J. B. \& Vlek, P. L. G. 1981. Rate control of ammonia volatilization from rice paddies. Atmos Environ, 15, pp. 131-140.

Cassman, K. G., Dobermann, A. \& Walters, D. T. 2002. Agroecosystems, nitrogen-use efficiency and nitrogen management. AMBIO: J Hum Environ, 31, pp. 132-140.

Chowdary, V. M., Rao, N. H. \& Sarma, P. B. S. 2004. A coupled soil water and nitrogen balance model for flooded rice fields in India. Agric Ecosyst Environ, 103, pp. 425441.

Confalonieri, R., Bregaglio, S., Adam, M., Ruget, F., Li, T., Hasegawa, T., Yin, X., Zhu, Y., Boote, K., Buis, S., Fumoto, T., Gaydon, D., Lafarge, T., Marcaida, M., Nakagawa, H., Ruane, A. C., Singh, B., Singh, U., Tang, L., Tao, F., Fugice, J., Yoshida, H., Zhang, Z., Wilson, L. T., Baker, J., Yang, Y., Masutomi, Y., Wallach, D., Acutis, M. \& Bouman, B. 2016. A taxonomy-based approach to shed light on the babel of mathematical models for rice simulation. Environ Model Softw, 85, pp. 332-341.

De Datta, S. K., Samson, M. I., Obcemea, W. N., Real, J. G. \& Buresh, R. J. 1991. Direct measurement of ammonia and denitrification fluxes from urea applied to rice. Soil Sci Soc Am J, 55, pp. 543-548.

Denmead, O. T., Freney, J. R. \& Simpson, J. R. 1982. Dynamics of ammonia volatilization during furrow irrigation of maize. Soil Sci Soc Am J, 46, pp. 149-155.

Dobermann, A., Gaunt, J. L., Neue, H. U., Grant, I. F., Adviento, M. A. \& Pampolino, M. F. 1994. Spatial and temporal variability of ammonium in flooded rice fields. Soil Sci Soc Am J, 58, pp. 1708-1717.

Fageria, N. K., Moreira, A., Moraes, L. a. C. \& Moraes, M. F. 2014. Nitrogen uptake and use efficiency in upland rice under two nitrogen sources. Commun Soil Sci Plant Anal, 45, pp. 461-469.

Fillery, I. R. P., Roger, P. A. \& De Datta, S. K. 1986. Ammonia volatilization from nitrogen sources applied to rice fields: II. Floodwater properties and submerged photosynthetic biomass. Soil Sci Soc Am J, 50, pp. 86-91.

Fillery, I. R. P., Simpson, J. R. \& De Datta, S. K. 1984. Influence of field environment and fertilizer management on ammonia loss from flooded rice. Soil Sci Soc Am J, 48, pp. 914-920.

Fumoto, T., Kobayashi, K., Li, C., Yagi, K. \& Hasegawa, T. 2008. Revising a process-based biogeochemistry model (DNDC) to simulate methane emission from rice paddy fields under various residue management and fertilizer regimes. Glob Change Biol, 14, pp. 382-402. 
Gaydon, D. S., Probert, M. E., Buresh, R. J., Meinke, H., Suriadi, A., Dobermann, A., Bouman, B. \& Timsina, J. 2012a. Rice in cropping systems - Modelling transition between flooded and non-flooded soil environments. Eur J Agron, 39, pp. 9-24.

Gaydon, D. S., Probert, M. E., Buresh, R. J., Meinke, H. \& Timsina, J. 2012b. Modelling the role of algae in rice crop nutrition and soil organic carbon maintenance. Eur J Agron, 39, pp. 35-43.

Gilhespy, S. L., Anthony, S., Cardenas, L., Chadwick, D., Del Prado, A., Li, C., Misselbrook, T., Rees, R. M., Salas, W., Sanz-Cobena, A., Smith, P., Tilston, E. L., Topp, C. F. E., Vetter, S. \& Yeluripati, J. B. 2014. First 20 years of DNDC (DeNitrification DeComposition): Model evolution. Ecol Model, 292, pp. 51-62.

Giltrap, D. L., Li, C. \& Saggar, S. 2010. DNDC: A process-based model of greenhouse gas fluxes from agricultural soils. Agric Ecosyst Environ, 136, pp. 292-300.

Godwin, D. C. \& Singh, U. 1991. Modelling nitrogen dynamics in rice cropping systems. In: Deturck, P. \& Ponnamperuma, F. N. (eds.) Rice Production on Acid Soils of the Tropics. Kandy: Institute of Fundamental Studies, pp. 287-294.

Godwin, D. C. \& Singh, U. 1998. Nitrogen balance and crop response to nitrogen in upland and lowland cropping systems. In: Tsuji, G. Y., Hoogenboom, G. \& Thornton, P. K. (eds.) Understanding Options for Agricultural Production. Springer Netherlands, pp. 55-77.

Hayashi, K., Nishimura, S. \& Yagi, K. 2008. Ammonia volatilization from a paddy field following applications of urea: Rice plants are both an absorber and an emitter for atmospheric ammonia. Sci Total Environ, 390, pp. 485-494.

Holzworth, D. P., Huth, N. I., Devoil, P. G., Zurcher, E. J., Herrmann, N. I., Mclean, G., Chenu, K., Van Oosterom, E., Snow, V., Murphy, C., Moore, A. D., Brown, H., Whish, J. P. M., Verrall, S., Fainges, J., Bell, L. W., Peake, A. S., Poulton, P. L., Hochman, Z., Thorburn, P. J., Gaydon, D. S., Dalgliesh, N. P., Rodriguez, D., Cox, H., Chapman, S., Doherty, A., Teixeira, E., Sharp, J., Cichota, R., Vogeler, I., Li, F. Y., Wang, E., Hammer, G. L., Robertson, M. J., Dimes, J., Carberry, P. S., Hargreaves, J. N. G., Macleod, N., Mcdonald, C., Harsdorf, J., Wedgwood, S. \& Keating, B. A. 2014. APSIM - Evolution towards a new generation of agricultural systems simulation. Environ Model Softw, 62, pp. 327-350.

Jayaweera, G. R. \& Mikkelsen, D. S. 1990. Ammonia volatilization from flooded soil systems: A computer model. I. Theoretical aspects. Soil Sci Soc Am J, 54, pp. 14471455.

Jayaweera, G. R. \& Mikkelsen, D. S. 1991. Assessment of ammonia volatilization from flooded soil systems. In: Brady, N. C. (ed.) Advances in Agronomy. San Diego: Academic Press, pp. 303-356.

Jayaweera, G. R., Paw U., K. T. \& Mikkelsen, D. S. 1990. Ammonia volatilization from flooded soil systems: A computer model. III. Validation of the model. Soil Sci Soc Am J, 54, pp. 1462-1468.

Jing, Q., Van Keulen, H. \& Hengsdijk, H. 2010. Modeling biomass, nitrogen and water dynamics in rice-wheat rotations. Agric Syst, 103, pp. 433-443

Jones, C. A. \& Kiniry, J. R. 1986. CERES-Maize: A Simulation Model of Maize Growth and Development. Texas: Texas A\&M University Press.

Katayanagi, N., Furukawa, Y., Fumoto, T. \& Hosen, Y. 2012. Validation of the DNDC-Rice model by using $\mathrm{CH}_{4}$ and $\mathrm{N}_{2} \mathrm{O}$ flux data from rice cultivated in pots under alternate wetting and drying irrigation management. Soil Sci Plant Nutr, 58, pp. 360-372.

Katayanagi, N., Ono, K., Fumoto, T., Mano, M., Miyata, A. \& Hayashi, K. 2013. Validation of the DNDC-Rice model to discover problems in evaluating the nitrogen balance at a paddy-field scale for single-cropping of rice. Nutr Cycl Agroecosyst, 95, pp. 255-268. 
Keating, B. A., Carberry, P. S., Hammer, G. L., Probert, M. E., Robertson, M. J., Holzworth, D., Huth, N. I., Hargreaves, J. N. G., Meinke, H., Hochman, Z., Mclean, G., Verburg, K., Snow, W., Dimes, J. P., Silburn, M., Wang, E., Brown, S., Bristow, K. L., Asseng, S., Chapman, S., Mccown, R. L., Freebairn, D. M. \& Smith, C. J. 2003. An overview of APSIM, a model designed for farming system simulation. Eur J Agron, 18, pp. 267288.

Keesman, K. J. 2011. System Identification: An Introduction. Springer UK.

Keesman, K. J. \& Van Straten, G. 1990. Set membership approach to identification and prediction of lake eutrophication. Water Resour Res, 26, pp. 2643-2652.

Kirchner, J. W., Hooper, R. P., Kendall, C., Neal, C. \& Leavesley, G. 1996. Testing and validating environmental models. Sci Total Environ, 183, pp. 33-47.

Kirk, G. J. D. \& Kronzucker, H. J. 2005. The potential for nitrification and nitrate uptake in the rhizosphere of wetland plants: A modelling study. Ann Bot, 96, pp. 639-646.

Kirk, G. J. D. \& Solivas, J. L. 1997. On the extent to which root properties and transport through the soil limit nitrogen uptake by lowland rice. Eur J Soil Sci, 48, pp. 613-621.

Li, C., Frolking, S. \& Frolking, T. A. 1992. A model of nitrous oxide evolution from soil driven by rainfall events: 1. Model structure and sensitivity. J Geophys Res: Atmos, 97, pp. 9759-9776.

Li, C., Frolking, S. \& Harriss, R. 1994. Modelling carbon biogeochemistry in agricultural soils. Glob Biogeochem Cycl, 8, pp. 237-254.

Li, C., Frolking, S., Xiao, X., Moore Iii, B., Boles, S., Qiu, J., Huang, Y., Salas, W. \& Sass, R. 2005. Modelling impacts of farming management alternatives on $\mathrm{CO}_{2}, \mathrm{CH}_{4}$ and $\mathrm{N}_{2} \mathrm{O}$ emissions: A case study for water management of rice agriculture of China. Glob Biogeochem Cycl, 19, pp.

Li, C., Mosier, A., Wassman, R., Cai, Z., Zheng, X., Huang, Y., Tsuruta, H., Boonjawat, J. \& Lantin, R. 2004. Modeling greenhouse gas emissions from rice-based production systems: Sensitivity and scaling. Glob Biogeochem Cycl, 18 pp. 1-19.

Liang, X., Yuan, J., He, M., Li, H., Liang, L. \& Tian, G. 2014. Modeling the fate of fertilizer $\mathrm{N}$ in paddy rice systems receiving manure and urea. Geoderma, 228-229, pp. 54-61.

Liang, X. Q., Chen, Y. X., Li, H., Tian, G. M., Ni, W. Z., He, M. M. \& Zhang, Z. J. 2007. Modelling transport and fate of nitrogen from urea applied to a near-trench paddy field. Environ Pollut, 150, pp. 313-320.

Makarim, A. K., Hidayat, A. \& Ten Berge, H. F. M. 1991. Dynamics of soil ammonium, crop nitrogen uptake and dry matter production in lowland rice. In: De Vries, P., ed. Simulation and System Analysis for Rice Production (SARP), Wageningen. PUDOC, 214-228.

Milanese, M., Norton, J. P. \& Piet-Lahanier, H. W., E. 1996. Bounding Approaches to Systems Identification. New York: Plenum Press.

Moeller, M. B. \& Vlek, P. L. G. 1982. The chemical dynamics of ammonia volatilization from aqueous solution. Atmos Environ, 16, pp. 709-717.

Nakasone, H., Abbas, M. A. \& Kuroda, H. 2004. Nitrogen transport and transformation in packed soil columns from paddy fields. Paddy Water Environ, 2, pp. 115-124.

Nieder, R. \& Benbi, D. K. 2008. Carbon and Nitrogen in the Terrestrial Environment. Springer Netherlands.

Nieder, R., Benbi, D. K. \& Scherer, H. W. 2011. Fixation and defixation of ammonium in soils: A review. Biol Fertil Soils, 47, pp. 1-14

Norton, J. P. 1994. Bounded-error estimation: Issue 1. Int J Adapt Control Signal Process, 8, pp.

Norton, J. P. 1995. Bounded-error estimation: Issue 2. Int J Adapt Control Signal Process, 9, pp. 
Nurulhuda, K., Struik, P. C. \& Keesman, K. J. 2015. Set-membership identification of an agro-ecosystems from a small data set: The case of ammonia volatilisation in a flooded rice field. In: MATHMOD 2015: 8th Vienna International Conference on Mathematical Modelling, Vienna, Austria. 580-585.

Pathak, H., Li, C. \& Wassmann, R. 2005. Greenhouse gas emissions from Indian rice fields: Calibration and upscaling using the DNDC model. Biogeosciences, 2, pp. 113-123.

Penning De Vries, F. W. T., Jansen, D. M., Ten Berge, H. F. M. \& Balema, A. 1989. Simulation of Ecophysiological Processes of Growth in Several Annual Crops. Wageningen: International Rice Research Institute, Los Banos and PUDOC.

Probert, M. E., Dimes, J. P., Keating, B. A., Dalal, R. C. \& Strong, W. M. 1998. APSIM's water and nitrogen modules and simulation of the dynamics of water and nitrogen in fallow systems. Agric Syst, 56, pp. 1-28.

Rao, P. S. C., Jessup, R. E. \& Reddy, K. R. 1984. Simulation of nitrogen dynamics in flooded soils. Soil Sci, 138, pp. 54-62.

Reddy, K. R., Rao, P. S. C. \& Jessup, R. E. 1990. Transformation and transport of ammonium nitrogen in a flooded organic soil. Ecol Model, 51, pp. 205-216.

Singh, R. \& Kirk, G. J. D. 1993a. A model for predicting the fate of nitrogen fertilizer in lowland ricefields. I. Theory. J Soil Sci, 44, pp. 271-283.

Singh, R. \& Kirk, G. J. D. 1993b. A model for predicting the fate of nitrogen fertilizer in lowland ricefields. II. Predicted dynamics of inorganic carbon, nitrogen and acidity in the soil and floodwater. J Soil Sci, 44, pp. 285-297.

Singh, U., Tsuji, G. Y. \& Godwin, D. C. 1991. The decision support system for agrotechnology transfer: Uses in rice research. In: Deturck, P. \& Ponnamperuma, F. N. (eds.) Rice Production on Acid Soils of the Tropics. Kandy, Sri Lanka: Institute of Fundamental Studies, pp. 279-286.

Snitwongse, P., Satrusajang, A. \& Buresh, R. J. 1988. Fate of nitrogen fertilizer applied to lowland rice on a Sulfic Tropaquept. Fert Res, 16, pp. 227-240.

Soares, J. R., Cantarella, H. \& Menegale, M. L. D. C. 2012. Ammonia volatilization losses from surface-applied urea with urease and nitrification inhibitors. Soil Biol Biochem, 52, pp. 82-89.

Vlek, P. L. G. \& Craswell, E. T. 1981. Ammonia volatilization from flooded soils. Fert Res, 2, pp. 227-245.

Walter, E. 1990. Parameter identifications with error bounds. Special Issue Math Comp Simul, 32, pp.

Yoshinaga, I., Feng, Y., Singh, R. K. \& Shiratani, E. 2004. Dissolved nitrogen model for paddy field ponded water during irrigation period. Paddy Water Environ, 2, pp. 145152.

Zhu, G., Wang, S., Wang, Y., Wang, C., Risgaard-Petersen, N., Jetten, M. S. M. \& Yin, C. 2011. Anaerobic ammonia oxidation in a fertilized paddy soil. ISME J, 5, pp. 19051912. 


\section{Appendix A. Supplementary information}

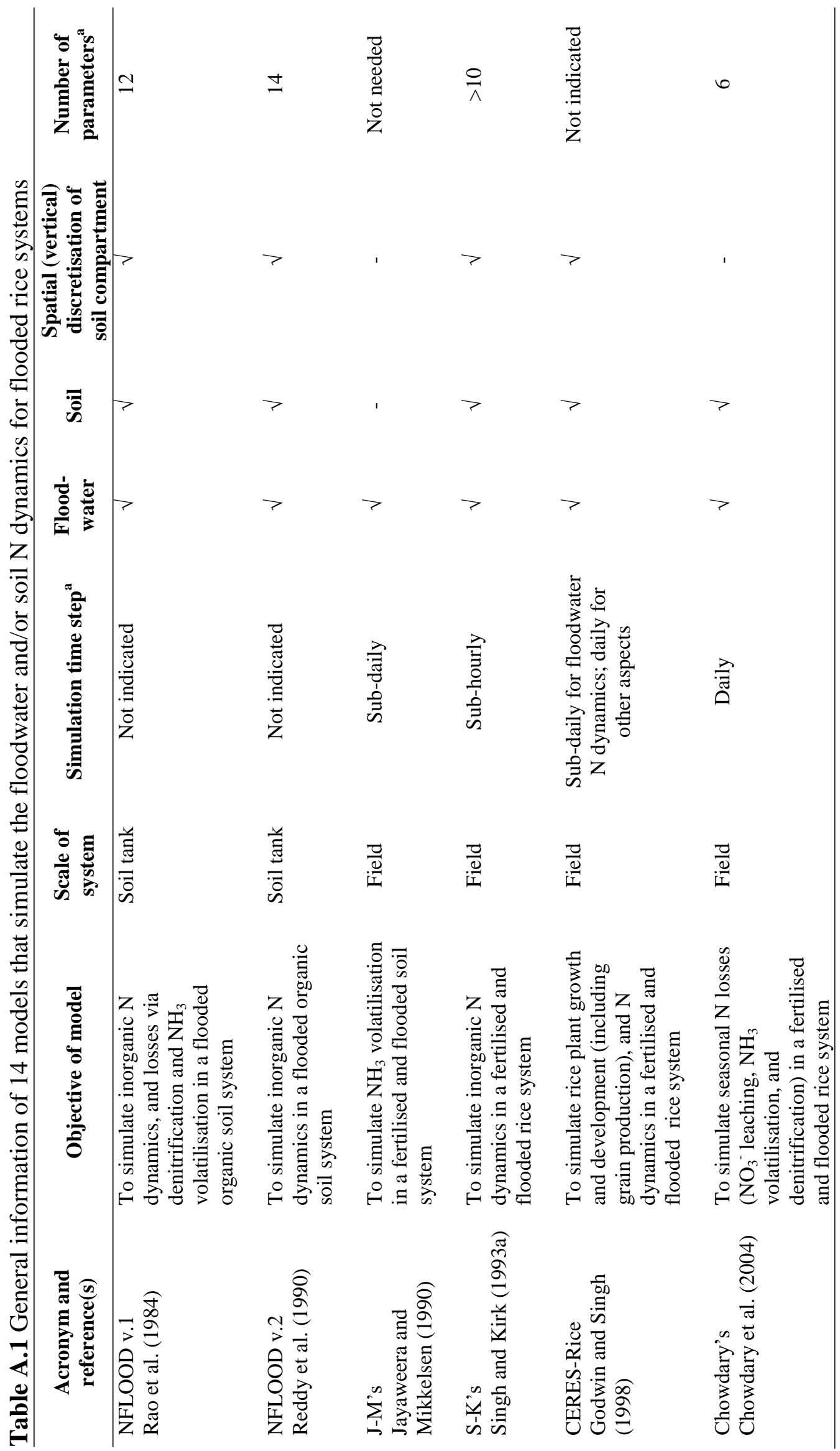




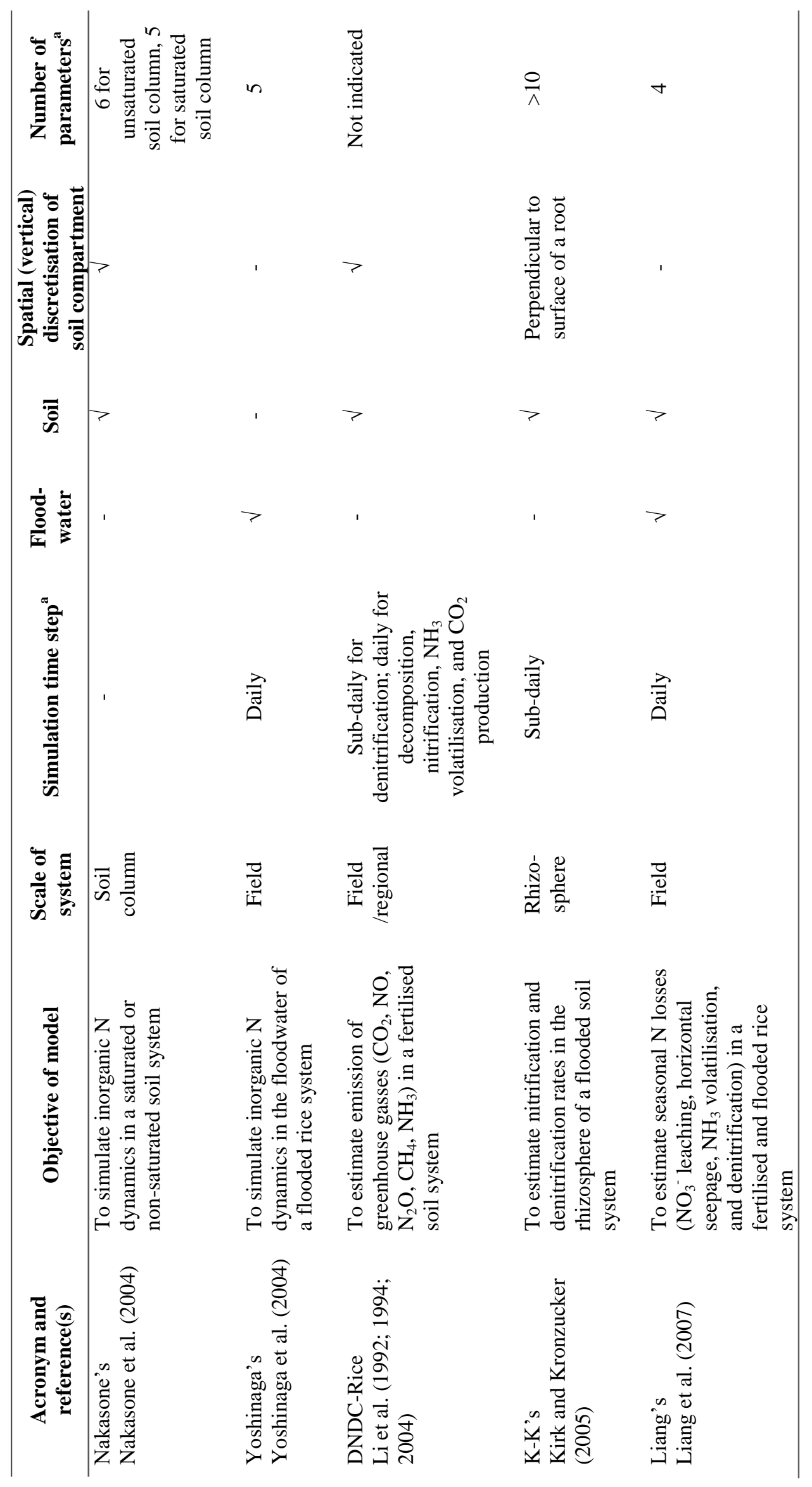


Chapter 2

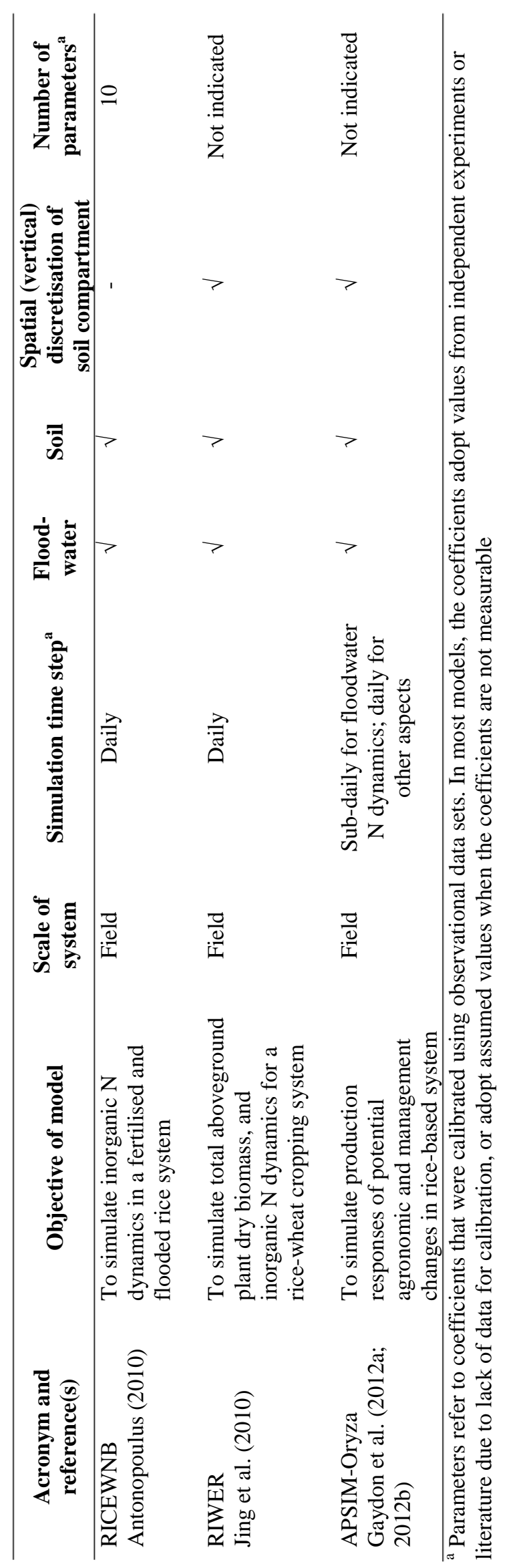




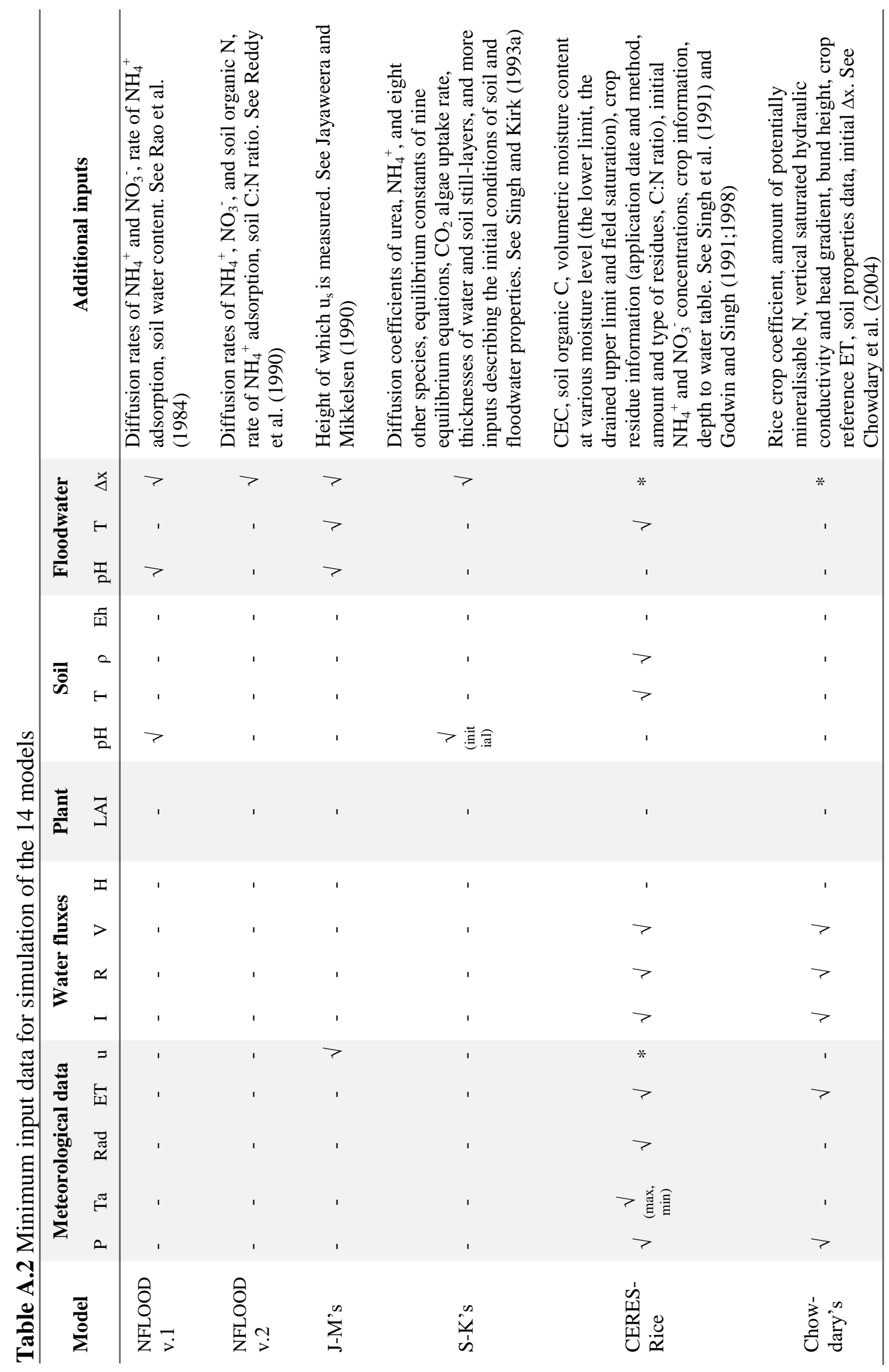




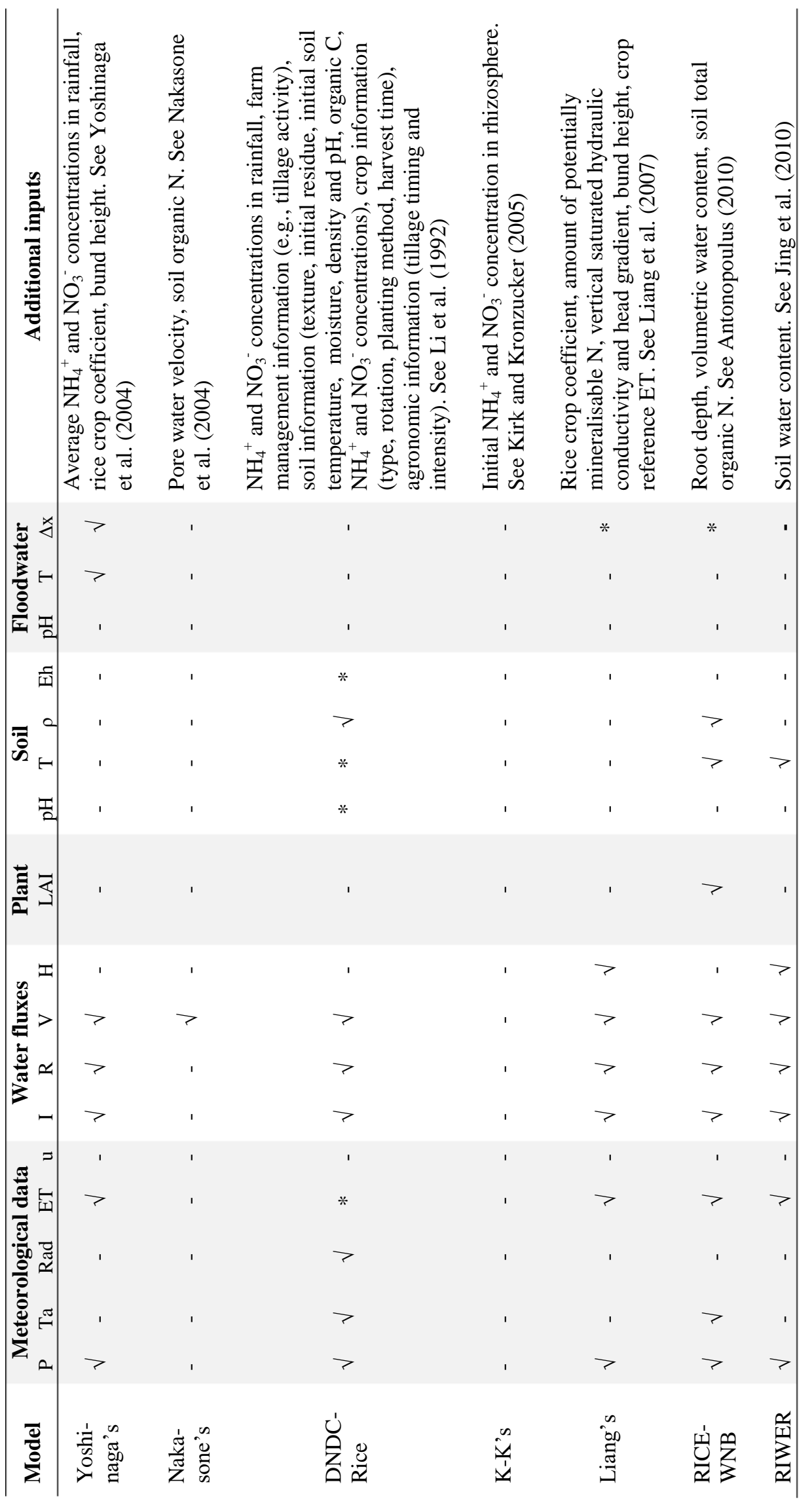




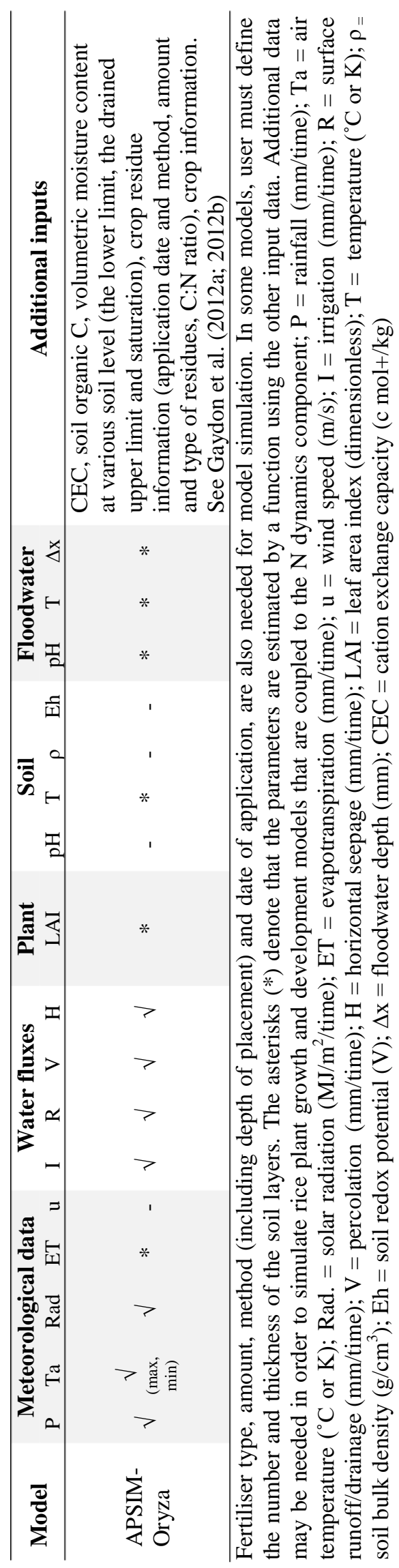




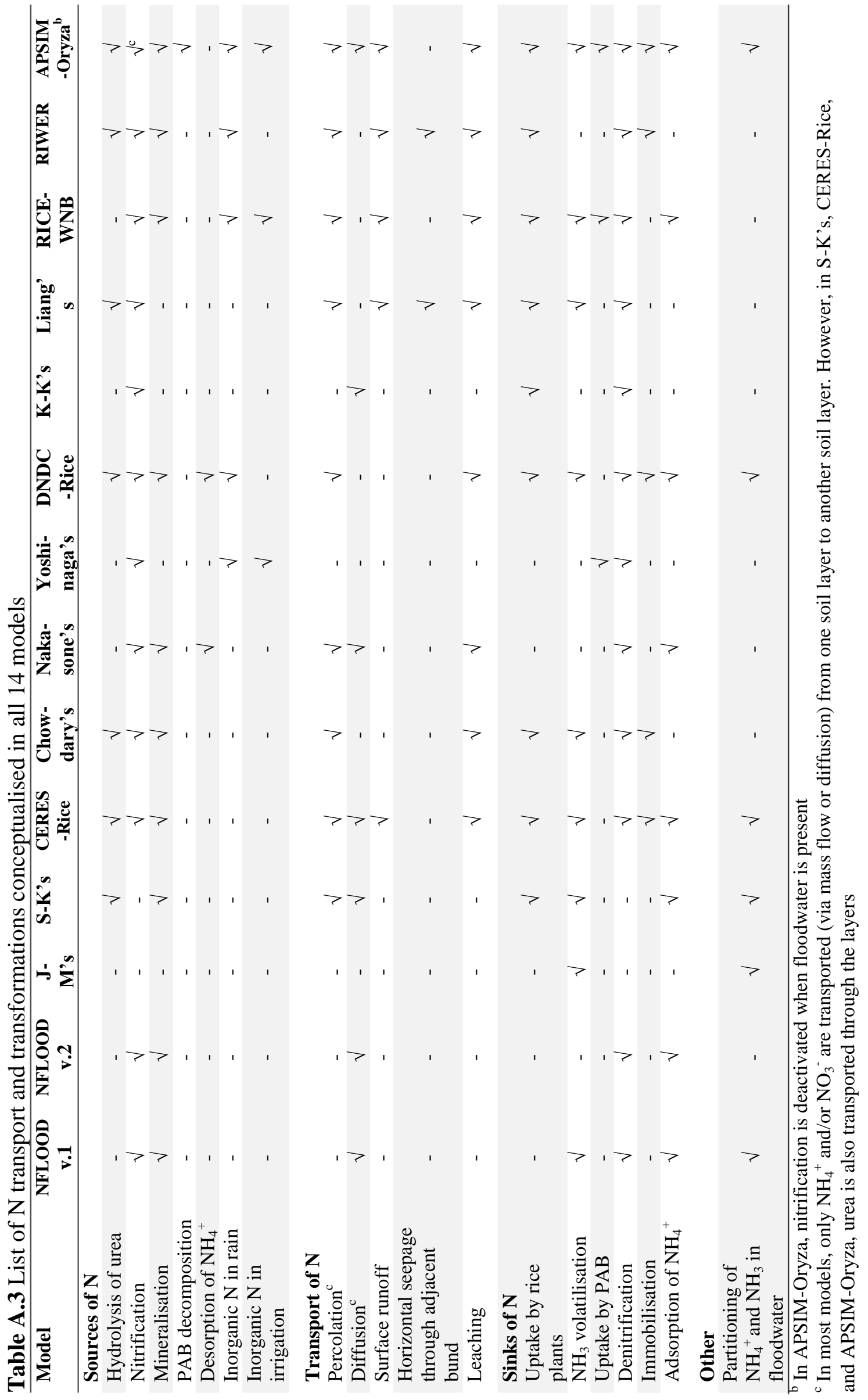


Table A.4 Types of $\mathrm{N}$ fertiliser and methods of application in all 14 models

\begin{tabular}{|c|c|c|c|c|c|}
\hline \multirow{2}{*}{ Model } & \multicolumn{3}{|c|}{ Inorganic fertiliser type } & \multicolumn{2}{|c|}{$\begin{array}{l}\text { Fertiliser application method in a rice } \\
\text { field }\end{array}$} \\
\hline & Urea & $\mathrm{NH}_{4}{ }^{+}$based & $\mathrm{NO}_{3}{ }^{-}$based & $\begin{array}{l}\text { Broadcasted into } \\
\text { floodwater }\end{array}$ & $\begin{array}{l}\text { Incorporated } \\
\text { into flooded soil }\end{array}$ \\
\hline NFLOOD v.1 & - & - & - & - & - \\
\hline NFLOOD v.2 & - & $\sqrt{ }$ & - & - & $\sqrt{ }$ \\
\hline J-M's & - & $\sqrt{ }$ & - & $\sqrt{ }$ & - \\
\hline S-K's & $\sqrt{ }$ & - & - & $\sqrt{ }$ & $\sqrt{ }$ \\
\hline CERES-Rice & $\sqrt{ }$ & $\sqrt{ }$ & $\sqrt{ }$ & $\sqrt{ }$ & $\sqrt{ }$ \\
\hline Chowdary's & $\sqrt{ }$ & - & - & $\sqrt{ }$ & - \\
\hline Nakasone's & - & - & $\sqrt{ }$ & $\sqrt{ }$ (mixed in water) & - \\
\hline Yoshinaga's & - & $\sqrt{ }$ & & $\sqrt{ }$ & - \\
\hline DNDC-Rice & $\sqrt{ }$ & $\sqrt{ }$ & $\sqrt{ }$ & - & $\sqrt{ }$ \\
\hline K-K's & - & - & - & - & - \\
\hline Liang's & $\sqrt{ }$ & - & - & $\sqrt{ }$ & - \\
\hline RICEWNB & - & - & - & - & $\sqrt{ }$ \\
\hline RIWER & $\sqrt{ }$ & - & - & $\sqrt{ }$ & $\sqrt{ }$ \\
\hline APSIM-Oryza $^{d}$ & $\sqrt{ }$ & $\sqrt{ }$ & $\sqrt{ }$ & $\sqrt{ }$ & $\sqrt{ }$ \\
\hline
\end{tabular}

${ }^{\mathrm{d}}$ If floodwater is absent, APSIM-Oryza by default incorporates applied $\mathrm{N}$ into the top soil layer

Table A.5 Factors that regulate rate of organic matter decomposition

\begin{tabular}{ll}
\hline Model & Factors \\
\hline DNDC-Rice & $\begin{array}{l}\text { Decomposition of FOM below ground surface: pool size (N availability) and } \\
\text { its specific potential decomposition rate coefficient, and soil properties such } \\
\text { as clay content, temperature, water content, and depth }\end{array}$ \\
& $\begin{array}{l}\text { Decomposition of FOM below ground surface (first-order kinetics): soil } \\
\text { CERES-Rice }\end{array}$ \\
& Decomposition of FOM below ground surface: soil water content \\
RIWER & Decomposition of FOM on soil surface (first-order kinetics): residue types, \\
APSIM-Oryza & soil temperature, soil water content, C:N ratio, and residue coverage \\
& Decomposition of FOM below ground surface (first-order kinetics): soil \\
& temperature, soil water content, and C:N ratio \\
& Turnover between labile microbial biomass and stable organic matter (first- \\
& order kinetics): soil temperature and water content \\
\hline
\end{tabular}

FOM is fresh organic matter 
Table A.6 Factors that regulate rates of nitrification and denitrification

\begin{tabular}{|c|c|c|c|c|}
\hline \multirow[t]{2}{*}{ Model } & \multicolumn{2}{|c|}{ Nitrification } & \multicolumn{2}{|c|}{ Denitrification } \\
\hline & Limiting factors & Location & Limiting factors & Location \\
\hline $\begin{array}{l}\text { NFLOOD } \\
\text { v.1 }\end{array}$ & - & $\begin{array}{l}\text { Aerobic soil layer } \\
\text { near ground } \\
\text { surface }\end{array}$ & $\mathrm{C}$ & Bulk soil \\
\hline $\begin{array}{l}\text { NFLOOD } \\
\text { v. } 2\end{array}$ & - & $\begin{array}{l}\text { Aerobic soil layer } \\
\text { near ground } \\
\text { surface }\end{array}$ & $\mathrm{C}$ & Bulk soil \\
\hline CERES-Rice & $\begin{array}{l}\text { Soil moisture content, } \\
\text { soil temperature }\end{array}$ & $\begin{array}{l}\text { Unsaturated soil } \\
\text { layer }\end{array}$ & $\begin{array}{l}\text { Soil moisture content, } \\
\text { soil temperature, } C\end{array}$ & $\begin{array}{l}\text { Saturated } \\
\text { soil layer }\end{array}$ \\
\hline Chowdary's & - & Floodwater & - & Bulk soil \\
\hline Nakasone's & Pore water velocity & Bulk soil & Pore water velocity & Bulk soil \\
\hline Yoshinaga's & $\begin{array}{l}\text { Floodwater depth and } \\
\text { temperature }\end{array}$ & $\begin{array}{l}\text { Floodwater-soil } \\
\text { interface }\end{array}$ & $\begin{array}{l}\text { Floodwater depth and } \\
\text { temperature }\end{array}$ & $\begin{array}{l}\text { Floodwater- } \\
\text { soil interface }\end{array}$ \\
\hline K-K's & $\mathrm{O}_{2}$ & Rhizosphere & $\mathrm{O}_{2}$ & Rhizosphere \\
\hline Liang's & - & Floodwater & - & Bulk soil \\
\hline RICEWNB & - & Bulk soil & - & Bulk soil \\
\hline RIWER & Soil moisture content & Bulk soil & $\begin{array}{l}\text { Soil moisture content, } \\
\text { soil temperature }\end{array}$ & Bulk soil \\
\hline $\begin{array}{l}\text { APSIM- } \\
\text { Oryza }\end{array}$ & $\begin{array}{l}\text { Soil moisture content, } \\
\text { soil temperature and } \\
\text { pH }\end{array}$ & $\begin{array}{l}\text { Unsaturated soil } \\
\text { layer }\end{array}$ & $\begin{array}{l}\text { Soil moisture content, } \\
\text { soil temperature, } \mathrm{C}\end{array}$ & $\begin{array}{l}\text { Saturated } \\
\text { soil layer }\end{array}$ \\
\hline
\end{tabular}

In all models, concentrations of $\mathrm{NH}_{4}^{+}$and $\mathrm{NO}_{3}$ are main limiting factors for nitrification and denitrification, respectively 


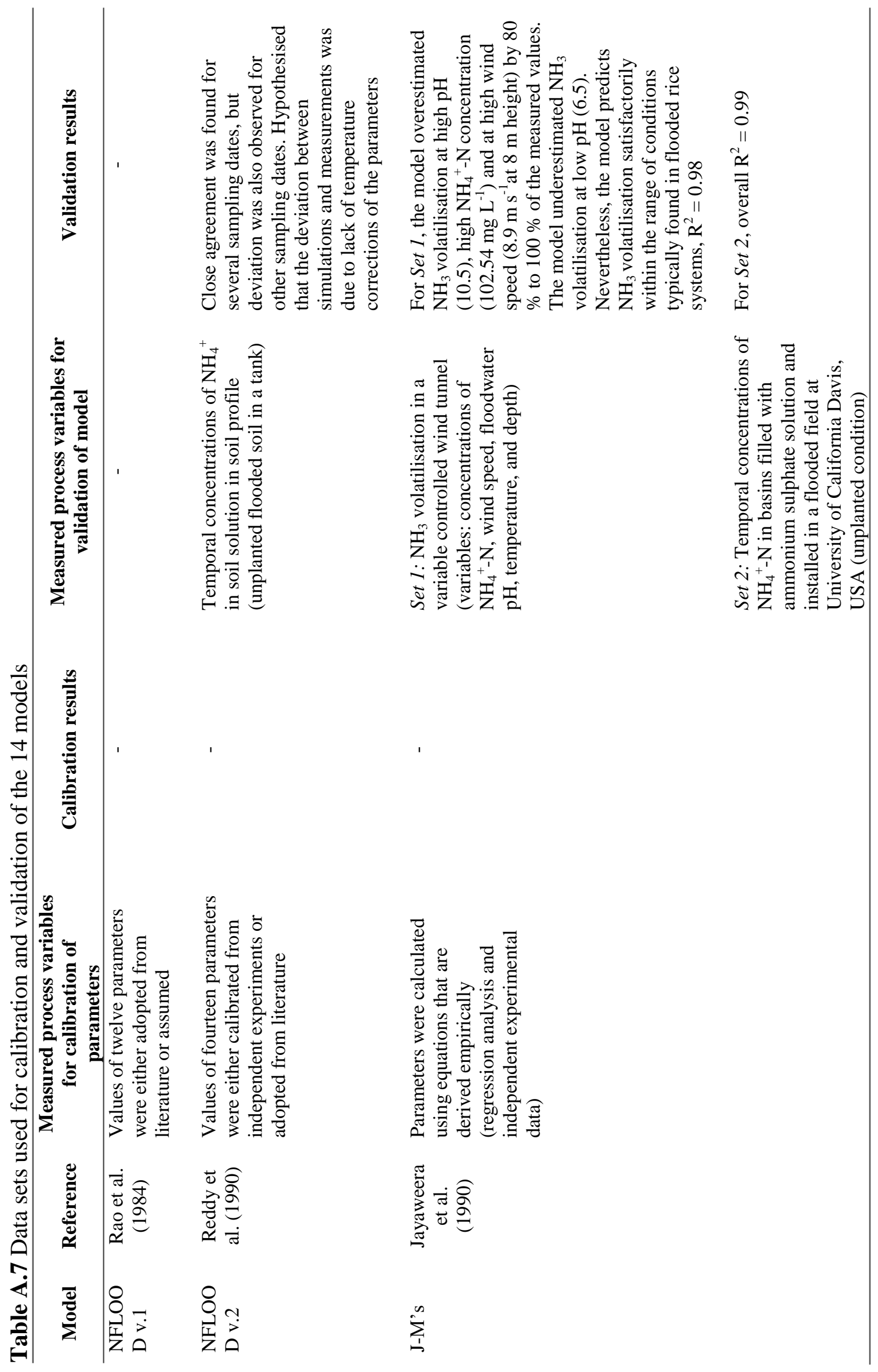


Chapter 2

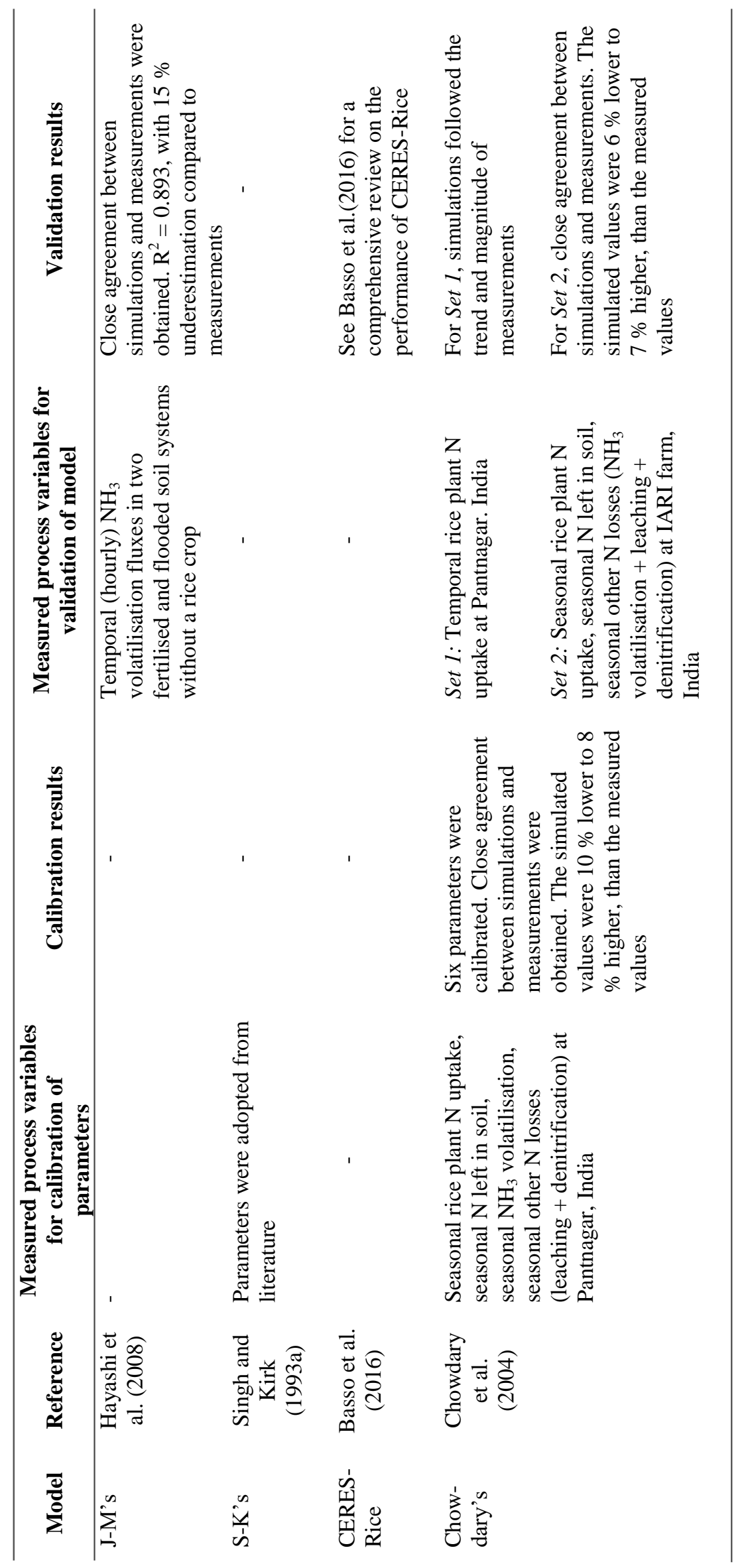




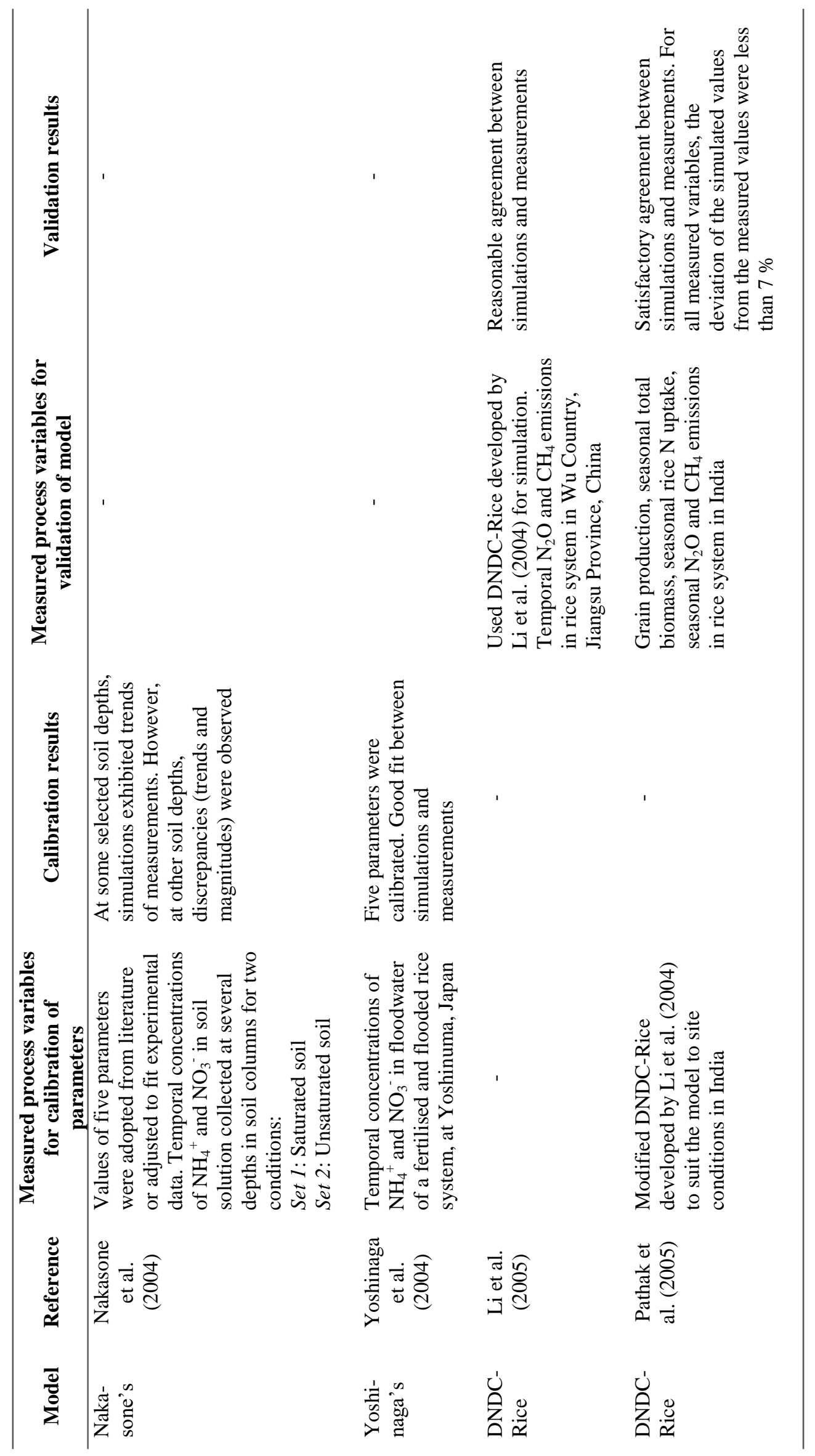




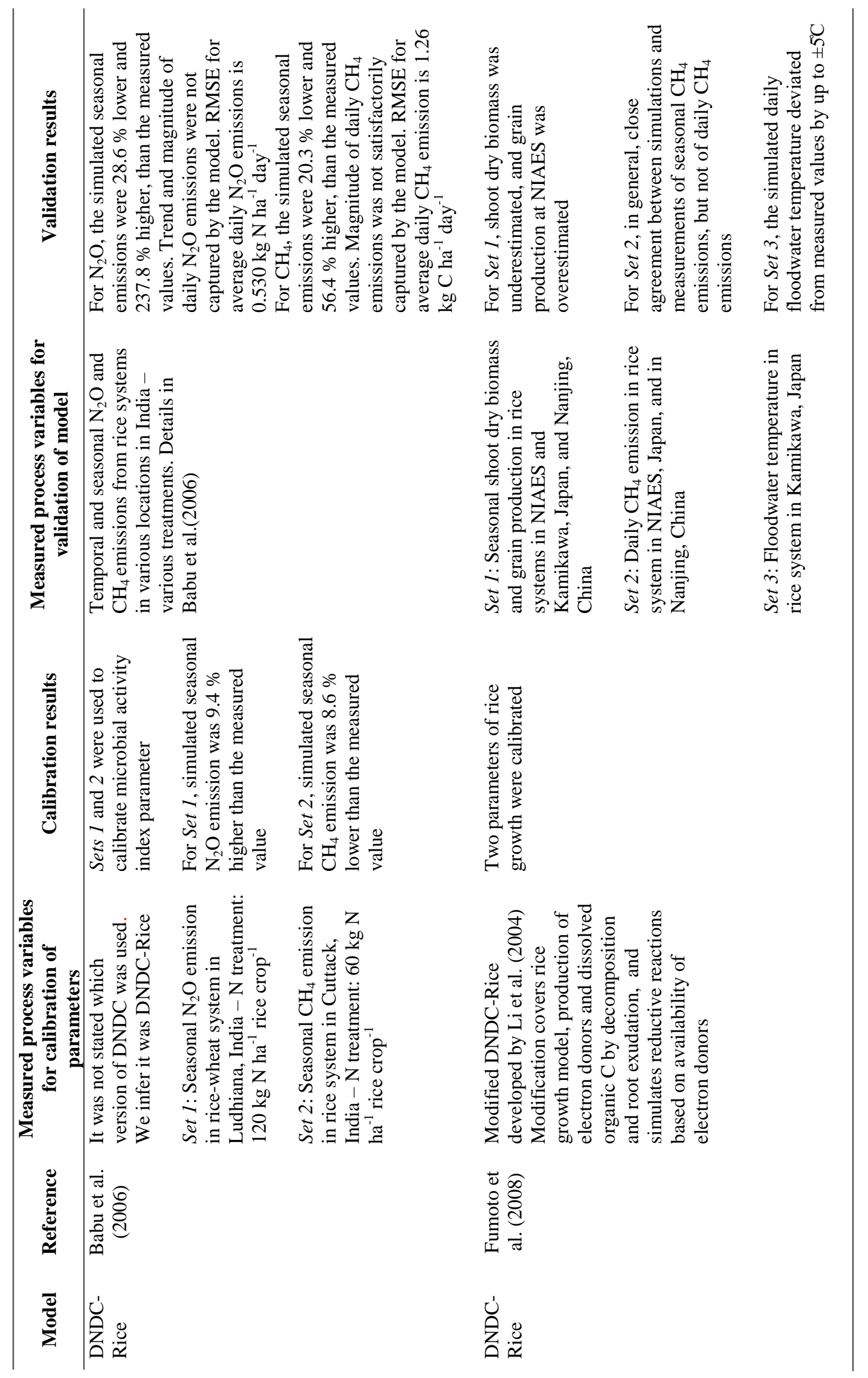




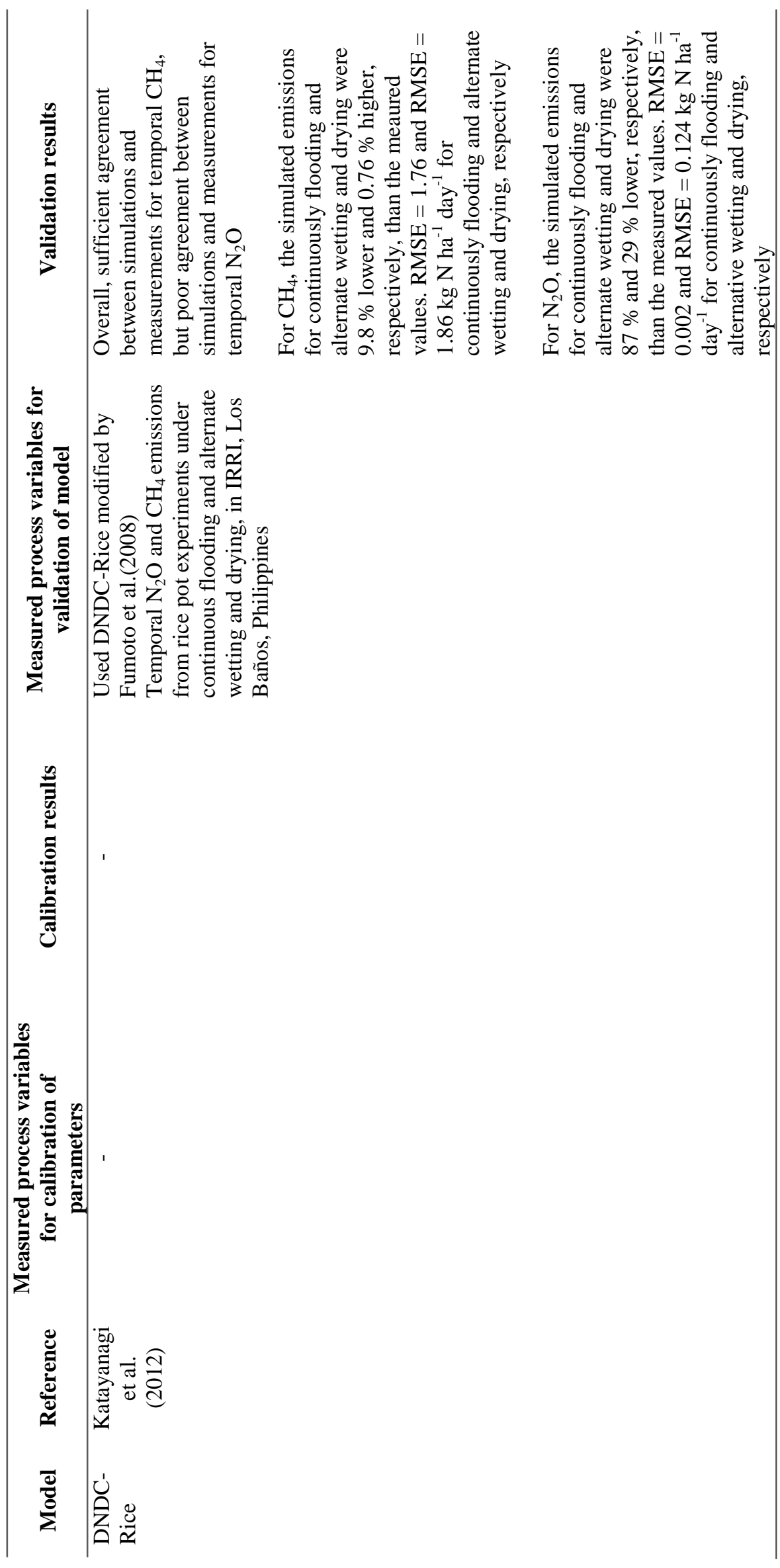




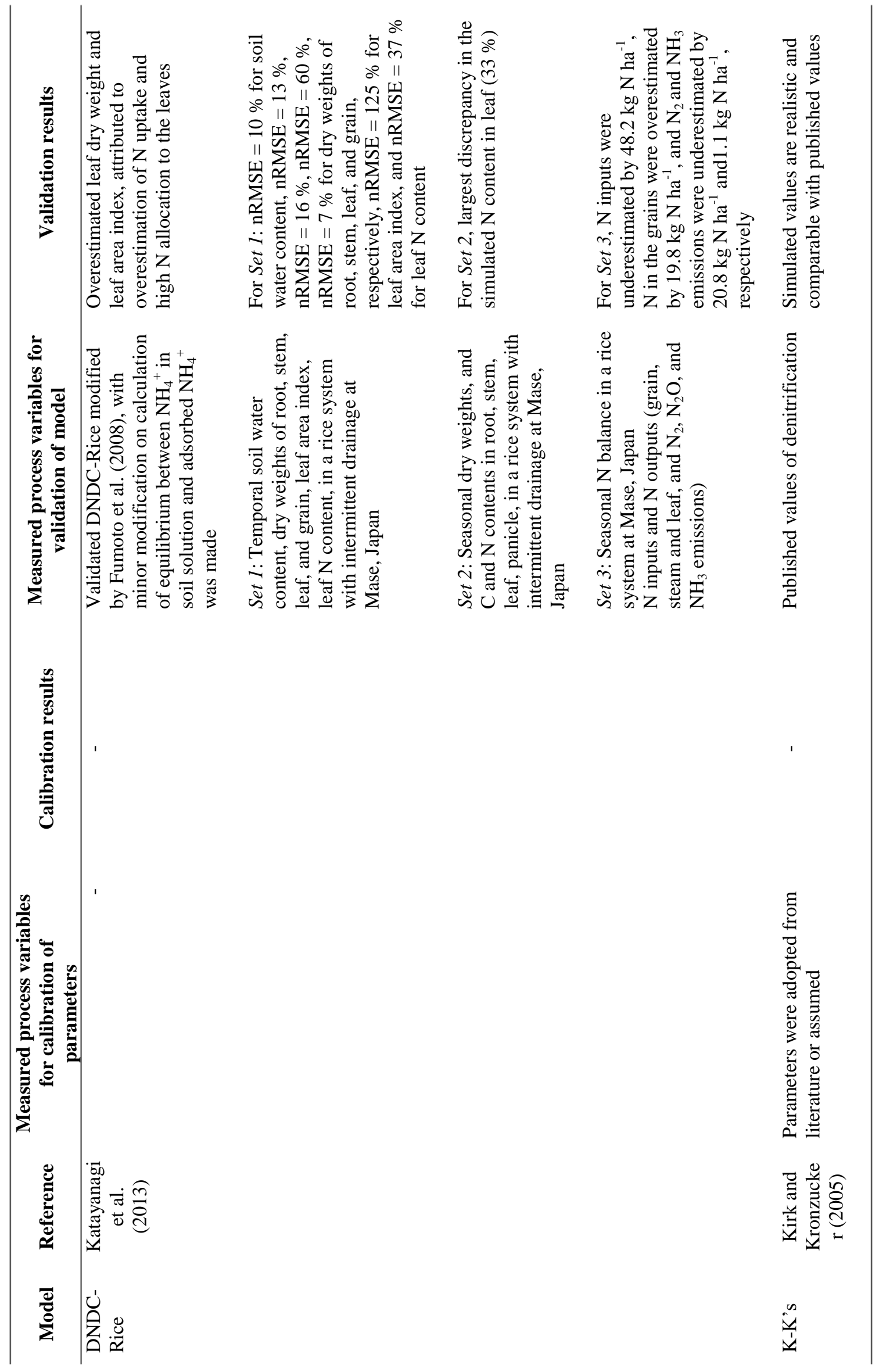




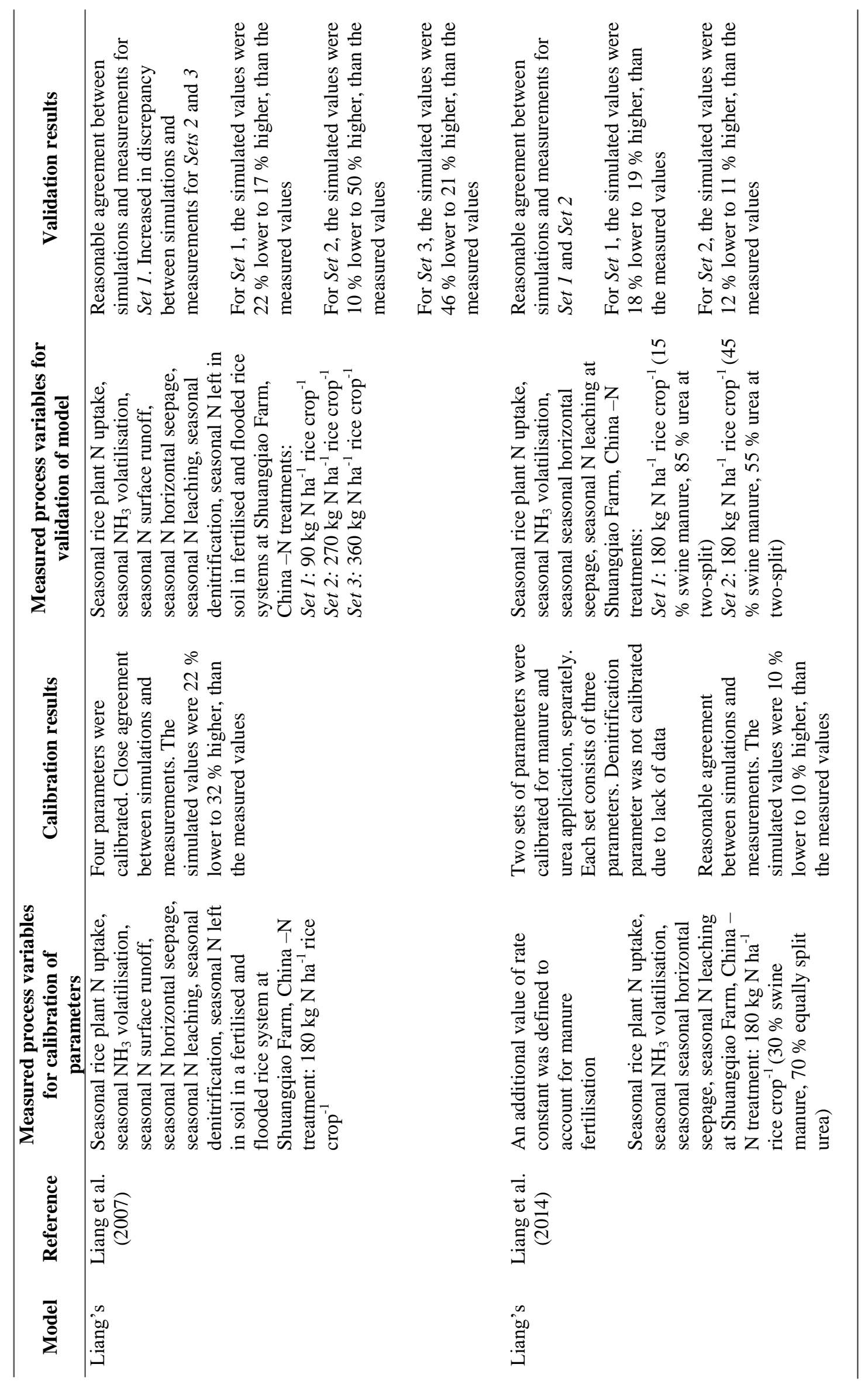




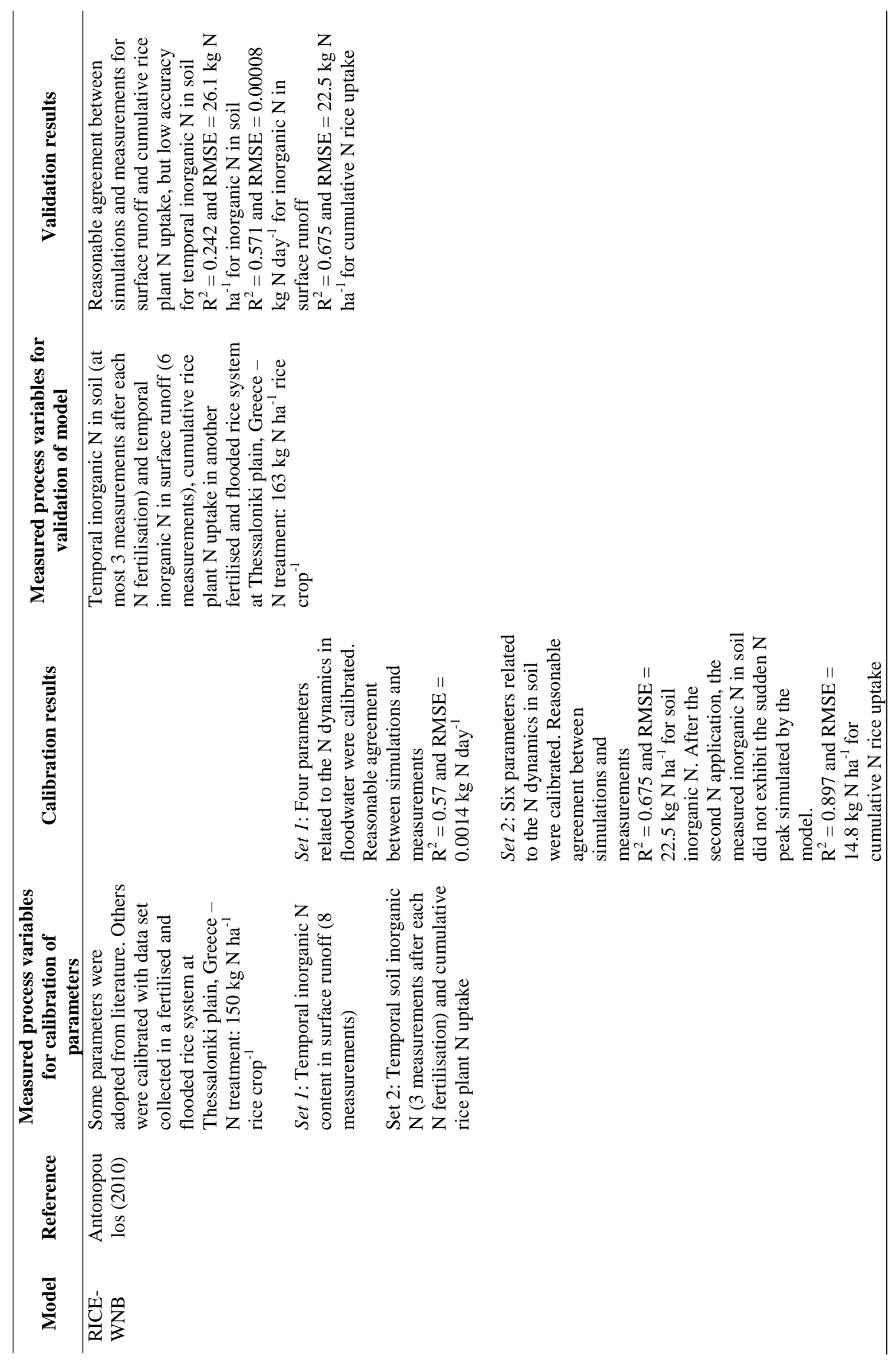




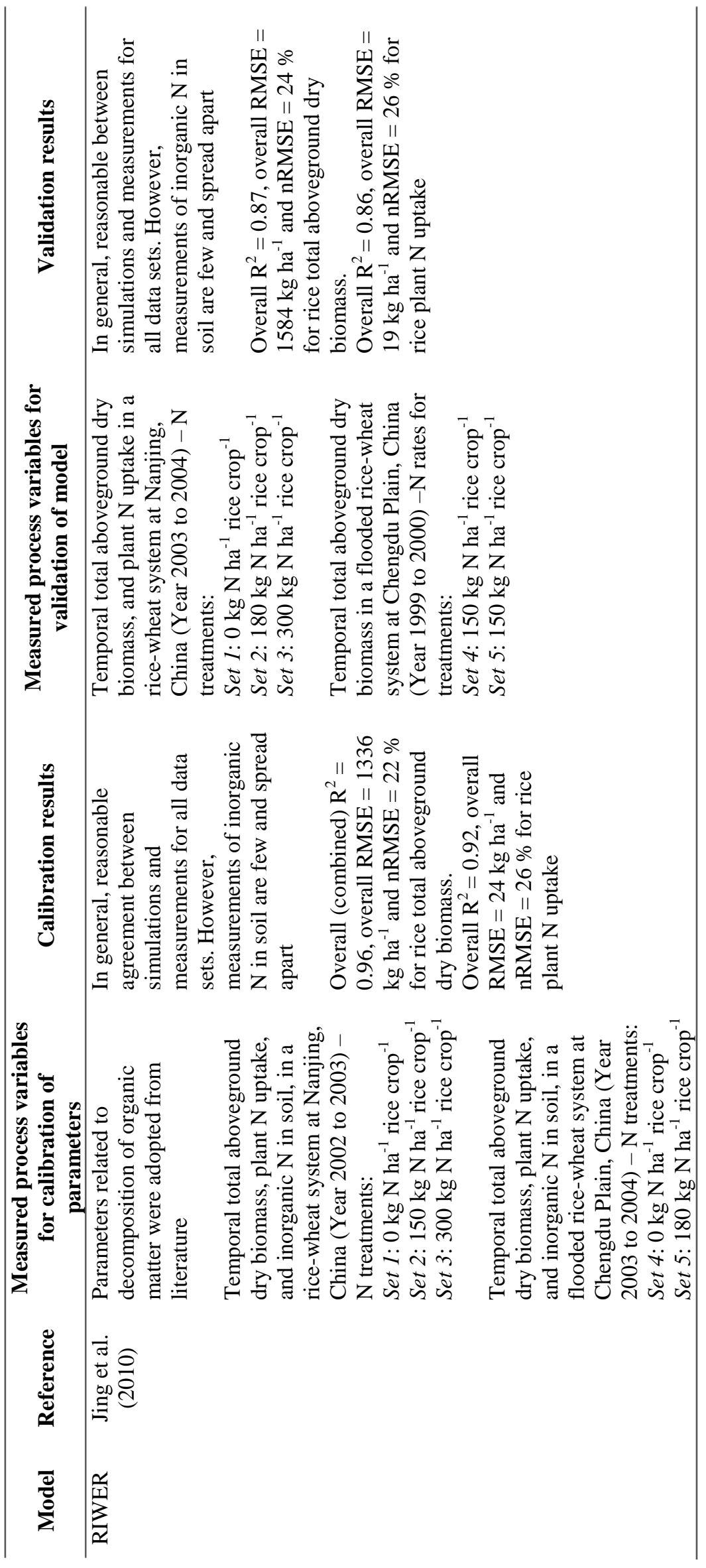




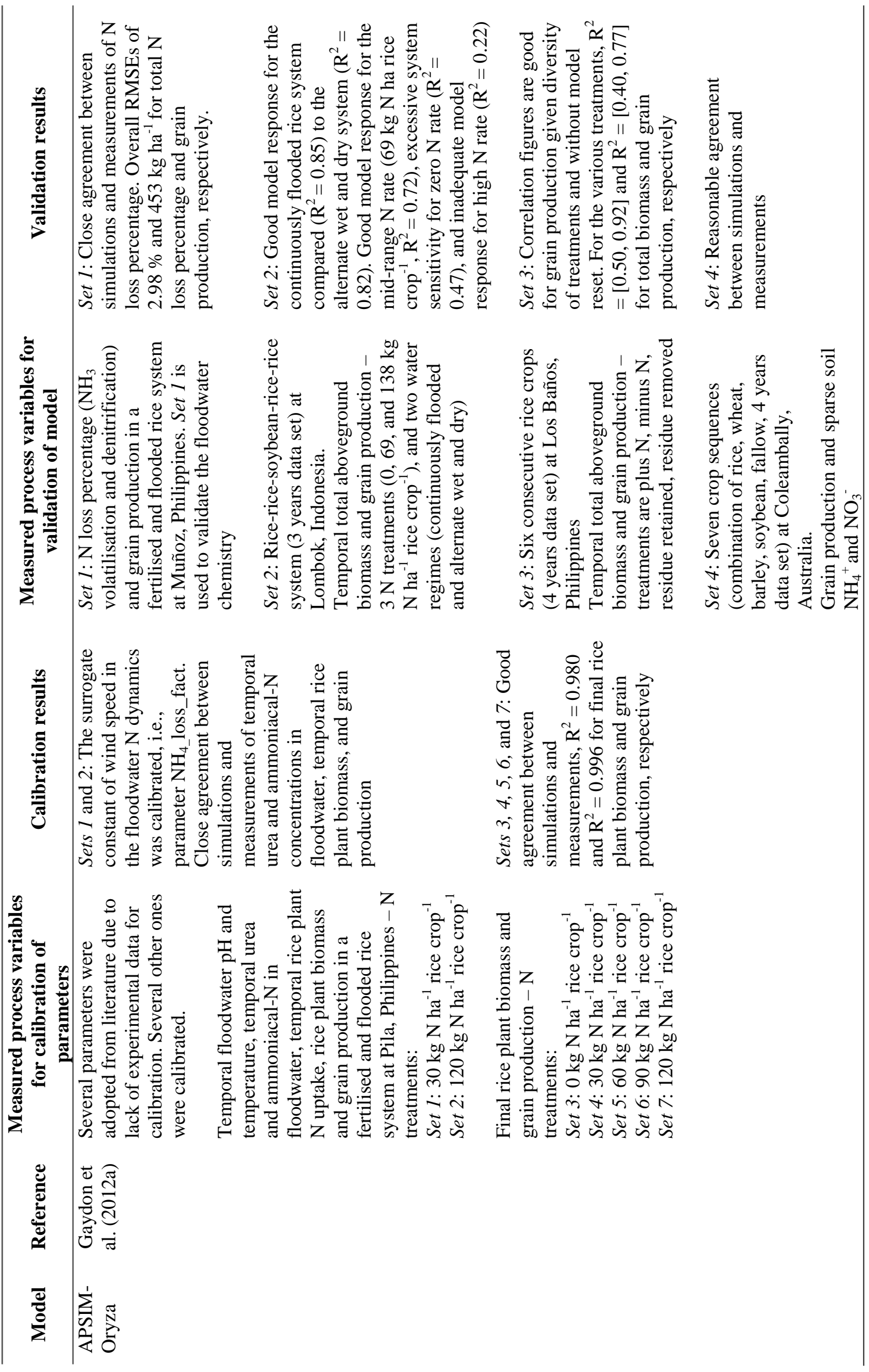




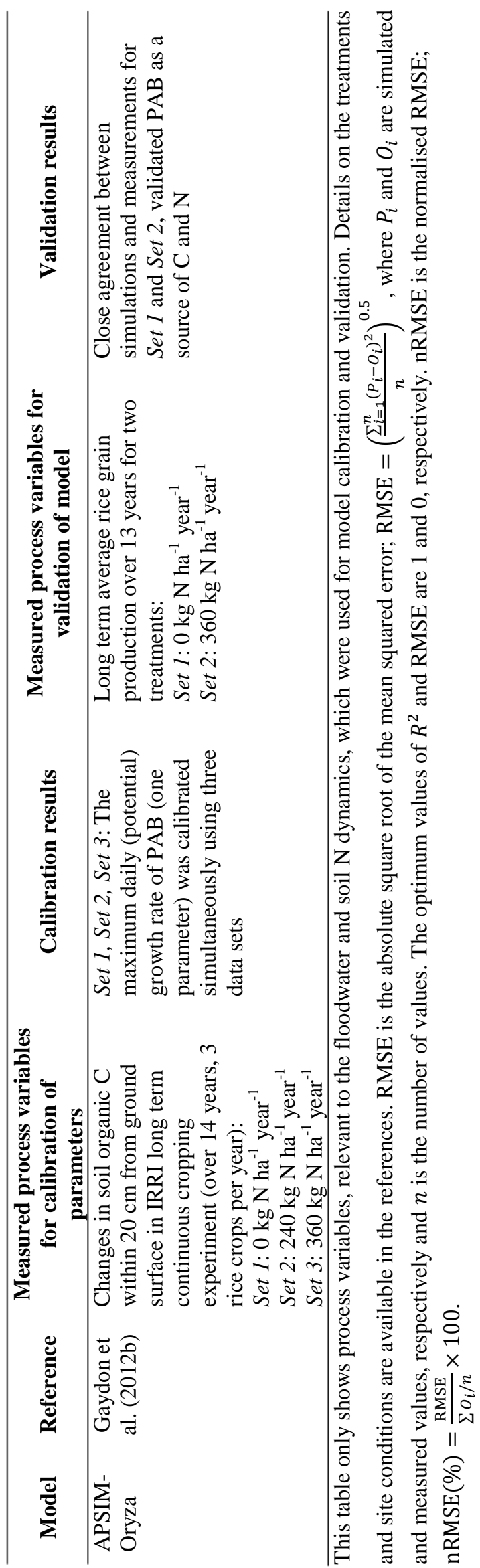



CHAPTER 3

A model study of

urea hydrolysis and ammonia volatilisation

in flooded rice systems

K. Nurulhuda ${ }^{1,2}$, M.P. Zakaria ${ }^{3}$, P.C. Struik ${ }^{4}$, and K.J. Keesman ${ }^{2}$

${ }^{1}$ Biological and Agricultural Engineering, Universiti Putra Malaysia, Malaysia

${ }^{2}$ Biobased Chemistry and Technology, Wageningen University, The Netherlands

${ }^{3}$ Institute of Ocean and Earth Sciences, University of Malaya, Malaysia

${ }^{4}$ Centre for Crop Systems Analysis, Wageningen University, The Netherlands 


\begin{abstract}
Evaluating model-output behaviour resulting from different modelling concepts is vital prior to adopting a specific model. Therefore, in this chapter, we co-validate existing modelling concepts of urea hydrolysis, ammonia $\left(\mathrm{NH}_{3}\right)$ volatilisation, and floodwater $\mathrm{pH}$, using a numerical-experimental approach. Despite detailing of the time-varying rate coefficient of urea hydrolysis in APSIM-Oryza, rates of urea hydrolysis simulated using APSIM-Oryza can be approximated by a first-order kinetics model, by adjusting its constant rate coefficient. For estimation of $\mathrm{NH}_{3}$ volatilisation in flooded soil systems without a rice crop, the intricate Jayaweera and Mikkelsen (1993a) model can be approximated by the simpler NFLOOD v.1 model, by adjusting the constant rate coefficient in NFLOOD v.1. The modelling concepts of floodwater $\mathrm{pH}$ in APSIM-Oryza and Singh and Kirk (1993a) led to significantly different outputs, but each model offered advantages for different applications.
\end{abstract}

Keywords: Nitrogen dynamics, numerical experimentation, urea hydrolysis, ammonia volatilisation, floodwater $\mathrm{pH}$, flooded rice, flooded soil, APSIM-Oryza, Jayaweera and Mikkelsen, NFLOOD 


\subsection{Introduction}

Extensive modelling studies of nitrogen $(\mathrm{N})$ dynamics in flooded soil systems, with or without a rice crop, have been published (Rao et al., 1984, Jayaweera and Mikkelsen, 1990a, Reddy et al., 1990, Godwin and Singh, 1998, Chowdary et al., 2004, Antonopoulos, 2010, Gaydon et al., 2012b). These models were developed for prediction and scenario studies, either to aid decision making in management of rice farming systems, or for scientific understanding.

The $\mathrm{N}$ dynamics in fertilised and flooded rice systems is complex with many interactive processes, including ammonia $\left(\mathrm{NH}_{3}\right)$ volatilisation, nitrification, denitrification, mineralisation of organic $\mathrm{N}$, immobilisation of inorganic $\mathrm{N}$, biological dinitrogen fixation, $\mathrm{N}$ transport in the soil, and rice crop N uptake (Reddy, 1982). Due to different modelling objectives, different assumptions were adopted by modellers to approximate the $\mathrm{N}$ processes in flooded rice systems. Consequently, the $\mathrm{N}$ processes were approximated by modelling concepts of different complexities. The question remains whether the differences in modelling concepts would result in substantial differences in model behaviours. This is a relevant question prior to adoption of the models, as inferred from Bennett et al. (2013).

To answer this question, the mathematical modelling concepts presented in literature can be evaluated with respect to observational data sets, or behaviours of the mathematical models can be presented using synthetic data sets and co-validated with each other (Bellocchi et al., 2010, Keesman, 2011, Bennett et al., 2013). Some of the existing N dynamics models for flooded rice systems have been evaluated by comparing outputs of the models to observational data sets (Chowdary et al., 2004, Antonopoulos, 2010, Gaydon et al., 2012a). However, selection of observational data sets is commonly driven by the modelling objectives. Therefore, each of these models was evaluated using different sets of data, which varied in terms of measured process variables, treatments applied, or site conditions during observations (Chowdary et al., 2004, Antonopoulos, 2010, Gaydon et al., 2012a, Gaydon et al., 2012b, Katayanagi et al., 2013). When different data sets are used, the validation outcomes of two models cannot be directly compared.

A posteriori model evaluation is powerful, provided the observational data sets are sufficiently large, reliable, and representative of the system (Bennett et al., 2013). However, flooded rice systems can be characterised as ill-defined systems, where observational data sets are small, in terms of the number of measured process variables, and the number of observed 
data points for each process variable. As an alternative, a priori evaluation of ill-defined complex systems, with tangling feedbacks, may provide additional insights pertinent to adoption of the model (Bennett et al., 2013).

Numerical experimentation can be performed at different scales: at full model scale, where all processes interact, or at a single process scale (Bellocchi et al., 2010). For complex systems with tangling feedbacks, such as fertilised and flooded rice systems, where an output of one process is an input for another process, or a process may have multiple inputs, the behaviour of a single process, simulated by two full models of different complexities, cannot be compared, due to interferences by the tangling feedbacks. For an 'apple to apple' comparison, the tangling feedbacks can be isolated to make them commensurable at process scale.

In this chapter, we restrict ourselves to processes in the floodwater that are relevant to $\mathrm{NH}_{3}$ volatilisation. Hydrolysis of urea occurs in the floodwater typically when urea is broadcast on the floodwater, without subsequent incorporation into the soil. Under this condition, the $\mathrm{NH}_{3}$ volatilisation was claimed as one of the major causes of $\mathrm{N}$ loss in fertilised flooded rice systems, which could reach up to $60 \%$ of total N applied (Fillery et al., 1984, De Datta et al., 1991). The $\mathrm{NH}_{3}$ volatilisation is regulated by wind speed and floodwater properties, such as the concentration of total ammoniacal- $\mathrm{N}$ in the floodwater, floodwater $\mathrm{pH}$, temperature, and depth (Bouwmeester and Vlek, 1981, Denmead et al., 1982, Jayaweera and Mikkelsen, 1990a, De Datta et al., 1991). Based on observational data sets, Fillery et al. (1984) hypothesised that the photosynthetic activity (PAB) activity regulates the diurnal trend of floodwater $\mathrm{pH}$. This hypothesis was conceptualised to simulate the hourly floodwater $\mathrm{pH}$ in CERES-Rice (Godwin and Singh, 1998), and later adopted in APSIM-Oryza (Gaydon et al., 2012b). PAB activity as one of the regulators of diurnal floodwater $\mathrm{pH}$ was also conceptualised by the Singh and Kirk (1993a) model as one of the regulators of diel fluctuations in floodwater $\mathrm{pH}$.

The objective of the chapter is to co-validate existing modelling concepts of urea hydrolysis, $\mathrm{NH}_{3}$ volatilisation, and floodwater $\mathrm{pH}$, using a numerical-experimental approach. Urea hydrolysis and $\mathrm{NH}_{3}$ volatilisation are two dominant $\mathrm{N}$ processes in the floodwater, whereas floodwater $\mathrm{pH}$ is a process variable that regulates urea hydrolysis and $\mathrm{NH}_{3}$ volatilisation. Hypothetically, differences in modelling concepts is expected to produce different outputs, but to what extent? In conventional sensitivity analysis the effects of variation in model-inputvariables and parameters on outputs of an individual model are studied (Rao et al., 1984, 
Singh and Kirk, 1993b). The focus of this chapter, however, is to assess the effects of different modelling concepts on the common outputs under typical conditions observed in flooded rice systems. Findings may be used by users to make an informed decision on which modelling concept would be suitable for their application, and to assess whether a more intricate modelling concept could be substituted by a simpler concept, without significant loss in model performance.

In Section 3.2, the modelling concepts with the respective equations, followed by the description of the conditions for scenario studies, are presented. The results are presented and discussed in Section 3.3. Finally, conclusions are drawn in Section 3.4.

\subsection{Materials and methods}

Co-validation of models at a process scale allows an 'apple to apple' comparison. To covalidate models at process scales, the relevant equations were extracted from the full models. The selected equations were simulated using synthetic data sets for the described scenarios, and simulation results were compared. Simulations were performed in MATLAB R2012a.

\subsubsection{Modelling concepts of urea hydrolysis in the floodwater}

Unlike the other types of inorganic $\mathrm{N}$ fertilisers, like ammonium sulphate that instantaneously dissociates into ammonium $\left(\mathrm{NH}_{4}^{+}\right)$and sulphate once in water, urea is hydrolysed into $\mathrm{NH}_{4}^{+}$. Urea hydrolysis is typically described by first-order kinetics, either with a constant rate coefficient or time-varying rate coefficient.

\subsubsection{First-order urea hydrolysis with constant rate coefficient}

For a constant floodwater depth, first-order urea hydrolysis in floodwater with a constant rate coefficient is mathematically described by the differential equation:

$\frac{d U^{w}}{d t}=-K_{h} U^{w}$

where, $K_{h}$ is a constant rate coefficient of urea hydrolysis (time-step ${ }^{-1}$ ), and $U^{w}$ is the amount of urea in the floodwater $\left(\mathrm{kg} \mathrm{N} \mathrm{ha}^{-1}\right)$. The total amount of urea hydrolysed during the time interval $\left[t_{0}, t_{f}\right], H y d\left(\mathrm{~kg} \mathrm{~N} \mathrm{ha}^{-1}\right)$, is calculated as $H y d=-\int_{t_{0}}^{t_{f}} K_{h} U^{w} d t$. The rate coefficient of urea hydrolysis was assumed constant in models of Kirk and Solivas (1997), Chowdary et 
al. (2004), Jing et al. (2010) (i.e., RIWER), and Antonopoulos (2010) (i.e., RICEWNB).

\subsubsection{First-order urea hydrolysis with time-varying rate coefficient}

Alternatively, the rate of urea hydrolysis in the floodwater is regulated by the time-varying rate coefficient given by (Godwin and Singh, 1998, Gaydon et al., 2012b):

$F U H Y D R=\widetilde{K}_{h} \times U^{w}$

where, FUHYDR is floodwater urea hydrolysis rate $\left(\mathrm{kg} \mathrm{N} \mathrm{ha}^{-1}\right.$ time-step $\left.{ }^{-1}\right), U^{w}$ is the amount of urea in the floodwater $\left(\mathrm{kg} \mathrm{N} \mathrm{ha}^{-1}\right)$, and $\widetilde{K}_{h}$ is the time-varying rate coefficient of urea hydrolysis (time-step ${ }^{-1}$ ), which is described by empirical relationships and expressed in variable names of APSIM-Oryza, and is given by (Gaydon et al., 2012b):

$\widetilde{K}_{h}=\max ($ pot_hydrolysis, UALGCT $) \times T E M P F U$

where, pot_hydrolysis $=0.008+(0.005 \times O C \%) \quad\left(\right.$ time-step $\left.^{-1}\right)$, and $U A L G C T=0.1 \times$ algact (time-step ${ }^{-1}$ ). OC $\%$ is the percentage of organic carbon in the top soil layer, and algact $=\min (a l i, f t i, f n i, f p i)$ is the $\mathrm{PAB}$ activity index factor that ranges from zero through unity (see Gaydon et al. (2012b)). The variable ali is the available light index, fti is the floodwater temperature index, $f n i$ is the floodwater $\mathrm{N}$ index, and $f p i$ the floodwater phosphorus (P) index (see Appendix $\mathrm{C}$ for full equations). UALGCT ranges from 0 to 0.9 . $T E M P F U=0.04 \times\left(T^{w}+0.2\right)$, is dimensionless and ranges from 0 through 0.9 , where $T^{w}$ is the interpolated floodwater temperature in ${ }^{\circ} \mathrm{C}$, for a specific time-step.

\subsubsection{Scenario studies of urea hydrolysis}

To simulate the dynamics of urea hydrolysis, the first-order kinetics model with constant rate coefficient (Eq. 1) was simulated for two scenarios: $K_{h}=0.0333$ two-hours ${ }^{-1}$ (Scenario 1.1, Table 1), and $K_{h}=0.0667$ two-hour $^{-1}$ (Scenario 1.2, Table 1), which are the minimum and maximum values suggested by Chowdary et al. (2004).

Next, to study the dynamics of urea hydrolysis simulated by APSIM-Oryza (Eqs. 2 and 3) under typical conditions in tropical flooded rice systems seven scenarios were simulated (Scenarios 1.3 to 1.9 , Table 1). 


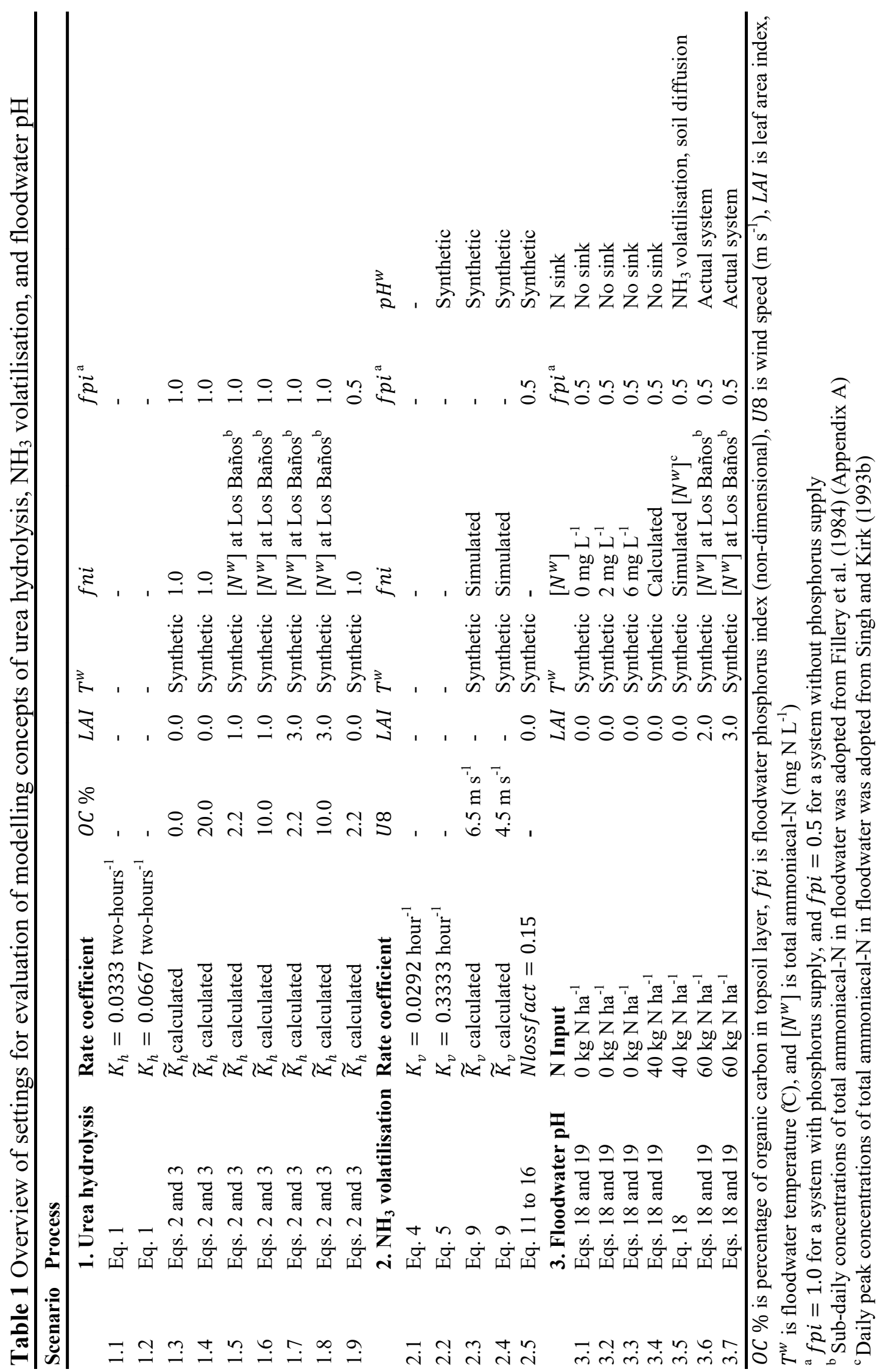


For all scenarios, the synthetic floodwater temperatures (Appendix A) were used as input to simulate $f t i$ in UALGACT, and TEMPFU (Eq. 3). The floodwater depth was assumed constant at $0.10 \mathrm{~m}$. A solar radiation of $16.5 \mathrm{MJ} \mathrm{m}^{-2}$ day $^{-1}$ was used to calculate ali for all scenarios. The solar radiation was the average observed at Los Baños (Freney et al., 1981).

Scenarios 1.3 and 1.4 were simulated for soil organic $\mathrm{C}$ percentages of $0 \%$ and $20 \%$, respectively. The rice crop canopy cover, and $\mathrm{N}$ and $\mathrm{P}$ content in the floodwater, were assumed not limiting. Therefore, $L A I=0.0$ for the calculation of ali, which is close to 1.0, $f n i=1.0$, and $f p i=1.0$.

Scenarios 1.5 and 1.6 assumed flooded soil systems with young rice crop. Therefore, $L A I=$ 1.0, assuming sufficient light is available for photosynthetic activity. To emulate the effect of a typical trend of total ammoniacal-N in the floodwater on the $f n i$, the concentrations of total ammoniacal-N in floodwater observed in a flooded rice systems, for the duration from 14 days through 27 days after transplanting, in Los Baños (Fillery et al., 1984), were interpolated on a two-hourly basis, and used as input (see Fig. A.3, Appendix A, for observational data set at Los Baños). The observed data at Los Baños represents the actual temporal trend of total ammoniacal-N observed in fertilised and flooded rice systems. The percentage of soil organic C was set to $2.2 \%$ and $10 \%$ for Scenarios 1.5 and 1.6, respectively. For both scenarios, the supply of $\mathrm{P}$ was assumed not limiting, $f p i=1.0$.

Similar conditions as in Scenarios 1.5 and 1.6 were used in Scenarios 1.7 and 1.8. However, Scenarios 1.7 and 1.8 assumed flooded systems with rice crop in a more advanced stage of development. In this case, $L A I=3.0$.

All previous scenarios assumed that the supply of $\mathrm{P}$ was not limiting, $f p i=1.0$. Thus, Scenario 1.9 was simulated assuming an insufficient supply of $\mathrm{P}, f p i=0.5$. Other factors were assumed not limiting, and thus, $L A I=0.0$, and $f n i=1.0$.

Next, by applying an initial input of $150 \mathrm{~kg}$ urea- $\mathrm{N} \mathrm{ha}^{-1}$, the rates of hydrolysed urea and the storage of urea- $\mathrm{N}$ in the floodwater were simulated using for urea hydrolysis with constant rate coefficient (Eq. 1), and with a time-varying rate coefficient (Eq. 2 and 3). Eq. 1 was simulated for $K_{h}=0.0333$ two-hour $^{-1}$ and $K_{h}=0.0667$ two-hour ${ }^{-1}$, and Eqs. 2 and 3 were simulated using $\widetilde{K}_{h}$ that resulted from Scenarios 1.3 to 1.9 . Eq. 1 was solved via numerical integration using the function ode45, with a simulation time-step of 0.1 hour, whereas Eqs. 2 
and 3 were solved using an Euler Forward scheme, with a simulation time-step of 2.0 hours.

\subsubsection{Modelling concepts of ammonia volatilisation from the floodwater}

The total ammoniacal-N in the floodwater, which was produced through hydrolysis of urea, is susceptible to $\mathrm{NH}_{3}$ volatilisation, if conditions permit. The $\mathrm{NH}_{3}$ volatilisation is typically described by a first-order process, with either a constant rate coefficient or a time-varying rate coefficient. Instead of process-based equations, the $\mathrm{NH}_{3}$ volatilisation can also be calculated from regression equations.

\subsubsection{First-order ammonia volatilisation with constant rate coefficient}

The $\mathrm{NH}_{3}$ volatilisation can be described by first-order kinetics with constant rate coefficient and given by:

$\frac{d N H_{3}^{g}}{d t}=+K_{v}\left[N^{w}\right] V$

where, $\mathrm{NH}_{3}^{g}$ is $\mathrm{NH}_{3}$ volatilisation $\left(\mathrm{kg} \mathrm{N} \mathrm{ha}{ }^{-1}\right), K_{v}$ is a constant rate coefficient of $\mathrm{NH}_{3}$ volatilisation (time-step $\left.{ }^{-1}\right),\left[N^{w}\right]$ is total ammoniacal-N concentration in the floodwater $(\mathrm{kg} \mathrm{N}$ $\left.\mathrm{m}^{-3}\right)$, and $V=10000 X^{w}$ is volume of floodwater per hectare of land $\left(\mathrm{m}^{3}\right)$ with $X^{w}$ the floodwater depth (m). This concept did not include the partitioning of $\mathrm{NH}_{4}{ }^{+}$and $\mathrm{NH}_{3}$, and was applied in Chowdary et al. (2004) and Antonopoulos (2010).

Rao et al. (1984), with their model called NFLOOD, also conceptualised $\mathrm{NH}_{3}$ volatilisation in terms of first-order kinetics, but in their study, the amount of potentially volatilised $\mathrm{NH}_{3}$ was regulated by floodwater $\mathrm{pH}$, through partitioning of $\mathrm{NH}_{4}{ }^{+}$and $\mathrm{NH}_{3}$ in the floodwater, given by (Rao et al., 1984):

$\frac{d N H_{3}^{g}}{d t}=+K_{v} \frac{P^{w}}{\left(P^{w}+1\right)}\left[N^{w}\right] V$

where, $\mathrm{NH}_{3}^{g}$ is $\mathrm{NH}_{3}$ volatilisation $\left(\mathrm{kg} \mathrm{N} \mathrm{ha}^{-1}\right), K_{v}$ is the rate coefficient of $\mathrm{NH}_{3}$ volatilisation $\left(\right.$ time-step $\left.{ }^{-1}\right), P^{w}=5.8 \times 10^{\left(p H^{w}-10\right)}$, and $\left[N^{w}\right]$ is total ammoniacal-N concentration in the floodwater $\left(\mathrm{kg} \mathrm{N} \mathrm{m}^{-3}\right)$. The variable $p H^{w}$ is the floodwater $\mathrm{pH}$. Note that the concentration of $\mathrm{NH}_{3}$ in the floodwater is given by $\frac{P^{w}}{\left(P^{w}+1\right)}\left[N^{w}\right]$. 


\subsubsection{First-order ammonia volatilisation with a time-varying rate coefficient}

In Jayaweera and Mikkelsen (1990a), the $\mathrm{N}$ dynamics in the floodwater with a time-varying rate coefficient were described by:

$$
\begin{aligned}
& \frac{d\left[N H_{4}^{+}\right]}{d t}=-k_{d}\left[N H_{4}^{+}\right]+k_{a}\left[N H_{3}\right][H] \\
& \frac{d\left[N H_{3}\right]}{d t}=+k_{d}\left[N H_{4}^{+}\right]-k_{a}\left[N H_{3}\right]\left[H^{+}\right]-\widetilde{K}_{v}\left[N H_{3}\right]
\end{aligned}
$$

where, $\left[\mathrm{NH}_{4}^{+}\right]$is concentration of $\mathrm{NH}_{4}{ }^{+}$in floodwater $(\mathrm{mol} \mathrm{N} \mathrm{L}),\left[\mathrm{NH}_{3}\right]$ is concentration of $\mathrm{NH}_{3}$ in floodwater $\left(\mathrm{mol} \mathrm{N} \mathrm{L}{ }^{-1}\right),\left[H^{+}\right]=10^{-p H^{w}}$ is hydrogen concentration $\left(\mathrm{mol} \mathrm{H} \mathrm{L}^{-1}\right), k_{a}$ is association constant $\left(\mathrm{mol} \mathrm{N}^{-1} \mathrm{~L}_{\text {time-step }}{ }^{-1}\right), k_{d}$ is dissociation constant (time-step ${ }^{-1}$ ), and $\widetilde{K}_{v}$ is the time-varying rate coefficient of $\mathrm{NH}_{3}$ volatilisation (time-step ${ }^{-1}$ ). Full equations for calculation of $k_{a}=f\left(T^{w}\right), k_{d}=f\left(T^{w}, k_{a}\right)$, and $\widetilde{K}_{v}=f\left(X^{w}, p H^{w}, T^{w}, U_{8}\right)$ are given in Appendix B, with $T^{w}$ floodwater temperature, $X^{w}$ floodwater depth, $p H^{w}$ floodwater $\mathrm{pH}$, and $U_{8}$ wind speed.

By using Eq. 6, and assuming $\frac{d\left[\mathrm{NH}_{3}\right]}{d t}=0$ at equilibrium, and using $\left[\mathrm{N}^{w}\right]=\left[\mathrm{NH}_{4}^{+}\right]+\left[\mathrm{NH}_{3}\right]$, the rate of change in $\mathrm{NH}_{4}^{+}$concentration in the floodwater is given by Jayaweera and Mikkelsen (1990a):

$\frac{d\left[N H_{4}^{+}\right]}{d t}=k_{a}\left\{\frac{k_{d}\left(\left[N^{w}\right]-\left[N H_{3}\right]\right)}{k_{a}\left[H^{+}\right]+\widetilde{K}_{v}}\right\}\left[H^{+}\right]-k_{d}\left(\left[N^{w}\right]-\left[N H_{3}\right]\right)$

where, $\left[N^{w}\right]$ is concentration of total ammoniacal-N in floodwater $\left(\mathrm{mol} \mathrm{N} \mathrm{L}{ }^{-1}\right)$. Jayaweera and Mikkelsen (1990a) approximated the rate of $\mathrm{NH}_{3}$ volatilisation by the rate of change in $\mathrm{NH}_{4}{ }^{+}$ concentration in the floodwater (Eq. 7), assuming there are no other $\mathrm{N}$ leakages. In the study of Jayaweera and Mikkelsen (1990a), $\left[N^{w}\right]$ and $p H^{w}$ were measured, whereas $\left[\mathrm{NH}_{3}\right], k_{a}, k_{d}$, and $\widetilde{K}_{v}$ were calculated (Appendix B).

Instead of using $\left[\mathrm{NH}_{3}\right]=\frac{K_{d}\left[\mathrm{NH}_{4}^{+}\right]}{K_{a}\left[\mathrm{H}^{+}\right]+\widetilde{K}_{v}}$ from Eq. 6, which is derived by assuming $\frac{d\left[\mathrm{NH}_{3}\right]}{d t}=0$, (Jayaweera and Mikkelsen, 1990a) used:

$\left[N H_{3}\right]=\frac{10^{\left(p H^{w}-0.0897\right.} \frac{2729}{\left.T^{w}\right)}}{1+10^{\left(p H^{w}-0.0897-\frac{2729}{T^{w}}\right)}} \times\left[N^{w}\right]$ 
which includes effects of floodwater temperature $(\mathrm{K})$ and $\mathrm{pH}$.

In Eq. 6, note that the rate of $\mathrm{NH}_{3}$ volatilisation (mol N L $\mathrm{N}^{-1}$ time-step ${ }^{-1}$ ) is defined by $\widetilde{K}_{v}\left[N_{3}\right]$. Substituting Eq. 8 into this term, resulted in the rate of $\mathrm{NH}_{3}$ volatilisation given by:

$\frac{d\left[N H_{3}^{g}\right]}{d t}=\widetilde{K}_{v} \frac{10^{\left(p H^{w}-0.0897-\frac{2729}{T^{w}}\right)}}{1+10^{\left(p H^{w}-0.0897-\frac{2729}{T^{w}}\right)}}\left[N^{w}\right]$

$\left[\mathrm{NH}_{3}^{g}\right]$ is $\mathrm{NH}_{3}$ volatilisation in $\mathrm{mg} \mathrm{N} \mathrm{L}{ }^{-1}$, and $\left[N^{w}\right]$ is also in $\mathrm{mg} \mathrm{N} \mathrm{L}^{-1}$. In this chapter, and unlike the procedure proposed by Jayaweera and Mikkelsen (1990a), we solved Eq. 9 as an alternative to Eq. 6, because Eq. 9 is in a more straightforward form. Instead of working in the unit of molar concentration $\left(\mathrm{mol} \mathrm{N} \mathrm{L}^{-1}\right)$, we worked in the unit of mass concentration $(\mathrm{mg} \mathrm{N}$ $\left.\mathrm{L}^{-1}\right)$. This was possible as calculation of $\left[\mathrm{H}^{+}\right]$was no longer required. Nevertheless, the effect of time-varying rate coefficient of $\mathrm{NH}_{3}$ volatilisation conceptualised in the Jayaweera and Mikkelsen (1990a) model (Eq. 6) were retained in Eq. 9.

\subsubsection{3 $\mathrm{NH}_{3}$ volatilisation using regression equations}

In CERES-Rice (Godwin and Singh, 1998), $\mathrm{NH}_{3}$ volatilisation is described by a regression equation given by (APSIM-Oryza, 2015):

amlo $_{C R}=(0.036 \times f n h 3 p)+$

$$
\left\{0.0082+\left(0.000036 \times f n h 3 p^{2} \times X^{w}\right)\right\} \times \text { windspeed }
$$

where, $\operatorname{amlos}_{C R}$ is the $\mathrm{NH}_{3}$ volatilisation $\left(\mathrm{kg} \mathrm{ha}^{-1}\right.$ two-hour $\left.{ }^{-1}\right), f n h 3 p$ is the partial pressure of $\mathrm{NH}_{3}$, and $X^{w}$ is floodwater depth. The windspeed in Eq. 10 is expressed as a function of pan evaporation rate and LAI (McGechan and Wu, 2001).

Eq. 10 is adopted in APSIM-Oryza, but the effect of wind speed is slightly modified by removing the effect of $L A I$, and is given by (Gaydon et al., 2012b):

$\operatorname{amlo}_{A O}=(0.036 \times f n h 3 p)+$

$$
\left\{0.0082+\left(0.000036 \times f n h 3 p^{2} \times X^{w}\right)\right\} \times(\text { Nlossfact } \times \text { evap })
$$

where, Nlossfact is the dimensionless calibrated constant, evap is pan evaporation rate (mm 
two-hour ${ }^{-1}$ ), and $X^{w}$ is floodwater depth (mm); note the difference in unit of $X^{w}$ compared with other models.

The partial pressure of $\mathrm{NH}_{3}$ above the floodwater, fnh3p (Eq. 11), in APSIM-Oryza is calculated using equations given by (APSIM-Oryza, 2015):

$$
\begin{aligned}
& \ln h k=155.559-\frac{8621.06}{T^{w}}-25.6767 \ln T^{w}+0.035388 T^{w} \\
& h k=e^{\ln h k} \\
& f n h 3 m=\left[N H_{3}\right] \times\left(\frac{0.001}{14}\right) \\
& f n h 3 p=\max \left(0, \frac{f n h 3 m \times 10}{h k}\right) \\
& {\left[N H_{3}\right]=\frac{1}{\left.1+10^{(0.00901} \frac{2729.92}{T^{w}}-p H^{w}\right)} \times\left[N^{w}\right]}
\end{aligned}
$$

where, $T^{w}$ is floodwater temperature $(K),\left[\mathrm{NH}_{3}\right]$ is concentration of $\mathrm{NH}_{3}$ in the floodwater $\left.(\mathrm{mg} \mathrm{N} \mathrm{L})^{-1}\right)$, and $\left[N^{w}\right]$ is concentration of total ammoniacal-N in floodwater $\left(\mathrm{mg} \mathrm{N} \mathrm{L}^{-1}\right)$. Definitions and units of $h k$ and $f n h 3 m$ are not available in the source code, but we infer that $h k$ is the Henry's constant, and $f n h 3 m$ is molar concentration of $\mathrm{NH}_{3}$ in floodwater (mol N $\left.\mathrm{L}^{-1}\right)$.

Alternatively, in Denmead et al. (1982), the $f n h 3 p$ is given by:

$$
f n h 3 p=\frac{0.00488 \times\left[\mathrm{NH}_{3}\right] \times T^{w}}{10^{\left(\frac{14777.8}{T^{w}}-1.6937\right)}}
$$

where, $f n h 3 p$ is in mbar, $T^{w}$ in $\mathrm{K}$, and $\left[\mathrm{NH}_{3}\right]$ in $\mathrm{mg} \mathrm{N} \mathrm{L} \mathrm{N}^{-1}$. The $\left[\mathrm{NH}_{3}\right]$ is also calculated using Eq. 16. However, the trends of $f n h 3 p$ simulated using Eq. 15 differed from those of Eq. 17.

\subsubsection{Scenario studies of $\mathrm{NH}_{3}$ volatilisation}

To simulate all equations, the initial total ammoniacal-N content in the floodwater was set to $150 \mathrm{~kg} \mathrm{~N} \mathrm{ha}^{-1}$ day $^{-1}$. The initial total ammoniacal-N mass was converted to equivalent units of concentration, when necessary. In all simulations, the only $\mathrm{N}$ loss was assumed through $\mathrm{NH}_{3}$ 
volatilisation.

The $\mathrm{NH}_{3}$ volatilisation described by first-order kinetics with a constant rate coefficient (Eq. 4) was simulated for $K_{v}=0.0292$ hour $^{-1}$ (Scenario 2.1, Table 1), so that all $\mathrm{NH}_{3}$ was volatilised within seven days, for comparison with outputs simulated using the Jayaweera and Mikkelsen (1990a) model. For the same reason, the constant rate coefficient of NFLOOD v.1 was set at $K_{v}=0.3333$ hour $^{-1}$ (Scenario 2.2, Table 1). The time-varying $\mathrm{NH}_{3}$ volatilisation rate coefficient of Jayaweera and Mikkelsen (1990a) was calculated for two wind speeds, i.e., 6.5 $\mathrm{m} \mathrm{s}^{-1}$ (Scenario 2.3) and $4.5 \mathrm{~m} \mathrm{~s}^{-1}$ (Scenario 2.4). The APSIM-Oryza was first simulated using Nlossfact $=0.40$, which was a value obtained through calibration by Gaydon et al. (2012b). However, simulation results that were obtained by defining Nlossfact $=0.15$ was selected for display (Scenario 2.5). In these simulations the evaporation rate evap $=4 \mathrm{~mm}$ day $^{-1}$.

For all simulations, floodwater depth was assumed constant at $0.10 \mathrm{~m}$. Synthetic floodwater $\mathrm{pH}$ and temperatures (Appendix A) were used as inputs for simulating Scenario 2.2 to 2.5 (Table 1). Eqs. 4, 5, and 9 are in continuous-time form. These equations were solved via numerical integration using the function ode45, with a simulation time step of 0.1 hour. Eq. 11 to 16, however, are in regression form, and, thus, were computed using an Euler Forward scheme, with a simulation time step of 2.0 hours.

\subsubsection{Modelling concepts of floodwater pH}

Notice that floodwater $\mathrm{pH}$ and temperature are needed to calculate $\left[\mathrm{NH}_{3}\right]$ in the floodwater. However, modelling of floodwater temperature is not a part of this study. Therefore, synthetic floodwater temperature profiles were used (Appendix A). In the following, equations for the floodwater $\mathrm{pH}$ will be presented.

Currently, only two models (Godwin and Singh, 1998, Singh and Kirk, 1993a) are available to estimate the floodwater $\mathrm{pH}$ in a flooded rice system. The routine developed by Godwin and Singh (1998) was adopted in APSIM-Oryza by Gaydon et al. (2012b). In APSIM-Oryza, the floodwater $\mathrm{pH}$ is approximated by a function that follows an absolute sine curve, and is given by (Gaydon et al., 2012b):

$\overline{p H}^{w}=7+\left[(0.5+(2 \times\right.$ algact $\left.)) \times \sin \left(\frac{3.142 \times i}{12}\right)\right]$ 
where, algact is the $\mathrm{PAB}$ activity that is defined in Appendix $\mathrm{C}$, and time index $i=$ $1,2, \ldots, 12$. At time 12:00 hours: $i=6$.

The effect of urea hydrolysis on floodwater $\mathrm{pH}$ was added whenever the urea hydrolysis rate (in floodwater) was greater than $0.05 \mathrm{~kg} \mathrm{~N} \mathrm{ha}^{-1}$ two-hour ${ }^{-1}$ (Gaydon et al., 2012b):

$p H^{w}=\overline{p H}^{w}+\left(\frac{a l i \times\left(10-p H^{w} \_u h y d\right)}{10}\right)$

where, $p H^{w} \_$_uhyd $=f(F U H D Y R)$ is calculated using equations given in Appendix C.

The model developed by Singh and Kirk (1993a) can also predict the diurnal fluctuations in floodwater $\mathrm{pH}$. The sub-daily floodwater $\mathrm{pH}$ was calculated from the number of protons added or consumed when there was net change of $\mathrm{HCO}_{3}{ }^{-}$or $\mathrm{NH}_{4}{ }^{+}$, due to processes like urea hydrolysis, $\mathrm{NH}_{3}$ and $\mathrm{CO}_{2}$ volatilisation, $\mathrm{CO}_{2}$ consumption by $\mathrm{PAB}$, soil $\mathrm{CO}_{2}$ production, and transfer of protons between soil and floodwater. The diurnal uptake or release of $\mathrm{CO}_{2}$ by the PAB in the floodwater within 24 hours was approximated by a sine curve (Singh and Kirk, 1993a).

\subsubsection{Scenario studies of floodwater $\mathrm{pH}$}

The modelling concept of floodwater $\mathrm{pH}$ in APSIM-Oryza was evaluated for different scenarios of flooded soil systems. Due to the complexity of the floodwater $\mathrm{pH}$ routine developed by Singh and Kirk (1993a), we did not simulate their routines. Furthermore, a detailed sensitivity analysis of Singh and Kirk (1993a) model for flooded soil system without rice crop has already been performed by Singh and Kirk (1993b).

In this study, the diurnal fluctuations in floodwater $\mathrm{pH}$ simulated using APSIM-Oryza were compared to the simulation results reported by Singh and Kirk (1993b) for three scenarios: 1) Unfertilised flooded soil system without rice crop, 2) fertilised flooded soil system without rice crop and without $\mathrm{N}$ sink, and 3) fertilised flooded soil system without rice crop and with two $\mathrm{N}$ sinks, which were $\mathrm{NH}_{3}$ volatilisation and transport of $\mathrm{N}$ between soil and floodwater. For simulation of floodwater $\mathrm{pH}$ routine of APSIM-Oryza, and to meet the conditions described by Singh and Kirk (1993b), the inputs were generated as follows.

To simulate APSIM-Oryza for the unfertilised flooded soil system without rice crop (Scenario 3.1 to 3.3, Table 1), LAI was assumed to be zero. This system was simulated for three values 
of total ammoniacal-N background concentrations, namely $0 \mathrm{mg} \mathrm{N} \mathrm{L}^{-1}, 2 \mathrm{mg} \mathrm{N} \mathrm{L}^{-1}$, and $6 \mathrm{mg}$ $\mathrm{N} \mathrm{L}^{-1}$. The non-zero background concentrations were assumed contributed by traces of $\mathrm{N}$ in the irrigation water. However, note that Singh and Kirk (1993b) assumed a background concentration of $0 \mathrm{mg} \mathrm{N} \mathrm{L}^{-1}$.

To simulate the diurnal fluctuations in floodwater $\mathrm{pH}$ using APSIM-Oryza for a fertilised flooded soil system without rice crop, and without $\mathrm{N}$ sink (Scenario 3.4, Table 1), LAI was again assumed to be zero. The system was broadcasted with $40 \mathrm{~kg}$ urea-N ha ${ }^{-1}$ at 12:00 hours, following the amount described in Singh and Kirk (1993b). The difference in application time was noted in the analysis (Section 3.3). The urea hydrolysis was described by a first-order kinetics model with a time-varying rate coefficient that was driven by the PAB activity and percentage of soil organic C (Eq. 3). A constant floodwater depth of $0.05 \mathrm{~m}$ was assumed, following the value described in Singh and Kirk (1993b). The concentration of total ammoniacal-N in the floodwater, which was regulated by the rate of urea hydrolysis, was used to calculate the two-hourly floodwater $\mathrm{N}$ index ( $f n i$, Eq. C.1 Appendix C).

In order to simulate the changes in the floodwater $\mathrm{pH}$ using APSIM-Oryza for a fertilised flooded soil system with conditions comparable to the system described by Singh and Kirk (1993b) (Scenario 3.5, Table 1), the daily peaks of total ammoniacal-N concentrations in the floodwater predicted by Singh and Kirk (1993b) were used for estimating the floodwater N index $(f n i)$. For the unplanted system, $L A I=0.0$. The effect of urea hydrolysis on the floodwater $\mathrm{pH}$ (Eq. 19) was not included in this simulation.

In addition to the previously mentioned scenarios, the floodwater routine of APSIM-Oryza was simulated for two more scenarios: 1) Fertilised and flooded rice system with young rice crop, and 2) fertilised and flooded rice systems with more developed rice crop. Details of these scenarios are described in the following.

To assess the performance of the floodwater $\mathrm{pH}$ routine of APSIM-Oryza in fertilised and flooded rice systems (Scenario 3.6, Table 1), concentrations of total ammoniacal-N in the floodwater, for the duration from 14 days after transplanting through 27 days after transplanting, at Los Baños, Philippines (Fillery et al., 1984), were selected and used to calculate the floodwater $\mathrm{N}$ index $(f n i)$. The temporal dynamics of total ammoniacal-N concentrations in the floodwater was a result of interacting $\mathrm{N}$ processes (i.e., $\mathrm{N}$ transport into soil for rice $\mathrm{N}$ uptake, $\mathrm{NH}_{3}$ volatilisation, and other $\mathrm{N}$ sources/sinks), and, thus, were considered 
an adequate representation of actual fertilised and flooded rice systems. The system was broadcasted with $60 \mathrm{~kg} \mathrm{~N} \mathrm{ha}^{-1}$ without subsequent incorporation in the soil. Two-hourly rates of urea hydrolysis were calculated (Eqs. 2 and 3), and subsequently used to calculate the effect of urea hydrolysis on the floodwater $\mathrm{pH}$ (Eq. 19). A mean solar radiation of $16.5 \mathrm{MJ} \mathrm{m}^{-2}$ day $^{-1}$ was assumed, in order to calculate the two-hourly available light index (ali). LAI was assumed to be 2.0, to represent a system with young rice crop (at 14 days after transplanting). To observe the effect of rice crop growth stage on the floodwater $\mathrm{pH}$, the simulation was repeated for $L A I=3.0$, to represent an increase in crop canopy cover in a system with more advanced growth stage (Scenario 3.7, Table 1).

For all systems simulated using APSIM-Oryza, the $f t i$ was calculated as a function of floodwater temperature (Eq. C.1 in Appendix C, with synthetic floodwater temperatures given in Appendix A), and $f p i=0.5$, because phosphorus was not applied. The percentage of soil organic $\mathrm{C}$ in the top soil was set at $2.2 \%$, which was the concentration defined in APSIMOryza (Gaydon et al., 2015, pers. comm.). Eq. 19 and 18 were computed using an Euler Forward scheme, with simulation time-step of 2.0 hours.

\subsection{Results and discussion}

\subsubsection{Scenario studies of urea hydrolysis in floodwater}

Fig. 1a shows the dynamics of the rate coefficient of urea hydrolysis $\left(K_{h}\right.$ or $\left.\widetilde{K}_{h}\right)$ simulated using conditions typically reported in tropical flooded rice systems. Chowdary et al. (2004) assumed a constant $K_{h}$, which ranged from 0.0333 two-hour $^{-1}$ to 0.0667 two-hour $^{-1}$, throughout a cropping season. Unlike Chowdary et al. (2004), in APSIM-Oryza, the timevarying rate $\widetilde{K}_{h}$ was regulated by three factors, namely the PAB activity (UALGCT), percentage of organic $\mathrm{C}$ in the soil top layer $(O C \%)$, and floodwater temperature (TEMPFU) (Eq. 3).

Calculations showed that when floodwater temperature is $22.3{ }^{\circ} \mathrm{C}$ or above, TEMPFU is constant at 0.9. The synthetic floodwater temperatures used in all simulations ranged from $25^{\circ} \mathrm{C}$ to $38^{\circ} \mathrm{C}$. Therefore, TEMPFU is constant at 0.9 in all simulations. Consequently, TEMPFU only affects the magnitude, but not the trend of $\widetilde{K}_{h}$. This indicates that TEMPFU can be fixed at 0.9 for simulations of tropical flooded rice systems, to simplify the model of APSIM-Oryza. The trend of $\widetilde{K}_{h}$ simulated by APSIM-Oryza can either vary with time or 
remain constant, depending on the $\mathrm{PAB}$ activity or soil organic $\mathrm{C} \%$ (Fig. 1a, Table 1).

The PAB activity had no effect on hydrolysis of urea when the soil organic $\mathrm{C}$ was about $20 \%$ or greater (Scenario 1.4, Fig. 1a). Unless buffered by a high percentage of soil organic C, lower urea hydrolysis rate was observed in the first few hours after application of urea; Scenario 1.5 versus 1.6, and Scenario 1.7 versus 1.8 . The lower urea hydrolysis rate was due to a gradual build-up of total ammoniacal-N in the floodwater (Fig. A.3, Appendix A), which limited the effect of PAB activity on urea hydrolysis, UALGCT (Eq. 3). For low soil organic C, higher values of $\widetilde{K}_{h}$ during the first four days after urea application were observed in a flooded system with young rice crop (Scenario 1.5, Fig. 1a), compared with a flooded system with more developed rice crop (Scenarios 1.7 , Fig. 1a). The $\widetilde{K}_{h}$ was lower in the system with more developed rice crop due to lower available light for PAB activity (ali), which was a function of leaf area index $(L A I)$. After four days, the values of $\widetilde{K}_{h}$ of both scenarios converged, due to limited $\mathrm{N}$ content in the floodwater $(f n i)$ in both systems. On the contrary, when the percentage of organic $\mathrm{C}$ in the top soil layer was high enough to buffer the effect of crop growth stage (Scenarios 1.6 and 1.8, Fig. 1a), fewer or smaller discrepancies between values of $\widetilde{K}_{h}$ of a flooded system with young rice crop, and those of a flooded system with more developed rice crop, were observed.

By using the simulated two-hourly rate coefficients of urea hydrolysis (Fig. 1a), and assuming an impulse input of $150 \mathrm{~kg} \mathrm{~N} \mathrm{ha}^{-1}$, the rates of urea hydrolysis (Fig. 1b) and the total urea-N in the floodwater (Fig. 1c) were simulated. Largest discrepancies between rates of hydrolysed urea simulated with various scenarios were observed within the first day after urea application (Fig. 1b). The discrepancies were basically due to variation in trends and magnitudes of $K_{h}$ or $\widetilde{K}_{h}$ (Fig. 1a).

However, about two days after urea application, the discrepancies among models were significantly reduced (Fig. 1b), despite the variation in $K_{h}$ or $\widetilde{K}_{h}$ (Fig. 1a). The amount of urea-N in the floodwater was highest in the beginning of urea application, and was reduced to about less than half of the total urea-N applied after one to two days. More precisely, for constant $K_{h}$, this occurred after $\ln 0.5 / K_{h}$ days. This demonstrates that accurate estimation of the rate coefficient of urea hydrolysis is crucial right after application of urea. 

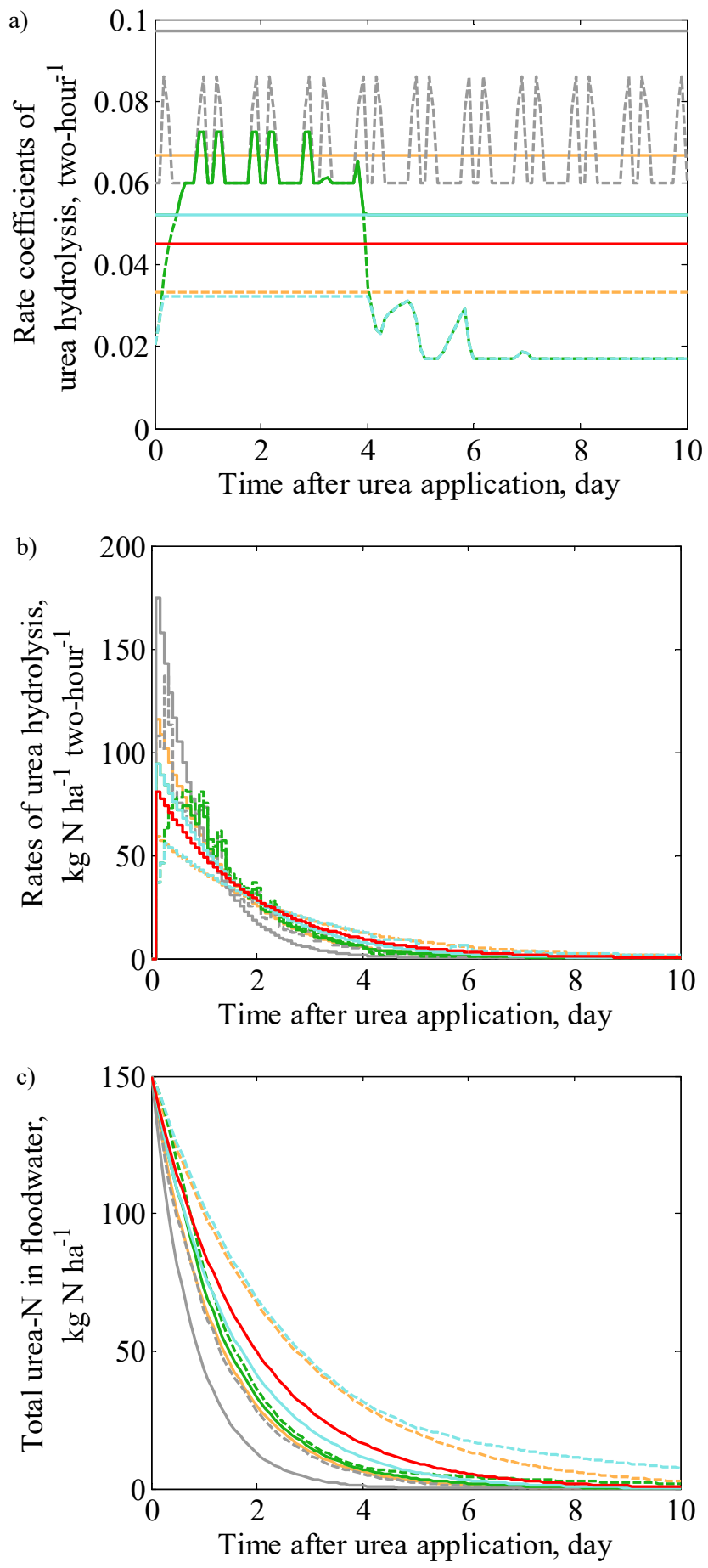

Fig. 1 a) Rate coefficients of urea hydrolysis, b) rates of urea hydrolysis, and c) the corresponding total urea- $\mathrm{N}$ in the floodwater after urea hydrolysis, in a fertilised and flooded soil system with an initial condition of $150 \mathrm{~kg} \mathrm{~N} \mathrm{ha}^{-1}$ in the floodwater: Scenario 1.1 (dash orange line), Scenario 1.2 (solid orange line), Scenario 1.3 (dash grey line), Scenario 1.4 (solid grey line), Scenario 1.5 (dash green line), Scenario 1.6 (solid green line), Scenario 1.7 (dash blue line), Scenario 1.8 (solid blue line), Scenario 1.9 (solid red line) 
Fillery et al. (1984) reported that urea hydrolysis was completed within seven days. In our simulation, almost all applied urea was completely hydrolysed on the fifth day after urea application for all scenarios, except for Scenario 1.1 and for Scenario 1.7 (Fig. 1c, Table 1).

Unless buffered by a high percentage of soil organic C in top soil layer, a flooded system with more developed rice crop $(L A I=3.0)$ required more than seven days to complete hydrolysis of urea (Scenario 1.7). Meanwhile, a flooded system with $20 \%$ of top soil organic C required the shortest time to complete urea hydrolysis, irrespective of the PAB activity (Scenario 1.5, Fig. 1c).

The results revealed the importance of good estimates of percentage of organic $\mathrm{C}$ in top soil layer, for reliable simulations with APSIM-Oryza. Notice that the conceptualisation of the $\mathrm{PAB}$ activity resulted in fluctuations of the simulated rates of hydrolysed urea within a day (Scenarios 1.5 and 1.6, Fig. 1b). However, these fluctuations were relatively small in magnitudes compared with the daily average values, and, thus, were expected to have a negligible effect on the daily rates of urea hydrolysis.

Notice that the model outputs simulated by APSIM-Oryza for Scenario 1.7 overlapped the model output simulated by a first-order kinetics model with a constant rate coefficient, $K_{h}=0.0333$ two-hour ${ }^{-1}$. The rate of urea hydrolysis simulated using a first-order kinetics model with a constant $K_{h}=0.0333$ two-hour $^{-1}$ (Scenario 1.1) was also comparable to that of APSIM-Oryza when percentage of soil organic $\mathrm{C}$ was set to $12.3 \%$ and $L A I=1.0$ (results not shown). The results demonstrate that the main difference between the modelling concepts of first-order kinetics of urea hydrolysis with a constant rate coefficient and that of APSIMOryza lies in the conceptualisation of soil organic C \% and LAI in APSIM-Oryza.

Discrepancies between simulated rates of urea hydrolysis were more prominent within the first two days after application of urea (Fig. 1b). The discrepancies suggest that the hourly measurements of urea- $\mathrm{N}$ and total ammoniacal-N in the floodwater within two days after urea application are essential for validation of urea hydrolysis in the floodwater. However, considering many time-varying $\mathrm{N}$ sinks in actual flooded rice field systems, quantification of hourly rates of urea hydrolysis may require complex experimental set ups. Therefore, from a modelling point of view, further detailing of the urea hydrolysis process is not needed, as data sets may not allow validation of detailed dynamics descriptions of the urea hydrolysis process. 


\subsubsection{Scenario studies of $\mathrm{NH}_{3}$ volatilisation from floodwater surface}

In the Jayaweera and Mikkelsen (1990a) model, the time-varying rate coefficient of $\mathrm{NH}_{3}$ volatilisation $\left(\widetilde{K}_{v}\right)$ was calculated as a function of five factors, namely the total ammoniacal-N concentration, wind speed, floodwater depth, $\mathrm{pH}$, and temperature. For various combinations of the five factors, $\widetilde{K}_{v}$ ranged from 0.0033 hour $^{-1}$ through 9.000 hour $^{-1}$ (Jayaweera and Mikkelsen, 1990b). However, assuming typical conditions in a tropical flooded rice system at mid-day, we calculated a $\widetilde{K}_{v}$ value of about 0.3411 hour $^{-1}$. The values of $\widetilde{K}_{v}$ calculated using the Jayaweera and Mikkelsen (1990b) model were higher compared with the values recommended in Chowdary et al. (2004), which ranged from $K_{v}=8.333 \times 10^{-4}$ hour $^{-1}$ to $K_{v}=0.0029$ hour $^{-1}$, and in Antonopoulos (2010), which ranged from $K_{v}=0.0013$ hour $^{-1}$ to $K_{v}=0.0333$ hour $^{-1}$. Fig. 2a, as a result of evaluations of Scenarios 2.1 to 2.5 (Table 1), shows that for complete volatilisation of the total ammoniacal- $\mathrm{N}$ in the floodwater by the seventh day, the rate coefficient of $\mathrm{NH}_{3}$ volatilisation for NFLOOD v.1 ( $K_{v}=0.3333$ hour $^{-1}$, Scenario 2.2) was higher than that of the first-order kinetics with a constant rate coefficient $\left(K_{v}=0.0292\right.$ hour $^{-1}$, Scenario 2.1).

A smaller value of the rate coefficient was required when the $\mathrm{NH}_{3}$ volatilisation was described by a first-order kinetics model with a constant rate coefficient, as $\mathrm{NH}_{3}$ was continuously volatilised at every time-instant. When the partitioning of $\mathrm{NH}_{4}{ }^{+}$and $\mathrm{NH}_{3}$ was conceptualised, the rate coefficient of $\mathrm{NH}_{3}$ volatilisation required a higher value, because the amount of $\mathrm{NH}_{3}$ in the floodwater susceptible to volatilisation is regulated by floodwater $\mathrm{pH}$, and, thus, resulted in diurnal trend of $\mathrm{NH}_{3}$ volatilisation. This analysis demonstrates that the underlying concepts of an $\mathrm{NH}_{3}$ volatilisation model determine the appropriate values of the rate coefficient of $\mathrm{NH}_{3}$ volatilisation. Hence, it is vital to understand the modelling concepts, prior to adopting or comparing values of the $\mathrm{NH}_{3}$ volatilisation rate coefficient.

The diurnal trend of $\mathrm{NH}_{3}$ volatilisation as observed in Fillery et al. (1986) cannot be simulated by a first-order kinetics model with a constant rate coefficient (Eq. 4), unless the effect of $\mathrm{NH}_{4}{ }^{+}$and $\mathrm{NH}_{3}$ partitioning in the floodwater was conceptualised, as in NFLOOD v.1 (Eq. 5, Fig. 2b). The Jayaweera and Mikkelsen (1990a) model, which includes conceptualisation of $\mathrm{NH}_{4}{ }^{+}$and $\mathrm{NH}_{3}$ partitioning and the time-varying rate coefficient $\left(\widetilde{K}_{v}\right)$, was also able to simulate the diurnal trend in $\mathrm{NH}_{3}$ volatilisation (Fig. 2b). 

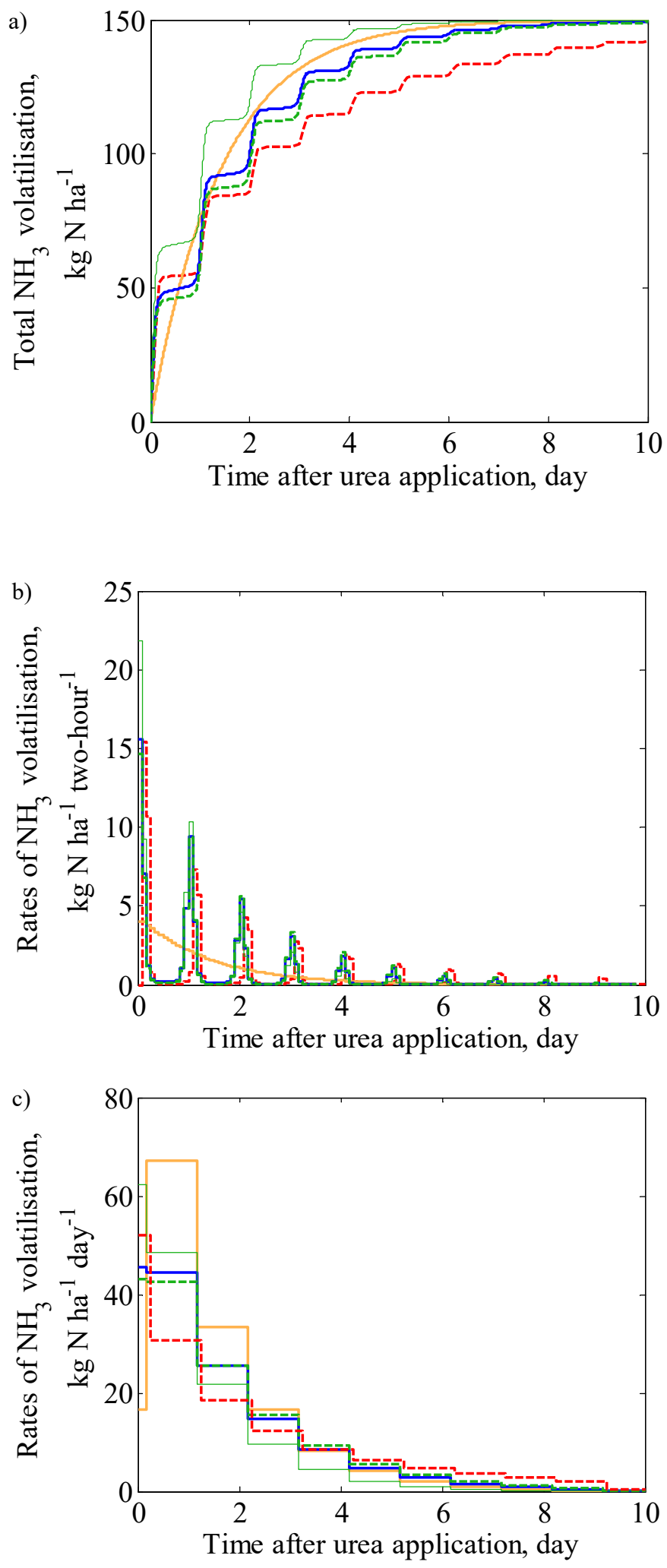

Fig. 2 a) Total $\mathrm{NH}_{3}$ volatilisation, b) the corresponding two-hourly rates of $\mathrm{NH}_{3}$ volatilisation, and c) the corresponding daily rates of $\mathrm{NH}_{3}$ volatilisation, in a fertilised and flooded soil system with an initial condition of $150 \mathrm{~kg} \mathrm{~N} \mathrm{ha}^{-1}$ in the floodwater: Scenario 2.1 (orange solid line), Scenario 2.2 (blue solid line), Scenario 2.3 (green solid line), Scenario 2.4 (green dash line), and Scenario 2.5 (red dash line) 
More importantly, notice that the trends of the two-hourly $\mathrm{NH}_{3}$ volatilisation rates simulated by the NFLOOD v.1. and the Jayaweera and Mikkelsen (1990a) model were comparable (Fig. 2b). At first, we run the Jayaweera and Mikkelsen (1990a) model for wind speed, $6 \mathrm{~m} \mathrm{~s}^{-1}$, and observed discrepancies in the magnitude of each daily peak (Scenario 2.3, Fig. 2b). We suspected that this discrepancy was due an overestimation of the wind speed. Therefore, the simulation with the Jayaweera and Mikkelsen (1990a) model was repeated with wind speed reduced from $6 \mathrm{~m} \mathrm{~s}^{-1}$ to $4.5 \mathrm{~m} \mathrm{~s}^{-1}$. As a result, our hypothesis was confirmed as the peaks simulated using the Jayaweera and Mikkelsen (1990a) model fitted the peaks simulated using the NFLOOD v.1 model (Scenario 2.2 versus 2.4, Fig. 2b). The corresponding time-varying rate coefficient of $\mathrm{NH}_{3}$ volatilisation simulated using the Jayaweera and Mikkelsen (1990a) model ranged from $\widetilde{K}_{v}=0.20$ hour $^{-1}$ to $\widetilde{K}_{v}=0.23$ hour $^{-1}$. These values were slightly lower than the estimate used in NFLOOD v.1, which was $K_{v}=0.3333$ hour $^{-1}$.

Despite the comparable outputs, note the differences in modelling concepts underlying the NFLOOD v.1. and the Jayaweera and Mikkelsen (1990a) model (Sections 3.2.2.1 and 3.2.2.2). To simulate partitioning between $\mathrm{NH}_{4}{ }^{+}$and $\mathrm{NH}_{3}$ in the floodwater, both floodwater $\mathrm{pH}$ and temperature were used in the Jayaweera and Mikkelsen (1990a) model, and only floodwater $\mathrm{pH}$ was used in NFLOOD v.1. The rate coefficient of $\mathrm{NH}_{3}$ volatilisation in NFLOOD v. 1 is a constant, whereas the rate coefficient of $\mathrm{NH}_{3}$ volatilisation in the Jayaweera and Mikkelsen (1990a) model is time-varying. Unlike all other models discussed in this chapter, the floodwater depth is inversely proportional to the rate coefficient of $\mathrm{NH}_{3}$ volatilisation in the Jayaweera and Mikkelsen (1990a) model. However, in this numerical experiment, the floodwater depth was assumed constant.

The effect of wind speed was conceptualised in the Jayaweera and Mikkelsen (1990a) model, but not in the NFLOOD v.1. Wind speed is an important regulator of $\mathrm{NH}_{3}$ volatilisation (Vlek and Craswell, 1981), but wind speed data is often not available. Consequently, newer models, such as CERES-Rice (Godwin and Singh, 1998) and APSIM-Oryza (Gaydon et al., 2012b), approximated wind speed by other measurable variables, i.e. pan evaporation or $L A I$.

The simulation results suggest that, in the absent of wind speed data, the $\mathrm{NH}_{3}$ volatilisation routine in NFLOOD v.1 may be substituted by the Jayaweera and Mikkelsen (1990a) model. For different constant wind speeds, Table 2 provides the corresponding values of rate coefficient of $\mathrm{NH}_{3}$ volatilisation for NFLOOD v.1, which would produce outputs comparable 
with those simulated by the Jayaweera and Mikkelsen (1990a) model.

Table 2 Corresponding constant $\mathrm{NH}_{3}$ volatilisation rate coefficients for NFLOOD v.1 $\left(K_{v}\right)$, for constant wind speeds, that would produce rates of $\mathrm{NH}_{3}$ volatilisation similar to those simulated using the Jayaweera and Mikkelsen (1990a) model

\begin{tabular}{cc}
\hline Wind speed $\left(\mathbf{m ~ s}^{-1}\right)$ & Values of $\boldsymbol{K}_{\boldsymbol{v}}\left(\right.$ hour $\left.^{-1}\right)$ \\
\hline 2 & 0.12 \\
4 & 0.26 \\
5 & 0.50 \\
8 & 0.80 \\
\hline
\end{tabular}

Note that the time-shift observed for APSIM-Oryza was due to the Euler Forward discretisation scheme (Scenario 2.5, Fig. 2b). Results show that by fitting the trend of twohourly $\mathrm{NH}_{3}$ volatilisation rates produced by APSIM-Oryza to those of NFLOOD v.1 (Fig. $2 \mathrm{~b}$ ), we overestimated the amount of total ammoniacal-N that was left in the floodwater on the final day (Fig. 2a). By fitting the amount of total ammoniacal-N left in the floodwater, we overestimated the rate of $\mathrm{NH}_{3}$ volatilisation within the first day after urea application. This result suggests that the $\mathrm{NH}_{3}$ volatilisation routine of APSIM-Oryza is not comparable with those of the NFLOOD v.1 and Jayaweera and Mikkelsen (1990a) models.

To investigate whether the daily $\mathrm{NH}_{3}$ volatilised simulated by the discussed models were comparable, the rates of daily $\mathrm{NH}_{3}$ volatilisation were calculated from 18:00 hours to 18:00 hours (Fig. 2c). Results show that the first-order kinetics model with a constant rate coefficient (Scenario 2.1) estimated higher daily rates of $\mathrm{NH}_{3}$ volatilisation in comparison with the NFLOOD v.1 (Scenario 2.2) and Jayaweera and Mikkelsen (1990a) (Scenario 2.4) models, during the first two days, after which the discrepancies were reduced (Fig. 2c).

\subsubsection{Scenario studies of floodwater $\mathrm{pH}$}

In addition to wind speed, floodwater $\mathrm{pH}$ and temperature are also key regulators of $\mathrm{NH}_{3}$ volatilisation. The floodwater temperature can easily be measured and was pre-defined in this study (Appendix A). Also, the floodwater $\mathrm{pH}$ can easily be measured. However, semi-physical modelling of the floodwater $\mathrm{pH}$ dynamics allows understanding of the underlying mechanisms, reduces the number of input data required for simulation, and allows prediction of $\mathrm{NH}_{3}$ volatilisation. So far, $\mathrm{NH}_{3}$ volatilisation was calculated for a fixed $\mathrm{NH}_{3}$ volatilisation rate coefficient or time-varying rate coefficient, with pre-defined two-hourly floodwater $\mathrm{pH}$ (Fig. A.1). 
In this section, the modelling concepts of floodwater $\mathrm{pH}$ in APSIM-Oryza were evaluated for different settings of flooded soil systems (Scenarios 3.1 to 3.7, Table 1). For selected scenarios, the diurnal fluctuations in floodwater $\mathrm{pH}$ simulated using APSIM-Oryza were compared with those of the Singh and Kirk (1993a) model.

First, we consider unfertilised flooded soil systems without rice crop (Scenarios 3.1 to 3.3, Table 1). For this system, the diurnal floodwater $\mathrm{pH}$ simulated using APSIM-Oryza followed an absolute sine curve, with daily peaks occurring at 12:00 hours (Fig. 3a). For this system, the magnitude of floodwater $\mathrm{pH}$, which is dependent on the PAB activity index (algact), was regulated by the floodwater $\mathrm{N}$ index $(f n i)$ throughout ten days after urea application. Unlike APSIM-Oryza, in which the PAB activity was approximated as index factor regulated by the most limiting of factors (ali, fti,fni,fpi), the PAB activity in Singh and Kirk (1993a) model is pre-defined as a rate constant of $\mathrm{CO}_{2}$ consumption by $\mathrm{PAB}$ at mid-day, which can be calibrated to suit local conditions.

For an unfertilised flooded soil systems without rice crop and without PAB activity, simulation of the Singh and Kirk (1993a) model resulted in a floodwater $\mathrm{pH}$ of about 8.2 that stayed constant within 24 hours (Singh and Kirk, 1993b). This pH value was higher than those simulated using APSIM-Oryza for low PAB activity (i.e., algact $=f n i=0.1$, Fig. 3), where the diurnal fluctuations in floodwater $\mathrm{pH}$ were within the neutral range. The Singh and Kirk (1993a) model was able to produce higher $\mathrm{pH}$ levels despite zero PAB activity because the floodwater $\mathrm{pH}$ dynamics were calculated on the basis of the number of protons added, not only due to net change in $\mathrm{NH}_{4}{ }^{+}$, but also in $\mathrm{HCO}_{3}{ }^{-}$, in floodwater and soil (Singh and Kirk, 1993b).

Unlike the Singh and Kirk (1993a) model, APSIM-Oryza was never able to simulate a constant floodwater $\mathrm{pH}$ because the diurnal fluctuations in floodwater $\mathrm{pH}$ were assumed to follow an absolute sine curve (Eq. 18). Singh and Kirk (1993a) approximated the uptake or release of $\mathrm{CO}_{2}$ by the $\mathrm{PAB}$ in the floodwater by a sine curve, but the floodwater $\mathrm{pH}$, using the Singh and Kirk (1993a) model, can be either constant (zero PAB activity) or follow a sine curve (non-zero PAB activity) (Singh and Kirk, 1993b).

For an unfertilised flooded soil system without rice crop, but now with PAB activity defined as $5.6 \mathrm{nmol} \mathrm{dm}^{-3} \mathrm{~s}^{-1} \mathrm{CO}_{2}$ consumption rate at mid-day, the trend of floodwater $\mathrm{pH}$ within 24 hours simulated by Singh and Kirk (1993b) followed a sine curve, with increasing values 
from $\mathrm{pH} 7.8$ at 6:00 hours, to about $\mathrm{pH} 9.0$ at about 13:30 hours, and gradually decreasing to about $\mathrm{pH} 7.8$ at about 20:00 hours. APSIM-Oryza, however, cannot simulate daily peaks higher than $\mathrm{pH} 8.5$, because the $\mathrm{PAB}$ activity was limited by zero phosphorus supply, i.e., $f p i=0.5$ (Fig. 3b).
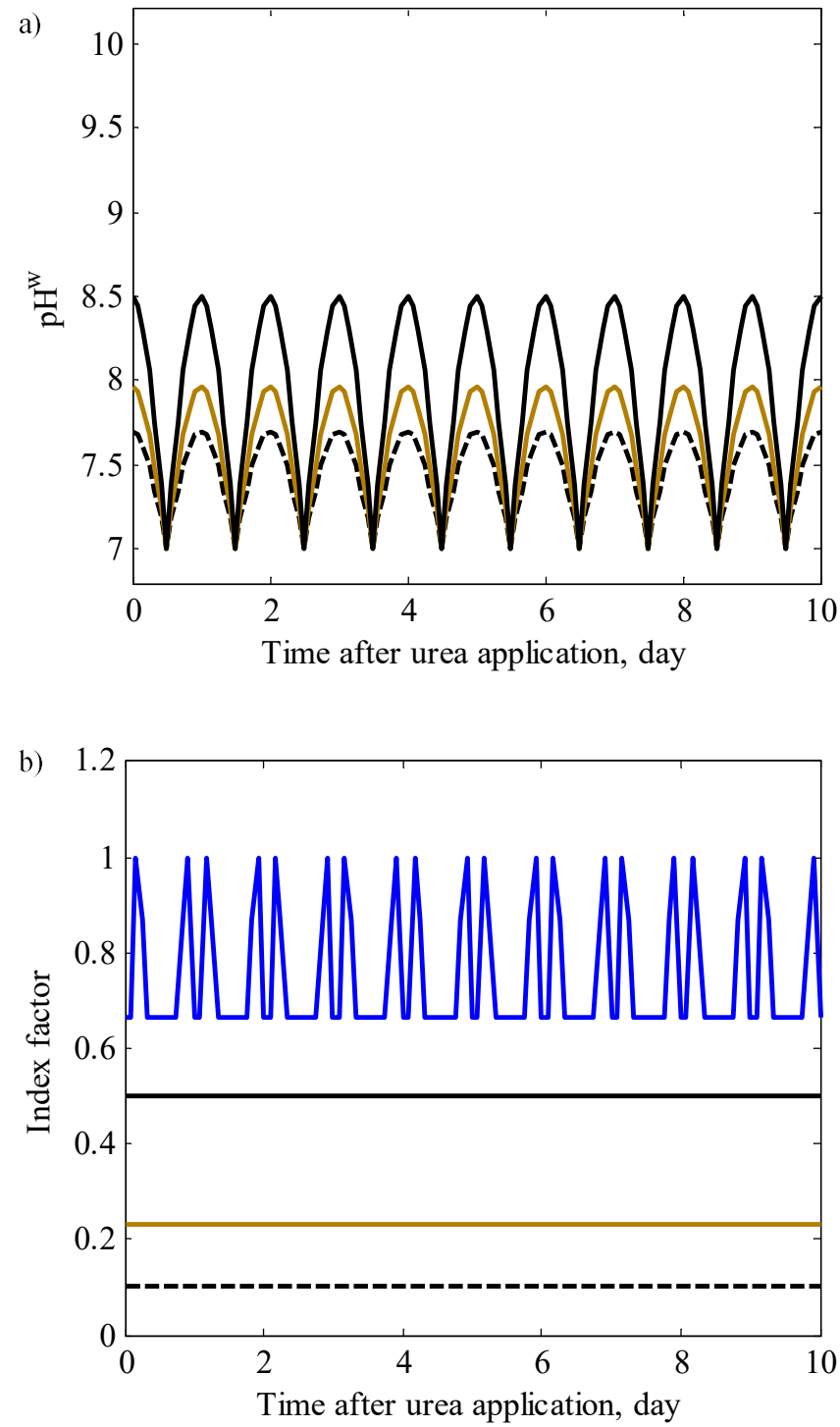

Fig. 3 a) Diurnal fluctuations in floodwater pH simulated using APSIM-Oryza: Scenario 3.1 (dash line), Scenario 3.2 (brown solid line), and Scenario 3.3 (black solid line), and b) the corresponding indexes that regulate the PAB activity: Floodwater N indexes for Scenario 3.1 (dash line), Scenario 3.2 (brown solid line), and Scenario 3.3 (black solid line), and the floodwater temperature index for all scenarios (blue solid line). These scenarios were performed for unfertilised and flooded soil systems

The PAB activity in APSIM-Oryza was predictably low, given low concentration of total ammoniacal-N. In contrast, a higher rate of PAB activity can be pre-defined in the Singh and 
Kirk (1993a) model, regardless of the total ammoniacal-N concentration.

In the next set of scenarios (Scenarios 3.4 to 3.5, Table 1), we consider fertilised flooded soil systems without rice crop, first without $\mathrm{N}$ sinks, and second with $\mathrm{N}$ sinks (i.e., $\mathrm{NH}_{3}$ volatilisation and $\mathrm{N}$ transport into the soil). The latter (Scenario 3.5, Table 1) was selected for comparison with the results by Singh and Kirk (1993b).

In a flooded soil system without rice crop, without $\mathrm{N}$ sink, and which was broadcasted with $40 \mathrm{~kg} \mathrm{~N} \mathrm{ha}^{-1}$ at 12:00 hours, the simulated floodwater $\mathrm{pH}$ using APSIM-Oryza followed an absolute sine curve (Fig. 4a). Initially, the magnitude of diurnal fluctuations in floodwater $\mathrm{pH}$ was limited by the slow build-up of total ammoniacal-N concentration (Fig. 4b). About 12 hours after urea application, the concentration of total ammoniacal-N in the floodwater exceeded $15 \mathrm{mg} \mathrm{N} \mathrm{L}^{-1}$. Thus, the floodwater $\mathrm{N}$ index ( $\mathrm{fni}$ ) was no longer a limiting factor as there was no $\mathrm{N}$ sink. Consequently, one day after urea application, the floodwater $\mathrm{pH}$ peak increased from about $\mathrm{pH} 8.5$ to slightly above $\mathrm{pH}$ 9.0. At this point, floodwater phosphorus content became the most limiting factor to the PAB activity, due to absent of phosphorus supply (i.e., $f p i=0.5)$. If phosphorus was applied $(f p i=1.0)$, the floodwater temperature index ( $f t i)$ would be the most limiting factor to PAB activity.

Notice that the rate of urea hydrolysis had an additional effect on the magnitude of floodwater $\mathrm{pH}$ (Eq. 19). The rates of urea hydrolysis were highest at about 12 hours after urea application (about $1.7 \mathrm{~kg} \mathrm{~N} \mathrm{ha}^{-1}$ two-hour ${ }^{-1}$ ), and gradually decreased towards zero in about six days after urea application. As the rates of urea hydrolysis declined, a slight decrease in the daily peaks of floodwater $\mathrm{pH}$ from first through six days after urea application was observed (Fig. 4a). A noticeable decrease in daily peak of floodwater $\mathrm{pH}$ was observed seven days after urea application due to completion of urea hydrolysis (Fig. 4a).

By using the Singh and Kirk (1993a) model, Singh and Kirk (1993b) predicted the diurnal floodwater $\mathrm{pH}$ in a fertilised flooded soil system with $\mathrm{N}$ sinks. In their simulations, the $\mathrm{NH}_{3}$ volatilisation and $\mathrm{N}$ transport into the soil were included as the only $\mathrm{N}$ sinks. We wished to simulate and compare the diurnal floodwater $\mathrm{pH}$ of a similar system using APSIM-Oryza. However, due to differences in modelling concepts of $\mathrm{NH}_{3}$ volatilisation, between the APSIM-Oryza and Singh and Kirk (1993a) models, different rates of $\mathrm{NH}_{3}$ volatilisation may result. The rates of $\mathrm{NH}_{3}$ volatilisation affect the estimates of floodwater $\mathrm{pH}$ by both models. Consequently, the estimates of floodwater $\mathrm{pH}$ obtained using APSIM-Oryza cannot be 
compared to those of Singh and Kirk (1993b).
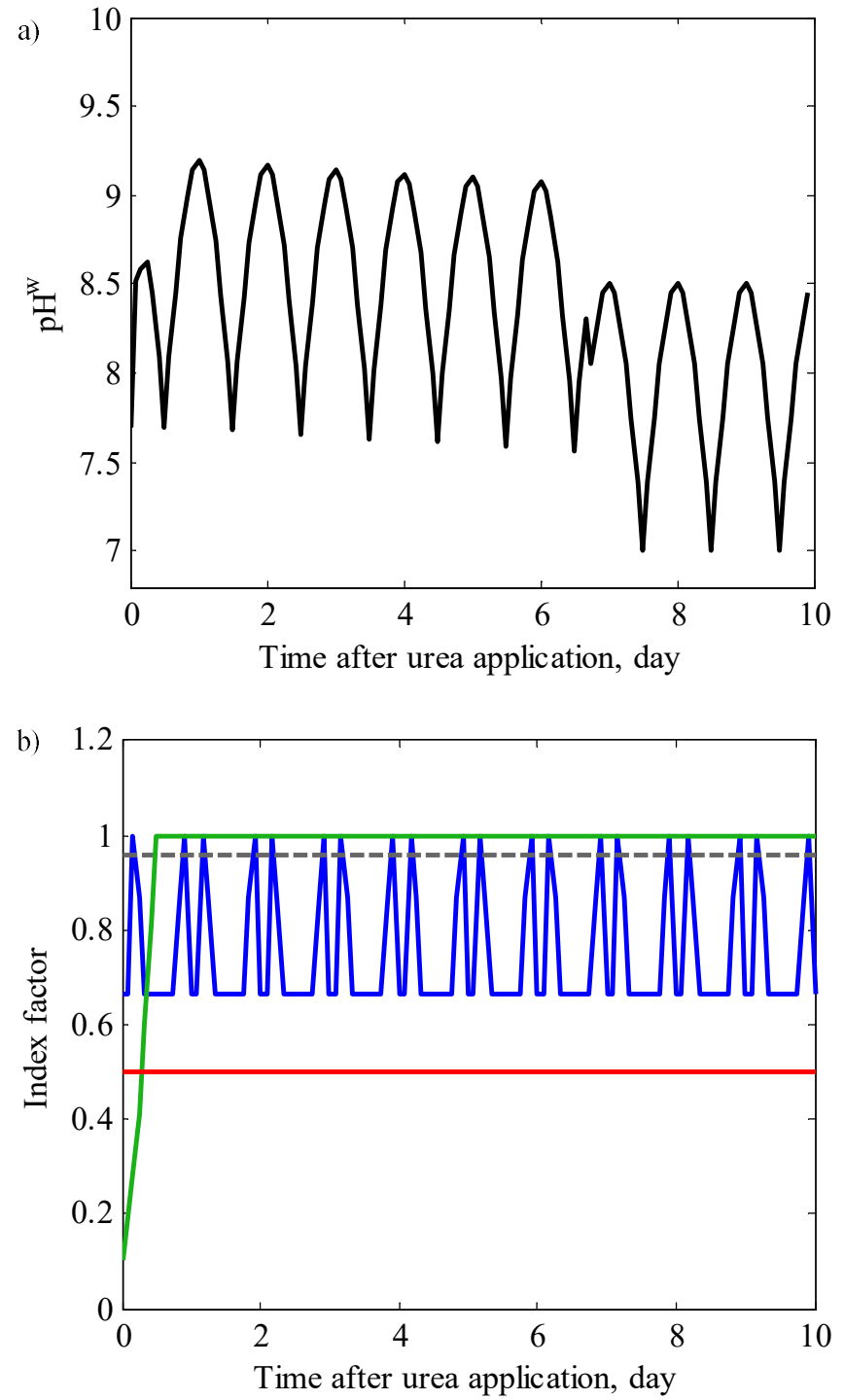

Fig. 4 a) Diurnal floodwater $\mathrm{pH}$ simulated using APSIM-Oryza and b) the factors that regulate the $\mathrm{PAB}$ activity for Scenario 3.4: Floodwater temperature index ( $f t i$, blue solid line), available light index (ali, dash grey line), floodwater $\mathrm{N}$ index ( $f n i$, green solid line), and floodwater $\mathrm{P}$ index ( $\mathrm{fpi}$, red solid line). Scenario 3.4 considers a fertilised and flooded soil system that was broadcast with $40 \mathrm{~kg}$ urea- $\mathrm{N} \mathrm{ha}^{-1}$, and with no $\mathrm{N}$ sink. $L A I=0.0$, $f p i=0.5$

Alternatively, daily peaks of total ammoniacal-N concentrations in the floodwater, predicted by Singh and Kirk (1993b), were used for estimating the 'effective' floodwater $\mathrm{N}$ index ( $f n i)$ in APSIM-Oryza. The daily peak of total ammoniacal-N concentration were highest (about $2.8 \mathrm{mg} \mathrm{N} \mathrm{L}^{-1}$ ) on the second day after urea application, and subsequently, the daily peak gradually declined to about $1.1 \mathrm{mg} \mathrm{N} \mathrm{L}^{-1}$ ten days after urea application (Singh and Kirk, 
1993b). To calculate the $f n i$ in APSIM-Oryza, the concentration of total ammoniacal-N was assumed constant throughout a day, and was approximated by the daily peak. Fig. 5a shows the resulting diurnal fluctuations in floodwater $\mathrm{pH}$ of the fertilised flooded soil system with $\mathrm{N}$ sinks which is comparable with the system defined in Singh and Kirk (1993b). For this system, the $f n i$ was the most limiting factor to PAB activity (Fig. 5b).
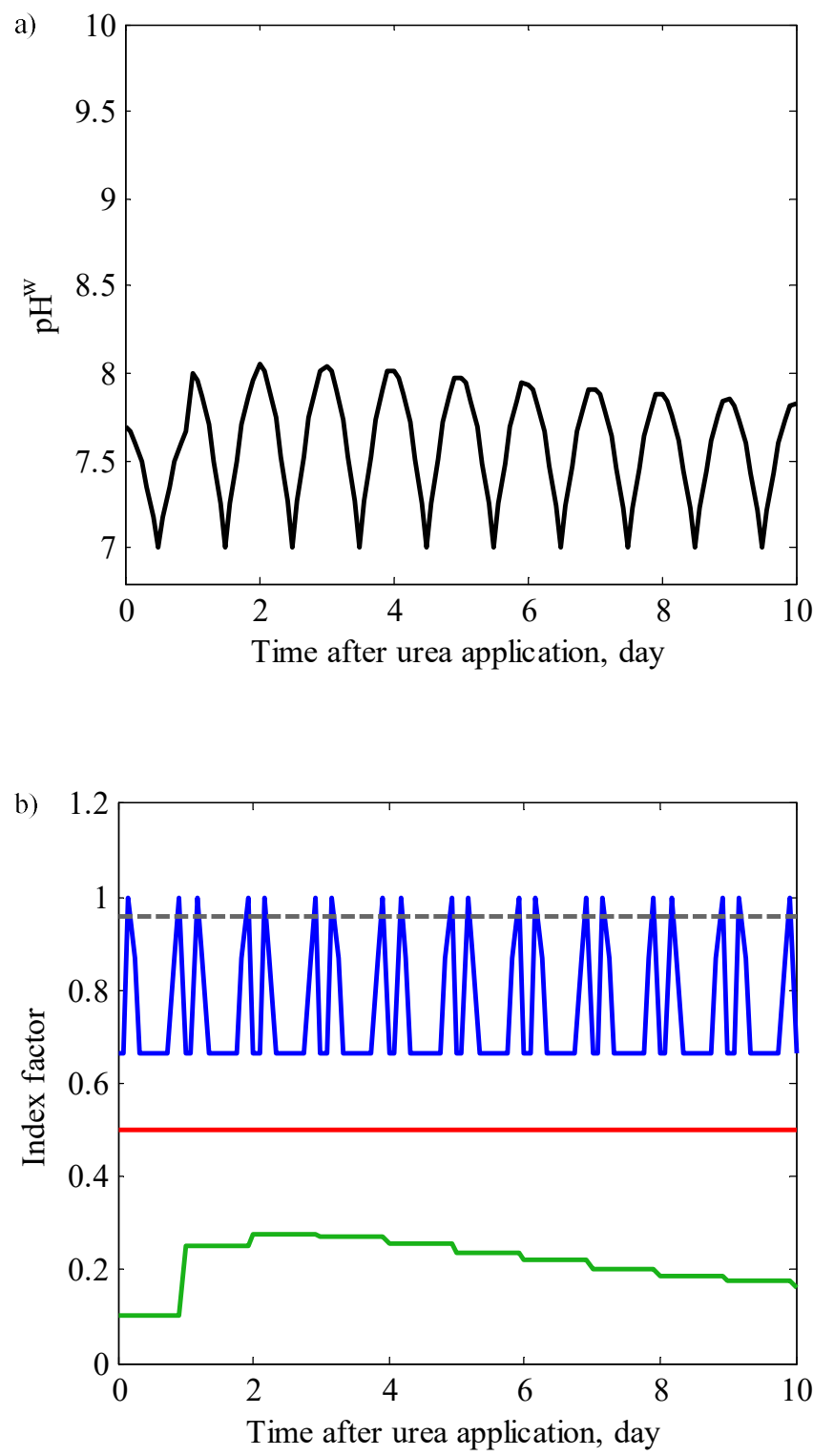

Fig. 5 a) Floodwater pH simulated using APSIM-Oryza and b) the factors that regulate the PAB activity for Scenario 3.5: Floodwater temperature index ( $f t i$, blue solid line), available light index (ali, grey dash line), floodwater $\mathrm{N}$ index ( $f n i$, green solid line), and floodwater $\mathrm{P}$ index ( $f p i$, red solid line). Scenario 3.5 considers a fertilised and flooded soil system that was broadcast with $40 \mathrm{~kg}$ urea-N ha ${ }^{-1}$, and with $\mathrm{N}$ sinks. $L A I=0.0$, and $f p i=0.5$

The daily peaks of the floodwater $\mathrm{pH}$ gradually decreased two days after urea application, as a 
result of continual decrease of total ammoniacal-N content in the floodwater. This result contradicts with Singh and Kirk (1993b), who predicted steady rise of daily peaks of floodwater $\mathrm{pH}$, four days after urea application as the rates of $\mathrm{NH}_{3}$ volatilisation decreased.

In a fertilised flooded system with young rice crop $(L A I=1.0$, Scenario 3.6, Table 1$)$, the simulated floodwater $\mathrm{pH}$ using the APSIM-Oryza's routine followed an absolute sine curve (Fig. 6b). The diurnal fluctuations in floodwater $\mathrm{pH}$ of this system were relatively similar to those of the fertilised flooded soil system without $\mathrm{N}$ sink (Fig. 4a). The major difference was the slightly lower magnitude of the overall floodwater $\mathrm{pH}$ from first through fourth day after urea application due to shading effects by the leaves $(L A I=3.0$, Scenario 3.7 , Table 1$)$, which affected the PAB activity (algact) through the available light index (ali) (Fig. 6). Four days after urea application, the floodwater $\mathrm{N}$ content became the most limiting factor to the PAB activity in the fertilised flooded systems with young and more developed rice crop (Fig. $6)$.

The effects of rice crop growth stages, which were reflected by the leaf area index, on the diurnal fluctuations in floodwater $\mathrm{pH}$, were not conceptualised in the Singh and Kirk (1993a) model. Nevertheless, these effects can be included by defining different rates of PAB activity (the rate of $\mathrm{CO}_{2}$ consumption at mid-day) for different rice growth stages.

Data showed that urea hydrolysis is typically completed within six days after urea application (see Fillery et al., 1984). Therefore, the effect of urea hydrolysis on floodwater $\mathrm{pH}$ was activated only within six days. Data also showed that the concentration of total ammoniacal-N was highest within the first three or four days after urea application (Fillery et al., 1984). These observations indicate that accurate prediction of floodwater $\mathrm{pH}$, for estimation of $\mathrm{NH}_{3}$ volatilisation is specifically crucial within the first four days after urea application.

Validation of the floodwater $\mathrm{pH}$ dynamics is a challenge because it is difficult to determine whether the difference in the $\mathrm{pH}$ levels was due to error in the model structure, or noises in the measurements (e.g., floodwater inhomogeneity, instruments accuracy). This raises the question whether the measurements are representative, or what would be the appropriate tolerance? Field measurements (Fillery et al., 1984) showed that for the same treatment, the variation in the daily peaks was only about $0.6 \mathrm{pH}$. To define a model-output-error tolerance smaller than $\mathrm{pH} 0.6$ implies that a high accuracy model is required to satisfy this tolerance. We conclude a good match, in absolute terms, between model output and observational data is 
Chapter 3

impossible to achieve. Instead, our focus should be on trends.
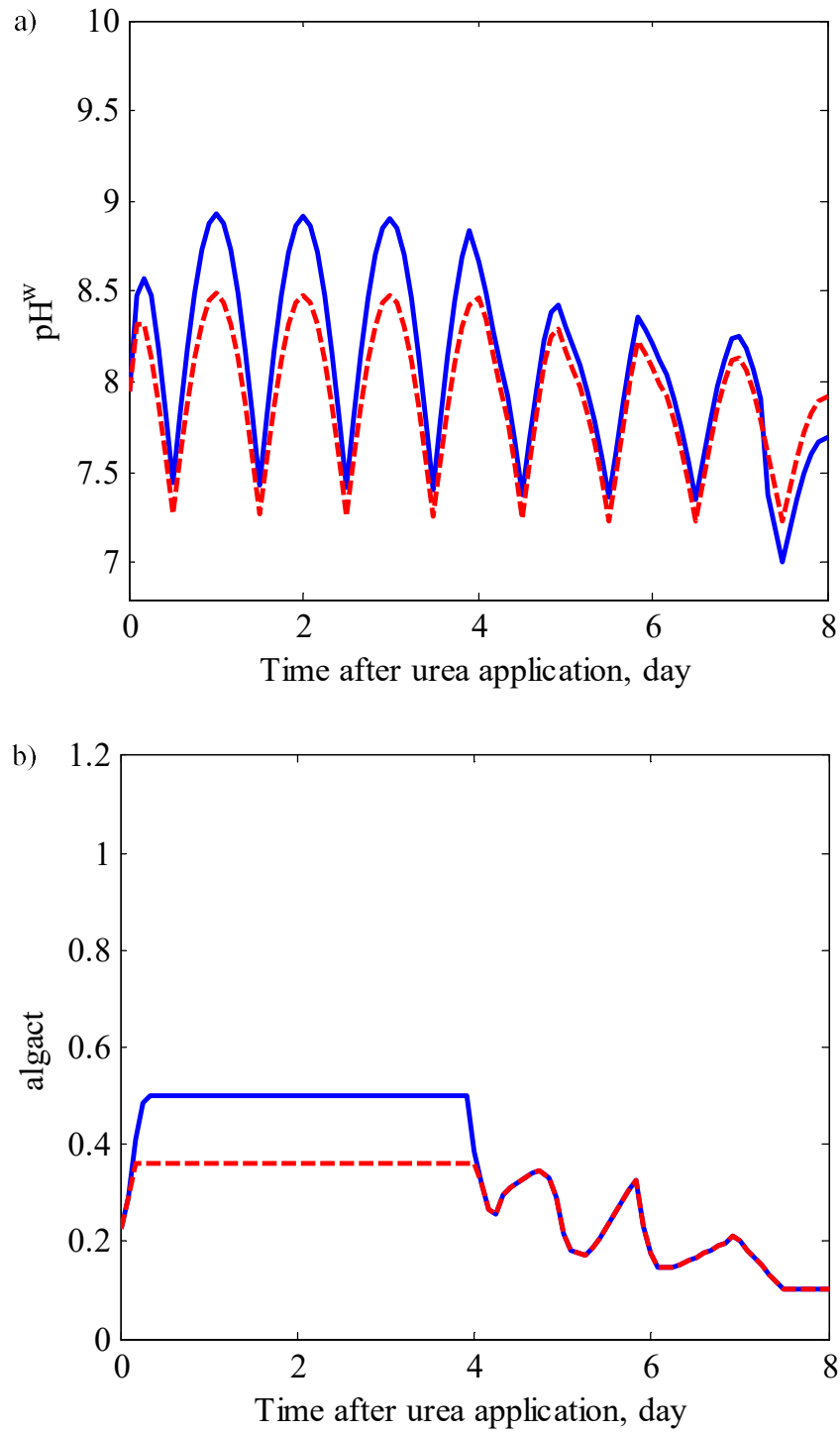

Fig. 6 a) Floodwater pH simulated using APSIM-Oryza for a fertilised and flooded system that was broadcast with $60 \mathrm{~kg}$ urea- $\mathrm{N} \mathrm{ha}^{-1}$, and $f p i=0.5$, and b) the $\mathrm{PAB}$ activity factor, algact. Scenario 3.6 considers young rice crop $(L A I=2.0$, blue solid line), and Scenario 3.7 considers well developed rice crop $(L A I=3.0$, red dash line)

Indeed, the floodwater $\mathrm{pH}$ dynamics are a result of number of protons added or consumed due to various processes. Physical modelling of these processes would result in an intricate model, i.e., the Singh and Kirk (1993a) model. The strength of the Singh and Kirk (1993b) model is that the model was based on balances of carbonate and ammoniacal species, making it more robust for a wider range of scenarios, i.e., fertilised or unfertilised flooded soil system. The Singh and Kirk (1993a) model has many rate coefficients that must be pre-determined, but this model is valuable for hypothesis testing in analysing $\mathrm{NH}_{3}$ loss reduction strategies (see 
Singh and Kirk, (1993b) for details). Meanwhile, the APSIM-Oryza offers straightforward routines to estimate diurnal floodwater $\mathrm{pH}$, which is then used for estimation of the diurnal fluctuation in $\mathrm{NH}_{3}$ volatilisation. Moreover, the floodwater $\mathrm{pH}$ routine in APSIM-Oryza can easily be integrated with other models.

\subsection{Conclusions}

A numerical-experimental approach was used to compare different modelling concepts of urea hydrolysis, $\mathrm{NH}_{3}$ volatilisation, and floodwater $\mathrm{pH}$. We found that the main difference between the modelling concepts of first-order kinetics of urea hydrolysis with a constant rate coefficient and that of APSIM-Oryza lies in the conceptualisation of soil organic $\mathrm{C} \%$ and leaf area index in APSIM-Oryza. The rates of urea hydrolysis produced by APSIM-Oryza can be approximated by adjusting the fixed urea hydrolysis rate coefficient of the first-order model to suit the local conditions, with respect to organic $\mathrm{C} \%$ or leaf area index. Despite substantial differences in modelling concepts of $\mathrm{NH}_{3}$ volatilisation between the Jayaweera and Mikkelsen (1993a) and NFLOOD v.1 models, the rates of $\mathrm{NH}_{3}$ volatilisation simulated using the Jayaweera and Mikkelsen (1993a) model can be approximated by adjusting the fixed rate coefficient of $\mathrm{NH}_{3}$ volatilisation in NFLOOD v.1. We found that the wind speed in the Jayaweera and Mikkelsen (1993a) model was proportional to the fixed rate coefficient in NFLOOD v.1. Differences in modelling concepts of floodwater $\mathrm{pH}$ in APSIM-Oryza and the Singh and Kirk (1993a) model, led to outputs that were significantly differed. New observational data may be used to investigate which model is more reliable under what conditions.

\section{References}

Antonopoulos, V. Z. 2010. Modelling of water and nitrogen balances in the ponded water and soil profile of rice fields in Northern Greece. Agric Water Manag, 98, pp. 321-330

Apsim-Oryza 2015. Pond routine. Australia: CSIRO.

Bellocchi, G., Rivington, M., Donatelli, M. \& Matthews, K. 2010. Validation of biophysical models: Issues and methodologies. A review. Agron Sustain Dev, 30, pp. 109-130.

Bennett, N. D., Croke, B. F. W., Guariso, G., Guillaume, J. H. A., Hamilton, S. H., Jakeman, A. J., Marsili-Libelli, S., Newham, L. T. H., Norton, J. P., Perrin, C., Pierce, S. A., Robson, B., Seppelt, R., Voinov, A. A., Fath, B. D. \& Andreassian, V. 2013. Characterising performance of environmental models. Environ Model Softw, 40, pp. 120.

Bouwmeester, R. J. B. \& Vlek, P. L. G. 1981. Rate control of ammonia volatilization from rice paddies. Atmos Environ, 15, pp. 131-140. 
Chowdary, V. M., Rao, N. H. \& Sarma, P. B. S. 2004. A coupled soil water and nitrogen balance model for flooded rice fields in India. Agric Ecosyst Environ, 103, pp. 425441.

De Datta, S. K., Samson, M. I., Obcemea, W. N., Real, J. G. \& Buresh, R. J. 1991. Direct measurement of ammonia and denitrification fluxes from urea applied to rice. Soil Sci Soc Am J, 55, pp. 543-548.

Denmead, O. T., Freney, J. R. \& Simpson, J. R. 1982. Dynamics of ammonia volatilization during furrow irrigation of maize. Soil Sci Soc Am J, 46, pp. 149-155.

Fillery, I. R. P., Roger, P. A. \& De Datta, S. K. 1986. Ammonia volatilization from nitrogen sources applied to rice fields: II. Floodwater properties and submerged photosynthetic biomass. Soil Sci Soc Am J, 50, pp. 86-91.

Fillery, I. R. P., Simpson, J. R. \& De Datta, S. K. 1984. Influence of field environment and fertilizer management on ammonia loss from flooded rice. Soil Sci Soc Am J, 48, pp. 914-920.

Freney, J. R., Denmead, O. T., Watanabe, I. \& Craswell, E. T. 1981. Ammonia and nitrous oxide losses following applications of ammonium sulfate to flooded rice. Aust J Agric Res, 32, pp. 37-45.

Gaydon, D. S., Probert, M. E., Buresh, R. J., Meinke, H., Suriadi, A., Dobermann, A., Bouman, B. \& Timsina, J. 2012a. Rice in cropping systems - Modelling transition between flooded and non-flooded soil environments. Eur J Agron, 39, pp. 9-24.

Gaydon, D. S., Probert, M. E., Buresh, R. J., Meinke, H. \& Timsina, J. 2012b. Modelling the role of algae in rice crop nutrition and soil organic carbon maintenance. Eur J Agron, 39, pp. 35-43.

Godwin, D. C. \& Singh, U. 1998. Nitrogen balance and crop response to nitrogen in upland and lowland cropping systems. In: Tsuji, G. Y., Hoogenboom, G. \& Thornton, P. K. (eds.) Understanding Options for Agricultural Production. Springer Netherlands, pp. $55-77$.

Jayaweera, G. R. \& Mikkelsen, D. S. 1990a. Ammonia volatilization from flooded soil systems: A computer model. I. Theoretical aspects. Soil Sci Soc Am J, 54, pp. 14471455.

Jayaweera, G. R. \& Mikkelsen, D. S. 1990b. Ammonia volatilization from flooded soil systems: A computer model. II. Theory and model results. Soil Sci Soc Am J, 54, pp. 1456-1462.

Jing, Q., Van Keulen, H. \& Hengsdijk, H. 2010. Modeling biomass, nitrogen and water dynamics in rice-wheat rotations. Agric Syst, 103, pp. 433-443

Katayanagi, N., Ono, K., Fumoto, T., Mano, M., Miyata, A. \& Hayashi, K. 2013. Validation of the DNDC-Rice model to discover problems in evaluating the nitrogen balance at a paddy-field scale for single-cropping of rice. Nutr Cycl Agroecosyst, 95, pp. 255-268.

Keesman, K. J. 2011. System Identification: An Introduction. Springer UK.

Kirk, G. J. D. \& Solivas, J. L. 1997. On the extent to which root properties and transport through the soil limit nitrogen uptake by lowland rice. Eur J Soil Sci, 48, pp. 613-621.

Mcgechan, M. B. \& Wu, L. 2001. A review of carbon and nitrogen processes in nine U.S. soil nitrogen dynamics models. In: Shaffer, M. J., Ma, L. \& Hansen, S. (eds.) Modelling carbon and nitrogen dynamics for soil management CRC Press.

Rao, P. S. C., Jessup, R. E. \& Reddy, K. R. 1984. Simulation of nitrogen dynamics in flooded soils. Soil Sci, 138, pp. 54-62.

Reddy, K. R. 1982. Nitrogen cycling in a flooded-soil ecosystem planted to rice (Oryza sativa L.). Plant Soil, 67, pp. 209-220.

Reddy, K. R., Rao, P. S. C. \& Jessup, R. E. 1990. Transformation and transport of ammonium nitrogen in a flooded organic soil. Ecol Model, 51, pp. 205-216. 
Singh, R. \& Kirk, G. J. D. 1993a. A model for predicting the fate of nitrogen fertilizer in lowland ricefields. I. Theory. J Soil Sci, 44, pp. 271-283.

Singh, R. \& Kirk, G. J. D. 1993b. A model for predicting the fate of nitrogen fertilizer in lowland ricefields. II. Predicted dynamics of inorganic carbon, nitrogen and acidity in the soil and floodwater. J Soil Sci, 44, pp. 285-297.

Vlek, P. L. G. \& Craswell, E. T. 1981. Ammonia volatilization from flooded soils. Fert Res, 2, pp. 227-245. 


\section{Appendix A. Synthetic data sets used for simulation of models}

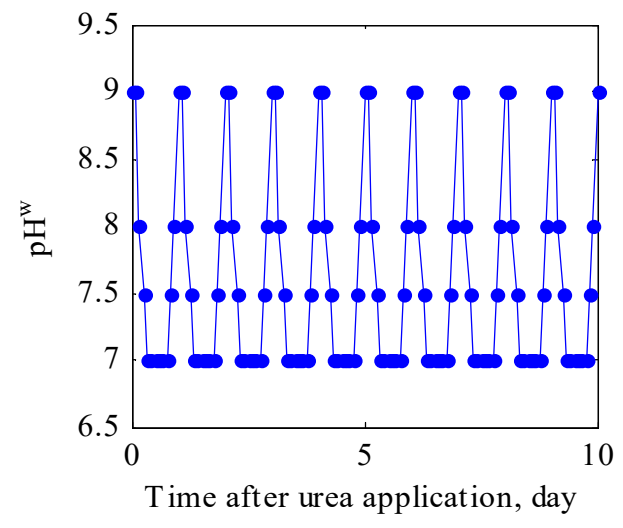

Fig. A.1 The synthetic two-hourly floodwater $\mathrm{pH}$

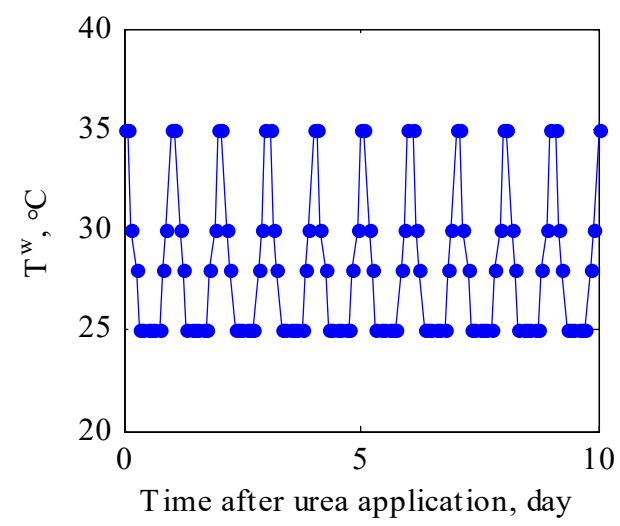

Fig. A.2 The synthetic two-hourly floodwater temperature

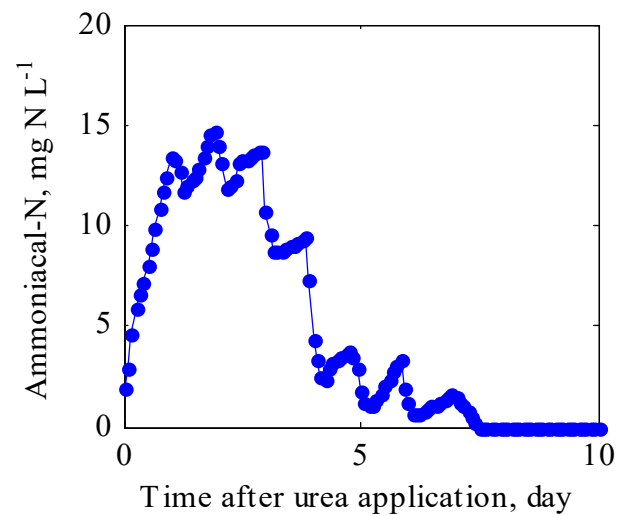

Fig. A.3 Concentrations of ammoniacal-N in floodwater of a fertilised and flooded rice system from 14 to 27 days after transplanting, at Los Baños, Philippines, digitised from Fillery et al. (1984). The system was broadcasted with $60 \mathrm{~kg}$ urea-N ha ${ }^{-1}$ 


\section{Appendix B. Selected equations from the Jayaweera and Mikkelsen (1990a) model}

\section{Time-varying rate coefficient of $\mathrm{NH}_{3}$ volatilisation}

The time-varying rate coefficient of $\mathrm{NH}_{3}$ volatilisation in hour ${ }^{-1}, \widetilde{K}_{v}=\frac{k_{O N}}{X^{w}}$

where,

$X^{w}$ is floodwater depth in $\mathrm{cm}$, and $k_{O N}=\frac{H_{n N} k_{g N} k_{l N}}{H_{n N} k_{g N}+k_{l N}}$, is in $\mathrm{cm} \mathrm{hour}^{-1}$.

Dimensionless Henry's law constant, $H_{n N}=\frac{H_{N}}{R T^{w}}$, with gas constant $R=8.315 \times 10^{-6} \mathrm{MPa}$ $\mathrm{m}^{3} \mathrm{~mol}^{-1} \mathrm{~K}^{-1}, T^{w}$ is floodwater temperature in $K$, and $H_{N}=\frac{P_{N}}{\left[\mathrm{NH}_{3}\right]_{\text {molar }}}$, with partial pressure of $\mathrm{NH}_{3}$ in the gas phase in equilibrium with the solution in $\mathrm{MPa}, P_{N}=18.62 \exp \left(-\frac{1229}{T^{w}}\right) X_{N}$, and $\left[\mathrm{NH}_{3}\right]_{\text {molar }}$ is molar concentration of $\mathrm{NH}_{3}$ in solution in $\mathrm{mol} \mathrm{N} \mathrm{m}$.

Dimensionless mole fraction of $\mathrm{NH}_{3}$ in floodwater solution, $X_{N}=\frac{\alpha\left[N^{w}\right] / 17.03}{\alpha\left[N^{w}\right] / 17.03+(1-\alpha)\left[N^{w}\right] / 18.04+10^{6} \rho_{w} / 18.02} \quad, \quad$ where $\quad\left[N^{w}\right] \quad$ is total ammoniacal-N concentration in $\mathrm{mg} \mathrm{N} \mathrm{L}^{-1}, \rho_{w}$ is density of water in $\mathrm{g} \mathrm{cm}^{-3}$ for a respective floodwater temperature, and dimensionless fraction of $\mathrm{NH}_{3}, \alpha=\frac{10^{p H^{w}-p K}}{1+10^{p H^{w}-p K}}$, with dimensionless temperature factor, $p K=0.0897+\frac{2729}{T^{w}}$, where $T^{w}$ is floodwater temperature in $\mathrm{K}$.

Gas phase exchange constant for $\mathrm{NH}_{3}$ in $\mathrm{cm} \mathrm{hour}^{-1}, k_{g N}=19.0895+742.3016 . U_{8}$, and liquid phase exchange constant for $\mathrm{NH}_{3}$ in $\mathrm{cm} \mathrm{hour}^{-1}, k_{l N}=\left(\frac{12.5853}{1+43.0565^{-0.4417 . U_{8}}}\right) 1.6075$, with $U_{8}$ is wind speed in $\mathrm{m} \mathrm{s}^{-1}$. See Jayaweera and Mikkelsen (1990a) for the complete model and its derivation.

\section{Association and dissociation constants}

The association constant in $\mathrm{s}^{-1}, k_{a}=3.8 \times 10^{11}-3.4 \times 10^{9} T^{w}+7509700 T^{w^{2}}$

The dissociation constant in mol N s${ }^{-1}, k_{d}=K \times k_{a}$, where $K=10^{-p}$ 
Chapter 3

\section{Appendix C. Selected equations from APSIM-Oryza (Gaydon et al., 2012b)}

\section{PAB activity}

algact $=\min ($ ali, fti, fni, fpi $)$

where,

available light index, ali $=1-\exp \left(-\frac{\text { frad }}{5.0}\right)$, with frad $=$ rad $\times\left(1-\right.$ water $\left._{\text {albedo }}\right) \times$ $\exp (-0.65 \times L A I)$, where rad is mean solar radiation in $\mathrm{MJ} \mathrm{m}^{-2}$ day $^{-1}$, and water $_{\text {albedo }}=$ 0.05 ,

floodwater temperature index, $f t i=\left\{\begin{array}{cl}0.0667 T^{w}-1.0 & \text { for } 15^{\circ} \mathrm{C} \leq T^{w} \leq 30^{\circ} \mathrm{C} \\ -0.0667 T^{w}+3.0 & \text { for } 30^{\circ} \mathrm{C}<T^{w} \leq 45^{\circ} \mathrm{C}\end{array}\right.$, with $T^{w}$ is floodwater temperature in ${ }^{\circ} \mathrm{C}$,

floodwater nitrogen index, $f n i=\frac{\left[N^{w}\right]}{15.0}+0.1$, with $\left[N^{w}\right]$ is concentration of total ammoniacal-N in the floodwater in $\mathrm{mg} \mathrm{N} \mathrm{L}^{-1}$ or $\mathrm{ppm}$,

and floodwater phosphorus index, $f p i= \begin{cases}0.5 & \text { when phosphorus is absent } \\ 1.0 & \text { when phosphorus is applied }\end{cases}$ $a l i, f t i, f n i$ and $f p i$ range from zero through unity

\section{Effect of urea hydrolysis on floodwater pH}

$p H^{w} \_$uhyd $=\min \left(10-\log _{10}(F U H Y D R M)\right)$

where, $F U H Y D R M=F U H Y D R C \times \frac{0.001}{14}$,

and $F U H Y D R C=\frac{F U H D Y R \times 100}{X^{w}}$

where, $p H^{w} \_$uhyd is the effect of urea hydrolysis on floodwater $\mathrm{pH}$ (Eq. 19), FUHYDRM is molar concentration of hydrolysed urea mol $\mathrm{N} \mathrm{L}^{-1}, F U H Y D R C$ is concentration of hydrolysed urea in $\mathrm{mg} \mathrm{N} \mathrm{L}^{-1}, F U H Y D R$ is rate if hydrolysed urea in $\mathrm{kg} \mathrm{N} \mathrm{ha}^{-1}$ (Eq. 2 and 3), and $X^{w}$ is floodwater depth in mm (APSIM-Oryza, 2015) 
CHAPTER 4

Process-based dynamic model

for predicting ammonia volatilisation

in fertilised and flooded rice systems

K. Nurulhuda ${ }^{1,2}$, M.P. Zakaria ${ }^{3}$, P.C. Struik ${ }^{4}$, and K.J. Keesman ${ }^{2}$

${ }^{1}$ Biological and Agricultural Engineering, Universiti Putra Malaysia, Malaysia

${ }^{2}$ Biobased Chemistry and Technology, Wageningen University, the Netherlands

${ }^{3}$ Institute of Ocean and Earth Sciences, University of Malaya, Malaysia

${ }^{4}$ Centre for Crop Systems Analysis, Wageningen University, the Netherlands 


\begin{abstract}
The objective of the chapter is to present and evaluate a process-based model for estimating ammonia $\left(\mathrm{NH}_{3}\right)$ volatilisation in fertilised and flooded rice systems, which is of a complexity appropriate for scarce soil nitrogen $(\mathrm{N})$ data. Based on model and data integration, urea hydrolysis in the floodwater was approximated by two first-order kinetics, and the uptake of $\mathrm{N}$ by rice crop was lumped with other $\mathrm{N}$ sinks and approximated by a sigmoid curve in the proposed model. The lumped $\mathrm{N}$ sink term avoids assumptions on soil parameters beyond what can be identified from the limited soil $\mathrm{N}$ data. The model was falsified by some data sets, but was also in good agreement with other data sets. Inadequate model structure may have led to the falsification of the model, but uncertainty in observations and in parameters could also have led to the falsification. For the flooded rice systems in the Philippines, conceptualisation of the partitioning between ammonium and $\mathrm{NH}_{3}$ and a time-varying rate coefficient of $\mathrm{NH}_{3}$ volatilisation in the proposed model improved the prediction of the net $\mathrm{NH}_{3}$ volatilisation.
\end{abstract}

Keywords: Nitrogen model, ammonia volatilization, flooded soil, rice field 


\subsection{Introduction}

About $95 \%$ of global rice production occurs on rice systems with soil flooded during at least part of the rice cropping period (Buresh et al., 2008). In flooded rice systems that are broadcast with urea, and without subsequent incorporation into the soil, ammonia $\left(\mathrm{NH}_{3}\right)$ volatilisation can be as high as $56 \%$ of total synthetic nitrogen $(\mathrm{N})$ applied (Freney et al., 1981, De Datta et al., 1991, Freney and Denmead, 1992, Cai, 1997, Buresh et al., 2008). In the year 1995, about $20 \%$ of the 11.8 million tons of synthetic $\mathrm{N}$ yearly applied in flooded rice fields globally was estimated to be lost via $\mathrm{NH}_{3}$ volatilisation (Bouwman et al., 2002).

Initiatives to minimise $\mathrm{NH}_{3}$ volatilisation in flooded rice systems are not straightforward. For instance, deep placement of urea super granules in the flooded soil was shown to substantially reduce $\mathrm{NH}_{3}$ volatilisation in fertilised and flooded rice systems (Craswell et al., 1981, Cao et al., 1984, De Datta et al., 1988, Liu et al., 2015), but the method may increase the risk of N leaching in flooded soils with high permeability (light-textured soils) (Vlek et al., 1980). Furthermore, deep placement of urea is also laborious. As long as feasible $\mathrm{N}$ fertilisation strategies are not demonstrated to farmers, and challenges in technology transfer are not critically addressed (Fujisaka, 1994, Corales et al., 2015), $\mathrm{NH}_{3}$ volatilisation may remain significant in fertilised and flooded rice systems.

Currently, there are many mathematical models that can estimate $\mathrm{NH}_{3}$ volatilisation in fertilised and flooded soil systems, with or without a rice crop, ranging from relatively simple process-based models, such as suggested by Bouwmeester and Vlek (1981), Chowdary et al. (2004), Liang et al. (2007), and Antonopolulos (2010), to complex process-based models, like the model by Singh and Kirk (1993), or a mix of both process-based and empirical regression equations, for instance, models by Jayaweera and Mikkelsen (1990), (CERES-Rice) by Godwin and Singh (1998), and (APSIM-Oryza) by Gaydon et al. (2012). These models are either used for estimation to replace intricate experimental set-ups, to obtain scientific insights, or to aid decision making in management of rice systems. Reliable estimation of $\mathrm{NH}_{3}$ volatilisation is important as this process can be a major pathway of $\mathrm{N}$ losses (Buresh et al., 2008 ) and partially determines the amount of total ammoniacal-N available for uptake by the rice crop.

$\mathrm{NH}_{3}$ volatilisation in fertilised and flooded rice systems is dependent on key regulators such as the amount of total ammoniacal- $\mathrm{N}$ in the floodwater, wind speed, and floodwater $\mathrm{pH}$, 
temperature, and depth (Fillery et al., 1984, Fillery et al., 1986, Jayaweera and Mikkelsen, 1991). However, these process variables are not always conceptualised in the existing models. Assumptions underlying the modelling concepts depend on the objective of the model, and availability of observational data sets for calibration and validation of the models.

The lumped-parameter model by Chowdary et al. (2004) is one of the simplest process-based models for predicting $\mathrm{NH}_{3}$ volatilisation in fertilised and flooded rice systems. Over the years, more lumped-parameter models were developed and evaluated with seasonal data sets, see, for instance, the work by Liang et al. (2007), Antonopoulos (2010), and Liang et al. (2014). In lumped-parameter models, many of the $\mathrm{N}$ processes including $\mathrm{NH}_{3}$ volatilisation are described by first-order kinetics, and each process is regulated by a constant rate coefficient. Such a modelling concept, process-based and yet kept simple, is appealing for ill-defined flooded rice systems with complex interactive N processes. According to Young (1978), a system is ill- or badly-defined when the size and complexity of the system prevent a full understanding a priori and when planned experimentation is difficult, if not impossible, and where observational data sets for calibration and cross-validation of models are often small.

Nevertheless, unlike the more detailed models, for instance the one by Jayaweera and Mikkelsen (1990), the one by Singh and Kirk (1993), CERES-Rice by Godwin and Singh (1998), and APSIM-Oryza by Gaydon et al. (2012), the models by Chowdary et al. (2004), Antonopoulos (2010) and Liang et al. (2014) did not conceptualise the key regulators of $\mathrm{NH}_{3}$ volatilisation, which drive the partitioning between ammonium and $\mathrm{NH}_{3}$. Furthermore, evaluation of the performance of lumped-parameter models are currently limited to total $\mathrm{NH}_{3}$ volatilisation measured at the end of a cropping season (Chowdary et al., 2004, Liang et al., 2007, Antonopoulos, 2010, Liang et al., 2014). Therefore, it is not known whether these simpler models are also suitable for estimating $\mathrm{NH}_{3}$ volatilisation after each urea (split) application, as the key regulating factors of $\mathrm{NH}_{3}$ volatilisation were not conceptualised. It is also not known whether the estimation of $\mathrm{NH}_{3}$ volatilisation using these models can be improved by conceptualising some of the key regulators.

In order to simulate $\mathrm{NH}_{3}$ volatilisation in fertilised and flooded soil systems with a rice crop, other dominant $\mathrm{N}$ losses should be conceptualised in a model, for instance $\mathrm{N}$ uptake by the rice crop. This point of view sometimes led to detailed modelling of soil $\mathrm{N}$ dynamics (Rao et al., 1984, Singh and Kirk, 1993, Gaydon et al., 2012), including nitrification, denitrification, 
mineralisation, and immobilisation processes (Rao et al., 1984, Chowdary et al., 2004, Liang et al., 2007, Antonopoulos, 2010). Detailed modelling of soil $\mathrm{N}$ dynamics may easily result in an over-parameterised model, as observational data sets for the calibration of the unknown rate coefficients (parameters) are inadequate.

Model development is an iterative process (Jakeman et al., 2006, Bellocchi et al., 2010, Bennett et al., 2013). Improvement of a model that aims at a right balance between a priori knowledge and data information content includes re-structuring the model in order to reduce the number of parameters (calibrated rate coefficients), or addition, omission or simplification of processes or process variables (Keesman, 2011).

In this chapter, by selecting and re-structuring modelling concepts from several existing $\mathrm{N}$ dynamics models, our objectives are to present and evaluate an alternative process-based model that can capture trends of $\mathrm{NH}_{3}$ volatilisation in fertilised and flooded rice systems, and is of a complexity that matches the scarcity of soil $\mathrm{N}$ data. The performance of the proposed model is assessed using temporal cumulative $\mathrm{NH}_{3}$ volatilisation data and co-validated against the model by Chowdary et al. (2004).

\subsection{Materials and methods}

\subsubsection{Modelling concepts}

Our starting point is the $\mathrm{N}$ dynamics modelling concept of Chowdary et al. (2004), in which urea hydrolysis and $\mathrm{NH}_{3}$ volatilisation are described by first-order kinetics, each with a constant rate coefficient. The modelling concept of our proposed model is shown in Fig. 1.

\subsubsection{Water balance of a flooded rice field}

The water balance of a flooded rice field, allowing a time-varying floodwater depth, is given by:

$\frac{d X^{w}}{d t}=R+I-E T-\tilde{Q}$

where, $X^{w}$ is floodwater depth $(\mathrm{m}), R$ is rainfall $\left(\mathrm{m} \mathrm{day}^{-1}\right), I$ is irrigation $\left(\mathrm{m}\right.$ day $\left.^{-1}\right), E T$ is evapotranspiration $\left(\mathrm{m} \mathrm{day}^{-1}\right)$, and $\tilde{Q}$ is floodwater loss $\left(\mathrm{m}\right.$ day $\left.^{-1}\right)$ due to surface runoff and percolation $\left(\mathrm{m} \mathrm{day}^{-1}\right)$. 


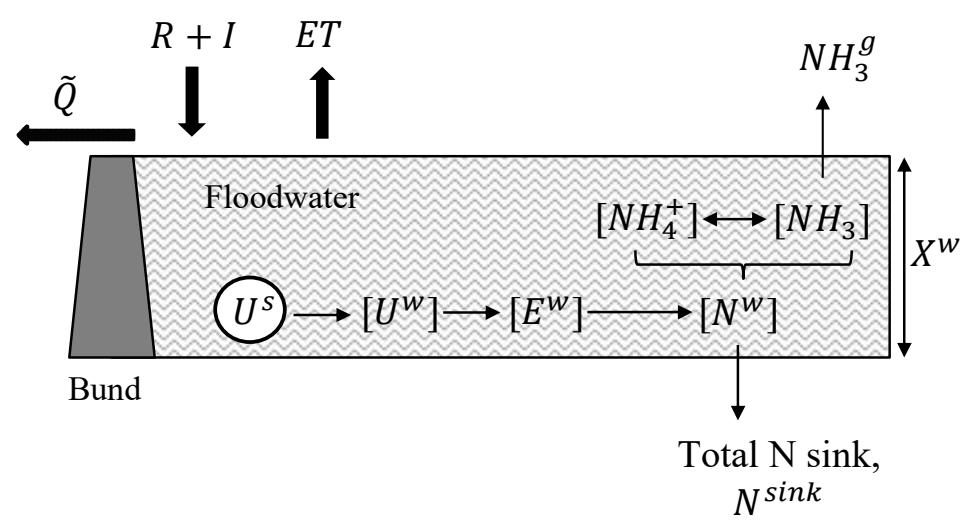

Fig. 1 Modelling concepts of the proposed model. $\tilde{Q}$ is floodwater loss due to surface runoff and percolation, $R$ is rainfall, $I$ is irrigation, $E T$ is evapotranspiration, $X^{w}$ is floodwater depth, $U^{S}$ is rate of urea-N applied, $\left[U^{w}\right]$ is concentration of dissolved urea, $\left[E^{w}\right]$ is slow urease activity, $\left[\mathrm{N}^{w}\right]$ is concentration of total ammoniacal-N, $\left[\mathrm{NH}_{4}^{+}\right]$is concentration of ammonium, $\left[\mathrm{NH}_{3}\right]$ is concentration of ammonia, $\mathrm{NH}_{3}^{g}$ is cumulative ammonia volatilisation, and $N^{\text {sink }}$ is total $\mathrm{N}$ sink

\subsubsection{Urea hydrolysis}

Urea is widely used in flooded rice system (Soares et al., 2012), and resulted in higher $\mathrm{NH}_{3}$ volatilisation compared to other forms of $\mathrm{N}$ sources (Fillery et al., 1986). Estimation of the urea hydrolysis rate is vital as the process pre-determines how much total ammoniacal-N is available in the floodwater, and how much is susceptible to $\mathrm{NH}_{3}$ volatilisation. In our model, hydrolysis of urea is conceptualised in the floodwater, assuming urea is broadcast on the floodwater without subsequent incorporation into the soil. Initially, urea hydrolysis is described as a one-step process.

\section{One-step urea hydrolysis}

The mass balance of urea-N with the one-step urea hydrolysis described in terms of first-order kinetics is given by

$\frac{d\left[U^{w}\right]}{d t}=\frac{1}{X^{w}}\left(+U^{s}-K_{h}\left[U^{w}\right] X^{w}+\left[U^{w}\right]\{-R-I+E T\}\right)$

where, $U^{S}$ is rate of urea-N applied $\left(\mathrm{kg} \mathrm{m}^{-2}\right.$ day $\left.{ }^{-1}\right),\left[U^{w}\right]$ is concentration of urea-N in floodwater $\left(\mathrm{kg} \mathrm{m}^{-3}\right)$, and $K_{h}$ is urea hydrolysis rate coefficient $\left(\right.$ day $\left.^{-1}\right)$. The one-step first-order kinetics is conceptualised in most $\mathrm{N}$ dynamics models (Kirk and Solivas, 1997, Chowdary et 
al., 2004, Jing et al., 2010). Note that solute concentration, i.e., $\left[U^{w}\right]$, multiplied with $\{-R-I+E T\}$ represents the dilution effect as a result of changes in floodwater depth (see Appendix A for derivation of Eq. 2).

In this chapter, it will be shown that calibration of the model with observational data suggests that urea hydrolysis may be described as a two-step process in flooded rice systems with low urease activity.

\section{Two-step urea hydrolysis}

Thus, as an alternative to the one-step urea hydrolysis, the two-step urea hydrolysis was conceptualised, as rapid disappearance of urea in the floodwater is not followed by rapid appearance of ammoniacal-N in the floodwater, presumably due to low urease activity in the floodwater. The first step is given by Eq. 2. This first step is followed by second step which is given by

$\frac{d\left[E^{w}\right]}{d t}=\frac{1}{X^{w}}\left(+K_{h}\left[U^{w}\right] X^{w}-K_{E}\left[E^{w}\right] X^{w}-\left[E^{w}\right]\{-R-I+E T\}\right)$

where, $\left[E^{w}\right]$ is an interim state that emulates low urease activity in floodwater $\left(\mathrm{kg} \mathrm{m}^{-3}\right)$, which slows down the overall urea hydrolysis rate, and $K_{E}$ is the second step urea hydrolysis rate coefficient $\left(\right.$ day $\left.^{-1}\right)$.

\subsubsection{Ammonia volatilisation}

Chowdary et al. (2004), Antonopoulos (2010) and Liang et al. (2014) conceptualised $\mathrm{NH}_{3}$ volatilisation by a first-order process, but the partitioning between $\mathrm{NH}_{4}{ }^{+}$and $\mathrm{NH}_{3}$ in the floodwater was not conceptualised. Theoretically, partitioning between $\mathrm{NH}_{4}{ }^{+}$and $\mathrm{NH}_{3}$ must be conceptualised as only $\mathrm{NH}_{3}$ is susceptible to volatilisation, and to capture the diurnal trend of $\mathrm{NH}_{3}$ volatilisation, as observed by Craswell et al. (1981), Fillery et al. (1984), and Fillery et al. (1986) in fertilised and flooded rice systems. Therefore, we adopted the concept of Jayaweera and Mikkelsen (1990) to approximate the partitioning between $\mathrm{NH}_{4}{ }^{+}$and $\mathrm{NH}_{3}$ in the floodwater. Thus, the cumulative $\mathrm{NH}_{3}$ volatilisation, $\mathrm{NH}_{3}^{g}\left(\mathrm{~kg} \mathrm{~N} \mathrm{ha}^{-1}\right)$, is calculated as follows

$$
\frac{d N H_{3}^{g}}{d t}=+K_{v} \alpha\left[N^{w}\right] V
$$


where, $\left[N^{w}\right]$ is concentration of total ammoniacal-N in the floodwater $\left(\mathrm{kg} \mathrm{N} \mathrm{m}^{-3}\right), K_{v}$ is rate coefficient of $\mathrm{NH}_{3}$ volatilisation $\left(\right.$ day $\left.^{-1}\right)$, and $V=10000 X^{w}$, is the volume of floodwater per hectare of land in $\mathrm{m}^{3}$. Furthermore,

$\alpha=\frac{10^{p H^{w}-p K}}{10^{p H^{w}-p K}+1}$

where, $\alpha$ is fraction of $\mathrm{NH}_{3}-\mathrm{N}$ from total ammoniacal-N (dimensionless), and $p K$ is floodwater temperature factor (dimensionless), given by:

$p K=0.0897+\left(\frac{2729}{273.14+T^{w}}\right)$

with $T^{w}$ is the floodwater temperature ( $\left.{ }^{(} \mathrm{C}\right)$. Eq. 6 relating $p K$ to $T^{w}$ was derived by regression analysis (Jayaweera and Mikkelsen, 1990).

\subsubsection{Total nitrogen sink}

To estimate $\mathrm{NH}_{3}$ volatilisation in fertilised and flooded rice systems, $\mathrm{N}$ uptake by the rice crop cannot be neglected. Conventionally, modellers assumed that the inorganic $\mathrm{N}$ in the floodwater must first enter the soil compartment, prior to $\mathrm{N}$ uptake by rice crop (Singh and Kirk, 1993, Chowdary et al., 2004, Godwin and Singh, 1998, Gaydon et al., 2012). Such an approach increases model complexity due to the need to approximate percolation and diffusion rates of inorganic N (Rao et al., 1984, Singh and Kirk, 1993, Gaydon et al., 2012), and motivates conceptualisation of other soil $\mathrm{N}$ processes, i.e., denitrification, organic $\mathrm{N}$ mineralisation, inorganic $\mathrm{N}$ immobilisation, and fixation and de-fixation of $\mathrm{NH}_{4}{ }^{+}$(Rao et al., 1984, Reddy et al., 1990, Chowdary et al., 2004, Antonopoulos, 2010).

Although such details are valuable for scientific understanding, and may increase the scope of applications of the model, the parameters related to the interactive soil $\mathrm{N}$ processes (simultaneous nitrification and denitrification, organic $\mathrm{N}$ mineralisation, inorganic $\mathrm{N}$ immobilisation, and fixation and defixation of $\mathrm{NH}_{4}{ }^{+}$) in the soil may be unidentifiable, given limited and non-informative soil N data sets. Studies of Makarim et al. (1991) and Dobermann et al. (1994) have demonstrated low concentrations of inorganic nitrogen (from 0 to $3 \mathrm{mg} \mathrm{N} \mathrm{L}^{-1}$ ) in fertilised and flooded rice systems. Given these low concentrations of soil inorganic $\mathrm{N}$ and the inhomogeneity of the soil compartment, soil available $\mathrm{N}$ data most likely 
lead to unidentifiable parameters, and therefore, may not warrant proper calibration or validation of the interactive soil $\mathrm{N}$ dynamics (Cassman et al., 2002).

Large recovery of broadcast $\mathrm{N}$ fertiliser, without incorporation into the soil, was observed by Cassman et al. (1998), where for $100 \mathrm{~kg} \mathrm{~N} \mathrm{ha}^{-1}$ applied on $42 \mathrm{DAT}$, about 8 to $10 \mathrm{~kg} \mathrm{~N}^{-1} \mathrm{day}^{-}$ ${ }^{1}$ was absorbed by the rice crop. By simulating the Singh and Kirk (1993) model, Kirk and Solivas (1997) showed that urea-N and ammoniacal-N do not penetrate too deep into the flooded soil; at most within $0.03 \mathrm{~m}$ from the flooded soil surface. Therefore, Kirk and Solivas (1997) hypothesised that most of the broadcast $\mathrm{N}$ must be absorbed by the dense root mat at the floodwater-soil interface.

The efficient $\mathrm{N}$ uptake observed by Cassman et al. (1998) and the hypothesis by Kirk and Solivas (1997), together with the scarce and low accuracy of soil $\mathrm{N}$ data suggested that the $\mathrm{N}$ uptake by rice crop, and other $\mathrm{N}$ losses (i.e., simultaneous nitrification and denitrification), can be lumped into one total $\mathrm{N}$ sink term. The fact that rice roots accumulate within the top 20 cm (Cassman et al., 2002) and these rice roots can be seen protruding at the floodwater-soil surface strengthens our conceptualisation.

Thus, the total $\mathrm{N}$ sink is conceptualised as an out flux directly from the floodwater. By assuming a dominant contribution of $\mathrm{N}$ uptake by rice crop on the total $\mathrm{N}$ sink term, the term is described by a sigmoid curve, in which the variable $S$ (dimensionless) describes the trend of total $\mathrm{N}$ sink over time and follows from

$\frac{d S}{d t}=\beta S(1-S)$

where, $\beta$ defines the rate of change in $S\left(\right.$ day $\left.^{-1}\right)$. The total $\mathrm{N}$ sink increases with rice crop growth stage as $\mathrm{N}$ uptake by the rice crop increases. Consequently, the cumulative $\mathrm{N}$ sink, $N^{\operatorname{sink}}\left(\mathrm{kg} \mathrm{N} \mathrm{ha}^{-1}\right)$, follows from

$\frac{d N^{\sin k}}{d t}=+K_{\sin k} S V\left[N^{w}\right]$

where, $K_{\text {sink }}$ is the rate coefficient of total $\mathrm{N} \operatorname{sink}\left(\right.$ day $\left.^{-1}\right)$, which drives the magnitude of total $\mathrm{N}$ sink, and $\left[N^{w}\right]$ and $V$ are defined in Eq. 4. However, still an expression for $\left[N^{w}\right]$ is missing. 


\subsubsection{Total ammoniacal-nitrogen in floodwater}

The concentration of total ammoniacal-N in floodwater $\left(\left[N^{w}\right]\right.$ in $\left.\mathrm{kg} \mathrm{N} \mathrm{m}^{-3}\right)$ is regulated by floodwater depth (Eq. 1), and rates of urea hydrolysis (Eqs. 2 to 3), $\mathrm{NH}_{3}$ volatilisation (Eqs. 4 to 6), and $\mathrm{N}$ sink (Eqs. 7 to 8 ) (Fig. 1), and is given by:

$\frac{d\left[N^{w}\right]}{d t}=\frac{1}{X^{w}}\left(+N_{i n}^{w} X^{w}-K_{v} \alpha\left[N^{w}\right] X^{w}-K_{\text {sink }} S\left[N^{w}\right] X^{w}-\left[N^{w}\right]\{-R-I-E T\}\right)$

where, $N_{i n}^{w}=K_{h}\left[U^{w}\right]$ for one-step urea hydrolysis, or $N_{i n}^{w}=K_{E}\left[E^{w}\right]$ for two-step urea hydrolysis (Eqs. 2 to 3). Hence, the cumulative $\mathrm{NH}_{3}$ volatilisation (Eq. 4) can be calculated from Eqs. 1 to 7, and 9.

\subsubsection{Model evaluation}

\subsubsection{Secondary data sets}

Observational data sets reported by Fillery et al. (1984) and Li et al. (2008) were digitised and used for evaluation of the model (Table 1).

In experiments related to the observational data sets DSetLB84 and DSetM84, urea was applied at three time instants: 1) just before transplanting of rice seedlings, 2) at about 14 or 21 days after transplanting (DAT), and 3) at about 27 or 52 DAT. The observed state variables are sub-daily concentrations of urea-N, concentrations of total ammoniacal-N and $\mathrm{NH}_{3}$ fluxes. Fillery et al. (1984) reported the rate of $\mathrm{NH}_{3}$ volatilisation ( $\mathrm{kg} \mathrm{N}^{-1} \mathrm{hour}^{-1}$ ), but we transformed this into temporal cumulative $\mathrm{NH}_{3}$ volatilisation with a time interval of half a day.

The observed floodwater $\mathrm{pH}$ values in the study by Fillery et al. (1984) were interpolated and used as data inputs to the model. The floodwater $\mathrm{pH}$ was measured only between 6:00 hours and 22:00 hours. Therefore, the floodwater $\mathrm{pH}$ between 22:00 hours and 6:00 hours was assumed constant at 7.0 for each day (Appendix B). Different floodwater temperatures were observed for DsetLB84 and DSetM84 (Table 1), but details were not reported in Fillery et al. (1984). Thus, as a first guestimate, we used the same synthetic floodwater temperature as model input data for both locations. Floodwater temperature was assumed constant at $25{ }^{\circ} \mathrm{C}$ at between 20:00 hours and 6:00 hours, and gradually reaches a maximum temperature of $40{ }^{\circ} \mathrm{C}$ at 12:00 hours at both locations (Appendix B). The floodwater $\mathrm{pH}$ and temperature were used 


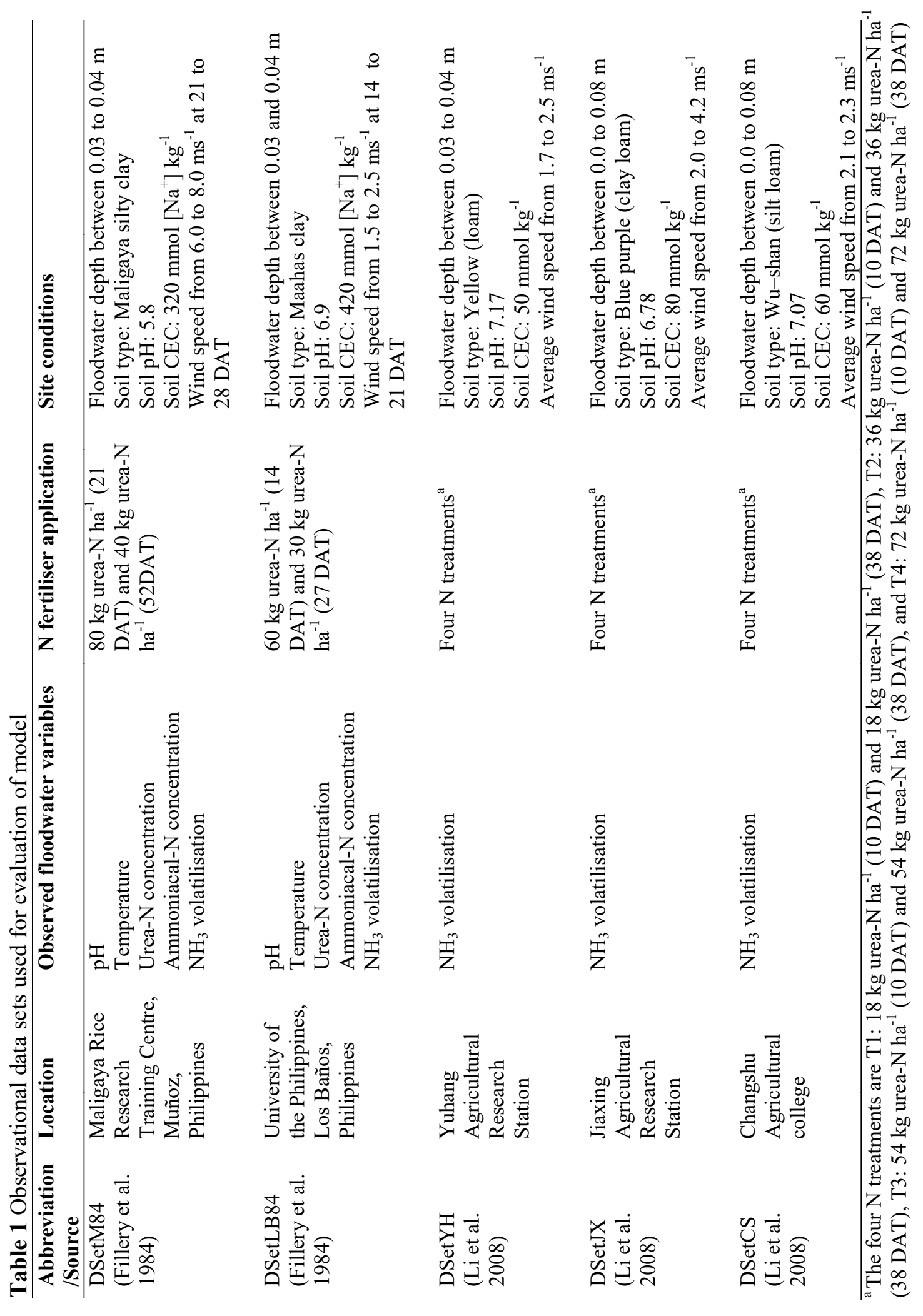


to calculate the fraction of $\mathrm{NH}_{3}$ from total ammoniacal-N in the floodwater using Eqs. 5 and 6. For DSetM84 and DSetLB84, the floodwater depth was assumed constant at $0.035 \mathrm{~m}$, which was the average observed for DSetM84 and DSetLB84 due to lack of meteorological data.

In experiments related to the observational data sets DSetYH, DSetJX, and DSetCS, urea was also applied at three time instants: 1) just before transplanting of rice seedlings, 2) at about 10 DAT, and 3) at about 38 DAT. At each location, urea was applied at four rates for each application, i.e., 18, 36, 54, and $72 \mathrm{~kg} \mathrm{~N} \mathrm{ha}^{-1}$. Li et al. (2008) reported daily rates of $\mathrm{NH}_{3}$ volatilisation after each urea application. Frequent observations of total ammoniacal-N concentration, and floodwater $\mathrm{pH}$ and temperature were not reported in $\mathrm{Li}$ et al. (2008). For DSetYH, DSetJX and DSetCS, the floodwater depth was reported to vary between 0.10 to $0.80 \mathrm{~m}$, and, thus, we assumed an average floodwater depth of $0.045 \mathrm{~m}$.

For all data sets, urea was broadcast and incorporated into the soil just before transplanting, but observations at this stage were not used in the model evaluation as the model was developed to simulate the effect of urea application in the floodwater without subsequent incorporation into the soil. The effect of urea application, just before transplanting of seedlings, on the soil $\mathrm{N}$ content, was assumed negligible after several days.

In the following, the sources of uncertainty introduced when retrieving the data are addressed. Errors may be introduced after careful digitisation (extraction) of the data from figures provided by Fillery et al. (1984) and Li et al. (2008). For DSetLB84 and DSetM84, the dates of urea applications were reported, but not the exact time of the applications. The exact date of transplanting of rice seedlings was also not provided. Despite these limitations, these two data sets were selected because other pertinent details that are relevant to $\mathrm{NH}_{3}$ volatilisation, especially the floodwater $\mathrm{pH}$ and dynamics of urea-N and total ammoniacal-N concentrations, were well documented. The missing information was carefully estimated based on other information provided.

Fillery et al. (1984) measured $\mathrm{NH}_{3}$ volatilisation using one of the micrometeorological methods, whereas $\mathrm{Li}$ et al. (2008) used the dynamic chamber method. The micrometeorological methods measure net flux of $\mathrm{NH}_{3}$ volatilisation and do not alter the environment, and, thus, the observations are more representative of the net flux in rice systems compared to observations obtained using chamber methods (Sommer et al., 2004). 
Despite the limitations of the dynamic chamber methods, data sets reported by Li et al. (2008) were selected for evaluation of the model because these data sets are recent, included four $\mathrm{N}$ treatments at each location, and excluded the effect of time and location dependent wind speed on the observed $\mathrm{NH}_{3}$ loss from the floodwater surface, and, thus, allowed for evaluation of the model performance across locations and treatments. Furthermore, observations of $\mathrm{NH}_{3}$ volatilisation using micrometeorological methods are scarce. From 90 peer-reviewed publications, Zhou et al. (2016) reported that since the 1990's $96 \%$ of the $\mathrm{NH}_{3}$ loss measurements over Chinese cropland were measured using dynamic or static chamber methods. See for instance, Li et al. (2008), Xu et al. (2012), and Chen et al. (2015).

Li et al. (2008), Xu et al. (2012), Cao et al. (2013), and Chen et al. (2015) reported standard errors ranging from about $2 \mathrm{~kg} \mathrm{~N} \mathrm{ha}^{-1}$ to about $5 \mathrm{~kg} \mathrm{~N} \mathrm{ha}^{-1}$ for daily cumulative $\mathrm{NH}_{3}$ volatilisation observed using static and dynamic chamber methods. Cao et al. (2013) and Liu et al. (2015) reported standard errors ranging from about $2 \mathrm{mg} \mathrm{N} \mathrm{L}^{-1}$ to about $5 \mathrm{mg} \mathrm{N} \mathrm{L}^{-1}$, and occasionally as large as $15 \mathrm{mg} \mathrm{N} \mathrm{L}^{-1}$ (Cao et al., 2013) for observed concentrations of total ammoniacal-N in the floodwater.

\subsubsection{Calibration and cross-validation of model}

The model (Eqs. 1 to 9) was run using MATLAB R2012a. The differential equations were solved using the function ode45. The simulation time-step was half-hourly and the simulation run time was about 0.3 hours on a machine with INTEL® CORE ${ }^{\mathrm{TM}}$ i7-3612QM CPU @ 2.10GHzprocessor and 8 GB RAM memory. For all simulations, the floodwater depth was assigned a constant value, and, thus, the dilution effect, with $-R-I+E T=0$, was subsequently omitted from the equations.

The proposed model was calibrated using three different data sets, and after each calibration the model was cross-validated. The term cross-validation denotes evaluation of the model with respect to observations that were not used during calibration.

First, the model was calibrated using DSetM84 (Table 1). The initial conditions of all states variables were assumed zero on the day of transplanting, except for the initial $S_{0}$. Five unknown rate coefficients $\left(K_{h}, K_{E}, K_{\text {sink }}, \beta, K_{v}\right)$ and $S_{0}$ were calibrated manually from DSetM84. The calibrated model was then cross-validated using DSetLB84. 
Second, the proposed model was re-calibrated using both DsetLB84 and DSetM84. By calibrating the model using two data sets simultaneously, the number of training data was increased, and, thus, more constraints on the possible values of the estimated coefficients were expected. Again, the initial conditions of all states variables were assumed zero on the day of transplanting, except for $S_{0}$. The five unknown rate coefficients and $S_{0}$ were gradually varied to fit the observations at DsetLB84 and DSetM84 simultaneously. The calibrated model was then cross-validated using DSetYH T3 (54 kg urea-N ha ${ }^{-1}$ per application).

Third, the proposed model was re-calibrated using only DSetYH T3, as it appeared that the rate coefficients needed to be calibrated for site specific conditions. The calibrated model was then cross-validated using the rest of DSetYH, DSetJX and DSetCS. In addition, the calibrated model was also cross-validated using DSetM84 and DSetLB84.

\subsubsection{Accuracy of the model}

For each of the three aforementioned calibration steps, the root mean square errors (RMSE), as an estimate of the standard deviation of the residuals, and the least-squares coefficient of determination $\left(\mathrm{R}^{2}\right)$, were calculated for three observational data: urea- $\mathrm{N}$ concentration, ammoniacal-N concentrations, and cumulative $\mathrm{NH}_{3}$ volatilisation.

The RMSE and $\mathrm{R}^{2}$ are defined as

$$
\begin{aligned}
& \text { RMSE }=\sqrt{\frac{\sum_{j}\left(\hat{y}_{j}-y\right)^{2}}{N}} \\
& R^{2}=1-\frac{\sum_{j}\left(y_{j}-\hat{y}\right)}{\sum_{j}\left(y_{j}-\bar{y}\right)}
\end{aligned}
$$

where, $y_{j}$ is observed data, $\hat{y}$ is the model output, $\bar{y}$ is the mean value of the observational data set, and $N$ is number of observed data.

\subsubsection{Co-validation of models}

Co-validation with competitive models is an alternative to model cross-validation (Bellocchi et al., 2010). The modelling concepts developed by Chowdary et al. (2004) were selected to co-validate our model with respect to their common outputs: concentrations of urea-N in the 
floodwater, concentrations of total ammoniacal-N in the floodwater, and cumulative $\mathrm{NH}_{3}$ volatilisation.

As the differential equations were not given in Chowdary et al. (2004), we reproduced the equations based on the modelling concepts described by the authors. In Chowdary et al. (2004), $\mathrm{NH}_{3}$ volatilisation is only affected by the interactive processes in the floodwater. Hence, co-validation of the models involves only the floodwater $\mathrm{N}$ dynamics. Thus, only mathematical equations related to the floodwater $\mathrm{N}$ dynamics are given (Appendix $\mathrm{C}$ ). All $\mathrm{N}$ processes are described by first-order kinetics, each with a constant rate coefficient. The model developed by Chowdary et al. (2004) was calibrated to fit observations in DSetM84.

\subsubsection{Sensitivity analysis}

The sensitivity of a predicted model outputs, $\hat{y}(t, \hat{\theta})$, with respect to an estimated rate coefficient, $\widehat{\theta}_{l} \in\left\{K_{h}, K_{E}, K_{\text {sink }}, \beta, K_{v}\right\}$, is defined as $\frac{d \hat{y}(t, \widehat{\theta})}{d \widehat{\theta}} \cong \frac{\Delta \hat{y}(t, \widehat{\theta})}{\Delta \widehat{\theta}}$, where $t$ is a time instant, $\Delta \hat{y}(t, \hat{\theta}):=\hat{y}(t, 1.1 \widehat{\theta})-\hat{y}(t, 0.9 \hat{\theta})$, and $\Delta \widehat{\theta}_{l}:=1.1 \widehat{\theta}_{l}-0.9 \widehat{\theta}_{l}=0.2 \widehat{\theta}_{l}$. Next, the sensitivity matrix (Appendix D) for the multiple model output case was calculated for three process variables, namely $\hat{y}_{1}(t, \hat{\theta})=\left[U^{w}\right], \hat{y}_{2}(t, \hat{\theta})=\left[N^{w}\right]$, and $\hat{y}_{3}(t, \hat{\theta})=N H_{3}^{g}$, for DSetM84 and DSetLB84. The estimation covariance matrices and corresponding eigenvalue decompositions, to detect dominant combinations of rate coefficients (see Keesman, 2011 for details), follow from the corresponding sensitivity matrix, a weighting matrix, $W$, and estimated variance of residuals, $\sigma_{\varepsilon}^{2}$. The matrices for each of the two data sets are presented in supplements $\mathrm{S} 1$.

Simulations of $\left[U^{w}\right],\left[N^{w}\right]$, and $\mathrm{NH}_{3}^{g}$ were performed using observed floodwater $\mathrm{pH}$ and synthetic floodwater temperature as inputs to Eq. 5. The residuals $\varepsilon(t)$ are defined as the difference between observed data, $y(t)$ and predicted model output, $\hat{y}(t, \hat{\theta})$ at time $t$, given the estimated parameter vector $\hat{\theta}$. The values of the rate coefficients and $S\left(t_{0}\right)$ were taken from the re-calibration step and are given in Table 2.

To assess sensitivity of the predicted $\mathrm{NH}_{3}$ volatilisation with respect to its key process variables, the floodwater $\mathrm{pH}$, temperature, and depth were varied by \pm 0.5 unit, $\pm 5^{\circ} \mathrm{C}$, and $\pm 0.02 \mathrm{~m}$, respectively. 


\subsection{Results and discussion}

\subsubsection{Evaluation of proposed model}

Our model contains five unknown rate coefficients $\left(K_{h}, K_{E}, \beta, K_{\text {sink }}, K_{v}\right)$ and an initial state of $S_{0}$, which must be estimated from observational data sets. In addition to measurement errors, structural errors between model output and observational data sets were also foreseen.

For instance, discrepancies between simulated and observed concentrations of total ammoniacal-N in the floodwater can be caused by variation in floodwater depth, which was not captured as a model input. In this study, a constant floodwater depth was assumed for simulation due to lack of meteorological data. If not directly measured, floodwater depth is typically estimated from water balance equation (Eq. 1). However, it is unlikely for flooded rice systems to have homogeneous field gradients, and thus variation of floodwater depth across a field is expected. This variation implies that exact values of floodwater depth cannot be determined for a flooded rice system, while it may affect the prediction of urea-N and total ammoniacal-N concentrations in the floodwater. Thus, in this study, instead of merely data fitting, including process knowledge allows us to predict and interpret the observed trends and relative magnitudes.

In order to measure $\mathrm{NH}_{3}$ volatilisation, different measurement methods were used by Fillery et al. (1984) and Li et al. (2008) (Section 4.2.2.1). Therefore, it is expected that $K_{v}$ may not be compared directly and need to be adjusted.

\subsubsection{First evaluation of the proposed model}

First, the model with one-step urea hydrolysis (Section 4.2.1.2) was calibrated with DSetM84, by gradually varying the five unknown coefficients, and $S_{0}$. The rates of applied urea-N $\left(U^{S}\right)$ corresponds to 80 and $40 \mathrm{~kg}$ urea-N ha ${ }^{-1}$ day $^{-1}$, at 21 and 52 DAT, respectively (Table 1). As a result, good fit of initial peak and decay rate of urea-N was observed for $K_{h}=0.9$ day $^{-1}$ (Fig. 2a).

By assuming a one-step urea hydrolysis (Eq. 2), however, a surge of total ammoniacal-N was observed (Fig. 2b), despite the fact that reasonable amount of total $\mathrm{N}$ sink was considered (about $50 \%$ of total $\mathrm{N}$ applied was withdrawn from the floodwater). The sudden surge of total ammoniacal-N predicted by the model contradicts with the observations where the total 
ammoniacal-N in the floodwater only reached a peak concentration of about $15 \mathrm{mg} \mathrm{N} \mathrm{L} \mathrm{N}^{-1}$ (Fig. 2b).
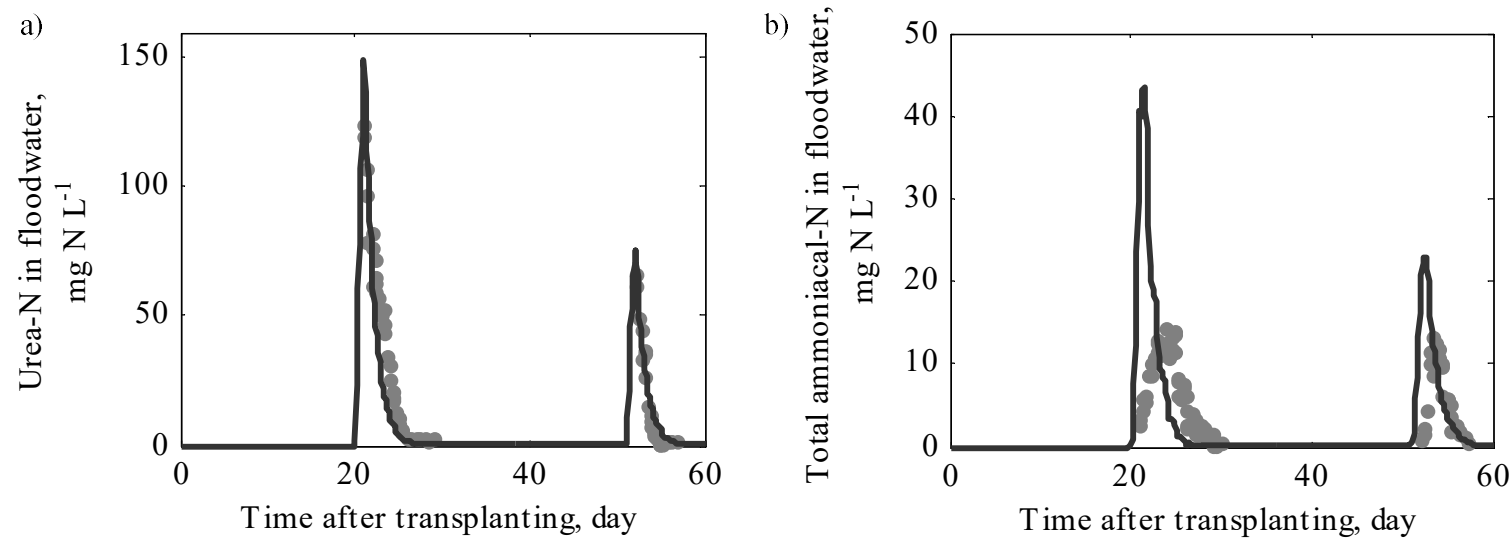

Fig. 2 a) Concentration of urea-N in floodwater as a result of one-step urea hydrolysis where applied urea-N was assumed to dissolved within one day and $K_{h}=0.90$ day $^{-1}$, and b) the corresponding concentration of total ammoniacal-N in floodwater

The effect of dilution by changing floodwater depth was overruled, as consistent overestimation of total ammoniacal-N concentration was observed after fertilisations on 21 and 52 DAT. Notice also that the total ammoniacal-N concentration peak was about $15 \mathrm{mg} \mathrm{N}$ $\mathrm{L}^{-1}$ despite the different rates of applied urea-N on 21 and 52 DAT. The relatively low and steady peaks of total ammoniacal-N concentrations for several days suggest potential delay in the conversion from dissolved urea $\left(\left[U^{w}\right]\right)$ to ammoniacal-N $\left(\left[N^{w}\right]\right)$, which was in agreement with Fillery et al. (1986), who also hypothesised slow urease activity at these locations.

In order to conceptualise slow urease activity, urea hydrolysis was described by two firstorder processes in series (Eqs. 2 and 3). The $S_{0}$ in the total $\mathrm{N}$ sink term was arbitrarily set at 0.40 (Eqs. 7 and 8), and the coefficient of $\mathrm{NH}_{3}$ volatilisation was assumed constant, $K_{v}=5.0$ day $^{-1}$. However, by assuming a constant $K_{v}$ throughout the cropping season, the proposed model overestimated the observed cumulative $\mathrm{NH}_{3}$ volatilisation at 52 DAT onwards (not shown).

We suspected that the wind speed had considerable effect on $\mathrm{NH}_{3}$ volatilisation, especially before panicle initiation. Thus, $K_{v}$ was split into two stages: $K_{v A T}=12.0$ day $^{-1}$ at 21 DAT onwards (before panicle initiation), and $K_{v P I}=4.0$ day $^{-1}$ at 52 DAT onwards (about panicle initiation). As a result of the two-step urea hydrolysis and the time-varying $K_{v A T}$, the 
simulated concentrations of urea-N and total ammoniacal- $\mathrm{N}$ in the floodwater, and cumulative $\mathrm{NH}_{3}$ volatilisation trends followed the observed trends better (Fig. 3).
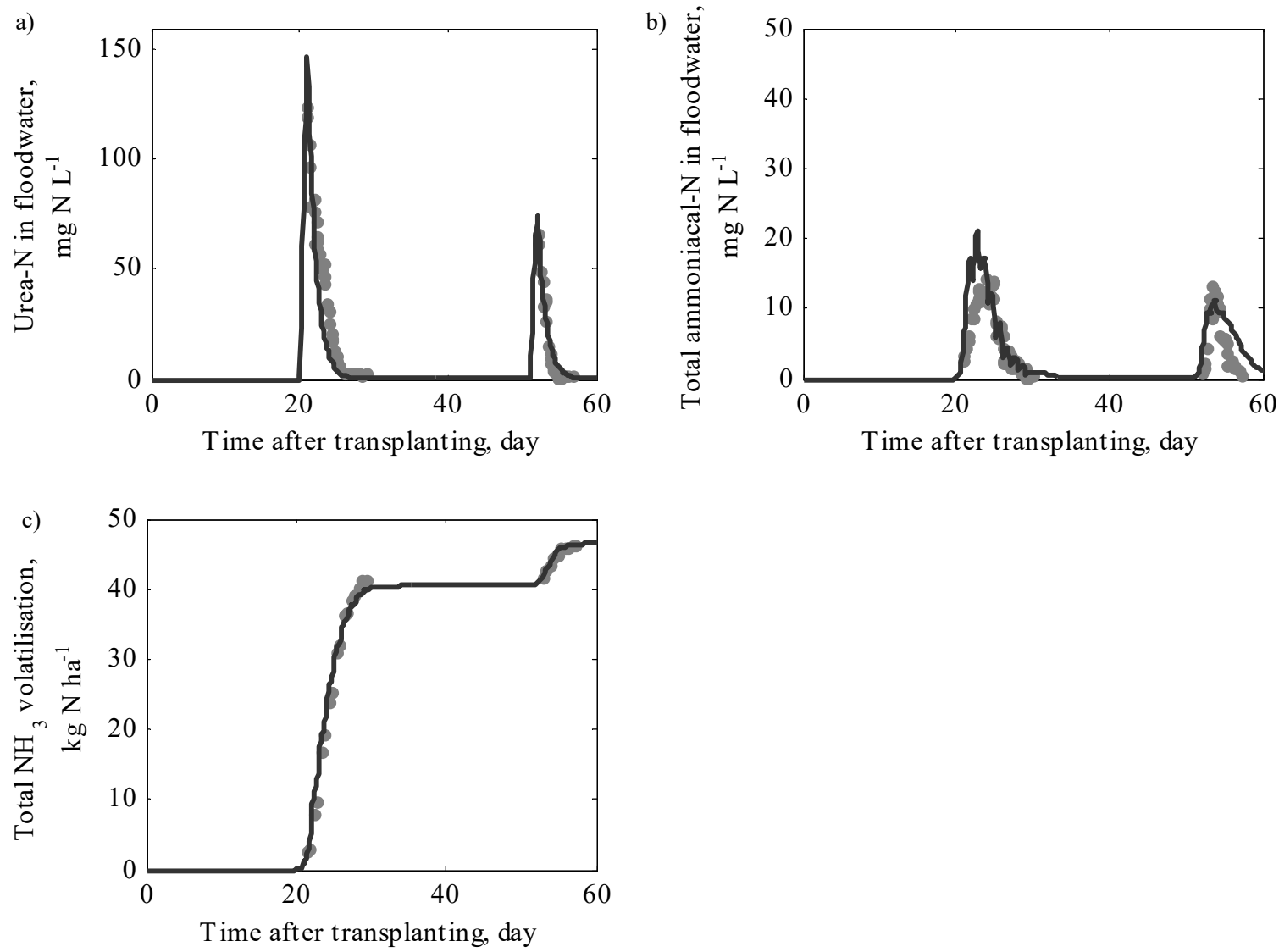

Fig. 3 Model calibration with DSetM84 (Table 2): a) Concentration of urea-N in floodwater, b) concentration of total ammoniacal-N in floodwater, and c) cumulative $\mathrm{NH}_{3}$ volatilisation

The RMSE values are about $12.24 \mathrm{mg} \mathrm{N} \mathrm{L}^{-1}$ for urea-N concentration, about $4.96 \mathrm{mg} \mathrm{N} \mathrm{L}^{-1}$ for total ammoniacal-N concentration, and about $1.33 \mathrm{~kg} \mathrm{~N} \mathrm{ha}^{-1}$ for cumulative $\mathrm{NH}_{3}$ volatilisation, respectively. The $\mathrm{R}^{2}$ for the estimation of urea-N concentration, total ammoniacal-N concentration, and cumulative $\mathrm{NH}_{3}$ volatilisation were $0.86,-0.31$, and 0.99 , respectively.

The negative $\mathrm{R}^{2}$ indicated that the sum of squares of residuals $\left(\sum_{i}\left(y_{i}-\hat{y}\right)\right)$ is greater than the total sum of squares $\left(\sum_{i}\left(y_{i}-\bar{y}\right)\right)$. The proposed model may be over-parameterised as such that the added process (two-step urea hydrolysis) cannot explain the trend of total ammoniacal-N concentration. However, by assuming only a one-step urea hydrolysis, surge of total ammoniacal-N concentration was observed despite reasonable amount of $\mathrm{N}$ sink was assumed (Fig. 2b). Therefore, the hypothesis of two-step urea hydrolysis due to slow urease 
activity was assumed reasonable for now. The calibrated coefficients using DSetM84 are given in Table 2 (Column 2).

Table 2 Estimates of parameters

\begin{tabular}{lccc}
\hline Parameter & $\begin{array}{c}\text { Calibration with } \\
\text { DSetM84 }\end{array}$ & $\begin{array}{c}\text { Calibration with } \\
\text { DSetM84 \& DSetLB84 }\end{array}$ & $\begin{array}{c}\text { Calibration with } \\
\text { DSetYH T3 }\end{array}$ \\
\hline$K_{h}\left(\right.$ day $\left.^{-1}\right)$ & 0.90 & 0.80 & 0.80 \\
$K_{E}\left(\right.$ day $\left.^{-1}\right)$ & 0.50 & 0.60 & 0.60 \\
$\beta\left(\right.$ day $\left.^{-1}\right)$ & 0.05 & 0.02 & 0.07 \\
$K_{\text {Sink }}\left(\right.$ day $\left.^{-1}\right)$ & 2.00 & 2.00 & 6.00 \\
$K_{v A T}\left(\right.$ day $\left.^{-1}\right)$ & 12.0 & $16.00^{\mathrm{a}}, 6.00^{\mathrm{b}}$ & 6.00 \\
$K_{v P I}\left(\right.$ day $\left.^{-1}\right)$ & 4.00 & $4.00^{\mathrm{a}}, 5.00^{\mathrm{b}}$ & 6.00 \\
$S_{0}\left(\right.$ dimensionless $^{\mathrm{b}}$ & 0.40 & 0.70 & 0.02 \\
\hline
\end{tabular}

${ }^{\mathrm{a}}$ For DSetM84

${ }^{\mathrm{b}}$ For DSetLB84

Next, the model and the calibrated coefficients were validated with DSetLB84. Crossvalidation of the model with DSetLB84 resulted in reasonable fits for observed urea-N (Fig. 4a) and total ammoniacal-N concentrations (Fig. 4b), but bad fit of $\mathrm{NH}_{3}$ volatilisation (Fig. 4c). Thus, as yet, our hypothesis with respect to urea hydrolysis is not falsified by the trends observed by Fillery et al. (1984).

The bad fit of $\mathrm{NH}_{3}$ volatilisation in Fig. 4c indicated the model did not capture some dominant underlying processes. The RMSE values for the calibration of urea-N concentration, total ammoniacal- $\mathrm{N}$ concentration, and cumulative $\mathrm{NH}_{3}$ volatilisation were $10.65 \mathrm{mg} \mathrm{N} \mathrm{L} \mathrm{N}^{-1}$, $4.22 \mathrm{mg} \mathrm{N} \mathrm{L}{ }^{-1}$, and $7.80 \mathrm{~kg} \mathrm{~N} \mathrm{ha}^{-1}$, respectively. The $\mathrm{R}^{2}$ for urea-N concentration, total ammoniacal- $\mathrm{N}$ concentration, and cumulative $\mathrm{NH}_{3}$ volatilisation were $0.91,0.13$, and -0.57 , respectively.

In this case, we suspected the neglected effect of wind speed in Muñoz and Los Baños. Therefore, the rate of $K_{v A T}$ and $K_{v P I}$ were adjusted to fit the observed $\mathrm{NH}_{3}$ volatilisation in DSetLB84 (Fig. 4d, with $K_{v A T}=6.0$ day $^{-1}$ and $K_{v P I}=5.0$ day $^{-1}$ ), while values of other rate coefficients were maintained (Table 2). As a result, better fit of cumulative $\mathrm{NH}_{3}$ volatilisation was obtained, where $\mathrm{R}^{2}$ is 0.96 (Fig. 4d). However, the fit for total ammoniacal-N concentration resulted in an $\mathrm{R}^{2}$ of -0.52 .

\subsubsection{Second evaluation of the proposed model}

To assess whether the misfits in the cross-validation step were due to model structure errors or just a local minimum problem (see Keesman, (2011)), the proposed model was re-calibrated 
with DSetM84 and DSetLB84, simultaneously. If a combination of the unknown rate coefficients that reasonably fit all observed trends of DSetM84 and DSetLB84 can be found, the model structure is not yet falsified by the observed trends.
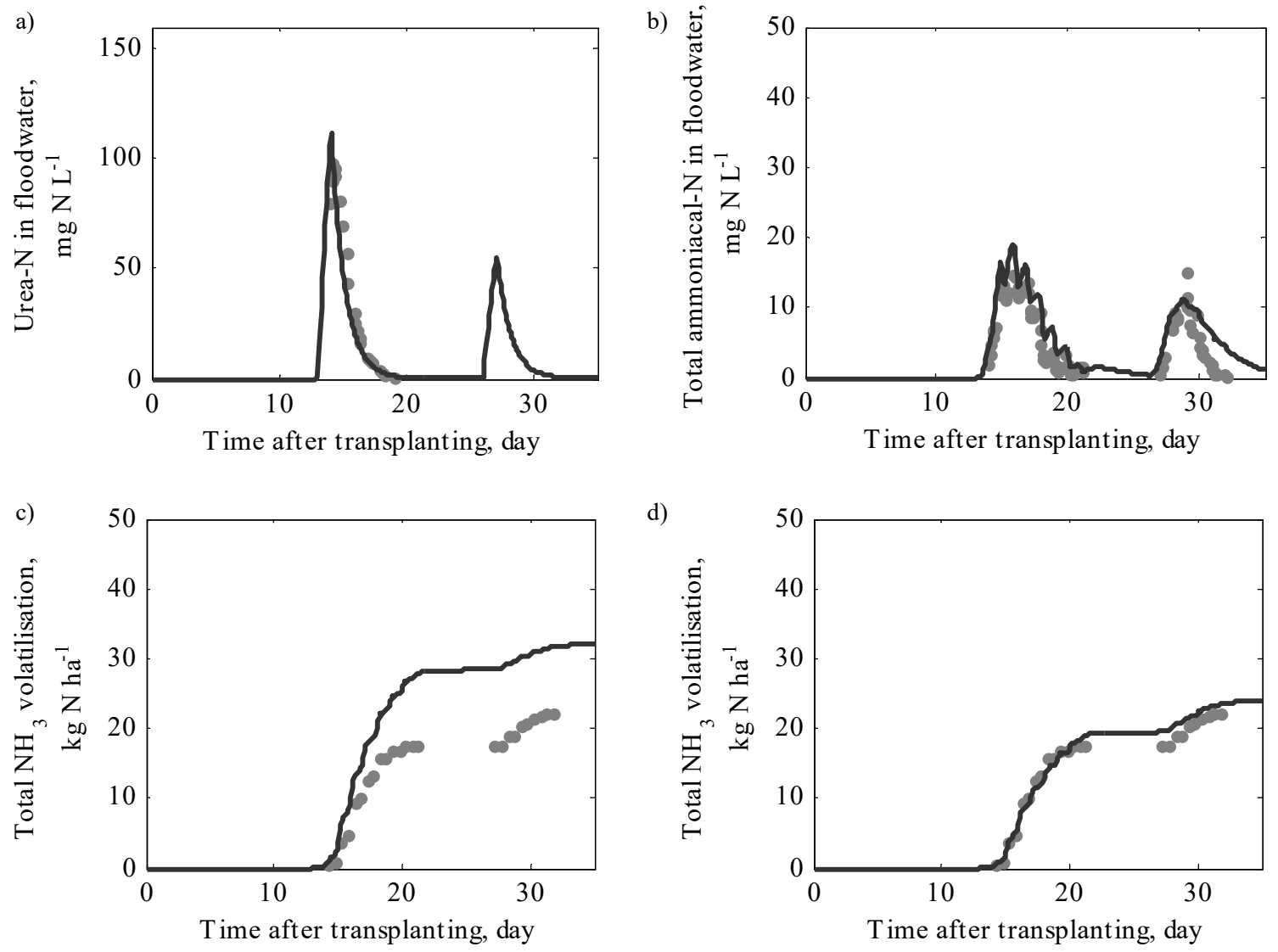

Fig. 4 Model validation with DSetLB84: a) Concentration of urea-N in floodwater, b) concentration of total ammoniacal-N in floodwater, c) cumulative $\mathrm{NH}_{3}$ volatilisation for $K_{v A T}=12.0$ day $^{-1}$ and $K_{v P I}=4.0$ day $^{-1}$, and d) cumulative $\mathrm{NH}_{3}$ volatilisation for $K_{v A T}=6.0$ day $^{-1}$ and $K_{v P I}=5.0$ day $^{-1}$

The values of re-calibrated coefficients are summarised in Table 2. In order to fit the model outputs to the observational data sets of DSetM84 and DSetLB84 simultaneously, as in the previous subsection, $K_{v}$ was assumed to be time-varying for each of the two rice crop growth stages, namely $K_{v A T}$ and $K_{v P I}$. The model with re-calibrated coefficients produced trends and magnitudes comparable to observations (Fig. 5).

The re-calibrated rate coefficient $K_{v A T}=16.0$ day $^{-1}$ for DSetM84 was about 2.7 times larger than $K_{v A T}=6.0$ day $^{-1}$ for DSetLB84. The average of the difference between the minimum and maximum wind speeds observed for DSetM84 and DSetLB84 were $7.0 \mathrm{~ms}^{-1}$ and $2.0 \mathrm{~ms}^{-1}$, respectively (Table 1). Thus, the average wind speed calculated for DSetM84 was 3.5 times 
larger than that of DSetLB84. Fillery et al. (1986) suggested that the $\mathrm{NH}_{3}$ volatilisation is linearly related to wind speed, but in this study, the increase in $K_{v A T}$ was not exactly linear with wind speed.

a)
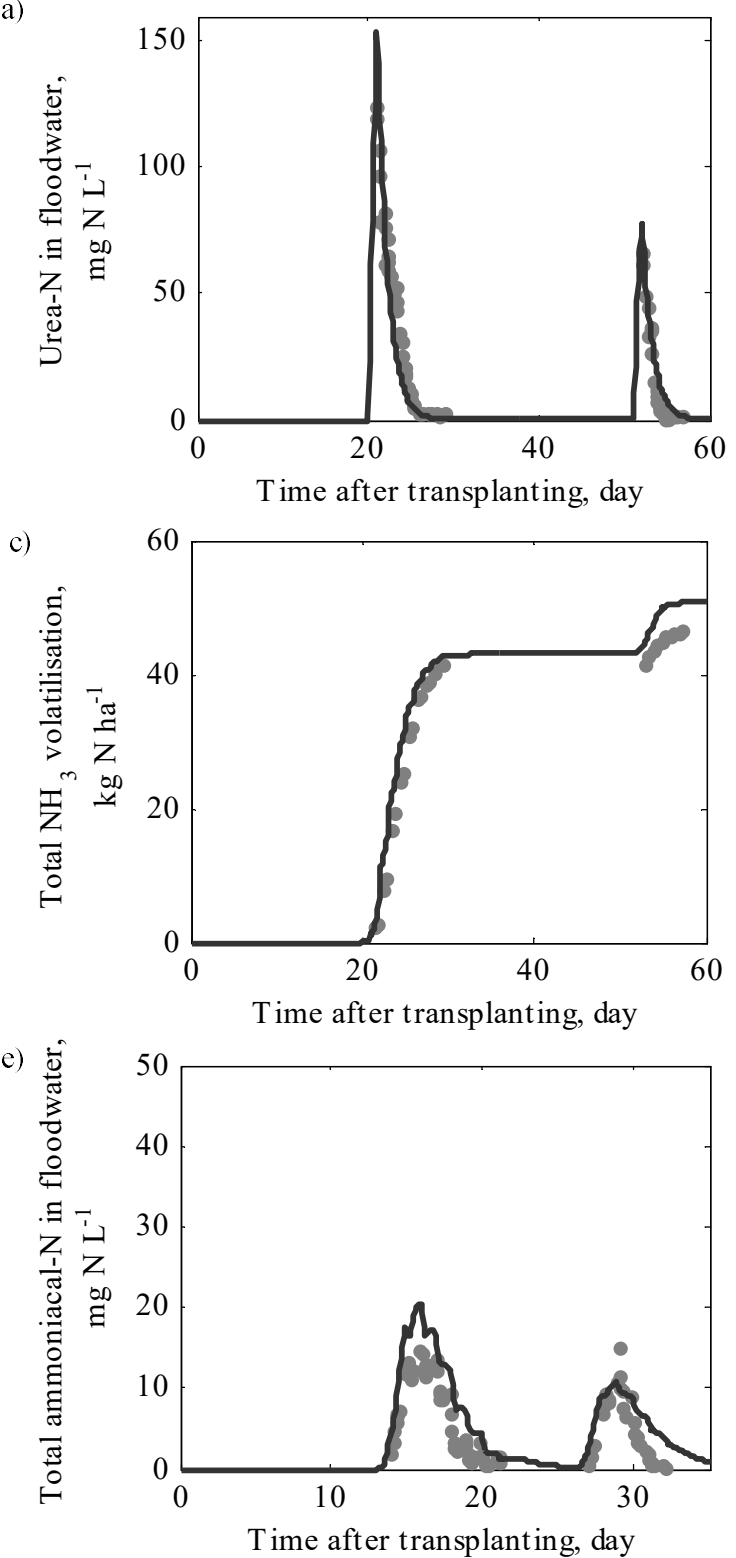
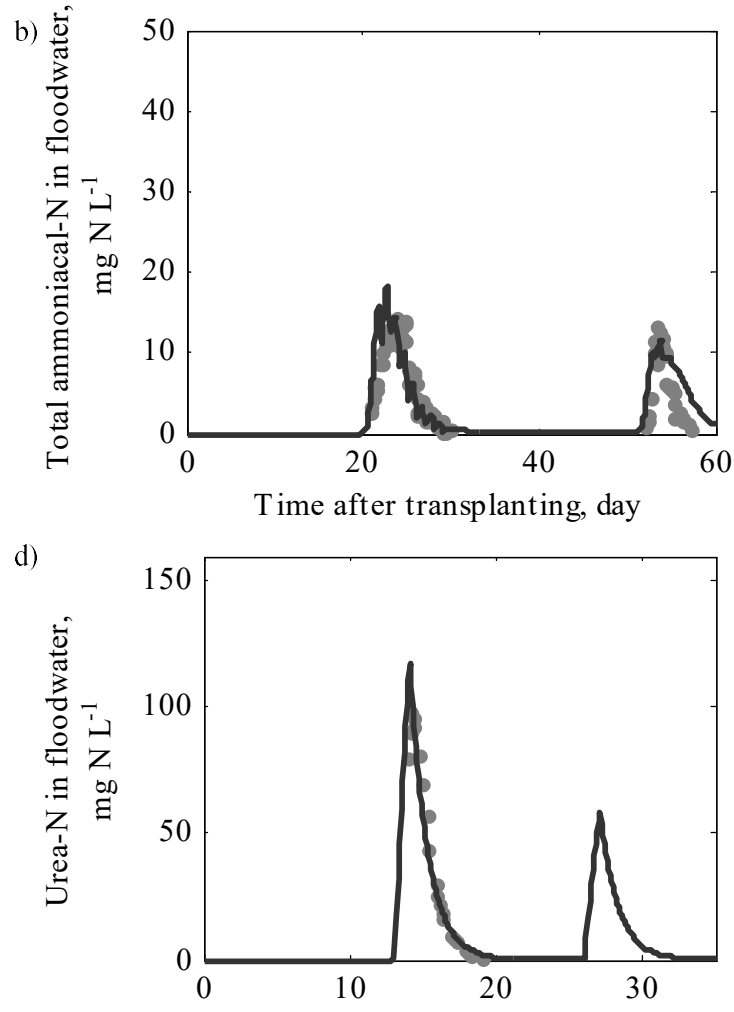

Time after transplanting, day

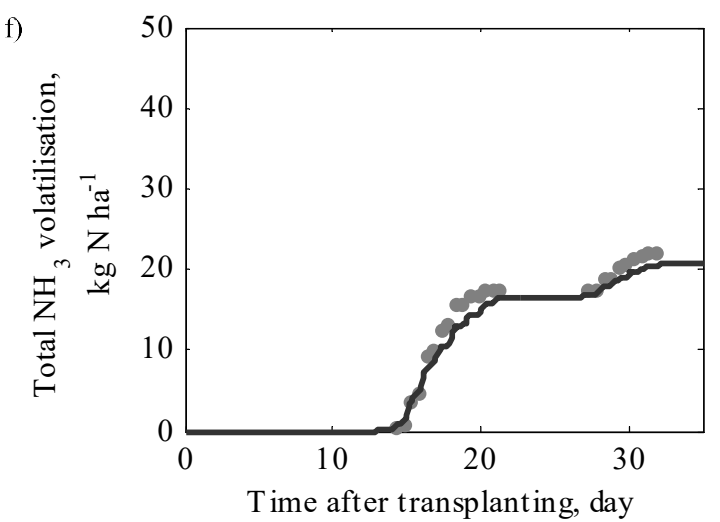

Fig. 5 Model re-calibration with DSetM84 and DSetLB84, simultaneously (Table 2): a) Concentration of urea- $\mathrm{N}$ in floodwater, b) concentration of total ammoniacal- $\mathrm{N}$ in floodwater, and c) cumulative $\mathrm{NH}_{3}$ volatilisation for DSetM84. d) Concentration of urea-N in floodwater, f) concentration of total ammoniacal-N in floodwater, and g) cumulative $\mathrm{NH}_{3}$ volatilisation for DSetLB84

The higher rate coefficient for DSetM84 $\left(K_{v A T}=16.0\right.$ day $\left.^{-1}\right)$ compared to that of DSetLB84 $\left(K_{v A T}=6.0\right.$ day $\left.^{-1}\right)$ suggested importance of wind speed in making reliable estimation of $\mathrm{NH}_{3}$ 
volatilisation, and thus, implies that the $\mathrm{NH}_{3}$ volatilisation rate coefficient in any model, simple or complex, is site specific, and can vary temporally.

However, notice that for DSetLB84, the estimate of $K_{v A T}$ is only slightly greater than the estimate of $K_{v P I}$ (Table 2). The values are also comparable to estimate of $K_{v P I}$ for DSetM84. We can only hypothesise that the slight differences in the estimates of $K_{v}$ indicated that the $K_{v}$ is only sensitive (time-varying) in systems with high wind speed (e.g., $>4 \mathrm{~ms}^{-1}$ ) and a young rice crop. For systems with low wind speed, a constant $K_{v}$ may suffice as the $\mathrm{N}$ uptake by rice crop competes efficiently with $\mathrm{NH}_{3}$ volatilisation as the crop develops over time. Without further details on the wind speed, crop variety and physiology (leaf area index) at both locations, further interpretation is not possible. Nevertheless, the time-varying rate coefficient of $\mathrm{NH}_{3}$ volatilisation suggests uncertainty in estimating $\mathrm{NH}_{3}$ volatilisation using a first-order kinetics regulated by a constant rate coefficient, see for examples, Rao et al. (1984), Chowdary et al. (2004), Antonopoulos (2010), and Liang et al. (2014).

Next, the calibrated model was validated with DSetYH. The average wind speed varied between the locations (Table 2), but we assumed $K_{v}=6$ day $^{-1}$ throughout the crop growth stages at all locations because the daily $\mathrm{NH}_{3}$ volatilisation rates of DSetYH were measured using the enclosure method. The simulation resulted in poor fit between simulated and observed cumulative $\mathrm{NH}_{3}$ volatilisation, especially after urea application on 10 DAT (Fig. 6). The poor fit indicated either a model structure error, or a site specific condition which requires re-calibration of the parameters that are related to the $\mathrm{N} \operatorname{sink}$ term $\left(\beta, K_{\text {sink }}\right.$ and $\left.S_{0}\right)$.

\subsubsection{Third evaluation of the proposed model}

The model was then manually re-calibrated with DSetYH T3 (54 kg urea-N ha ${ }^{-1}$ per application) (Fig. 7a). The calibrated model was then validated with the rest of DSetYH, DSetJX and DSetCS (Figs. 7a to d). The observed average wind speed differed among the three locations (Table 2), but we assumed $K_{v}=6$ day $^{-1}$ throughout the varying crop growth stages at all locations because the daily $\mathrm{NH}_{3}$ volatilisation rates were measured via the enclosure approach. 

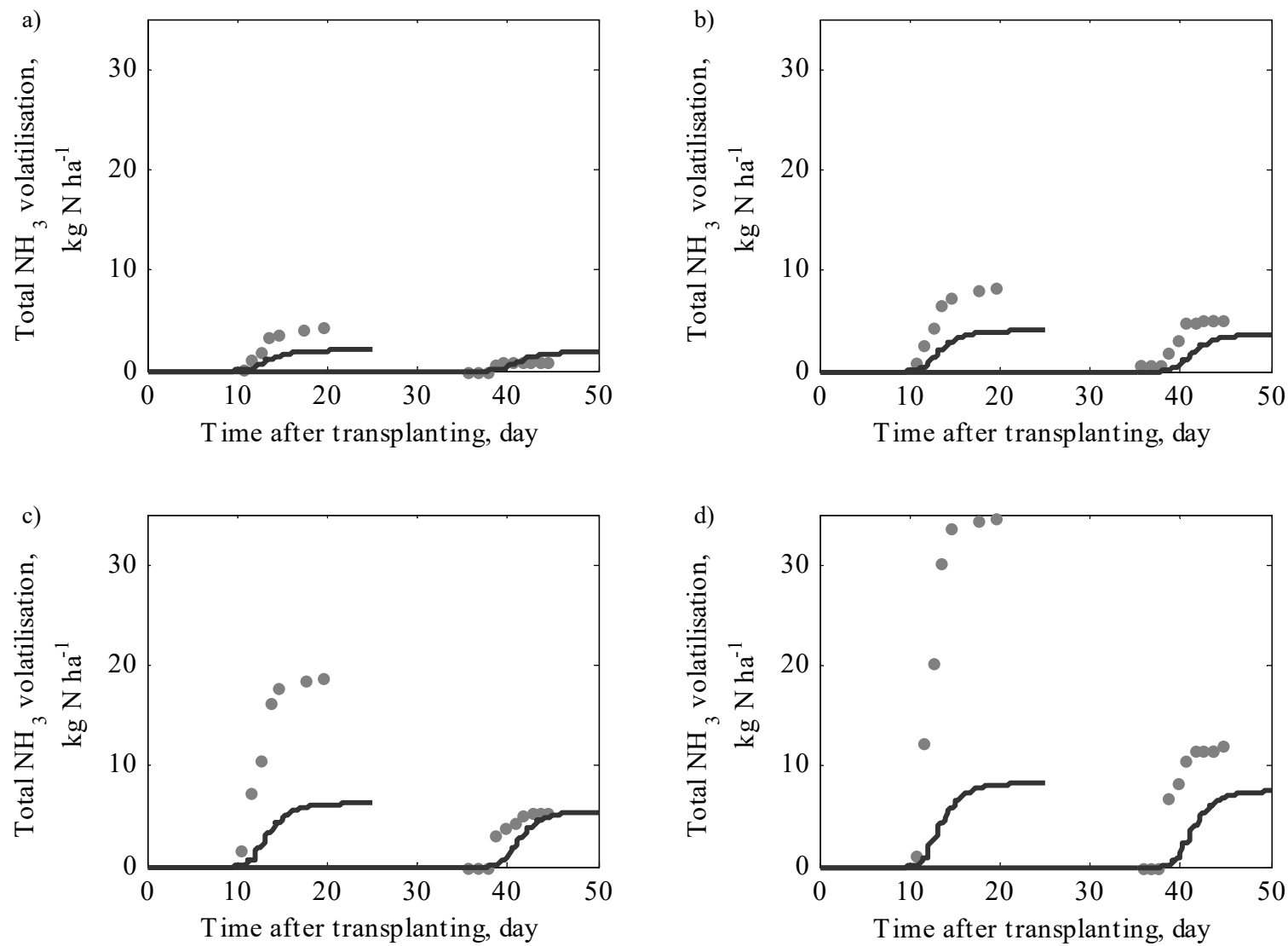

Fig. 6 Simulated and observed (dots) cumulative $\mathrm{NH}_{3}$ volatilisation for DSetYH that received split urea-N applications on 10 DAT and 38 DAT at a rate of a) $18 \mathrm{~kg}$ urea-N ha ${ }^{-1}$, b) $36 \mathrm{~kg}$ urea-N ha ${ }^{-1}$, c) $54 \mathrm{~kg}$ urea-N ha ${ }^{-1}$, and d) $72 \mathrm{~kg}$ urea-N ha ${ }^{-1}$ per application

Fig. 7 shows that re-calibration of the rate coefficients related to the $\mathrm{N}$ sink term $\left(\beta, K_{\operatorname{sink}}, S_{0}\right)$ resulted in reasonable estimations of cumulative $\mathrm{NH}_{3}$ volatilisation compared to previous validation in Section 4.3.1.2 (Fig. 6). Although poor fits were observed for some data sets, good fits were also obtained, in particular for DSetCS. Discrepancies between simulations and observations were more prominent when the urea application rate was highest, i.e., $72 \mathrm{~kg} \mathrm{~N}$ $\mathrm{ha}^{-1}$ per application. Several factors may have contributed to the bad fit. Firstly, the proposed model structure may be inadequate. Li et al. (2008) hypothesised that the variations in $\mathrm{NH}_{3}$ loss from the floodwater surface may also be due to the different values of soil cation exchange capacity for the three locations, but this effect was not modelled. The cation exchange capacity value is highest for DSetJX and lowest for DSetYH. Increase in floodwater depth was shown to reduce $\mathrm{NH}_{3}$ volatilisation (Freney et al., 1988). However, the floodwater depth was assumed constant at $0.045 \mathrm{~m}$ for all simulations. Moreover, the effect of floodwater depth on $\mathrm{NH}_{3}$ volatilisation cannot be captured by the model (Section 4.3.1.5). These factors would have led to bad fit. Secondly, the observations have high uncertainty due to 
measurement methods. The $\mathrm{NH}_{3}$ loss measured using the enclosure method is based on a small area and is prone to error when scaled up (Ni et al., 2015). Observations by Li et al. (2008) showed that the cumulative $\mathrm{NH}_{3}$ volatilisation varied across the three locations, despite similar urea application rates at all locations. Thirdly, the model input data may be incorrect. In all simulations, the same synthetic floodwater $\mathrm{pH}$ was used while in reality the floodwater $\mathrm{pH}$ may have differed across the locations. The discrepancies can be addressed by adjusting the values of floodwater $\mathrm{pH}$, in particular the peak of $\mathrm{pH}$ at mid-day, which will increase the
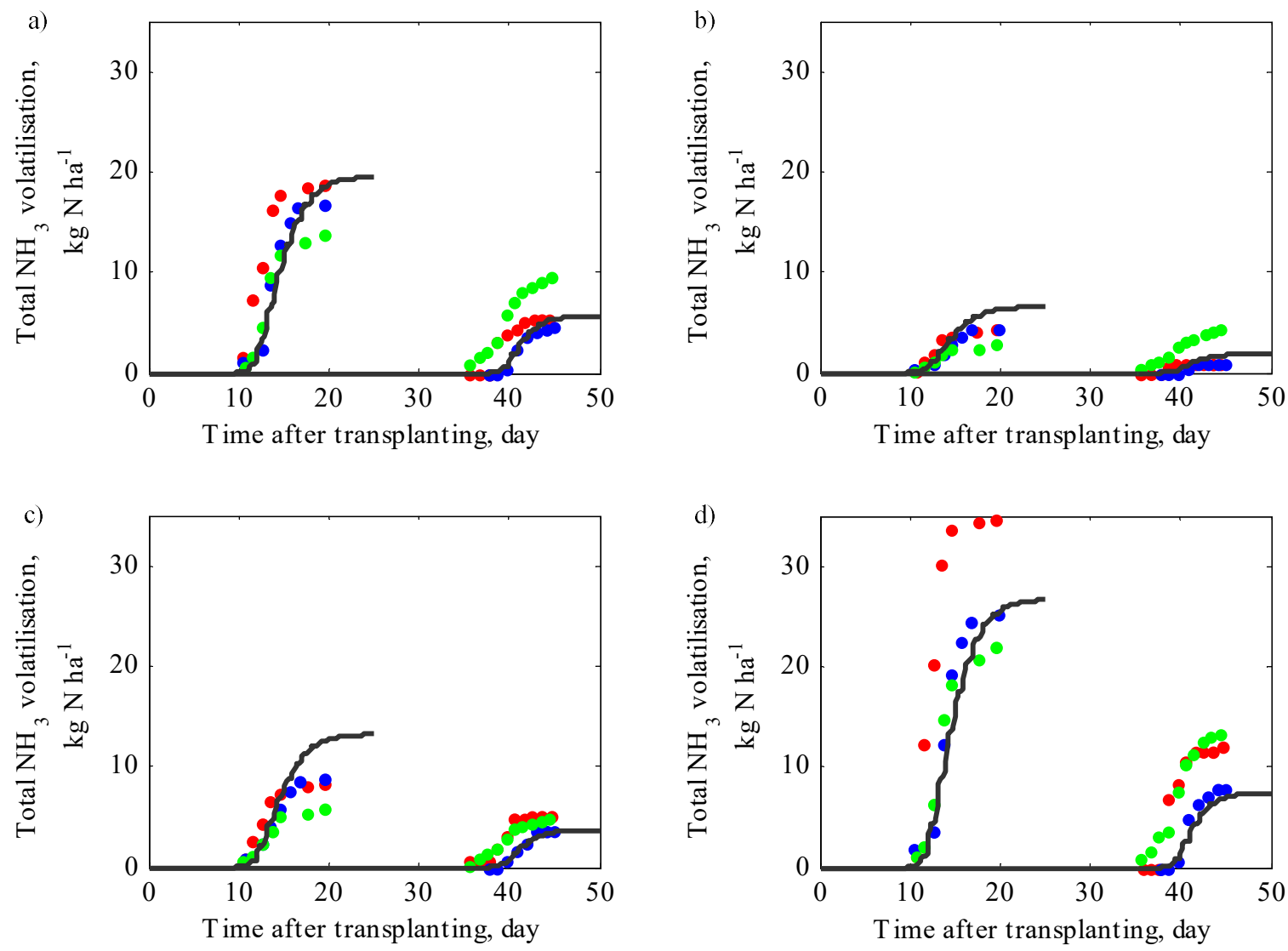

Fig. 7 Calibration of the proposed model with DSetYH that received two split application at a rate of a) $54 \mathrm{~kg} \mathrm{~N} \mathrm{ha}^{-1}$ per application (T3), and validation of proposed model with DSetYH, DSetJX, and DSetCS that received two split application at a rate of b) $18 \mathrm{~kg}_{\text {urea-N ha }}{ }^{-1}$ (T1), c) $36 \mathrm{~kg}$ urea-N ha- ${ }^{-1}$ (T2), and d) $72 \mathrm{~kg}$ urea-N ha ${ }^{-1}$ (T4) per application. Simulations (solid lines) and observations of DSetYH (red dots), DSetJX (green dots), and DSetCS (blue dots)

daily rates of $\mathrm{NH}_{3}$ volatilisation estimated by the proposed model. Any of these three factors could contribute to the bad fit. Furthermore, errors in the observations would also lead to uncertainty in the parameters. 
Cross-validation of the calibrated model with DSetM84 and DSetLB84, however, resulted in poor fit between observed and simulated cumulative $\mathrm{NH}_{3}$ volatilisation (results not shown). By adjusting values of $K_{v A T}$ and $K_{v P I}$, a better fit of cumulative $\mathrm{NH}_{3}$ volatilisation was obtained, but the model overestimated concentrations of total ammoniacal-N in the floodwater. It is plausible that the site specific rates of $\mathrm{N}$ leaching or vertical seepage, or other dominant $\mathrm{N}$ processes resulted in site specific values for $\beta, K_{\text {sink }}$ and $S_{0}$, as suggested in the preceding section.

\subsubsection{Co-validation of proposed model}

In addition to cross-validation and re-calibration on independent data sets, performance of the proposed model was compared to a model of different fundamentals with respect to the common outputs. The model by Chowdary et al. (2004) was selected for co-validation, as its complexity is comparable with the proposed model, in terms of the number of parameters, but differed in the modelling concepts. Both models were simulated for DSetM84 as this data set has frequently observed concentrations of urea-N and total ammoniacal- $\mathrm{N}$, and floodwater $\mathrm{pH}$ and temperature.

The model proposed in this study has six parameters, whereas the model by Chowdary et al. (2004) has six parameters. Both models conceptualised $\mathrm{NH}_{3}$ volatilisation by first-order kinetics, but Chowdary et al. (2004) neglected the partitioning between $\mathrm{NH}_{3}$ and and $\mathrm{NH}_{4}{ }^{+}$in the floodwater. On the other hand, Chowdary et al. (2004) detailed the soil N dynamics, whereas the proposed model simplified the $\mathrm{N}$ transport into the soil and the soil $\mathrm{N}$ dynamics into a lumped $\mathrm{N}$ sink term. The model developed by Chowdary et al. (2004) was also the starting point of the model proposed by Liang et al. (2007, 2014).

In the model of Chowdary et al. (2004), the $\mathrm{N}$ dynamics in the floodwater are regulated by four processes: Urea hydrolysis, nitrification, percolation, and $\mathrm{NH}_{3}$ volatilisation. Table 3 (second column) shows the estimates of three parameters and other inputs calibrated by Chowdary et al. (2004) using data sets from India. By using the estimates as reported by Chowdary et al., (2004) resulted in bad fit for DSetM84 (results not shown). Therefore, the estimates were re-calibrated for DSetM84.

The urea hydrolysis rate was calibrated to fit observed urea-N in the floodwater. Nitrification rate was given a slightly higher value than the estimate reported in Chowdary et al. (2004). 
Percolation rate was assumed about $10 \mathrm{~mm} \mathrm{day}^{-1}$, and consequently, the $\mathrm{NH}_{3}$ volatilisation rate coefficient was adjusted to fit the observed total ammoniacal-N and cumulative $\mathrm{NH}_{3}$ volatilisation in DSetM84 (Table 3).

Table 3 Estimates of parameters of Chowdary et al. (2004) model

\begin{tabular}{lll}
\hline Parameter & Chowdary et al. (2004) & Calibrated for DSetM84 \\
\hline$K_{h}\left(\right.$ day $\left.^{-1}\right)$ & 0.744 & 0.800 \\
$K_{n}\left(\right.$ day $\left.^{-1}\right)$ & 0.070 to 0.080 & 0.100 \\
$K_{v}\left(\right.$ day $\left.^{-1}\right)$ & 0.030 to 0.060 & 0.400 \\
Percolation rate $\left(m m\right.$ day $\left.^{-1}\right)$ & 8.4 & 10 \\
Floodwater depth $(\mathrm{m})$ & 0.050 & 0.035 \\
\hline
\end{tabular}

$K_{h}$ is first-order urea hydrolysis rate coefficient in the floodwater, $K_{n}$ is first-order nitrification rate coefficient in the floodwater, and $K_{v}$ is first-order volatilisation rate coefficient from the floodwater surface

The model of Chowdary et al. (2004) was able to correctly predict the urea-N concentration in the floodwater (Fig. 8a), but the model could not properly predict the trend of total ammoniacal-N in floodwater and cumulative $\mathrm{NH}_{3}$ volatilisation observed in DSetM84 (Figs. $8 \mathrm{~b}$ and $\mathrm{c}$ ). Notice the overestimation of total ammoniacal-N concentration by about 4 times compared to the observations. Although percolation rate was increased from $10 \mathrm{~mm} \mathrm{day}^{-1}$ to as high as $20 \mathrm{~mm} \mathrm{day}^{-1}$, it was not enough to reduce the overestimated peak of total ammoniacal-N in the floodwater to the observed levels. The result either supports the concept of two-step urea hydrolysis for rice systems with low urease activity, or there is a non-linear $\mathrm{N}$ out flux from the floodwater, and, thus, assuming constant percolation and nitrification rates may not reflect the actual $\mathrm{N}$ out flux from the floodwater.

Studies showed that total $\mathrm{NH}_{3}$ volatilisation at the end of a cropping season can be estimated using a first-order kinetics model independent of floodwater $\mathrm{pH}$ and wind speed (Chowdary et al., 2004, Liang et al. 2007., Antonopoulos, 2010, Liang et al., 2014), but our results suggest that such modelling concepts may over and under estimate the cumulative $\mathrm{NH}_{3}$ volatilisation at the end of each split urea application (Fig. 7c), as $\mathrm{NH}_{3}$ volatilisation is also regulated by wind speed and floodwater properties.

To summarise, we can conclude that $K_{h}$ is robust as it was validated with frequently observed urea-N concentration, and is within the range reported by Chowdary et al. (2004). The second step urea hydrolysis parameter $K_{E}$ may be site-specific and should be further assessed with observations of total ammoniacal-N concentrations. By conceptualising the two-step urea hydrolysis, the simulated total ammoniacal-N concentrations were less than $60 \mathrm{mg} \mathrm{N} \mathrm{L} \mathrm{N}^{-1}$, 
which is in line with the observations of total ammoniacal-N reported by Fillery et al. (1984) and Chen et al. (2015), who found concentrations of total ammoniacal-N less than $50 \mathrm{mg} \mathrm{N} \mathrm{L}^{-}$ ${ }^{1}$ in the floodwater of flooded rice systems. The parameters $K_{v}, \beta, K_{\text {sink }}$ and $S_{0}$ require sitespecific calibration.

a)

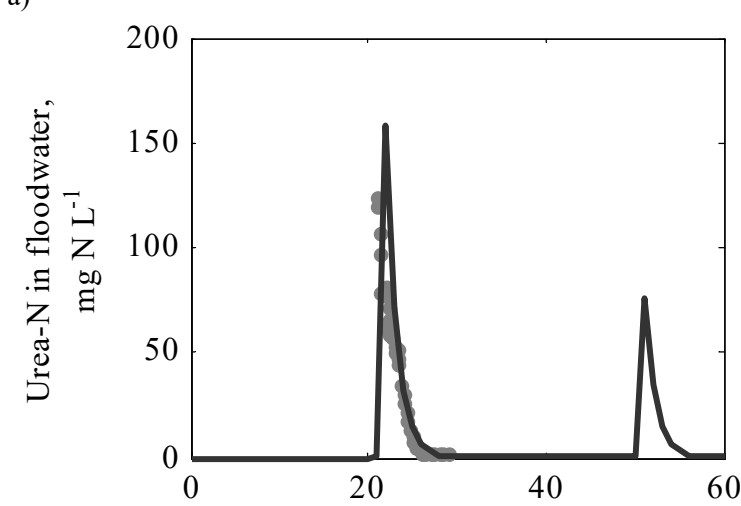

c)

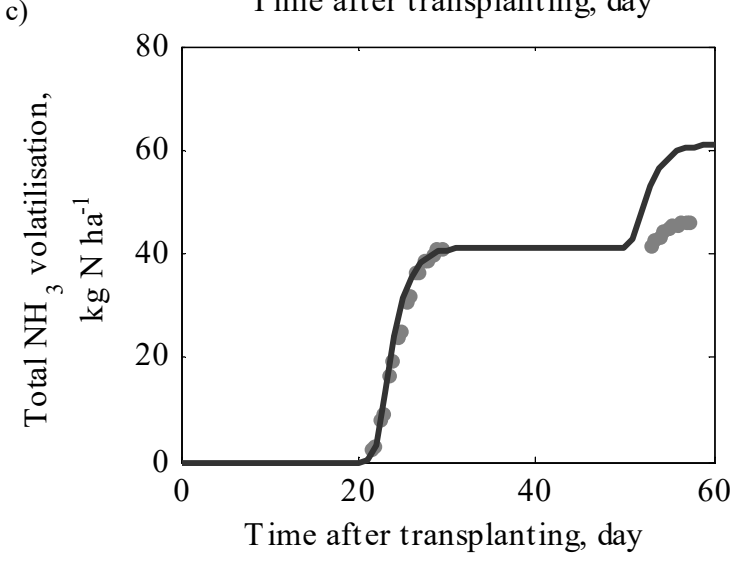

b)

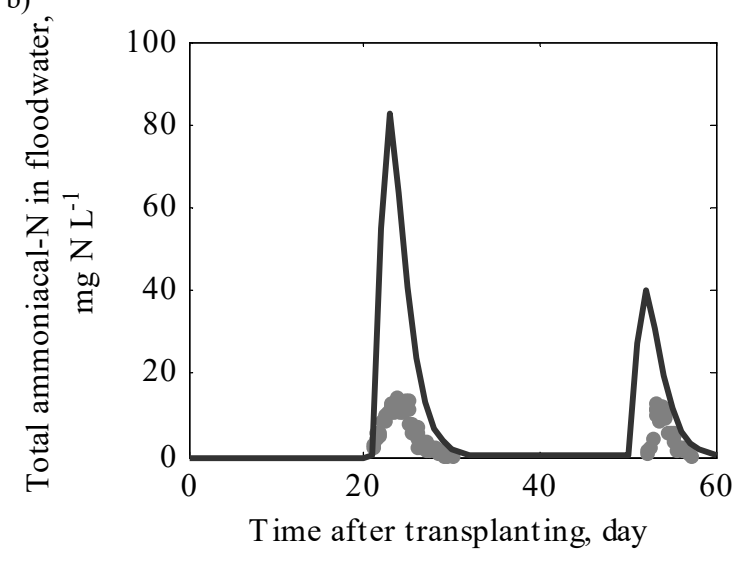

Fig. 8 Calibration of Chowdary et al. (2004)'s model concept with DSetM84: a) Concentration of urea- $\mathrm{N}$ in floodwater, b) concentration of total ammoniacal- $\mathrm{N}$ in floodwater, and c) cumulative $\mathrm{NH}_{3}$ volatilisation

\subsubsection{Sensitivity analysis of the proposed model}

A sensitivity analysis of the model based on an eigenvalue decomposition of the covariance matrix (Eq. D.1) will show which parameters or combination of parameters dominate the model outputs.

The eigenvalue decomposition of the covariance matrices calculated using DSetM84 (Supplement S1) showed that the proposed model is least sensitive to $K_{\text {sink }}$ and $K_{v}=$ $\left[K_{v A T}, K_{v P I}\right]$ because the corresponding eigenvalues and weights in the eigenvectors are the largest compared to that of other rate coefficients. However, the model is most sensitive to $\beta$ 
and a combination of $K_{h}$ and $K_{E}$ (see Keesman (2011) for details on this subject). $K_{h}$ regulates decay of urea-N concentration, while $K_{E}$ delays conversion of urea-N to ammoniacal-N. The parameter $\beta$ controls the steepness of the sigmoid curve, $S$, which regulates the total N sink. For DSetLB84, we obtained similar results (Supplement S1).

In addition to the sensitivity analysis of the parameters, we further investigated the effect of floodwater properties, such as floodwater $\mathrm{pH}$, temperature, and depth, on estimation of $\mathrm{NH}_{3}$ volatilisation. It appeared that $\mathrm{NH}_{3}$ volatilisation, is sensitive to changes in floodwater $\mathrm{pH}$ (Figs. 9a and b), and temperature (Figs. 9c and d). The estimated $\mathrm{NH}_{3}$ volatilisation is not sensitive to floodwater depth (Figs. 9e and f), because the floodwater compartment was conceptualised as a single homogenous compartment. This means that the observations and claims by Freney (1988), Hayashi (2006) and Win (2009) that the floodwater depth could regulate the rate of $\mathrm{NH}_{3}$ volatilisation, cannot be simulated and studied by models that assume a single homogeneous floodwater compartment as, for instance, in the proposed model and models by Chowdary et al. (2004), Antonopoulos (2010) and Liang et al. (2014). The floodwater depth would have an effect on the estimated $\mathrm{NH}_{3}$ volatilisation if the floodwater compartment was discretised into several homogeneous layers, but this would significantly increase the complexity of the model, and, thus, to potential over-parameterisation.

\subsection{Conclusion}

Relevant existing modelling concepts were integrated to develop a model, for the estimation of $\mathrm{NH}_{3}$ volatilisation in fertilised and flooded rice systems that is of appropriate complexity for small data sets. Two new concepts were introduced in the proposed model. First, the lumped $\mathrm{N}$ sink term avoids assumptions on soil $\mathrm{N}$ parameters beyond what can be identified from the limited observational data sets, and avoids detailed modelling of diffusion and percolation of N. Second, urea hydrolysis is typically approximated by first-order kinetics, but integration of model and observational data sets suggested that the process is better approximated by two-first order kinetics in series for flooded rice systems with low urease activity. The model was falsified by some data sets, but was also in good agreement with other data sets. Inadequate model structure may have led to the falsification of the model, but uncertainty in observations and in parameters could also have led to the falsification. Nevertheless, for the flooded rice systems in the Philippines, conceptualisation of the partitioning between ammonium and $\mathrm{NH}_{3}$ and a time-varying rate coefficient of $\mathrm{NH}_{3}$ 
volatilisation in the proposed model improved the prediction of the net $\mathrm{NH}_{3}$ volatilisation.

a)
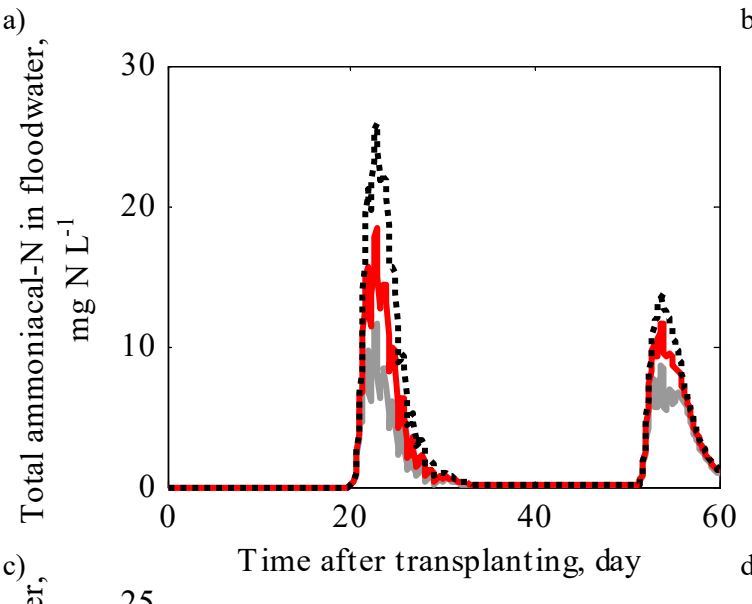

d)

b)
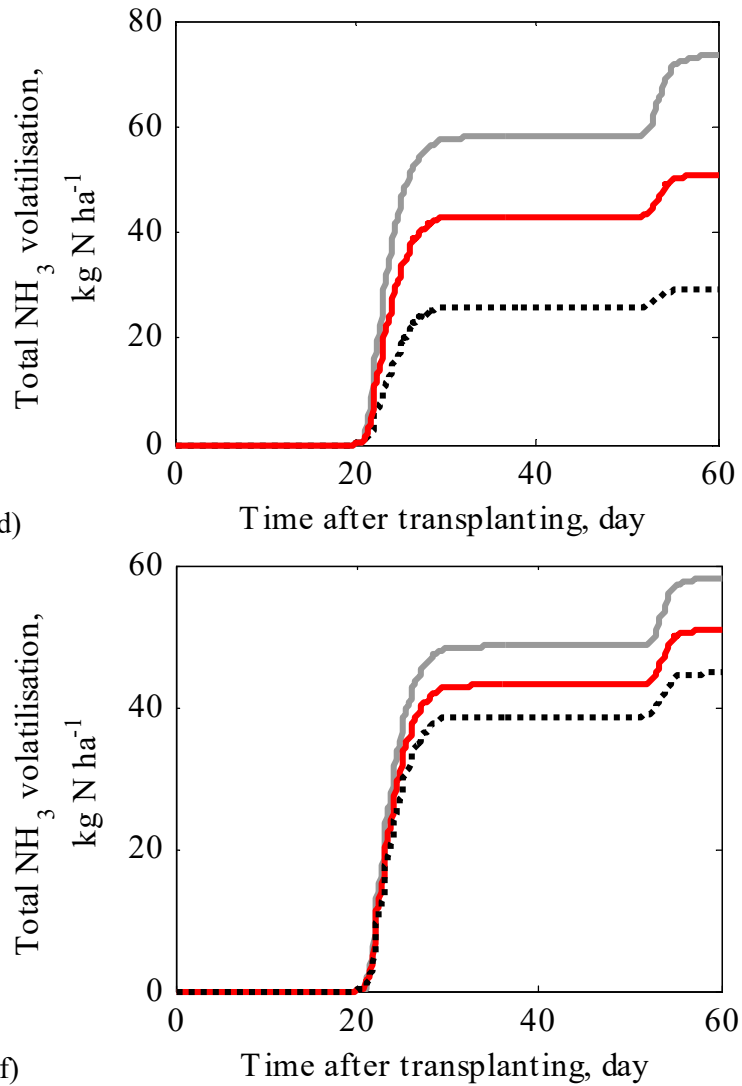

f)

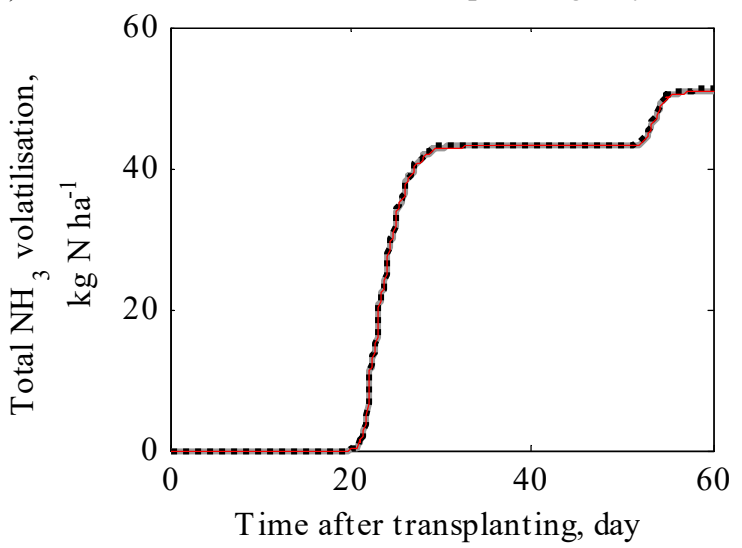

Fig. 9 Sensitivity analysis of model with respect to floodwater properties using values of coefficients obtained via simultaneous re-calibration for DSetM84 (Table 2, thin red line): a) concentration of total ammoniacal- $\mathrm{N}$, and b) cumulative $\mathrm{NH}_{3}$ volatilisation, when floodwater $\mathrm{pH}$ was increased by 0.5 unit (thick grey line) and reduced by 0.5 unit (black dotted line), c) concentration of total ammoniacal-N, and d) cumulative $\mathrm{NH}_{3}$ volatilisation, when floodwater temperature was increased by $5^{\circ} \mathrm{C}$ (thick grey line) and reduced by $5^{\circ} \mathrm{C}$ (black dotted line), and e) concentration of total ammoniacal- $\mathrm{N}$, and f) cumulative $\mathrm{NH}_{3}$ volatilisation, when floodwater depth was increased by $0.02 \mathrm{~m}$ (thick grey line) and reduced by $0.02 \mathrm{~m}$ (black dotted line) 
Calibration of unknown parameters even in a relatively simple model is challenging as available observational data sets are of poor quality in terms of errors in measurements, small number of (time-series) observations, and other relevant observations such as floodwater $\mathrm{pH}$ and temperature are rarely reported, and, therefore, a parameter estimation approach that considers all of these uncertainties is valuable for such systems.

\section{References}

Antonopoulos, V. Z. 2010. Modelling of water and nitrogen balances in the ponded water and soil profile of rice fields in Northern Greece. Agric Water Manag, 98, pp. 321-330

Bellocchi, G., Rivington, M., Donatelli, M. \& Matthews, K. 2010. Validation of biophysical models: Issues and methodologies. A review. Agron Sustain Dev, 30, pp. 109-130.

Bennett, N. D., Croke, B. F. W., Guariso, G., Guillaume, J. H. A., Hamilton, S. H., Jakeman, A. J., Marsili-Libelli, S., Newham, L. T. H., Norton, J. P., Perrin, C., Pierce, S. A., Robson, B., Seppelt, R., Voinov, A. A., Fath, B. D. \& Andreassian, V. 2013. Characterising performance of environmental models. Environ Model Softw, 40, pp. 120.

Bouwman, A. F., Boumans, L. J. M. \& Batjes, N. H. 2002. Estimation of global $\mathrm{NH}_{3}$ volatilization loss from synethetic fertilizers and animal manure applied to arable lands and grasslands. Glob Biogeochem Cycl, 16, pp. 8-1 - 8-14.

Bouwmeester, R. J. B. \& Vlek, P. L. G. 1981. Rate control of ammonia volatilization from rice paddies. Atmos Environ, 15, pp. 131-140.

Buresh, R. J., Reddy, K. R. \& Van Kessel, C. 2008. Nitrogen transformations in submerged soils. In: Schepers, J. S. \& Raun, W. R. (eds.) Nitrogen in Agricultural Systems. Madison: American Society of Agronomy, Crop Science Society of America, and Soil Science Society of America, pp. 401-436.

Cai, G.-X. 1997. Ammonia volatilization. In: Zhu, Z.-L., Wen, Q.-X. \& Freney, J. R. (eds.) Nitrogen in Soils of China. Netherlands: Springer pp. 193-213.

Cao, Y., Tian, Y., Yin, B. \& Zhu, Z. 2013. Assessment of ammonia volatilization from paddy fields under crop management practices aimed to increase grain yield and $\mathrm{N}$ efficiency. Field Crop Res, 147, pp. 23-31.

Cao, Z.-H., De Datta, S. K. \& Fillery, I. R. P. 1984. Nitrogen-15 balance and residual effects of urea-N in wetland rice fields as affected by deep placement techniques. Soil Sci Soc Am J, 48, pp. 203-208.

Cassman, K. G., Dobermann, A. \& Walters, D. T. 2002. Agroecosystems, nitrogen-use efficiency and nitrogen management. AMBIO: J Hum Environ, 31, pp. 132-140.

Cassman, K. G., Peng, S., Olk, D. C., Ladha, J. K., Reichardt, W., Dobermann, A. \& Singh, U. 1998. Opportunities for increased nitrogen-use efficiency from improved resource management in irrigated rice systems. Field Crop Res, 56, pp. 7-39.

Chen, A., Lei, B., Hu, W., Lu, Y., Mao, Y., Duan, Z. \& Shi, Z. 2015. Characteristics of ammonia volatilization on rice grown under different nitrogen application rates and its quantitative predictions in Erhai Lake Watershed, China. Nutr Cycl Agroecosyst, 101, pp. 139-152.

Chowdary, V. M., Rao, N. H. \& Sarma, P. B. S. 2004. A coupled soil water and nitrogen balance model for flooded rice fields in India. Agric Ecosyst Environ, 103, pp. $425-$ 441. 
Corales, A. M., Sibayan, E. B. \& Palis, F. G. 2015. Dissemination of natural resource management technology for irrigated rice in the Philippines: On-farm validation to national extension. Pertanika J Trop Agric Sci, 38, pp. 219-233.

Craswell, E. T., De Datta, S. K., Obcemea, W. N. \& Hartantyo, M. 1981. Time and mode of nitrogen fertilizer application to tropical wetland rice. Fert Res, 2, pp. 247-259.

De Datta, S. K., Samson, M. I., Obcemea, W. N., Real, J. G. \& Buresh, R. J. 1991. Direct measurement of ammonia and denitrification fluxes from urea applied to rice. Soil Sci Soc Am J, 55, pp. 543-548.

De Datta, S. K., Samson, M. I., Wang, K.-R. \& Buresh, R. J. 1988. Nitrogen use efficiency and nitrogen-15 balances in broadcast-seeded flooded and transplanted rice. Soil Sci Soc Am J, 52, pp. 849-855.

Dobermann, A., Gaunt, J. L., Neue, H. U., Grant, I. F., Adviento, M. A. \& Pampolino, M. F. 1994. Spatial and temporal variability of ammonium in flooded rice fields. Soil Sci Soc Am J, 58, pp. 1708-1717.

Fillery, I. R. P., Roger, P. A. \& De Datta, S. K. 1986. Ammonia volatilization from nitrogen sources applied to rice fields: II. Floodwater properties and submerged photosynthetic biomass. Soil Sci Soc Am J, 50, pp. 86-91.

Fillery, I. R. P., Simpson, J. R. \& De Datta, S. K. 1984. Influence of field environment and fertilizer management on ammonia loss from flooded rice. Soil Sci Soc Am J, 48, pp. 914-920.

Freney, J. R. \& Denmead, O. T. 1992. Factors controlling ammonia and nitrous oxide emissions from flooded rice fields. Ecological Bulletins, 42, pp. 188-194.

Freney, J. R., Denmead, O. T., Watanabe, I. \& Craswell, E. T. 1981. Ammonia and nitrous oxide losses following applications of ammonium sulfate to flooded rice. Aust J Agric Res, 32, pp. 37-45.

Freney, J. R., Trevitt, A. C. F., Muirhead, W. A., Denmead, O. T., Simpson, J. R. \& Obcemea, W. N. 1988. Effect of water depth on ammonia loss from lowland rice. Fert Res, 16, pp. 97-107.

Fujisaka, S. 1994. Learning from six reasons why farmers do not adopt innovations intended to improve sustainability of upland agriculture. Agric Syst, 46, pp. 409-425.

Gaydon, D. S., Probert, M. E., Buresh, R. J., Meinke, H. \& Timsina, J. 2012. Modelling the role of algae in rice crop nutrition and soil organic carbon maintenance. Eur J Agron, 39, pp. 35-43.

Godwin, D. C. \& Singh, U. 1998. Nitrogen balance and crop response to nitrogen in upland and lowland cropping systems. In: Tsuji, G. Y., Hoogenboom, G. \& Thornton, P. K. (eds.) Understanding Options for Agricultural Production. Springer Netherlands, pp. 55-77.

Hayashi, K., Nishimura, S. \& Yagi, K. 2006. Ammonia volatilization from the surface of a Japanese paddy field during rice cultivation Soil Sci Plant Nutr, 52, pp. 545-555.

Jakeman, A. J., Letcher, R. A. \& Norton, J. P. 2006. Ten iterative steps in development and evaluation of environmental models. Environ Model Softw, 21, pp. 602-614.

Jayaweera, G. R. \& Mikkelsen, D. S. 1990. Ammonia volatilization from flooded soil systems: A computer model. I. Theoretical aspects. Soil Sci Soc Am J, 54, pp. 14471455.

Jayaweera, G. R. \& Mikkelsen, D. S. 1991. Assessment of ammonia volatilization from flooded soil systems. In: Brady, N. C. (ed.) Advances in Agronomy. San Diego: Academic Press, pp. 303-356.

Jing, Q., Van Keulen, H. \& Hengsdijk, H. 2010. Modeling biomass, nitrogen and water dynamics in rice-wheat rotations. Agric Syst, 103, pp. 433-443

Keesman, K. J. 2011. System Identification: An Introduction. Springer UK. 
Kirk, G. J. D. \& Solivas, J. L. 1997. On the extent to which root properties and transport through the soil limit nitrogen uptake by lowland rice. Eur J Soil Sci, 48, pp. 613-621.

Li, H., Liang, X., Chen, Y., Tian, G. \& Zhang, Z. 2008. Ammonia volatilization from urea in rice fields with zero-drainage water management. Agric Water Manag, 95, pp. 887894.

Liang, X., Yuan, J., He, M., Li, H., Liang, L. \& Tian, G. 2014. Modeling the fate of fertilizer $\mathrm{N}$ in paddy rice systems receiving manure and urea. Geoderma, 228-229, pp. 54-61.

Liang, X. Q., Chen, Y. X., Li, H., Tian, G. M., Ni, W. Z., He, M. M. \& Zhang, Z. J. 2007. Modelling transport and fate of nitrogen from urea applied to a near-trench paddy field. Environ Pollut, 150, pp. 313-320.

Liu, T. Q., Fan, D. J., Zhang, X. X., Chen, J., Li, C. F. \& Cao, C. G. 2015. Deep placement of nitrogen fertilizers reduces ammonia volatilization and increases nitrogen utilization efficiency in no-tillage paddy fields in central China. Field Crop Res, 184, pp. 80-90.

Makarim, A. K., Hidayat, A. \& Ten Berge, H. F. M. 1991. Dynamics of soil ammonium, crop nitrogen uptake and dry matter production in lowland rice. In: De Vries, P., ed. Simulation and System Analysis for Rice Production (SARP), Wageningen. PUDOC, 214-228.

Ni, K., Köster, J. R., Seidel, A. \& Pacholski, A. 2015. Field measurement of ammonia emissions after nitrogen fertilization - A comparison between micrometeorological and chamber methods. Eur J Agron, 71, pp. 115-122.

Rao, P. S. C., Jessup, R. E. \& Reddy, K. R. 1984. Simulation of nitrogen dynamics in flooded soils. Soil Sci, 138, pp. 54-62.

Reddy, K. R., Rao, P. S. C. \& Jessup, R. E. 1990. Transformation and transport of ammonium nitrogen in a flooded organic soil. Ecol Model, 51, pp. 205-216.

Singh, R. \& Kirk, G. J. D. 1993. A model for predicting the fate of nitrogen fertilizer in lowland ricefields. I. Theory. J Soil Sci, 44, pp. 271-283.

Soares, J. R., Cantarella, H. \& Menegale, M. L. D. C. 2012. Ammonia volatilization losses from surface-applied urea with urease and nitrification inhibitors. Soil Biol Biochem, 52, pp. 82-89.

Sommer, S. G., Schjoerring, J. K. \& Denmead, O. T. 2004. Ammonia emission from mineral fertilizers and fertilized crops. Advances in Agronomy. Academic Press, pp. 557-622.

Vlek, P. L. G., Byrnes, B. H. \& Craswell, E. T. 1980. Effect of urea placement on leaching losses of nitrogen from flooded rice soils. Plant Soil, 54, pp. 441-449.

Win, K. T., Toyota, K., Motobayashi, T. \& Hosomi, M. 2009. Suppression of ammonia volatilization from a paddy soil fertilized with anaerobically digested cattle slurry by wood vinegar application and floodwater management. Soil Sci Plant Nutr, 55, pp. 190-202.

Xu, J., Peng, S., Yang, S. \& Wang, W. 2012. Ammonia volatilization losses from a rice paddy with different irrigation and nitrogen managements. Agric Water Manag, 104, pp. 184-192.

Young, P. C. 1978. A general theory of modeling for badly defined systems. In: Vansteenkiste, G. C. (ed.) Modeling, Identification and Control in Environmental Systems. Amsterdam: North Holland, pp. 103-135.

Zhou, F., Ciais, P., Hayashi, K., Galloway, J., Kim, D.-G., Yang, C., Li, S., Liu, B., Shang, Z. \& Gao, S. 2016. Re-estimating $\mathrm{NH}_{3}$ emissions from Chinese cropland by a new nonlinear model. Environ Sci Technol, 50, pp. 564-572. 


\section{Appendix A. Derivation of Eq. 2}

The derivation of the mass balance of urea- $\mathrm{N}$ in the floodwater starts with,

$\frac{d\left[U^{w}\right] V}{d t}=+A U^{s}-K_{h} V\left[U^{w}\right]-\widetilde{Q} A\left[U^{w}\right]$

where,,$U^{S}$ is rate of urea-N applied $\left(\mathrm{kg} \mathrm{m}^{-2}\right.$ day $\left.^{-1}\right),\left[U^{w}\right]$ is concentration of urea in floodwater $\left(\mathrm{kg} \mathrm{m}^{-3}\right), K_{h}$ is urea hydrolysis rate coefficient $\left(\right.$ day $\left.^{-1}\right)$, and $\widetilde{Q}$ is floodwater loss (m day $^{-1}$ ) due to surface runoff and percolation. $V=A X^{w}$ is volume of floodwater per the land area $\left(\mathrm{m}^{3}\right)$, where, $A$ is land area $\left(\mathrm{m}^{2}\right)$, and $X^{w}$ is floodwater depth $(\mathrm{m})$.

Note that $\frac{d\left[U^{w}\right] V}{d t}=+\left[U^{w}\right] \frac{d V}{d t}+V \frac{d\left[U^{w}\right]}{d t}$

The water balance in the floodwater is given by

$\frac{d V}{d t}=\frac{d X^{w}}{d t} \mathrm{~A}=+R A+I A-E T A-\tilde{Q} A$

where, $R$ is rainfall $\left(\mathrm{m} \mathrm{day}^{-1}\right), I$ is irrigation $\left(\mathrm{m} \mathrm{day}^{-1}\right), E T$ is evapotranspiration $\left(\mathrm{m} \mathrm{day}^{-1}\right)$, and $\widetilde{Q}$ is floodwater loss $\left(\mathrm{m} \mathrm{day}^{-1}\right)$ due to surface runoff and percolation. Equate Eq. A.2 to Eq.

A.1 as follows

$$
\begin{aligned}
& +\left[U^{w}\right] \frac{d V}{d t}+V \frac{d\left[U^{w}\right]}{d t}=+A U^{s}-K_{h} V\left[U^{w}\right]-\tilde{Q} A\left[U^{w}\right] \\
& \frac{d\left[U^{w}\right]}{d t}=\frac{1}{V}\left(+A U^{s}-K_{h} V\left[U^{w}\right]-\tilde{Q} A\left[U^{w}\right]-\left[U^{w}\right] \frac{d V}{d t}\right)
\end{aligned}
$$

Substitute Eq. A.3 into Eq. A.4

$\frac{d\left[U^{w}\right]}{d t}=\frac{1}{V}\left(+A U^{s}-K_{h} V\left[U^{w}\right]-\tilde{Q} A\left[U^{w}\right]+\left[U^{w}\right]\{-R A-I A+E T A+\tilde{Q} A\}\right)$

Note that $X^{w}=V / A(\mathrm{~m})$, and thus,

$\frac{d\left[U^{w}\right]}{d t}=\frac{1}{X^{w}}\left(+U^{s}-K_{h} X^{w}\left[U^{w}\right]+\left[U^{w}\right]\{-R-I+E T\}\right)$ which gives us Eq. 2 


\section{Appendix B. The model input data presented in this study}

The model input data used in this study is presented in Fig. B.

a)

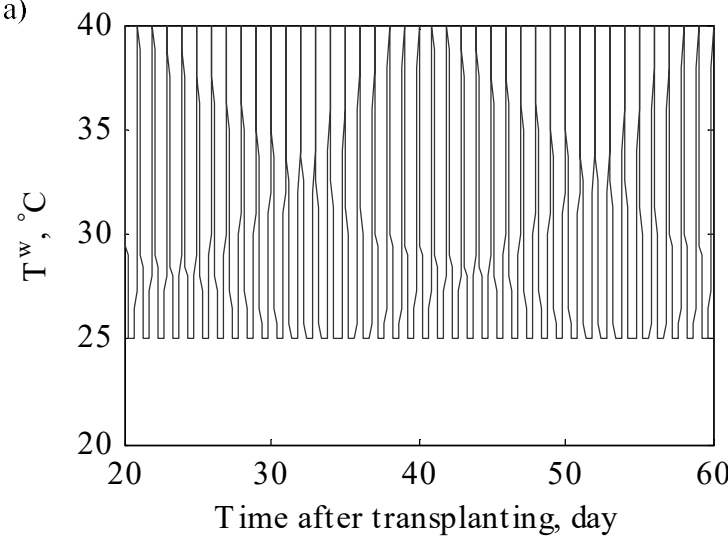

c)

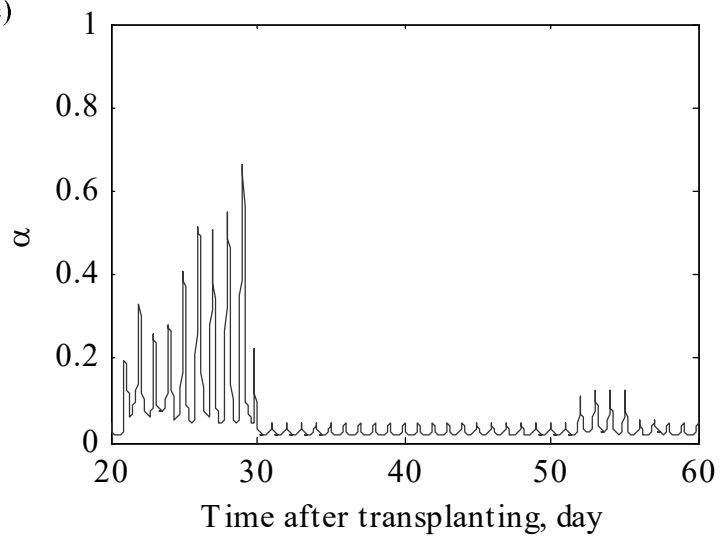

b)

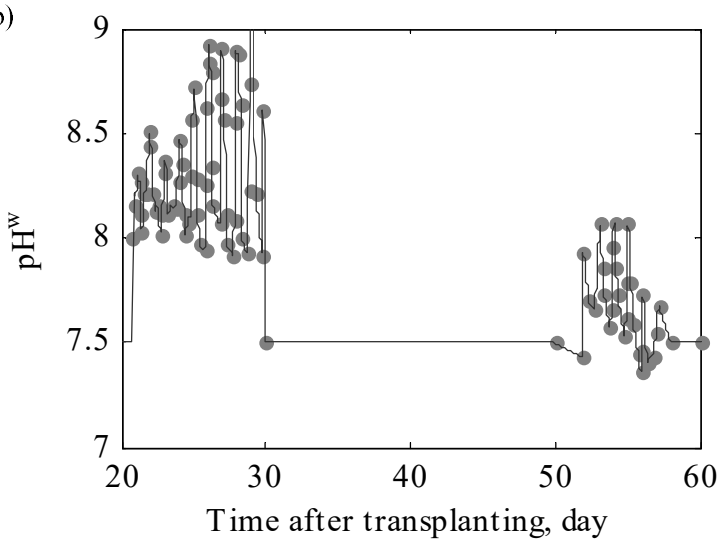

Fig. B.1 Model input data for DSetM84: a) Synthetic floodwater temperature, b) observed (dot) and interpolated (solid line) floodwater $\mathrm{pH}$, and c) calculated fraction of $\mathrm{NH}_{3}$ from total ammoniacal-N in floodwater 
a)
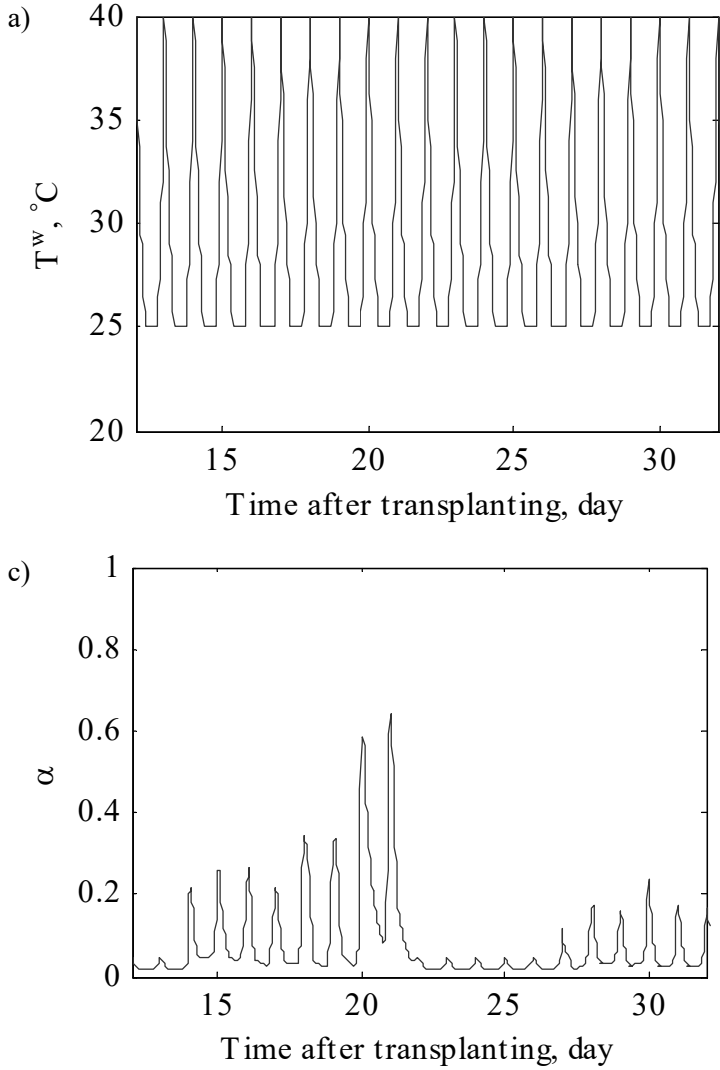

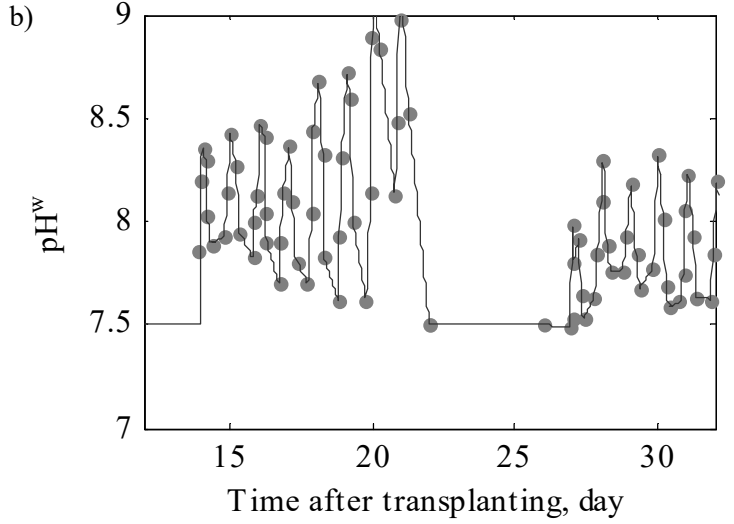

Fig. B.2 Model input data for DSetLB84: a) Synthetic floodwater temperature, b) observed (dot) and interpolated (solid line) floodwater $\mathrm{pH}$, and c) calculated fraction of $\mathrm{NH}_{3}$ from total ammoniacal-N in floodwater 

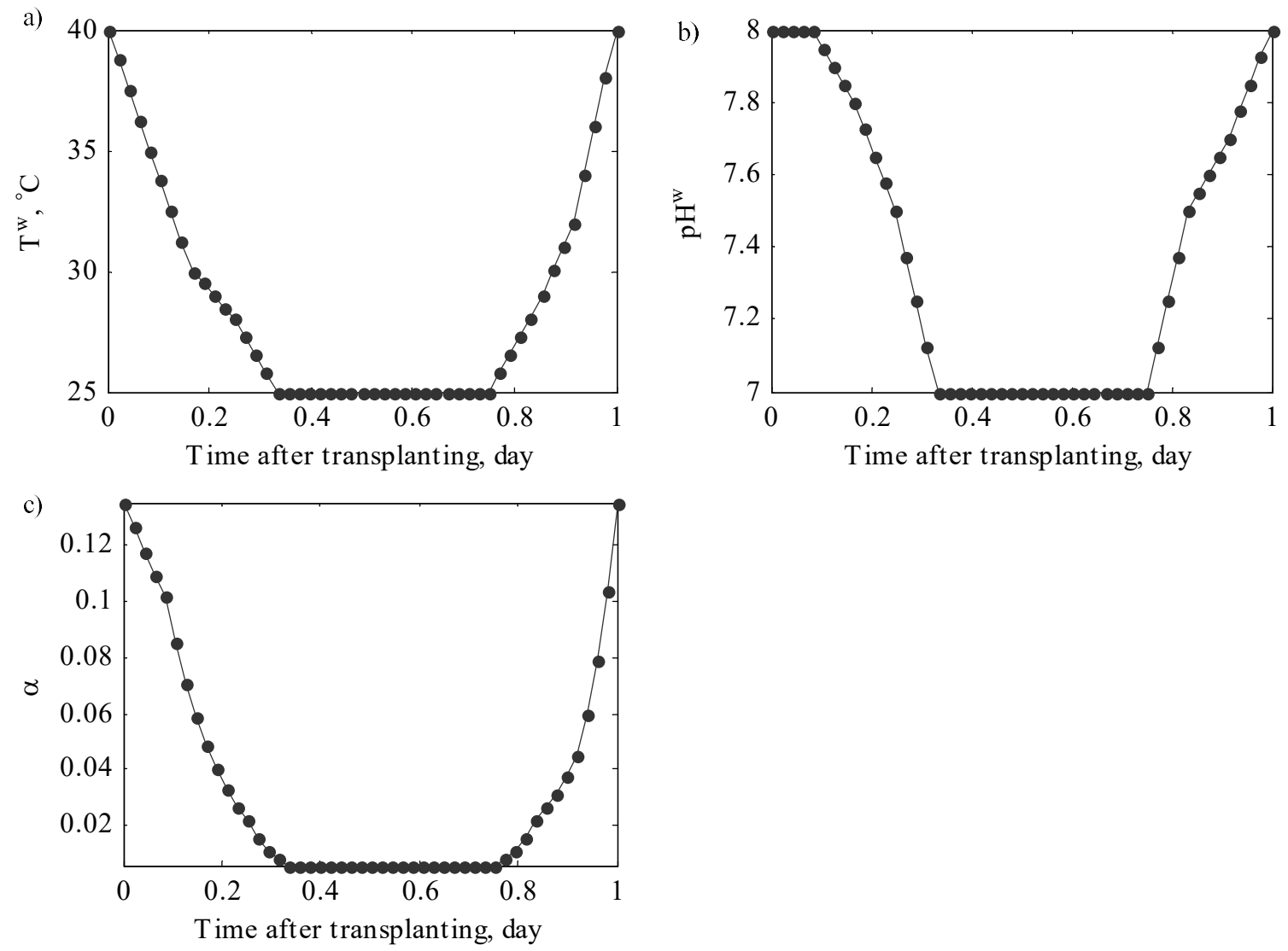

Fig. B.3 Model input data for DSetYH, DSetJX and DSetCS in one day: a) Synthetic floodwater temperature, b) synthetic floodwater $\mathrm{pH}$, and c) calculated fraction of $\mathrm{NH}_{3}$ from total ammoniacal-N in floodwater. The same trends repeat on each day throughout the simulation. 


\section{Appendix C. The model of Chowdary et al. (2004)}

Modelling concepts of the floodwater $\mathrm{N}$ dynamics described by Chowdary et al. (2004) were reproduced as sets of differential equations, and solved using the ode 45 function in MATLAB.

$\frac{d\left[U^{w}\right]}{d t}=+K_{h}\left[U^{w}\right]+\frac{U^{s}}{10000 X}$

where, $\left[U^{w}\right]$ is concentration of urea-N in the floodwater $\left(\mathrm{kg} \mathrm{N} \mathrm{m}^{-3}\right), U^{s}$ is rate of urea-N applied in the floodwater ( $\mathrm{kg} \mathrm{N} \mathrm{ha}^{-1}$ day), $K_{h}$ is rate coefficient of urea hydrolysis $\left(\right.$ day $\left.^{-1}\right)$, and $X^{w}$ is floodwater depth (m).

$\frac{d\left[N^{w}\right]}{d t}=+K_{h}\left[U^{w}\right]-\frac{D P}{X^{w}}\left[N^{w}\right]-K_{v}\left[N^{w}\right]-K_{n}\left[N^{w}\right]$

where, $\left[N^{w}\right]$ is concentration of total ammoniacal-N in the floodwater $\left(\mathrm{kg} \mathrm{N} \mathrm{m}^{-3}\right), D P$ is percolation rate $\left(\mathrm{m} \mathrm{day}^{-1}\right), K_{v}$ is rate coefficient of $\mathrm{NH}_{3}$ volatilisation $\left(\right.$ day $\left.^{-1}\right)$, and $K_{n}$ is rate coefficient of nitrification $\left(\right.$ day $\left.^{-1}\right)$.

$\frac{d\left[\mathrm{NO}_{3}^{-}\right]}{d t}=+K_{n}\left[N^{w}\right]-\frac{D P}{X^{w}}\left[N O_{3}^{-}\right]$

where, $\left[\mathrm{NO}_{3}^{-}\right]$is concentration of $\mathrm{NO}_{3}{ }^{-}$in the floodwater $\left(\mathrm{kg} \mathrm{N} \mathrm{m}^{-3}\right)$.

This model (Eqs. C.1 to C.3) was simulated with a daily time interval. 


\section{Appendix D. The sensitivity matrix}

The sensitivity matrix $X(\hat{\theta})$ is defined by

$$
X(\hat{\theta}):=\left[\begin{array}{ccccc}
\frac{\Delta \hat{y}_{1}\left(t_{1}, \widehat{\theta}\right)}{\Delta K_{h}} & \frac{\Delta \hat{y}_{1}\left(t_{1}, \widehat{\theta}\right)}{\Delta K_{E}} & \frac{\Delta \hat{y}_{1}\left(t_{1}, \widehat{\theta}\right)}{\Delta K_{\operatorname{sink}}} & \frac{\Delta \hat{y}_{1}\left(t_{1}, \widehat{\theta}\right)}{\Delta \beta} & \frac{\Delta \hat{y}_{1}\left(t_{1}, \widehat{\theta}\right)}{\Delta K_{v}} \\
\vdots & \vdots & \vdots & \vdots & \vdots \\
\frac{\Delta \hat{y}_{1}\left(t_{N}, \widehat{\theta}\right)}{\Delta K_{h}} & \frac{\Delta \hat{y}_{1}\left(t_{N}, \widehat{\theta}\right)}{\Delta K_{E}} & \frac{\Delta \hat{y}_{1}\left(t_{N}, \widehat{\theta}\right)}{\Delta K_{\operatorname{sink}}} & \frac{\Delta \hat{y}_{1}\left(t_{N}, \widehat{\theta}\right)}{\Delta \beta} & \frac{\Delta \hat{y}_{1}\left(t_{N}, \widehat{\theta}\right)}{\Delta K_{v}} \\
\frac{\Delta \hat{y}_{2}\left(t_{1}, \widehat{\theta}\right)}{\Delta K_{h}} & \frac{\Delta \hat{y}_{2}\left(t_{1}, \widehat{\theta}\right)}{\Delta K_{E}} & \frac{\Delta \hat{y}_{2}\left(t_{1}, \widehat{\theta}\right)}{\Delta K_{\operatorname{sink}}} & \frac{\Delta \hat{y}_{2}\left(t_{1}, \widehat{\theta}\right)}{\Delta \beta} & \frac{\Delta \hat{y}_{2}\left(t_{1}, \widehat{\theta}\right)}{\Delta K_{v}} \\
\vdots & \vdots & \vdots & \vdots & \vdots \\
\frac{\Delta \hat{y}_{2}\left(t_{N}, \widehat{\theta}\right)}{\Delta K_{h}} & \frac{\Delta \hat{y}_{2}\left(t_{N}, \widehat{\theta}\right)}{\Delta K_{E}} & \frac{\Delta \hat{y}_{2}\left(t_{N}, \widehat{\theta}\right)}{\Delta K_{\operatorname{sink}}} & \frac{\Delta \hat{y}_{2}\left(t_{N}, \widehat{\theta}\right)}{\Delta \beta} & \frac{\Delta \hat{y}_{2}\left(t_{N}, \widehat{\theta}\right)}{\Delta K_{v}} \\
\frac{\Delta \hat{y}_{3}\left(t_{1}, \widehat{\theta}\right)}{\Delta K_{h}} & \frac{\Delta \hat{y}_{3}\left(t_{1}, \widehat{\theta}\right)}{\Delta K_{E}} & \frac{\Delta \hat{y}_{3}\left(t_{1}, \widehat{\theta}\right)}{\Delta K_{\operatorname{sink}}} & \frac{\Delta \hat{y}_{3}\left(t_{1}, \widehat{\theta}\right)}{\Delta \beta} & \frac{\Delta \hat{y}_{3}\left(t_{1}, \widehat{\theta}\right)}{\Delta K_{v}} \\
\vdots & \vdots & \vdots & \vdots & \vdots \\
\frac{\Delta \hat{y}_{3}\left(t_{N}, \widehat{\theta}\right)}{\Delta K_{h}} & \frac{\Delta \hat{y}_{3}\left(t_{N}, \widehat{\theta}\right)}{\Delta K_{E}} & \frac{\Delta \hat{y}_{3}\left(t_{N}, \widehat{\theta}\right)}{\Delta K_{\operatorname{sink}}} & \frac{\Delta \hat{y}_{3}\left(t_{N}, \widehat{\theta}\right)}{\Delta \beta} & \frac{\Delta \hat{y}_{3}\left(t_{N}, \widehat{\theta}\right)}{\Delta K_{v}}
\end{array}\right]
$$

where, $\hat{y}_{1}=\left[U^{w}\right]$ (Eq. 2), $\hat{y}_{2}=\left[N^{w}\right]$ (Eq. 9), and $\hat{y}_{3}=N H_{3}^{g}$ (Eq. 4), and $N$ is number of model output evaluations. 


\section{Supplement S1. Eigenvalues and eigenvectors}

\section{DSetM84}

In the following, the estimation covariance matrix and the corresponding eigenvalue decomposition for DSetM84 are presented. The covariance matrix of the estimated rate coefficients $\left(K_{h}, K_{E}, K_{\text {sink }}, \beta, K_{v}\right)$ is given by

$\operatorname{Cov} \hat{\theta}=\sigma_{\varepsilon}^{2}\left(X(\hat{\theta})^{T} W X(\hat{\theta})\right)^{-1}$

with $X(\hat{\theta})$ defined by Eq. D.1, $W$ a weighting matrix, and $\sigma_{\varepsilon}^{2}$ the estimated variance of residuals. The weighting matrix is a diagonal matrix with elements inversely proportional to the corresponding variances of the residuals. For details see (Keesman, 2011). The estimation variance of an individual rate coefficient $(\hat{\theta})$ is found from the corresponding $i$ th diagonal element of $\operatorname{Cov} \hat{\theta}$, which is given by

$\operatorname{Cov} \hat{\theta}=\left[\begin{array}{ccccc}0.1123 & -0.0322 & 0.2116 & -0.0078 & 0.3312 \\ -0.0322 & 0.0793 & 0.1551 & -0.0015 & -0.2140 \\ 0.2116 & 0.1551 & 2.3753 & -0.0758 & 2.9858 \\ -0.0078 & -0.0015 & -0.0758 & 0.0047 & -0.0381 \\ 0.3312 & -0.2140 & 2.9858 & -0.0381 & 14.8770\end{array}\right]$

For further interpretation, we define the eigenvalue decomposition $\operatorname{Cov} \hat{\theta}$ as

$\operatorname{Cov} \hat{\theta}:=V \Lambda V^{T}$

where, the corresponding eigenvalues (diagonal of $\Lambda$ ) are given by

$\operatorname{diag}(\Lambda)=\left[\begin{array}{lllll}15.5645 & 1.7355 & 0.1215 & 0.0259 & 0.0012\end{array}\right]^{T}$

and, the corresponding eigenvectors are given by

$$
V=\left[\begin{array}{ccccc}
-0.0239 & 0.0789 & \mathbf{0 . 8 3 6 9} & \mathbf{- 0 . 5 3 8 1} & -0.0572 \\
0.0113 & 0.1172 & \mathbf{- 0 . 5 4 5 7} & \mathbf{- 0 . 8 1 5 8} & -0.1513 \\
-0.2210 & \mathbf{0 . 9 6 4 6} & -0.0092 & 0.1306 & 0.0594 \\
0.0035 & -0.0379 & -0.0349 & -0.1647 & \mathbf{0 . 9 8 5 0} \\
\mathbf{- 0 . 9 7 4 9} & -0.2194 & -0.0249 & -0.0264 & -0.0103
\end{array}\right]
$$

Each element of vector $\operatorname{diag}(\Lambda)$ is related to a corresponding column of matrix $V$. Each column in matrix $V$ contains weighting factors related to a rate coefficient, in the following order: $K_{h}, K_{\mathrm{E}}, K_{\text {sink }}, \beta$, and $K_{v}$. 


\section{DSetLB84}

The estimation covariance matrix with corresponding eigenvalue decomposition for DSetLB84 are given by

The covariance matrix is given by

$$
\operatorname{Cov} \hat{\theta}=\left[\begin{array}{ccccc}
0.0404 & -0.0213 & 0.0473 & -0.0060 & -0.0095 \\
-0.0213 & 0.0312 & 0.0036 & 0.0031 & 0.0323 \\
0.0473 & 0.0036 & 0.4245 & -0.0296 & 0.1871 \\
-0.0060 & 0.0031 & -0.0296 & 0.0027 & -0.0017 \\
-0.0095 & 0.0323 & 0.1871 & -0.0017 & 0.6973
\end{array}\right]
$$

where, the corresponding eigenvalues (diagonal of $\Lambda$ ) are given by

$$
\operatorname{diag}(\Lambda)=\left[\begin{array}{lllll}
0.7941 & 0.3394 & 0.0511 & 0.0113 & 0.0001
\end{array}\right]^{T}
$$

and, the corresponding eigenvectors are given by

$$
V=\left[\begin{array}{ccccc}
-0.0164 & 0.1575 & \mathbf{0 . 7 2 1 7} & \mathbf{- 0 . 6 7 3 7} & 0.0092 \\
-0.0393 & -0.0484 & \mathbf{- 0 . 6 7 2 6} & \mathbf{- 0 . 7 3 2 0} & -0.0888 \\
-0.4543 & \mathbf{0 . 8 7 4 7} & -0.1302 & 0.0770 & 0.0749 \\
0.0189 & -0.0778 & -0.0559 & -0.0649 & \mathbf{0 . 9 9 3 1} \\
\mathbf{0 . 8 8 9 6} & -0.4491 & 0.0817 & 0.0040 & -0.0134
\end{array}\right]
$$

Each element of vector $\operatorname{diag}(\Lambda)$ is related to a column of matrix $V$. Each column in matrix $V$ contains weighting factors related to a rate coefficient, in the following order: $K_{h}, K_{\mathrm{E}}, K_{\text {sink }}, \beta$, and $K_{v}$. 
CHAPTER 5

Set-membership estimation from poor quality data sets: Modelling ammonia volatilisation in flooded rice systems

\begin{abstract}
K. Nurulhuda ${ }^{1,2}$, P.C. Struik ${ }^{3}$, and K.J. Keesman ${ }^{2}$
${ }^{1}$ Biological and Agricultural Engineering, Universiti Putra Malaysia, Malaysia

${ }^{2}$ Biobased Chemistry and Technology, Wageningen University, The Netherlands

${ }^{3}$ Centre for Crop Systems Analysis, Wageningen University, The Netherlands
\end{abstract}

This chapter has been published in

Environmental Modelling \& Software 88 (2017) pp. 138-150 


\begin{abstract}
A set-membership (bounded-error) estimation approach can handle small and poor quality data sets as it does not require testing of statistical assumptions which is possible only with large informative data sets. Thus, set-membership estimation can be a good tool in the modelling of agri-environmental systems, which typically suffers from limited and poor quality observational data sets. The objectives of the chapter are (i) to demonstrate how six parameters in an agri-environmental model, developed to estimate $\mathrm{NH}_{3}$ volatilisation in flooded rice systems, were estimated based on two data sets using a setmembership approach, and (ii) to compare the set-membership approach with conventional non-linear least-squares methods. Results showed that the set-membership approach is efficient in retrieving feasible parameter-vectors compared with non-linear least-squares methods. The set of feasible parameter-vectors allows the formation of a dispersion matrix of which the eigenvalue decomposition reflects the parameter sensitivity in a region.
\end{abstract}

Keywords: Set-membership approach, bounded-error, parameter estimation, uncertainty analysis, model calibration, ammonia volatilization, flooded rice 


\subsection{Introduction}

Nitrogen $(\mathrm{N})$ deficiency results in severe yield reduction, and, thus, $\mathrm{N}$ is considered as one of the most important nutrients for rice crops (Makino, 2011). However, about $20 \%$ of the 11.8 million tons of $\mathrm{N}$ yearly applied in flooded rice systems globally was estimated to be lost via ammonia $\left(\mathrm{NH}_{3}\right)$ volatilisation (Bouwman et al., 2002). In the process of making $\mathrm{N}$ fertilisers, about 875 cubic metres of natural gas are used in producing one metric tonne of $\mathrm{NH}_{3}$ (Zuberer, 2005). Therefore, $\mathrm{NH}_{3}$ volatilisation is a waste of natural resource. $\mathrm{NH}_{3}$ volatilisation also has negative effects on the environment, and is recently claimed by Stokstad (2014) as a concern for public health.

In order to minimise $\mathrm{NH}_{3}$ volatilisation in fertilised and flooded rice systems, a number of models have been developed to study the mechanism of $\mathrm{NH}_{3}$ volatilisation, or have been used as an integrated decision making tool for management of the systems (Rao et al., 1984, Jayaweera and Mikkelsen, 1990, Singh and Kirk, 1993, Godwin and Singh, 1998, Chowdary et al., 2004, Antonopoulos, 2010). Many of these models comprise a number of parameters that need to be estimated from observational data sets.

Thus, applying an appropriate parameter estimation technique is important in developing models. For specific application to environmental models we refer to, for instance, Beck ( 2002), Jakeman et al. (2006), Wang and Garnier (2012), and Marsili-Libelli (2016). Numerous experiments have been conducted in flooded rice systems to measure $\mathrm{NH}_{3}$ volatilisation and its regulating process variables, such as wind speed, floodwater $\mathrm{pH}$ and temperature over time (Fillery et al., 1984, Fillery et al., 1986, De Datta et al., 1991, Chen et al., 2015). However, from the perspective of probabilistic parameter estimation, these time series are considered small. Estimation of the parameters may also be hampered by interactive $\mathrm{N}$ processes, leading to strongly correlated parameter estimates. Probabilistic parameter estimation approaches are not adequate for small and poor quality data sets, as these do not allow a detailed error characterisation in terms of probability density functions and correlations (Keesman, 1990, Walter and Piet-Lahanier, 1990).

Alternatively, parameters can be estimated using a set-membership (bounded-error) approach. Unlike the classical methods, which result in an optimal parameter-vector, the setmembership approach with its bounded-error characterisation aims to find equally acceptable parameter-vectors, represented by a so-called feasible parameter-vector set (FPS) (Schweppe, 
1968, Belforte and Milanese, 1981, Norton, 1987, Walter and Piet-Lahanier, 1990, Norton, 1994, Milanese et al., 1996). Another advantage is that the approach avoids any assumptions beyond the structure of the model and the output error-bounds (Keesman and Van Straten, 1990). The set-membership approach has recently been used for applications other than environmental systems (Amairi, 2015, Cerone et al., 2015). However, for the set-membership estimation of parameters in environmental models we refer to Keesman (1990), Keesman and Van Straten (1990), Milanese and Novara (2004), Mocenni and Vicino (2006), Keesman et al. (2013), and Nurulhuda et al. (2015).

The objective of the chapter is to demonstrate how six parameters in an agri-environmental model, developed to estimate $\mathrm{NH}_{3}$ volatilisation in flooded rice systems, can be estimated based on two data sets from two different locations, using a sampling-based set-membership approach, and to compare the approach with conventional non-linear least-squares methods. In the following section, a procedure for set-membership estimation and a description of the model are given.

\subsection{Background}

\subsubsection{Non-linear set-membership parameter estimation}

In this study, the starting point was the general non-linear parametrised model

$\boldsymbol{y}=\boldsymbol{F}(\boldsymbol{\vartheta})+\boldsymbol{e}$

where, $\boldsymbol{y}$ is a vector of $N$ samples of observed outputs of the system, $\boldsymbol{F}(\boldsymbol{\vartheta})$ consists of the corresponding output samples from an underlying (possibly non-linear, spatially distributed, dynamic) simulation model, and $\boldsymbol{e}$ is the $N$-dimensional error vector. In our application, as described in Sections 5.2.2 (model) and 5.3.1 (data), we have time series of three observed system outputs. Consequently, in this case and in terms of the model structure (1), $\boldsymbol{y}$ is an $\mathrm{N}$ dimensional vector of the time series stacked on top of each other. Furthermore, the parametrised model (Eq. 1) is non-linear in the $p$-dimensional parameter-vector $\boldsymbol{\vartheta}$.

The set-membership framework takes the $N$-dimensional prediction error vector $\boldsymbol{e}$ to be bounded within a specified range. In what follows, $\boldsymbol{e}$ is assumed to have the same bounds (symmetric to about zero for convenience) over each element $e_{k}$. This amounts to bounding the infinity norm, i.e., the largest absolute value of $e_{k}$ for $k=1, \ldots, N$ : 


$$
\|e\|_{\infty} \leq \varepsilon
$$

where $\varepsilon$ is a fixed positive number. This error characterisation leads to the hypercubic acceptable-error set

$\Omega_{e}:=\left\{\boldsymbol{e} \in \mathbb{R}^{N}:\|\boldsymbol{e}\|_{\infty} \leq \varepsilon\right\}$

Note that the set-membership concept also allows bounding in other norms and of other aspects of model behaviour, see e.g., Young et al. (1978) and Keesman (1989). The related measurement uncertainty set, containing all model-output vector values $\overline{\boldsymbol{y}}$ consistent with the observations $\boldsymbol{y}$ and with Eq. 2, is defined as

$\Omega_{\bar{y}}:=\left\{\overline{\boldsymbol{y}} \in \mathbb{R}^{N}:\|\boldsymbol{y}-\overline{\boldsymbol{y}}\|_{\infty} \leq \varepsilon\right\}$

This set also is a hypercube, but now centred around $\boldsymbol{y}$. The feasible parameter-vector set (FPS) is given by

$\Omega_{\vartheta}:=\left\{\boldsymbol{\vartheta} \in \mathbb{R}^{p}:\|\boldsymbol{y}-\boldsymbol{F}(\boldsymbol{\vartheta})\|_{\infty} \leq \varepsilon\right\}$

The set-membership estimation problem is to further characterise the FPS, given the model (Eq. 1), the observed data $\boldsymbol{y}$ and the output error-bounds (Eq. 2), without any assumption of a uniform or any other distribution between the bounds.

The image set of the entire parameter-space is defined as

$\Omega_{\tilde{y}}:=\left\{\widetilde{\boldsymbol{y}} \in \mathbb{R}^{N}: \widetilde{\boldsymbol{y}}=\boldsymbol{F}(\boldsymbol{\vartheta}) ; \boldsymbol{\vartheta} \in \mathbb{R}^{p}\right\}$

This comprises all responses that can be produced by the model. The image set of the FPS, the unfalsified (feasible) model-output set, is given by

$\Omega_{\hat{y}}:=\left\{\widehat{\boldsymbol{y}} \in \mathbb{R}^{N}: \widehat{\boldsymbol{y}}=\boldsymbol{F}(\boldsymbol{\vartheta}) ; \boldsymbol{\vartheta} \in \Omega_{\vartheta}\right\}=\Omega_{\tilde{y}} \cap \Omega_{\bar{y}}$

As shown by Eq. 7, it is generally a subset of the measurement uncertainty set (Eq. 4), since the model may not be capable of producing all trajectories allowed by the observations and the model-output error-bounds. 
Thus, instead of trying to find an optimal value of the parameter-vector, as in least-squares or in statistical estimation, the goal of set-membership parameter estimation is to find the FPS $\left(\Omega_{\vartheta}\right)$ consistent with the model and the data, subject to the specified error-bounds. This approach avoids any assumptions beyond the structure of the model and the output errorbounds.

Before continuing with refinements in the estimation procedure, let us graphically summarise a sampling-based set-membership estimation method (Fig. 1), thus combining Eqs. 1 through 7 with a one-step sampling based algorithm, as presented in Section 5.3.3.

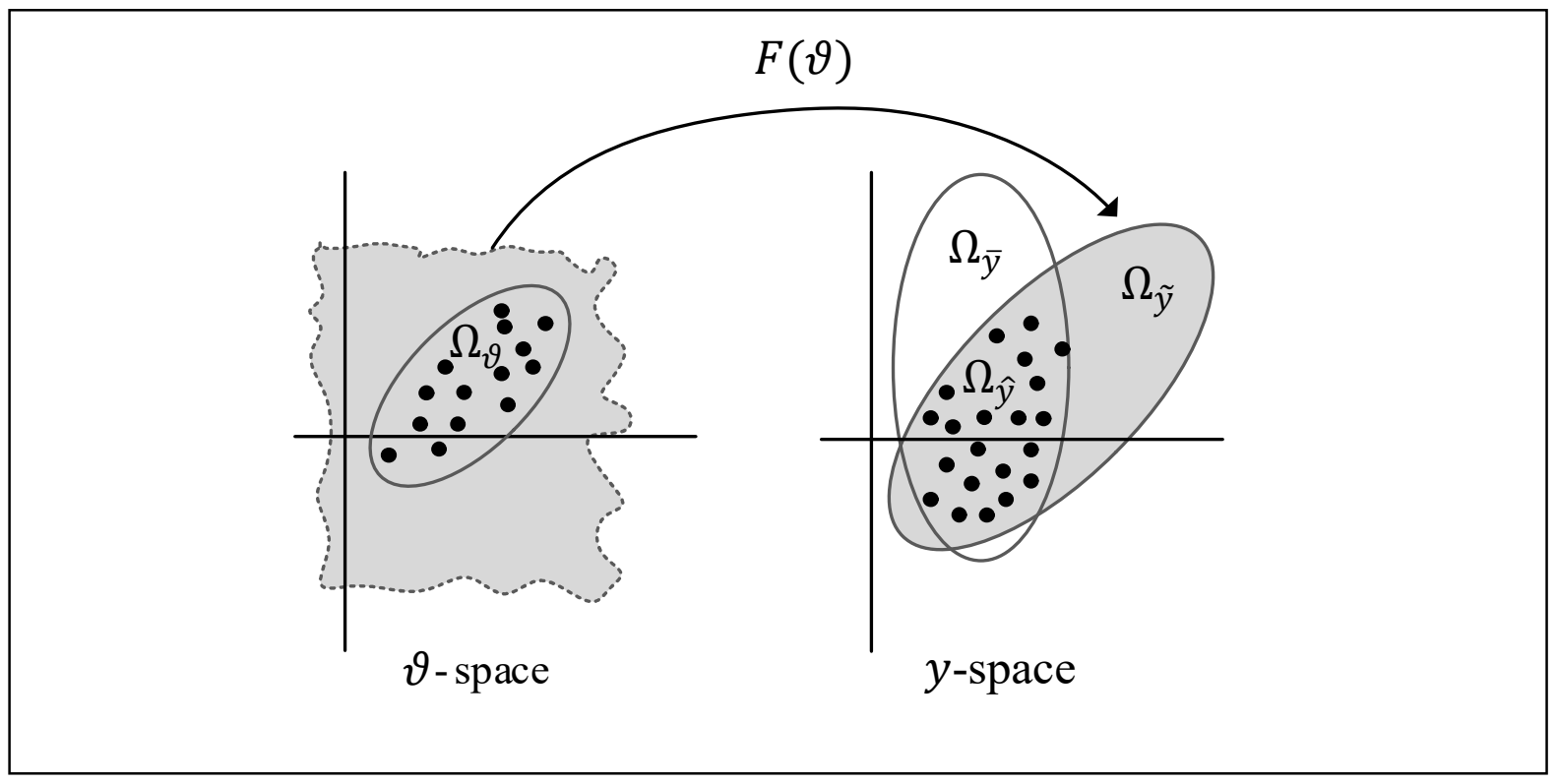

Fig. 1 Graphic illustration (Venn diagram) of one-step sampling-based set-membership parameter estimation. $\Omega_{\vartheta}$ (Eq. 5) is the discrete feasible parameter-vector set, $\Omega_{\tilde{y}}$ (Eq. 6) is the image set of the entire parameter space, $\Omega_{\hat{y}}$ (Eq. 7) is the discrete unfalsified model-output set, and $\Omega_{\bar{y}}$ (Eq. 4) is the measurement uncertainty set centred around the measured output vector $\boldsymbol{y}$

\subsubsection{Model for estimation of ammonia volatilisation in flooded rice systems}

The proposed model for the estimation of ammonia volatilisation in fertilised and flooded rice systems is described in Chapter 4. Similar to Chowdary et al. (2004), the proposed model assumes first-order kinetics reactions to describe $\mathrm{NH}_{3}$ volatilisation. Partitioning between ammonium and ammonia in the floodwater, which was lacking in the model of Chowdary et al. (2004), is an important process in regulating $\mathrm{NH}_{3}$ volatilisation in flooded rice systems, and, therefore, was conceptualised in the proposed model. 
The model has six state variables: concentration of urea- $\mathrm{N}$ in floodwater $\left[U^{w}\right]$ in $\mathrm{kg} \mathrm{N} \mathrm{m}^{-3}$, an interim state that emulates low urease activity in floodwater $\left[E^{w}\right]$ in $\mathrm{kg} \mathrm{N} \mathrm{m}^{-3}$, concentration of total ammoniacal-N in floodwater $\left[N^{w}\right]$ in $\mathrm{kg} \mathrm{N} \mathrm{m}^{-3}$, dimensionless trend of total $\mathrm{N}$ sink over time $S$, cumulative $\mathrm{N}$ sink $\left[N^{\sin k}\right]$ in $\mathrm{kg} \mathrm{N} \mathrm{ha}^{-1}$, and cumulative $\mathrm{NH}_{3}$ volatilisation $\mathrm{NH}_{3}^{g}$ in $\mathrm{kg} \mathrm{N} \mathrm{ha}^{-1}$. The initial conditions are defined by $\left[U^{w}\right]=0 \mathrm{~kg} \mathrm{~N} \mathrm{~m}^{-3},\left[E^{w}\right]=0 \mathrm{~kg} \mathrm{~N} \mathrm{~m}^{-3}$, $\left[N^{w}\right]=0 \mathrm{~kg} \mathrm{~N} \mathrm{~m}{ }^{-3},\left[N^{\operatorname{sink}}\right]=0 \mathrm{~kg} \mathrm{~N} \mathrm{ha}^{-1}$, and $N H_{3}^{g}=0 \mathrm{~kg} \mathrm{~N} \mathrm{ha}^{-1}$, on the day of transplanting. Model simulations always begin on the day of transplanting.

Unlike the other state variables, the initial condition for $S\left(S_{0}\right)$ is not known and therefore, is treated as an additional parameter that needs to be estimated. In addition, the proposed model contains five unknown parameters: $K_{h}$ rate coefficient of first step urea hydrolysis $\left(\right.$ day $\left.^{-1}\right), K_{E}$ rate coefficient of second step urea hydrolysis $\left(\right.$ day $\left.^{-1}\right), \beta$ trend of $\mathrm{S}\left(\right.$ day $\left.^{-1}\right), K_{\text {sink }}$ rate coefficient of total $\mathrm{N}$ sink term $\left(\right.$ day $\left.^{-1}\right)$, and $K_{v}$ rate coefficient of $\mathrm{NH}_{3}$ volatilisation $\left(\right.$ day $\left.^{-1}\right)$. Later, it will be shown that $K_{v}$ needs to be split into two parameters: $K_{v A T}$, the volatilisation rate coefficient after the first urea application after transplanting, and $K_{v P I}$, the volatilisation rate coefficient after the second urea application after transplanting (at about panicle initiation). The model requires four inputs: rate of urea-N application, floodwater temperature, $\mathrm{pH}$, and depth.

\subsection{Materials and methods}

\subsubsection{Secondary data sets}

In order to estimate the unknown parameters in the model, field observations in rice fields in Los Baños and Muñoz, Philippines, collected by Fillery et al. (1984), were used. At Los Baños, $60 \mathrm{~kg} \mathrm{~N} \mathrm{ha}{ }^{-1}$ was applied before transplanting, $60 \mathrm{~kg} \mathrm{~N} \mathrm{ha}^{-1}$ on 14 days after transplanting (DAT), and $30 \mathrm{~kg} \mathrm{~N}^{-1}$ on 27 DAT (about panicle initiation). At Muñoz, $80 \mathrm{~kg}$ $\mathrm{N} \mathrm{ha}^{-1}$ was applied before transplanting, $80 \mathrm{~kg} \mathrm{~N} \mathrm{ha}^{-1}$ on $21 \mathrm{DAT}$, and $40 \mathrm{~kg} \mathrm{~N} \mathrm{ha}^{-1}$ on 52 DAT (about panicle initiation). At both sites, urea was used as the fertiliser. Note that in Chapter 4, Los Baños and Muñoz data sets are referred as DSetLB84 and DSetM84, respectively.

Note that the proposed model is limited to flooded soils with broadcast application of urea without subsequent incorporation into the soil. Therefore, observations before transplanting were not used in this study. 
The observed floodwater $\mathrm{pH}$ values in the study by Fillery et al. (1984) were interpolated and used as data inputs to the model. Note that the floodwater $\mathrm{pH}$ was measured only between 6:00 hours and 22:00 hours. Therefore, the floodwater $\mathrm{pH}$ between 22:00 hours and 6:00 hours was assumed constant at 7.0 for each day.

Furthermore, Fillery et al. (1984) reported only the ranges of daily floodwater temperature at Los Baños (from $21^{\circ} \mathrm{C}$ to $40{ }^{\circ} \mathrm{C}$ ) and Muñoz (from $17^{\circ} \mathrm{C}$ to $34^{\circ} \mathrm{C}$ ). Due to lack of hourly values and for simplification, the floodwater temperature at both locations was assumed constant at $25^{\circ} \mathrm{C}$ between $20: 00$ hours and 6:00 hours, and to gradually reach a maximum temperature of $40{ }^{\circ} \mathrm{C}$ at 12:00 hours. Details on the floodwater $\mathrm{pH}$ and temperature as data inputs to the model are given in Appendix A.

Fillery et al. (1984) also reported that the floodwater depth was maintained between $0.03 \mathrm{~m}$ and $0.04 \mathrm{~m}$. Due to lack of meteorological data to calculate the time-varying floodwater depth, the floodwater depth was assumed constant at $0.035 \mathrm{~m}$ for all simulations.

Three observed process variables, namely concentration of urea-N in floodwater, concentration of total ammoniacal-N in floodwater, and hourly rate of $\mathrm{NH}_{3}$ volatilisation, were used to estimate the six unknown parameters: $K_{h}, K_{E}, \beta, K_{\text {sink }}, S_{0}$, and $K_{v}\left(K_{v A T}\right.$ and $\left.K_{v P I}\right)$.

For Los Baños, Fillery et al. (1984) reported 17 observations of urea-N concentrations and 49 observations of total ammoniacal-N concentrations after the first urea application after transplanting, and 35 observations of total ammoniacal-N concentrations after the second urea application after transplanting. Fillery et al. (1984) also reported the rate of $\mathrm{NH}_{3}$ volatilisation ( $\mathrm{kg} \mathrm{N}$ ha $^{-1}$ hour ${ }^{-1}$ ), but we transformed this to cumulative $\mathrm{NH}_{3}$ volatilisation with a time interval of 0.5 day $^{-1}$, resulting in 15 and 10 observations of cumulative $\mathrm{NH}_{3}$ volatilisation after the first and second urea applications, respectively.

For Muñoz, Fillery et al. (1984) reported 32 observations of urea-N concentrations and 55 observations of total ammoniacal-N concentrations after the first urea application after transplanting, and 26 observations of urea-N concentrations and 31 observations of total ammoniacal-N concentrations after the second urea application after transplanting. The same approach used for Los Baños was applied to obtain the cumulative $\mathrm{NH}_{3}$ volatilisation, 
resulting in 17 and 10 observations after the first and second urea applications after transplanting, respectively.

In the following, the sources of uncertainty introduced when retrieving the data are addressed. The dates of urea applications were reported, but not the exact time of the applications. The exact date of transplanting of rice seedlings was also not provided. The missing information was carefully estimated based on other information provided. Errors may also be introduced after careful digitisation (extraction) of the data from figures provided by Fillery et al. (1984). Despite these limitations, these two data sets were selected because other pertinent details that are relevant to $\mathrm{NH}_{3}$ volatilisation, especially the floodwater $\mathrm{pH}$ and dynamics of urea-N and total ammoniacal-N concentrations, were well documented.

As a starting point for our choices of the error-bounds in the set-membership approach, we used the following reference studies. For instance, Li et al. (2008), Xu et al. (2012), Cao et al. (2013), and Chen et al. (2015) reported standard errors ranging from about $2 \mathrm{~kg} \mathrm{~N} \mathrm{ha}^{-1}$ to about $5 \mathrm{~kg} \mathrm{~N}$ ha $^{-1}$ for daily cumulative $\mathrm{NH}_{3}$ volatilisation observed using static and dynamic chamber methods. Cao et al. (2013) and Liu et al. (2015) reported standard errors ranging from about $2 \mathrm{mg} \mathrm{N} \mathrm{L}^{-1}$ to about $5 \mathrm{mg} \mathrm{N} \mathrm{L}^{-1}$, and occasionally as large as $15 \mathrm{mg} \mathrm{N} \mathrm{L}^{-1}$ (Cao et al., 2013) for observed concentrations of total ammoniacal-N in the floodwater.

The prediction errors for seasonal $\mathrm{NH}_{3}$ volatilisation simulated using model of Chowdary et al. (2004) for a rice system in Pantnagar, India is $0.81 \mathrm{~kg} \mathrm{~N} \mathrm{ha}^{-1}$ and using model of Liang et al. (2007) for rice systems in Shuangqiao, China ranged from $4.70 \mathrm{~kg} \mathrm{~N}^{--1}$ to $16.57 \mathrm{~kg} \mathrm{~N}$ $\mathrm{ha}^{-1}$.

\subsubsection{Exploratory parameter estimation}

The six unknown parameters, $K_{h}, K_{E}, \beta, K_{\text {sink }}, S_{0}$, and $K_{v}$, were gradually varied to fit the observational data sets of Los Baños and Muñoz, simultaneously. Initially, we assumed $K_{v}$ was constant throughout the crop growth stage, but this resulted in a bad fit between modeloutput and the corresponding observed data. Therefore, based on physical knowledge, $K_{v}$ was divided into two stages: $K_{v A T}$ and $K_{v P I}$ after the first and second urea applications after transplanting, respectively. Note that the second fertiliser application after transplanting was at about panicle initiation stage. The $K_{v A T}$ at Muñoz was estimated about 2.7 times larger than the $K_{v A T}$ at Los Baños due to greater wind speed at Muñoz than at Los Baños (Fillery et al., 
1984). However, for both sites, the effect of wind speed was reduced at about panicle initiation. For Muñoz, the $K_{v P I}$ was estimated about 4.0 times lower than $K_{v A T}$ and for Los Baños it was estimated about 1.2 times lower. The exploratory estimates obtained for Los Baños and Muñoz are given in Table 1, and were used as the basis for defining the a priori parameter region needed for applying the sampling-based set-membership estimation approach.

Table 1 The exploratory estimates obtained via simultaneous calibration for Los Baños and Muñoz

\begin{tabular}{lll}
\hline Parameter & Exploratory estimates \\
\hline$K_{h}\left(\right.$ day $\left.^{-1}\right)$ & 0.80 & \\
$K_{E}\left(\right.$ day $\left.^{-1}\right)$ & 0.60 & \\
$\beta\left(\right.$ day $\left.^{-1}\right)$ & 0.02 & \\
$K_{\text {Sink }}\left(\right.$ day $\left.^{-1}\right)$ & 2.00 & \\
$\left.S_{0}(\text { dimensionless })^{-1}\right)$ & 0.70 & \\
$K_{v A T}\left(\right.$ day $\left.^{-1}\right)$ & $16.00^{\mathrm{a}}$, & $6.00^{\mathrm{b}}$ \\
$K_{v P I}\left(\right.$ day $\left.^{-1}\right)$ & $4.00^{\mathrm{a}}$, & $5.00^{\mathrm{b}}$ \\
\hline
\end{tabular}

${ }^{\mathrm{a}} M u \tilde{n} O z$

${ }^{\mathrm{b}} \operatorname{Los}$ Baños

\subsubsection{Set-membership parameter estimation}

The flow chart of the set-membership approach, as applied in this study, is summarised graphically in Fig. 2. First, an a priori p-dimensional hypercubic parameter region was constructed, where $p$ is the number of estimated parameters in the model. In order to define the bounds of the a priori parameter region, the exploratory estimates in Table 1 were used as the 'mid-points'.

Subsequently, a Latin-hypercube sampling scheme was used to sample $N_{\vartheta}$ parameter-vectors from the $p$-dimensional hypercube in the parameter-space. The set of a priori parametervectors is represented by the $N_{\vartheta} \times p$ matrix $\boldsymbol{\vartheta}$.

Next, the model was simulated with each of the $N_{\vartheta}$ sampled parameter-vectors. Discrepancies between simulated model-outputs and the observed outputs were determined by calculating the prediction error $e(t)=\tilde{y}(t)-y(t)$, where $\tilde{y}(t)$ is the simulated model-output and $y(t)$ is observed output at time $t$.

Initially, a hard-bound condition as in Eq. (5) was assumed, where a parameter-vector was accepted only when all of the prediction errors in absolute terms were not greater than the pre- 
defined error-bound $\varepsilon$, i.e. $\|\boldsymbol{e}\|_{\infty} \leq \varepsilon$. However, as for finding feasible parameter-vectors very large error-bounds for each of the time series were required, a soft error-bound condition (see also Lahanier et al. (1987); Walter and Pronzato, (1997)) was introduced, allowing $\alpha \%$ of the prediction errors to be larger than $\varepsilon$ with $\alpha>0$. The tolerance $\alpha$ was gradually increased in order to retrieve some feasible parameter-vectors. The discrete approximations of FPS were collected in an $N_{X} \times p$ matrix $X$, where $N_{X}$ is the number of feasible parameter samples.

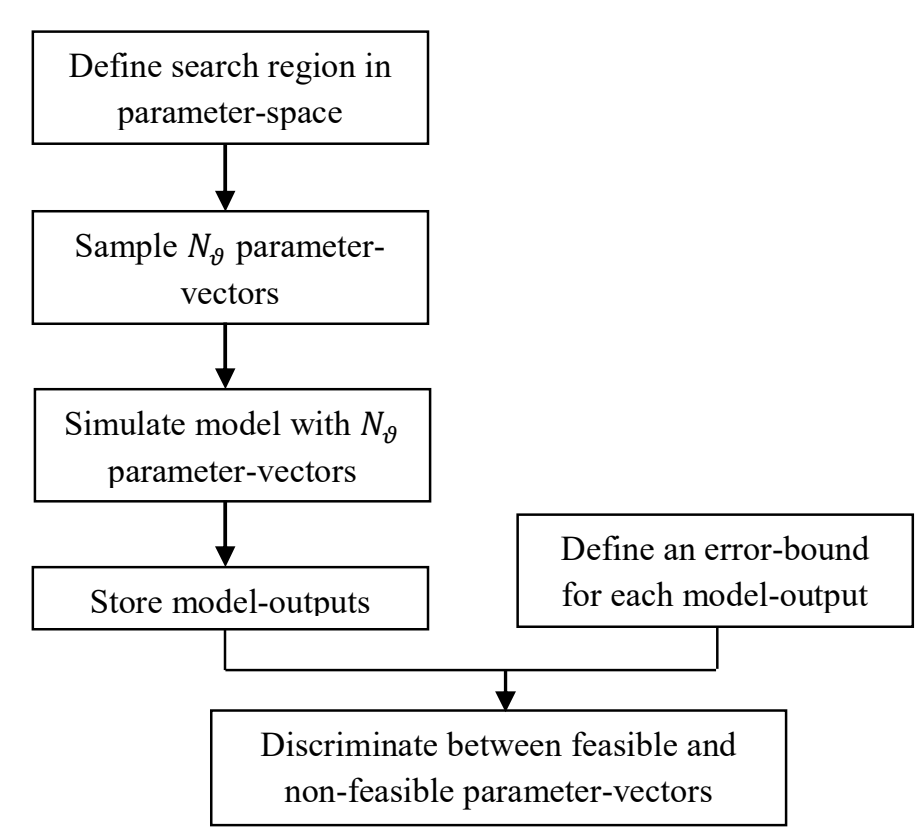

Fig. 2 Flow chart of the set-membership approach as applied in this study

In the following sections, the unknown parameters in a process-based model, namely $K_{h}, K_{E}, \beta, K_{\text {sink }}, S_{0}, K_{v A T}$, and $K_{v P I}$, were estimated using a sampling-based set-membership approach with soft error-bounds (Fig. 2) and using conventional non-linear least-squares methods.

All simulations in this study were performed using MATLAB software. The model given in Chapter 4 was solved using the differential equation solver ode45, which numerically integrates the differential equations. The computational time for a single simulation run is about 0.27 and 0.41 minute on a machine with INTEL ${ }^{\circledR}$ CORETM i7-3612QM CPU @2.10GHzprocessor and 8 GB RAM memory for Los Baños and Muñoz, respectively. 


\subsubsection{Estimation of $K_{h}$}

Preliminary analysis revealed that $K_{h}$ can be calibrated independently of other unknown parameters as $K_{h}$ could be estimated from observations of concentrations of urea-N in the floodwater $\left(\boldsymbol{y}_{1}\right)$ only. In the following, boldface symbols are used to indicate a vector or a matrix, and thus, e.g., $\boldsymbol{y}_{1} \triangleq\left[\begin{array}{llll}y_{11} & y_{12} & \cdots & y_{1 n}\end{array}\right]^{\boldsymbol{T}}$. By estimating $K_{h}$ independently of the other unknown parameters, the dimension of the parameter-vectors was reduced in the next estimation step (Section 5.3.5). In order to estimate $K_{h}$, only Eq. 2 in Chapter 4 needed to be simulated.

Based on the exploratory estimate of $K_{h}$ as the 'mid-point' (Table 1), the parameter interval of $K_{h}$ was defined from 0.5 to 1.0 . A Latin-hypercube sampling scheme was used to sample 500 a priori parameter-vectors. These 500 sampled parameter-vectors were used to simulate urea hydrolysis (Eq. 2 in Chapter 4) for Los Baños, and subsequently for Muñoz.

The prediction errors for the concentrations of urea-N for each location were calculated, and put in the prediction error vectors $\boldsymbol{e}_{\mathbf{1}_{\boldsymbol{A}}}$ and $\boldsymbol{e}_{\mathbf{1}_{\boldsymbol{I}}}$, respectively. The subscript $A T$ corresponds to observations after the first urea application after transplanting, and subscript PI corresponds to observations after the second urea application after transplanting (at about panicle initiation). At Los Baños, urea-N concentration in the floodwater at PI was not observed by Fillery et al. (1984).

Based on the information presented in Section 5.3.1, the error-bound was chosen as $\varepsilon_{1}:=5$ $\operatorname{mg~N~L}{ }^{-1}$. The $\varepsilon_{1}$ was about $5 \%$ of the maximum scale of the urea-N concentration. First, a hard error-bound condition was assumed with $\left\|\boldsymbol{e}_{\mathbf{1}_{A T}}\right\|_{\infty} \leq \varepsilon_{1}$ and $\left\|\boldsymbol{e}_{\boldsymbol{1}_{\boldsymbol{P I}}}\right\|_{\infty} \leq \varepsilon_{1}$, but no feasible parameter-vectors was found. Subsequently, a soft error-bound condition was applied by gradually increasing $\alpha$, the percentage of $\boldsymbol{e}_{\mathbf{1}}$ that violates the condition $\left\|\boldsymbol{e}_{\mathbf{1}_{\boldsymbol{A}}}\right\|_{\infty} \leq \varepsilon_{1}$ and $\left\|\boldsymbol{e}_{\mathbf{1}_{\boldsymbol{P I}}}\right\|_{\infty} \leq \varepsilon_{1}$. Feasible parameter-vectors were retrieved for the condition where at least 30 $\%$ of the elements in each of the vectors must satisfy the error-bound.

\subsubsection{Estimation of other parameters}

Next, the other six unknown parameters, $K_{E}, \beta, K_{\text {sink }}, S_{0}, K_{v A T}$, and $K_{v P I}$, were estimated using the set-membership approach. Based on the feasible range of $K_{h}$ in Section 5.4.1 and the 
least-squares results in Table 4 (Section 5.4.2), $K_{h}$ was set at 0.8 . As concentrations of urea-N in the floodwater were not informative for estimating $K_{E}, \beta, K_{\text {sink }}, S_{0}, K_{v A T}$ and $K_{v P I}$, only concentrations of total ammoniacal-N in the floodwater $\left(\boldsymbol{y}_{2}\right)$ and the cumulative $\mathrm{NH}_{3}$ volatilisation $\left(\boldsymbol{y}_{3}\right)$ were used for estimating these six parameters.

The parameter intervals of these parameters were defined based on the exploratory estimates in Table 1. First, for Los Baños, a Latin-hypercube sampling scheme was used to sample 1000 parameter-vectors from the six-dimensional a priori parameter region. The sampling procedure was conducted two times, and each was labelled as replicates 1 and 2 . The sampled parameter-vectors of replicates 1 and 2 were used to simulate the dynamic system behaviour at Los Baños.

Similar to Section 5.3.4, the prediction errors for the concentrations of total ammoniacal-N and cumulative $\mathrm{NH}_{3}$ volatilisation for each location were calculated, i.e. $\boldsymbol{e}_{\mathbf{2}_{\boldsymbol{A T}}}$ and $\boldsymbol{e}_{\mathbf{2}_{\boldsymbol{P I}}}, \boldsymbol{e}_{\mathbf{3}_{\boldsymbol{A}} \boldsymbol{T}}$ and $\boldsymbol{e}_{\mathbf{3}_{P I}}$, respectively.

Based on the information given in Section 5.3.1, the error-bounds for total ammoniacal-N concentrations and cumulative $\mathrm{NH}_{3}$ volatilisation were chosen as $\varepsilon_{2}:=5 \mathrm{mg} \mathrm{N} \mathrm{L}{ }^{-1}$, and $\varepsilon_{3}:=5 \mathrm{~kg} \mathrm{~N}^{-1}$, respectively. The $\varepsilon_{2}$ was about $20 \%$ of the maximum scale of the total ammoniacal-N concentration, and the $\varepsilon_{3}$ was about $4 \%$ of the maximum scale of cumulative $\mathrm{NH}_{3}$ volatilisation.

A soft error-bound condition was required for elements in $\boldsymbol{e}_{2}$, and a hard-bound condition was applied for elements in $\boldsymbol{e}_{3}$. The soft error-bound condition for elements in $\boldsymbol{e}_{\mathbf{2}}$ requires that at least $90 \%$ of the elements in each of the vectors satisfies the error-bound $\varepsilon_{2}$. The same procedure was repeated for the rice system at Muñoz.

Based on the outcomes of the above analysis, the following steps were taken in order to increase the number $\left(N_{X}\right)$ of parameter samples found to be feasible. For Los Baños, sampling was repeated for the same parameter intervals, but with $N_{\vartheta}=2000$. However, for Muñoz, the a priori parameter region was modified due to a low value of $N_{X}$. The parameter intervals for the modified a priori parameter region were defined by the lower and upper bounds of the feasible parameter-vectors that resulted from replicates 1 and 2 of Muñoz. Subsequently, $N_{\vartheta}=1000$ parameter-vectors were sampled from the modified a priori parameter region. In 
order to retrieve the feasible parameter-vectors from the sampled parameter-vectors, the same error-bound conditions for $\boldsymbol{e}_{2}$ and $\boldsymbol{e}_{3}$ were applied.

\subsubsection{Eigenvalue decomposition of dispersion matrix of FPS}

The results from an eigenvalue decomposition of the dispersion matrix characterising the FPS can be interpreted in terms of the parameter sensitivities (Keesman, 2011). The following steps were taken in order to derive the $6 \times 6$ dispersion matrix, where the parameter $K_{h}$ was excluded from the eigenvalue decomposition analysis as the parameter was estimated separately.

All feasible parameter-vectors in the FPS were compiled in the $N_{X} \times p$ matrix $\boldsymbol{X}:=$ $\left[\begin{array}{lllllll}\boldsymbol{K}_{\boldsymbol{E}} & \boldsymbol{\beta} & \boldsymbol{K}_{\text {sink }} & \boldsymbol{S}_{\mathbf{0}} & \boldsymbol{K}_{\boldsymbol{v} A T} & \boldsymbol{K}_{\boldsymbol{v} P I}\end{array}\right]$. Next, the mean of the feasible parameter-vectors for each parameter, $\bar{K}_{E}, \bar{\beta}, \bar{K}_{\text {sink }}, \bar{S}_{0}, \bar{K}_{v A T}$, and $\bar{K}_{v P I}$, was calculated. Then, the feasible parameter-vectors were translated to the origin by subtracting from each element of matrix $\boldsymbol{X}$ the corresponding mean. Thus, $\boldsymbol{X}-\overline{\boldsymbol{X}}$, where $\overline{\boldsymbol{X}}=\left[\begin{array}{llllll}\overline{\boldsymbol{K}}_{\boldsymbol{E}} & \overline{\boldsymbol{\beta}} & \overline{\boldsymbol{K}}_{\sin \boldsymbol{k}} & \overline{\boldsymbol{S}}_{\mathbf{0}} & \overline{\boldsymbol{K}}_{\boldsymbol{v} A T} & \overline{\boldsymbol{K}}_{\boldsymbol{v} \boldsymbol{I I}}\end{array}\right]$ is also an $N_{X} \times p$ matrix.

The dispersion matrix of the translated feasible parameter-vectors was subsequently defined as $(\boldsymbol{X}-\overline{\boldsymbol{X}})^{\boldsymbol{T}}(\boldsymbol{X}-\overline{\boldsymbol{X}})$. The orientation and shape of the ellipsoidal approximation of the set of translated feasible parameter-vectors were found from an eigenvalue decomposition of the dispersion matrix, i.e., $(\boldsymbol{X}-\overline{\boldsymbol{X}})^{\boldsymbol{T}}(\boldsymbol{X}-\overline{\boldsymbol{X}}) \mathbf{V}=\mathbf{V D}$, with $\mathbf{V}$ the eigenmatrix and $\mathbf{D}$ a diagonal matrix of the eigenvalues.

\subsubsection{Non-linear least-squares methods}

The non-linear least-squares methods minimise the sum of squares of residuals, and require initial guesses of the unknown parameters. Similar to the set-membership approach, $K_{h}$ was estimated using urea-N concentrations in the floodwater observed at both Los Baños and Muñoz. For the estimation of $K_{h}$, the Levenberg-Marquardt algorithm was applied. Four initial guesses, i.e., $K_{h}=0.3, K_{h}=0.8, K_{h}=0.9$, and $K_{h}=1.3$, were specified.

For the estimation of the other parameters $\left(K_{E}, \beta, K_{\text {sink }}, S_{0}, K_{v A T}, K_{v P I}\right)$, total ammoniacal-N concentrations in the floodwater and cumulative $\mathrm{NH}_{3}$ volatilisation observed at Los Baños were used. Three algorithms, which are Levenberg-Marquardt, Trust-reflective region, and 
the well-known Nelder-Mead simplex method, were selected for the non-linear least squares estimations. Similar to the set-membership approach, we fixed $K_{h}:=0.8$. The exploratory estimates in Table 1 were used as initial guesses.

In MATLAB, the Levenberg-Marquardt and Trust-reflective-region algorithms were performed using the function lsqnonlin, whereas the Nelder-Mead simplex algorithm was performed using the function fminsearch. Unlike the function fminsearch, lsqnonlin directly provides a Jacobian matrix for the calculation of the covariance matrix of the estimates.

The standard deviation of each parameter estimate was calculated from the corresponding Jacobian matrix as follows. The estimated variance of the prediction error is given by:

$\hat{\sigma}_{e}^{2}=\frac{1}{N-p} \sum_{t=1}^{N} e^{2}(t)$

where, $N$ is number of observations, $p$ is number of estimated parameters, and $e(t)$ is the prediction error at time $t$. The $p \times p$ covariance matrix is then given by:

$\operatorname{Cov} \hat{\vartheta}=\hat{\sigma}_{e}^{2}\left[J(\hat{\vartheta})^{T} J(\hat{\vartheta})\right]^{-1}$

where, $J(\hat{\vartheta})$ is the $N \times p$ Jacobian matrix. The variances of the estimates are found on the diagonal of matrix $\operatorname{Cov} \hat{\vartheta}$. The standard deviation of each estimate is the square root of the respective variance, and the off-diagonal elements are the covariances between estimates.

\subsection{Results and discussion}

In this chapter, we demonstrate the estimation of seven parameters in a model developed for the estimation of $\mathrm{NH}_{3}$ volatilisation in fertilised and flooded rice systems based on two observational data sets from two locations using a sampling-based set-membership approach, leading to feasible parameter-vectors in the FPS, and using conventional non-linear leastsquares methods for comparison.

\subsubsection{Set-membership estimation approach}

One state variable, namely the concentration of urea-N in the floodwater, was only informative for the urea hydrolysis rate and, therefore, was used for estimating $K_{h}$. In the 
estimation of $K_{h}, 300$ feasible parameter-vectors were retrieved from 500 sampled parametervectors using Los Baños and Muñoz data sets simultaneously. The a priori $K_{h}$ interval, based on the findings of Chowdary et al. (2004), ranged from 0.5000 to 1.0000 , whereas the feasible $K_{h}$ retrieved using the set-membership estimation approach ranged from 0.7009 to 0.9998 .

The simulated model-outputs, using the feasible estimates of $K_{h}$, and corresponding smallest prediction errors (between observed data and simulated set of model-outputs), are given in Fig. 3. Non-zero sequences of the smallest prediction error indicate a structural modelling error for the chosen error-bound. Increasing the error-bound $\varepsilon_{1}$ will increase the range of the feasible $K_{h}$ estimates and subsequently increase the range of feasible model-outputs and consequently reduce the gap between observations and the range of feasible model-outputs. However, fine-tuning of the error bounds is beyond the scope of this study, and we refer to Keesman (1991) for a deeper analysis of this.

The other two state variables, namely concentration of total ammoniacal-N in the floodwater and cumulative $\mathrm{NH}_{3}$ volatilisation, were used to estimate the other parameters, i.e., $K_{E}, \beta, K_{\text {sink }}, S_{0}, K_{v A T}$, and $K_{v P I}$. Results are summarised in Table 2.

For computation, an average of 4.6 and 6.8 hours on a machine with INTEL® CORETM i73612QM CPU@2.10GHzprocessor and 8 GB RAM memory were needed to retrieve feasible parameter-vectors from $N_{\vartheta}=1000$ a priori parameter-vectors for Los Baños and Muñoz, respectively. The longer computation time for Muñoz was due to a longer simulation time span, i.e. 0 to 60 days after transplanting (DAT) for Muñoz compared with 0 to 34 DAT for Los Baños.

Notice that for each data set, comparable numbers of feasible parameter-vectors were retrieved from replicates 1 and 2. Replicates 1 and 2 each consisted of $N_{\vartheta}=1000$ a priori parameter-vectors. For Los Baños, about $10 \%$ of 1000 a priori parameter-vectors were retrieved as feasible parameter-vectors from replicates 1 and 2. For Muñoz, less than $1 \%$ of 1000 a priori parameter-vectors were retrieved as feasible parameter-vectors from replicates 1 and 2 .

The question remained whether $N_{\vartheta}=1000$ was sufficient to sample a six-dimensional $a$ priori parameter region. Visualisation of discrete (subsets of) FPS may reveal the complex 
shape of the set, and how parameters in the FPS relate to each other, but this approach is limited to at most a four-dimensional parameter space (Nurulhuda et al., 2015).
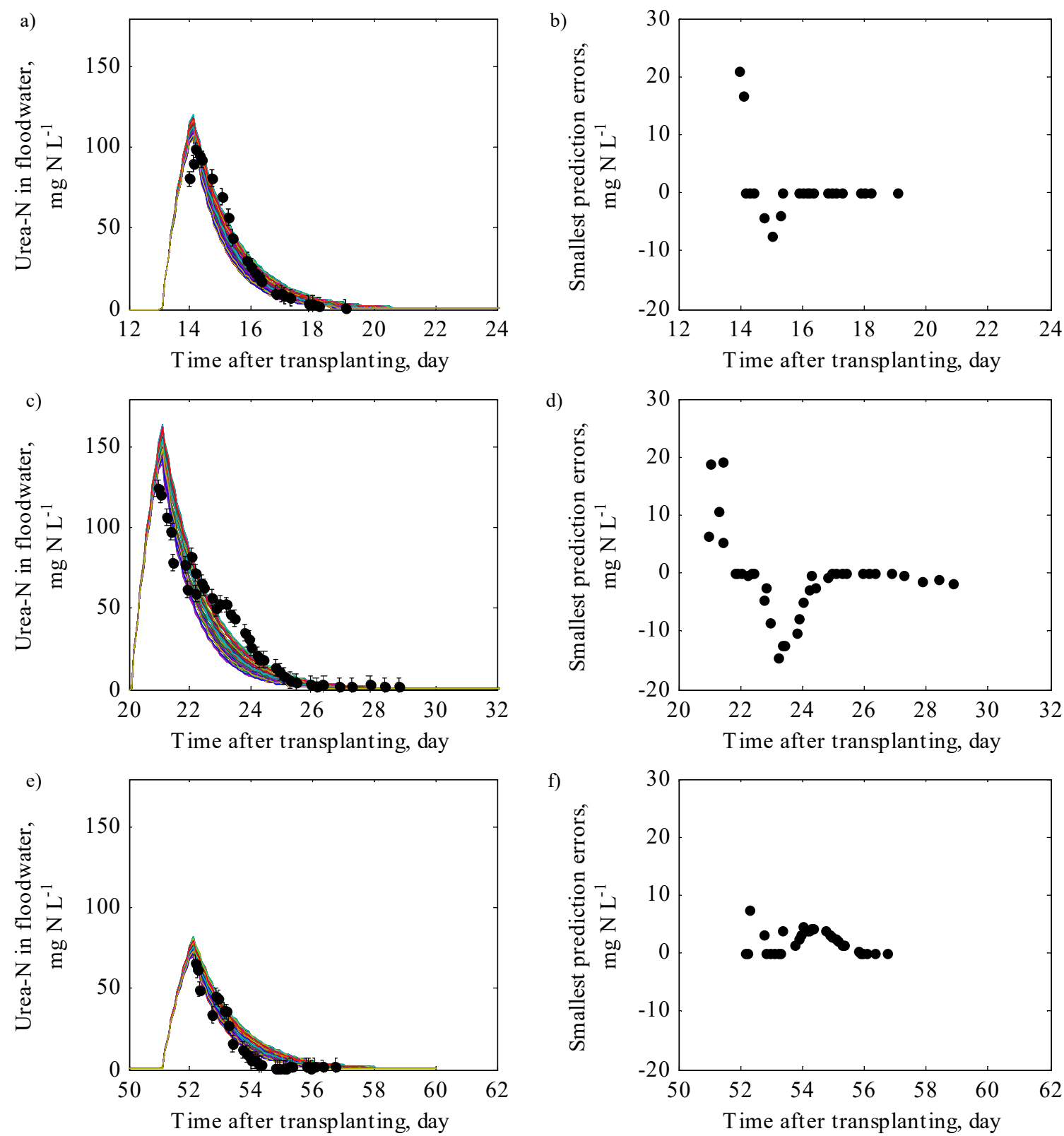

Fig. 3 Simulated model-outputs (lines) using 300 feasible estimates of $K_{h}$ compared to observed urea-N concentration in the floodwater (dots) from Fillery et al. (1984). For Los Baños a) from 12 to $24 \mathrm{DAT}$, and for Muñoz c) from 20 to $32 \mathrm{DAT}$, and e) from 50 to 62 DAT. The respective smallest prediction errors for Los Baños b) from 12 to 24 DAT, and for Muñoz d) from 20 to $32 \mathrm{DAT}$, and f) from 50 to $62 \mathrm{DAT}$, where the smallest prediction error is the smallest distance between observed data and simulated set of model-outputs and multiplied with +1 or -1 when the data is overestimated or underestimated, respectively 

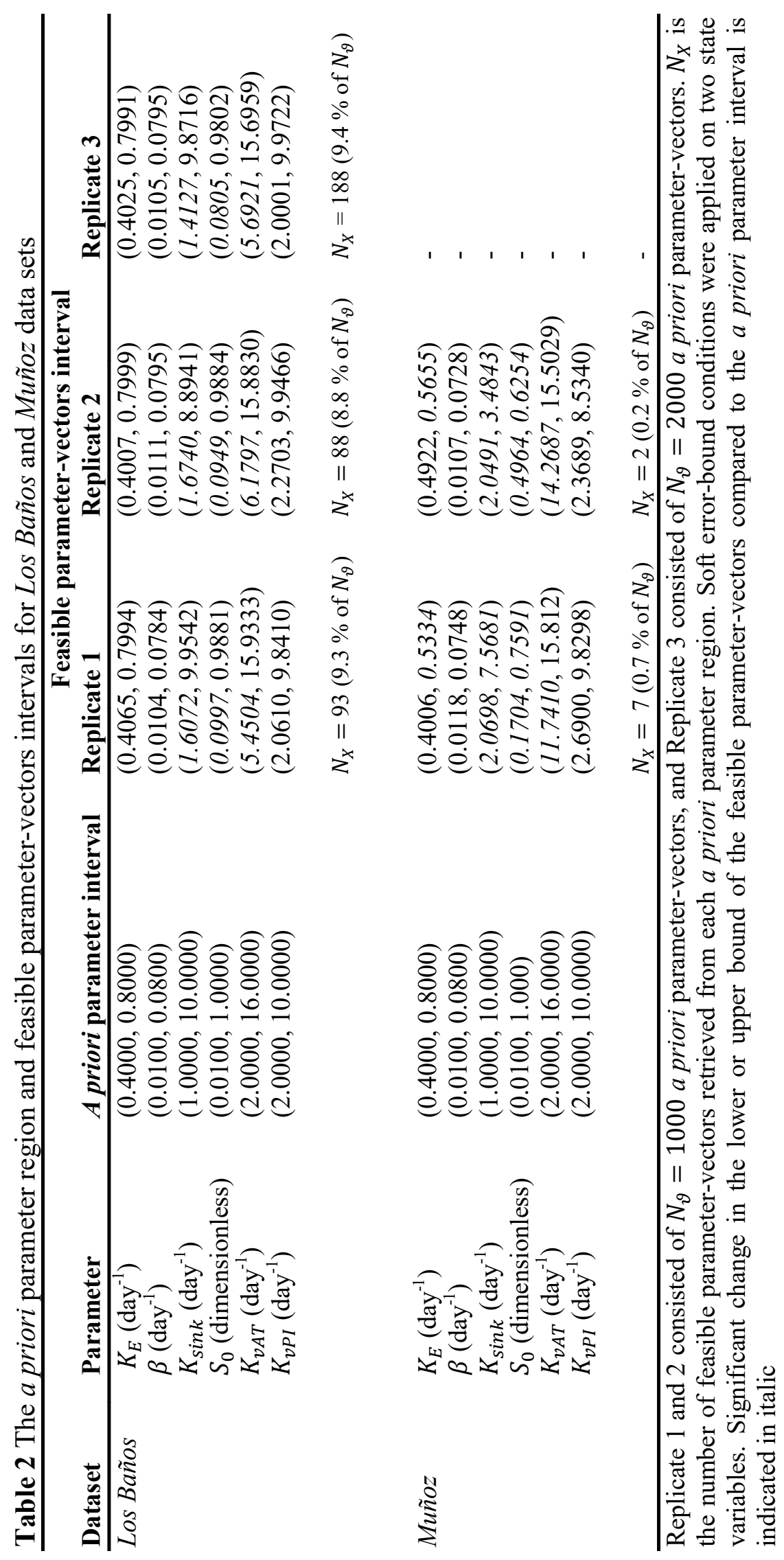
For Los Baños, when the sampled parameter-vectors were increased from $N_{\vartheta}=1000$ to $N_{\vartheta}=2000$, the number of feasible parameter-vectors retrieved almost doubled from those retrieved for replicates 1 and 2 (Table 2). However, notice that the percentage retrieved from the 2000 sampled parameter-vectors remained at $10 \%$, similar to the percentage retrieved for replicates 1 and 2. Notice also that the lower and upper bounds of the feasible parametervectors retrieved from $N_{\vartheta}=2000$ were comparable to those retrieved from replicates 1 and 2, with $N_{\vartheta}=1000$. Thus, it is inferred that in this case with $N_{\vartheta}=1000$ using a Latin hypercube sampling scheme may be sufficient.

Increasing the number of sampled parameter-vectors may ensure a thorough search within an a priori parameter region. However, a trade-off between computational time and the number of sampled parameter-vectors to cover the a priori parameter region was observed. Therefore, an efficient sampling scheme is crucial for a sampling-based set-membership estimation approach (see Keesman (1990) for details).

The number of feasible parameter-vectors retrieved for Muñoz was ten times lower than for Los Baños. Notice that the feasible parameter-vectors region of Muñoz was more constricted compared to that of Los Baños and, thus, may lead to smaller percentage of feasible parameter-vectors retrieved. In an attempt to increase the number of feasible parametervectors for Muñoz, a second a priori parameter region was defined using the lower and upper bounds of the feasible parameter-vectors that resulted from replicates 1 and 2 of Muñoz (Table 3).

Table 3 The second a priori parameter region for Muñoz data set in an attempt to increase the number of feasible parameter-vectors

\begin{tabular}{lll}
\hline $\begin{array}{l}\text { Parameter } \\
\text { interval }\end{array}$ & A priori parameter interval & Feasible parameter-vectors \\
\hline$K_{E}\left(\right.$ day $\left.^{-1}\right)$ & $(0.4000,0.6000)$ & $(0.4002,0.5867)$ \\
$\beta\left(\right.$ day $\left.^{-1}\right)$ & $(0.0100,0.0800)$ & $(0.0115,0.0729)$ \\
$K_{\text {sink }}\left(\right.$ day $\left.^{-1}\right)$ & $(2.0000,8.0000)$ & $(2.0083,7.4737)$ \\
$\left.S\left(t_{0}\right)(\text { dimensionless })^{-1}\right)$ & $(0.1000,0.8000)$ & $(0.1849,0.7594)$ \\
$K_{v A T}\left(\right.$ day $\left.^{-1}\right)$ & $(11.0000,16.0000)$ & $(13.2259,15.9228)$ \\
$K_{v P I}\left(\right.$ day $\left.^{-1}\right)$ & $(2.0000,10.0000)$ & $(2.0322,9.6021)$ \\
& & $N_{X}=28\left(2.8 \%\right.$ of $\left.N_{\vartheta}\right)$ \\
\hline
\end{tabular}

$K_{h}:=0.8$ for this simulation and $N_{\vartheta}=1000$

As a result, the number of the feasible parameter-vectors for Muñoz was increased to about 3 $\%$ of 1000 sampled parameter-vectors. Notice that the corresponding lower and upper bounds of the feasible parameter-vectors did not change significantly from the lower and upper 
a)
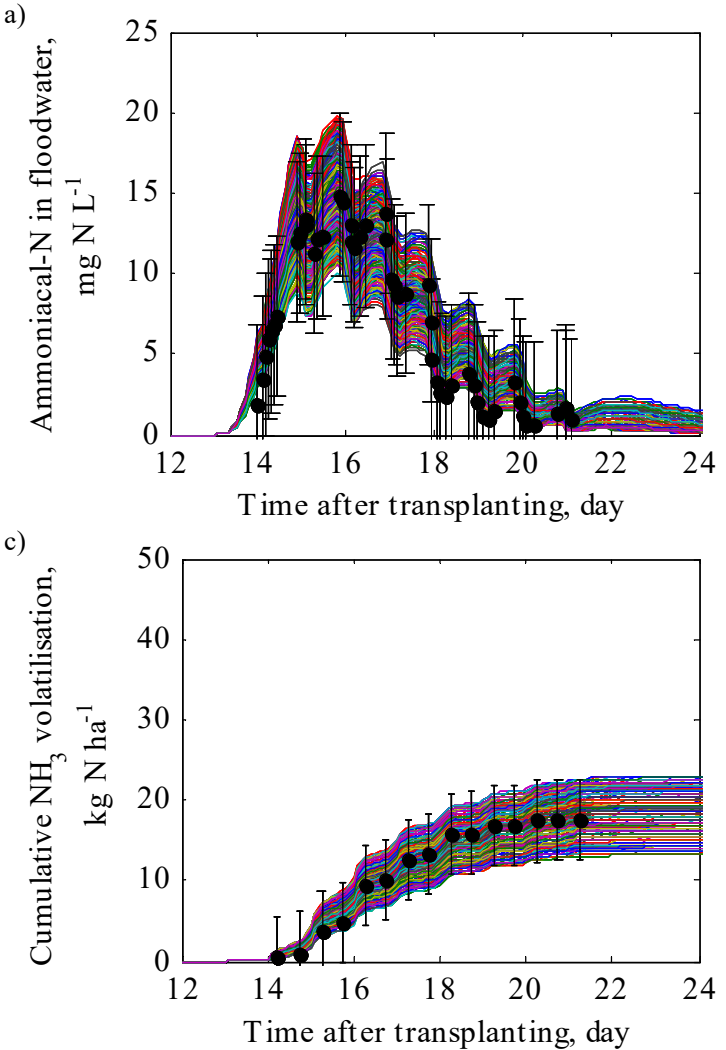

e)

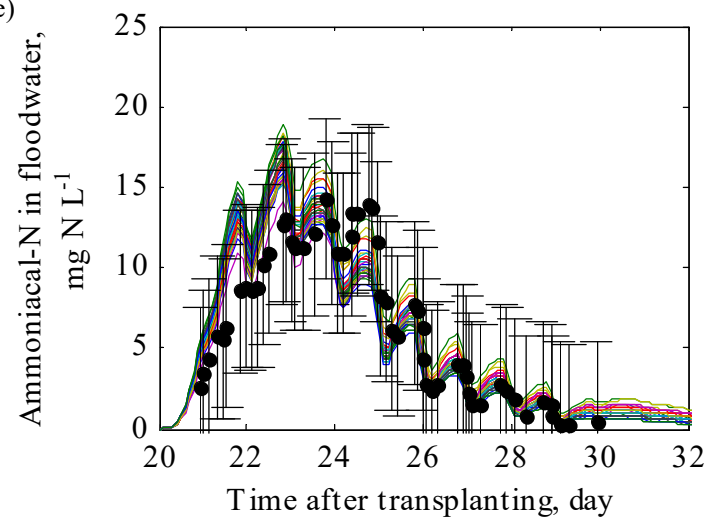

g)

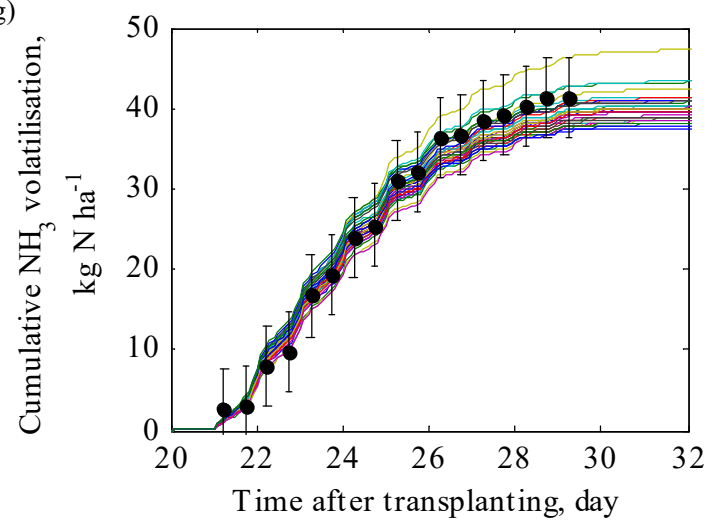

b)

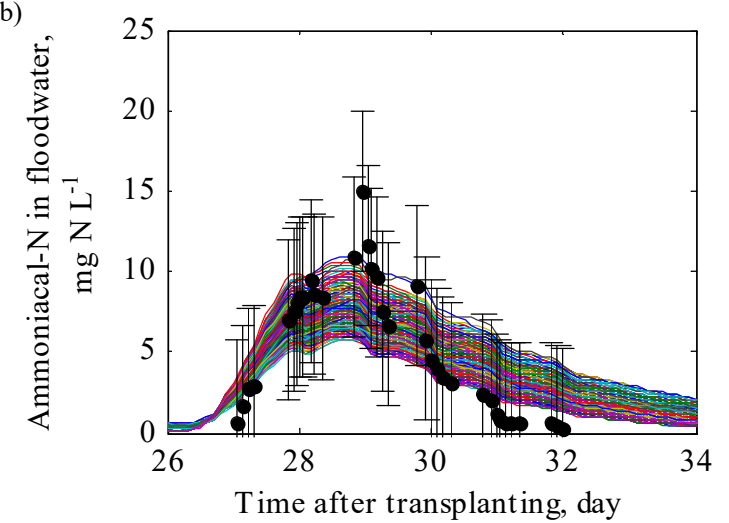

d)

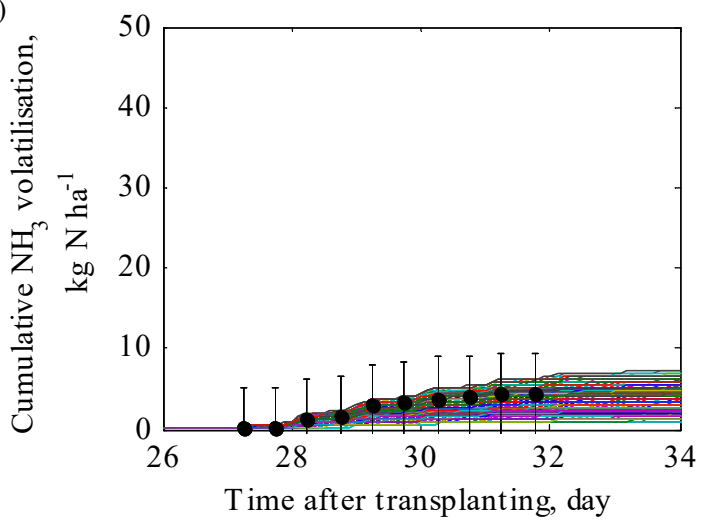

f)

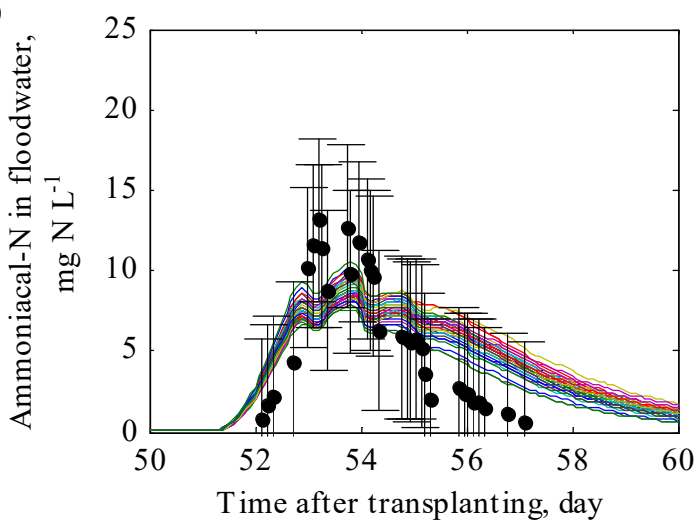

h)

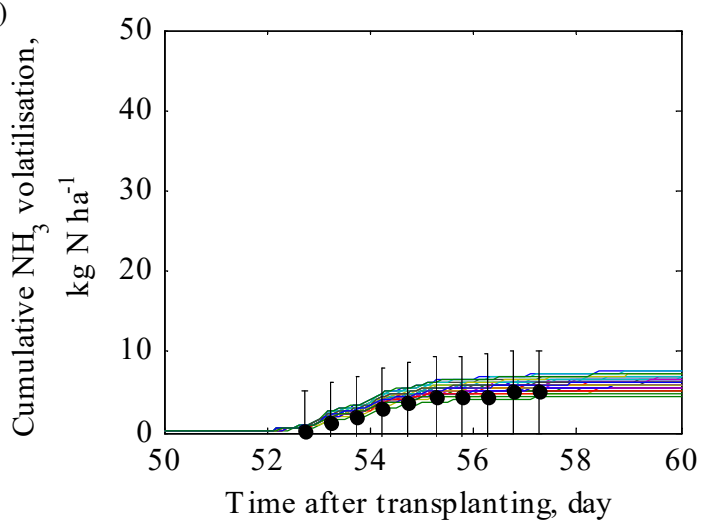

Fig. 4 Model-outputs (lines) simulated using 369 feasible parameter-vectors compared to observed data (dots) for Los Baños: a) Total ammoniacal-N concentration in floodwater from 12 to 24 DAT and b) from 26 to 34 DAT, c) cumulative $\mathrm{NH}_{3}$ volatilisation from 12 to 24 DAT and d) from 26 to 34 DAT. Model-outputs simulated using 37 feasible parameter-vectors compared to observed data for Muñoz: e) Total ammoniacal-N concentration in floodwater from 20 to $32 \mathrm{DAT}$ and f) from 50 to $60 \mathrm{DAT}, \mathrm{g}$ ) cumulative $\mathrm{NH}_{3}$ volatilisation from 20 to 32 DAT and h) from 50 to 60 DAT. Observed data were obtained from Fillery et al. (1984) 
bounds of the second a priori parameter region. Thus, the number of feasible parametervectors may be increased by increasing the number of sampled parameter-vectors $N_{\vartheta}$.

The model-outputs simulated using a total of 369 feasible parameter-vectors retrieved for Los Baños and a total of 37 feasible parameter-vectors retrieved for Muñoz are given in Fig. 4. The respective smallest prediction error at each observed time instant is given in Fig. 5.

Notice from Fig. 5 that especially for concentrations of total ammoniacal-N in the floodwater cannot be predicted well by the model and more specifically after the second urea application after transplanting (at about panicle initiation). Overall, the model performed better for Los Baños than for Muñoz. Again, increasing the error-bound, in this case $\varepsilon_{2}$ and $\varepsilon_{3}$, will reduce the gap between observations and the range of feasible model-outputs.
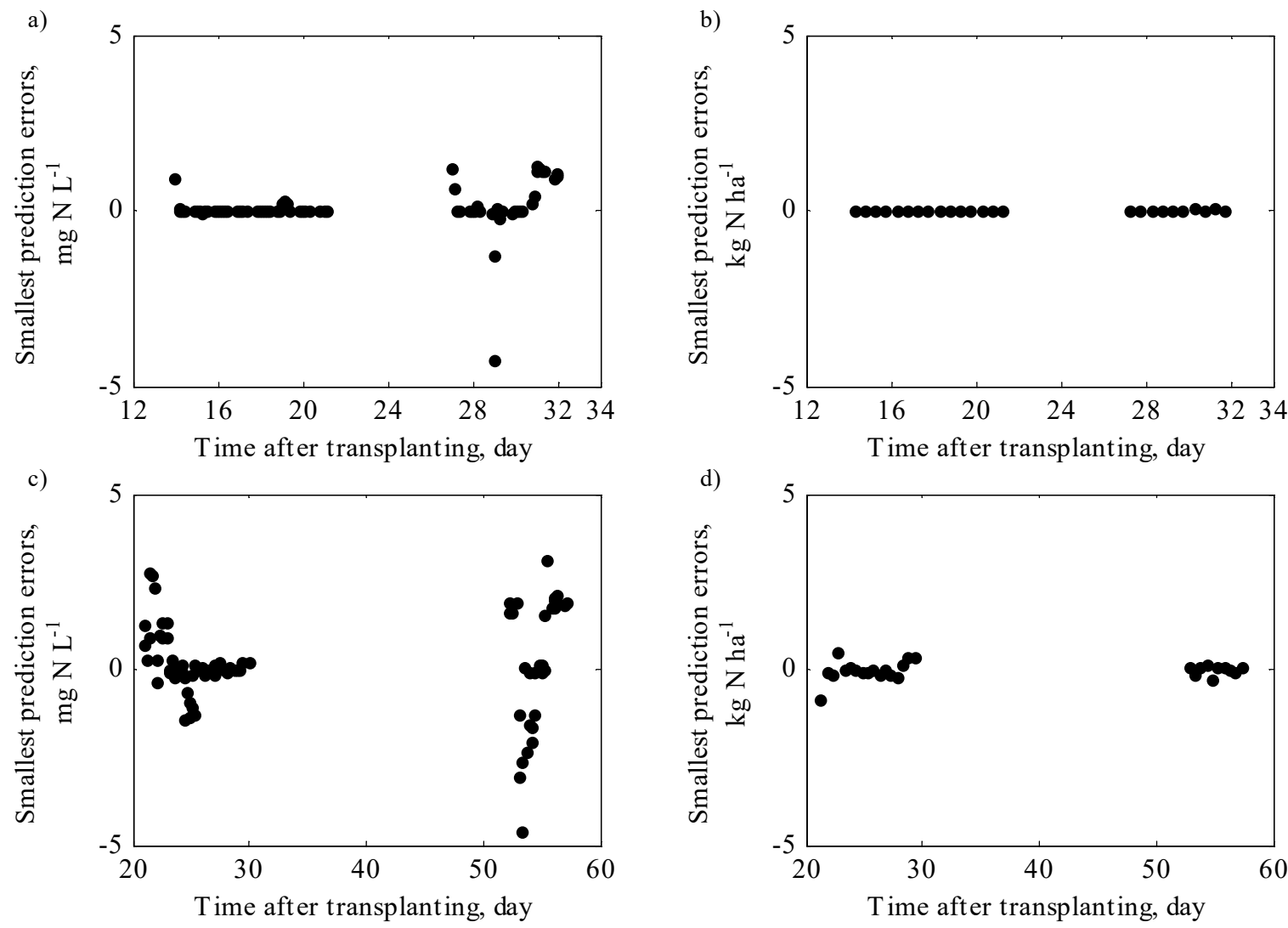

Fig. 5 Smallest prediction errors for Los Baños data set from 12 to 32 DAT: a) correspond to concentrations of total ammoniacal-N in the floodwater and $\mathrm{b}$ ) correspond to cumulative $\mathrm{NH}_{3}$ volatilisation, and for Muñoz data set from 20 to 60 DAT: c) correspond to concentrations of total ammoniacal-N in the floodwater and d) correspond to cumulative $\mathrm{NH}_{3}$ volatilisation 


\subsubsection{Eigenvalue decomposition of the dispersion matrix}

The eigenvalue decomposition analysis for Los Baños was based on 369 feasible parametervectors retrieved from a total of 4000 sampled parameter-vectors. The eigenvalue decomposition analysis for Muñoz was based on 37 feasible parameter-vectors retrieved from a total of 3000 sampled parameter-vectors (see Appendix B). Among the six parameters, the eigenvalue decomposition of the dispersion matrices that characterises the FPS of both Los Baños and Muñoz indicated that the model was most sensitive to $\beta$, followed by $K_{E}$ and $S_{0}$. The model was least sensitive to $K_{v A T}$ Los Baños and $K_{v P I}$ for Muñoz.

\subsubsection{Non-linear least squares method}

First, $K_{h}$ was estimated using the Levenberg-Marquardt algorithm using Los Baños and Muñoz data sets simultaneously. Four initial guesses of $K_{h}$ were defined, and the values of the estimated $K_{h}$ ranged from 0.7491 to 0.8473 (Table 4). The relatively small standard deviations compared to the estimates of $K_{h}$ indicated that the estimates were reliable. Notice that the estimates of $K_{h}$, using the Levenberg-Marquardt algorithm, were within the range of feasible $K_{h}$ estimates, obtained from the set-membership approach with soft error-bound conditions (Section 5.4.1).

Second, $K_{E}, \beta, K_{\text {sink }}, S_{0}, K_{v A T}$, and $K_{v P I}$ were estimated using three non-linear least-squares methods using only the Los Baños data set. The estimates and the respective standard deviations are also shown in Table 4. The Levenberg-Marquardt and Trust-reflective-region algorithms took from 0.22 hours to 0.67 hours to estimate the parameters. The Nelder-Mead algorithm was stopped after about 2.5 hours, giving the following estimates: $K_{E}=0.6116$ day $^{-1}, \beta=0.0201$ day $^{-1}, K_{\text {sink }}=2.0926$ day $^{-1}, S_{0}=0.6950, K_{v A T}=5.9342$ day $^{-1}, K_{v P I}=$ 4.9822 day $^{-1}$ ), which as for the Trust-reflective region algorithm did not deviate much from the initial guesses in Step 2. Thus, in step 2 neither Nelder-Mead nor Trust-reflective region algorithm converged.

Notice from Table 4 that especially the estimates obtained using the Levenberg-Marquardt algorithm deviated significantly from the initial guesses compared to those estimated using Trust-reflective-region algorithm. Furthermore, Step 3 in Table 4 shows that the new initial guesses led to new estimates and thus indicate the existence of local minima. Also, notice the large standard deviations of the estimates of $\beta$ and $S_{0}$, which indicate a strong correlation 
between these parameter estimates and was confirmed by the correlation matrix of the estimates.

Table 4 Parameters estimated using non-linear least-squares method

\begin{tabular}{|c|c|c|c|}
\hline \multirow{2}{*}{ Parameter } & \multirow{2}{*}{$\begin{array}{l}\text { Initial } \\
\text { guess }\end{array}$} & \multicolumn{2}{|c|}{ Estimate } \\
\hline & & Levenberg-Marquardt & Trust-reflective-region \\
\hline \multicolumn{4}{|l|}{ Step 1} \\
\hline \multirow[t]{4}{*}{$K_{h}\left(\right.$ day $\left.^{-1}\right)$} & 0.3 & $0.7491 \pm 0.0301(\mathrm{SSQ}: 13381)$ & - \\
\hline & 0.8 & $0.7951 \pm 0.0276($ SSQ: 11493$)$ & - \\
\hline & 0.9 & $0.8473 \pm 0.0230($ SSQ: 12018$)$ & - \\
\hline & 1.3 & $0.7953 \pm 0.0278$ (SSQ: 11493$)$ & - \\
\hline \multicolumn{4}{|l|}{ Step 2} \\
\hline$K_{E}\left(\mathrm{day}^{-1}\right)$ & 0.6000 & $0.5325 \pm 0.0234$ & $0.6000 \pm 0.0025$ \\
\hline$\beta\left(\right.$ day $\left.^{-1}\right)$ & 0.0200 & $0.1053 \pm 0.1030$ & $0.0200 \pm 0.0005$ \\
\hline$K_{\text {sink }}\left(\right.$ day $\left.^{-1}\right)$ & 2.0000 & $2.8900 \pm 1.1020$ & $1.9998 \pm 0.0026$ \\
\hline$S_{0}(-)$ & 0.7000 & $0.2253 \pm 0.1202$ & $0.7000 \pm 0.0037$ \\
\hline$K_{v A T}\left(\right.$ day $\left.^{-1}\right)$ & 6.0000 & $10.1069 \pm 0.4489$ & $6.0000 \pm 0.2676$ \\
\hline \multirow[t]{2}{*}{$K_{v P I}\left(\right.$ day $\left.^{-1}\right)$} & 5.0000 & $2.2007 \pm 2.2033$ & $5.0000 \pm 6.2085$ \\
\hline & & (SSQ: 374.86) & (SSQ: 1173.40) \\
\hline \multicolumn{4}{|l|}{ Step 3} \\
\hline$K_{E}\left(\right.$ day $\left.^{-1}\right)$ & 0.6000 & $0.6843 \pm 0.0411$ & $0.6276 \pm 0.0435$ \\
\hline$\beta\left(\right.$ day $\left.^{-1}\right)$ & 0.2000 & $0.1708 \pm 1.4394$ & $0.2643 \pm 0.3579$ \\
\hline$K_{\operatorname{sink}}\left(\right.$ day $\left.^{-1}\right)$ & 2.0000 & $2.1454 \pm 0.3156$ & $2.1694 \pm 0.1412$ \\
\hline$S_{0}(-)$ & 2.0000 & $3.0083 \pm 118.69$ & $8.6334 \pm 9.8734$ \\
\hline$K_{v A T}\left(\right.$ day $\left.^{-1}\right)$ & 10.0000 & $10.2616 \pm 0.4192$ & $10.2211 \pm 0.4372$ \\
\hline \multirow[t]{2}{*}{$K_{v P I}\left(\right.$ day $\left.^{-1}\right)$} & 2.0000 & $6.1104 \pm 1.6590$ & $2.2118 \pm 1.6679$ \\
\hline & & (SSQ: 270.70) & (SSQ: 305.09) \\
\hline
\end{tabular}

SSQ is the residual sum of squares provided by resnorm via lsqnonlin command in MATLAB

Note from Table 2 (Los Baños data set) that the estimates obtained using the LevenbergMarquardt algorithm in Table 4 were within the range of feasible parameter-vectors retrieved using the set-membership estimation, except for $\beta$, which was out of the a priori parameter region, and for the unreliable estimate of $S_{0}$ in step 3. These results imply that feasible parameter-vectors retrieved using the set-membership estimation will include estimates obtained from non-linear least-squares methods, provided appropriate error-bound conditions were defined.

Fig. 6 shows the simulated model-outputs using the estimates obtained using the LevenbergMarquardt and Trust-reflective-region algorithms for Los Baños. These results show the effects of local minima on the model responses and once more show the difficulty in fitting the Los Baños data for 26 to 34 DAT. 

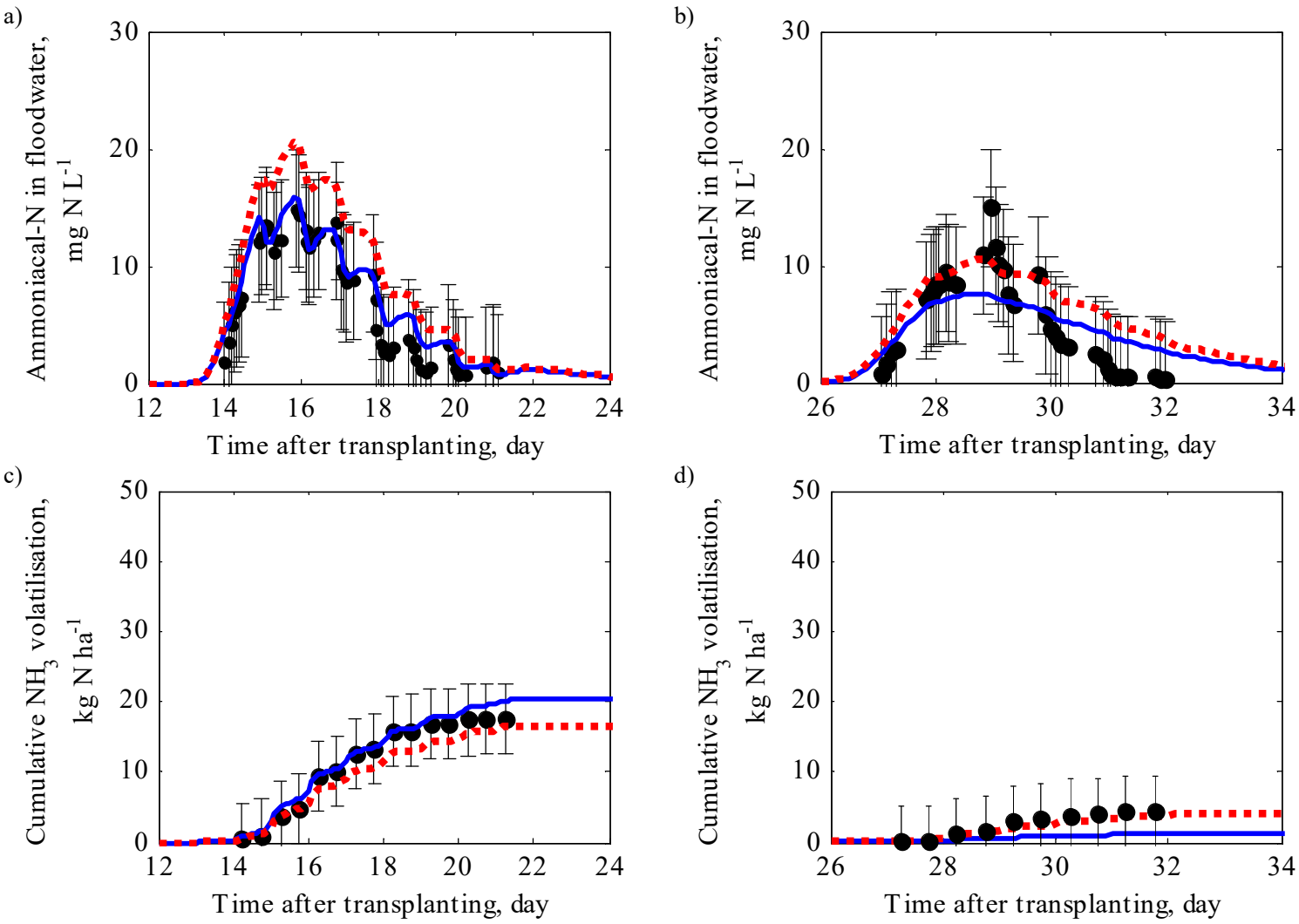

Fig. 6 Simulated model-outputs using estimates (Step 2 in Table 4) obtained using the Levenberg-Marquadt (blue solid lines) and Trust-reflective-region (red dash lines) algorithms for Los Baños: a) concentrations of total ammoniacal-N in floodwater from 12 to 24 DAT, and b) from 26 to $34 \mathrm{DAT}$, and c) cumulative $\mathrm{NH}_{3}$ volatilisation from 12 to $24 \mathrm{DAT}$, and d) from 26 to 34 DAT

\subsubsection{Trade-off between hard and soft error-bound conditions}

First, hard error-bound conditions with $\varepsilon_{1}=5 \mathrm{mg} \mathrm{N} \mathrm{L}^{-1}, \varepsilon_{2}=5 \mathrm{mg} \mathrm{N} \mathrm{L}^{-1}$, and $\varepsilon_{3}=5 \mathrm{~kg} \mathrm{~N}$ $\mathrm{ha}^{-1}$ were applied on the three state variables, and thus, for a parameter-vector to be an element of FPS, $\left\|\boldsymbol{e}_{\boldsymbol{i}}\right\|_{\infty} \leq \varepsilon_{i}$ for all $t$ and $i=1,2,3$. However, by applying the hard errorbound conditions on the three state variables, no feasible parameter-vectors were retrieved for the estimation of $K_{h}$ and the other six parameters.

These negative results could be due to errors in model structure, which may result from simplifications of the complex agri-environmental system with interactive biological and chemical processes, and/or errors in observational data sets, which may arise from digitisation (extraction) of the data from figures provided in Fillery et al. (1984), or inaccurate assumption on the exact timing of urea application. Such problems are not always avoidable for complex agri-environmental systems, where many interactive processes occur and detailed field and 
lab work are time consuming, laborious, and can be costly for developing countries with limited funds.

Detailed analysis showed that some elements in prediction error vectors that correspond to concentrations of urea- $\mathrm{N}$ and total ammoniacal-N violated the specified error-bounds $\varepsilon_{1}$ and $\varepsilon_{2}$, but almost all elements in the prediction error vectors that correspond to cumulative $\mathrm{NH}_{3}$ volatilisation obeyed the specified error-bound $\varepsilon_{3}$ (see Fig. 5b, d).

There are at least three possible ways to deal with unknown error-bounds. Choose: 1) hard error-bounds which are provisional (exploratory), in the absence of good information on the error sources and their properties, and adjust if necessary by trial and error, 2) soft-bounds each of which attaches a penalty to any error falling within a range between two specified values for that bound, i.e., over that range feasibility varies from 1 (perfectly feasible) and zero (infeasible) (Keesman and Van Straten, 1987), or 3) the soft error-bound conditions as demonstrated in this chapter.

In order to retrieve some feasible parameter-vectors, we opted to introduce the soft errorbound conditions. It was found that the first option required very large error-bounds to identify a non-empty FPS, i.e., $\varepsilon_{1}>25 \mathrm{mg} \mathrm{N} \mathrm{L}^{-1}$ and $\varepsilon_{2}>10 \mathrm{mg} \mathrm{N} \mathrm{L}^{-1}$. Therefore, in this study, soft error-bound conditions were applied for two state variables, which were concentrations of urea $\mathrm{N}$ and total ammoniacal- $\mathrm{N}$ in the floodwater, by gradually increasing the number of time instants for which the model-output violated the specified error-bounds, until some feasible parameter-vectors were retrieved.

For the estimation of $K_{h}$, for at least $30 \%$ of the sample time instants $t$, the following holds: $\left\|\boldsymbol{e}_{\mathbf{1}_{\boldsymbol{A}} \boldsymbol{T}}\right\|_{\infty} \leq \varepsilon_{1}$ and $\left\|\boldsymbol{e}_{\mathbf{1}_{\boldsymbol{P I}}}\right\|_{\infty} \leq \varepsilon_{1}$. Nevertheless, even with the high tolerance on the error, the quality of estimation obtained via a set-membership approach was comparable with conventional methods, in particular for the Los Baños data set, after the first urea application after transplanting (Fig. 3a) and for Muñoz after the second urea application after transplanting (Fig. 3c). For the estimation of $K_{E}, \beta, K_{\text {sink }}, S_{0}, K_{v A T}$, and $K_{v P I}$, for at least $90 \%$ of the sample time instants, the followings hold: $\| \boldsymbol{e}_{\mathbf{2}_{A T} \|_{\infty}} \leq \varepsilon_{2}$ and $\left\|\boldsymbol{e}_{\mathbf{2}_{\boldsymbol{P I}}}\right\|_{\infty} \leq \varepsilon_{2}$.

It was discovered that whenever a soft error-bound condition was applied, the prediction errors of different time-series should be grouped in different vectors. In this case, the 
prediction errors were separated into two vectors which were $\boldsymbol{e}_{\boldsymbol{i}_{\boldsymbol{A}} \boldsymbol{T}}$ and $\boldsymbol{e}_{\boldsymbol{i}_{\boldsymbol{P I}}}$ in order to ensure the prediction errors that corresponded to the first and second urea applications were equally accounted for in the soft error-bound conditions.

By applying the soft error-bounds conditions, we allowed the interaction between model and data to determine when to increase the error-bound, rather than pre-specifying a larger errorbound. Thus, for ill-defined systems with significant model structure inadequacies, a trade-off between hard error-bounds and soft-bound conditions should be considered.

\subsubsection{Comparison of parameter estimation methods}

One of the fundamental differences between the set-membership approach and the non-linear least-squares estimation method is that the former aims at finding multiple feasible parametervectors by specifying the maximally allowed prediction errors (specifically under a hard error-bound condition), whereas the latter aims at finding one optimal parameter-vector which minimises the sum of squares of prediction errors. However, Keesman (2011) states that in general a global minimum in numerical minimisation procedures, such as the non-linear leastsquares methods, cannot be guaranteed (see Table 4).

Furthermore, the presence of structural modelling errors (see Fig. 3), as is quite common in practical applications, most likely lead to biased parameter estimates and hamper the finding of a global minimum. Hence, an estimate of the covariance matrix evaluated at the biased parameter estimate (Section 5.3.7) will merely give a crude approximation of the uncertainties in the estimates. Even for the estimation of the single parameter $K_{h}$ from 75 observations of urea-N concentration the Levenberg-Marquardt algorithm gave four different estimates (Table 4), depending on the initial guesses in Step 2 and 3.

The estimation of $K_{E}, \beta, K_{\text {sink }}, S_{0}, K_{v A T}$ and $K_{v P I}$ from two observed state variables, further emphasised this situation, as the estimates did not only depend on the initial guesses, but also on the type of search algorithm used, as demonstrated in Section 5.4.2.

In this case, six unknown parameters were estimated from concentrations of urea-N and total ammoniacal-N. Although it is ideal to have sufficient observed process variables, lack of detailed data sets is typical for complex agri-environmental systems where only few state variables can be observed in experiments due to technical challenges and time, labour and 
cost constraints. In fact, some agri-environmental models were only evaluated against seasonal data sets, see Chowdary et al. (2004) and Liang et al. (2014).

However, as an alternative to the non-linear least-squares methods with corresponding estimate of the covariance matrix, a set-membership approach offers an efficient and transparent method in retrieving a potentially non-convex and non-connected set of feasible parameter-vectors that directly reflects the uncertainty in the estimates. Taking the Los Baños case, for instance, the set-membership estimation approach took an average of 4.6 hours to simulate for 1000 sampled parameter-vectors. The non-linear least-squares methods may only evaluate at most 21 vectors with initial guess within 4.6 hours, assuming 0.22 hours per optimisation (see Section 5.4.2 for details on computational time).

\subsection{Conclusion}

A set-membership (bounded-error) estimation approach can be a good tool in modelling agrienvironmental systems as the approach retrieves sets of feasible parameter-vectors that directly reflect the uncertainty in the estimates. An additional advantage of a sampling-based set-membership estimation approach is that it allows for sensitivity analysis of parameters in a parameter region. However, a sampling-based set-membership approach, although easy to implement, requires an efficient sampling scheme to ensure a good coverage of samples in the a priori parameter region.

\section{References}

Amairi, M. 2015. Recursive set-membership parameter estimation using fractional model. Circuits Syst Signal Process, 34, pp. 3757-3788.

Antonopoulos, V. Z. 2010. Modelling of water and nitrogen balances in the ponded water and soil profile of rice fields in Northern Greece. Agric Water Manag, 98, pp. 321-330

Beck, M. B. 2002. Environmental Foresight and Models: A Manifesto. Amsterdam: Elsevier.

Belforte, G. \& Milanese, M. 1981. Uncertainty intervals evaluation in presence of unknown but bounded errors. Nonlinear families of models. In: Proc. IASTED International Symposium: Modelling, Identification and Control, Davos. 75-79.

Bouwman, A. F., Boumans, L. J. M. \& Batjes, N. H. 2002. Estimation of global $\mathrm{NH}_{3}$ volatilization loss from synethetic fertilizers and animal manure applied to arable lands and grasslands. Glob Biogeochem Cycl, 16, pp. 8-1 - 8-14.

Cao, Y., Tian, Y., Yin, B. \& Zhu, Z. 2013. Assessment of ammonia volatilization from paddy fields under crop management practices aimed to increase grain yield and $\mathrm{N}$ efficiency. Field Crop Res, 147, pp. 23-31.

Cerone, V., Razza, V. \& Regruto, D. 2015. Set-membership estimation of fiber laser physical parameters from input-output power measurements. Automatica, 61, pp. 211-217. 
Chen, A., Lei, B., Hu, W., Lu, Y., Mao, Y., Duan, Z. \& Shi, Z. 2015. Characteristics of ammonia volatilization on rice grown under different nitrogen application rates and its quantitative predictions in Erhai Lake Watershed, China. Nutr Cycl Agroecosyst, 101, pp. 139-152.

Chowdary, V. M., Rao, N. H. \& Sarma, P. B. S. 2004. A coupled soil water and nitrogen balance model for flooded rice fields in India. Agric Ecosyst Environ, 103, pp. 425441.

De Datta, S. K., Samson, M. I., Obcemea, W. N., Real, J. G. \& Buresh, R. J. 1991. Direct measurement of ammonia and denitrification fluxes from urea applied to rice. Soil Sci Soc Am J, 55, pp. 543-548.

Fillery, I. R. P., Roger, P. A. \& De Datta, S. K. 1986. Ammonia volatilization from nitrogen sources applied to rice fields: II. Floodwater properties and submerged photosynthetic biomass. Soil Sci Soc Am J, 50, pp. 86-91.

Fillery, I. R. P., Simpson, J. R. \& De Datta, S. K. 1984. Influence of field environment and fertilizer management on ammonia loss from flooded rice. Soil Sci Soc Am J, 48, pp. 914-920.

Godwin, D. C. \& Singh, U. 1998. Nitrogen balance and crop response to nitrogen in upland and lowland cropping systems. In: Tsuji, G. Y., Hoogenboom, G. \& Thornton, P. K. (eds.) Understanding Options for Agricultural Production. Springer Netherlands, pp. 55-77.

Jakeman, A. J., Letcher, R. A. \& Norton, J. P. 2006. Ten iterative steps in development and evaluation of environmental models. Environ Model Softw, 21, pp. 602-614.

Jayaweera, G. R. \& Mikkelsen, D. S. 1990. Ammonia volatilization from flooded soil systems: A computer model. I. Theoretical aspects. Soil Sci Soc Am J, 54, pp. 14471455.

Keesman, K. J. 1989. On the dominance of parameters in structural models of ill-defined systems. Appl Math Comput, 30, pp. 133-147.

Keesman, K. J. 1990. Membership-set estimation using random scanning and principal component analysis. Math Comput Simul, 32, pp. 535-543.

Keesman, K. J. 1991. Robust identification and prediction for output error models. In: Proc. IFAC/IFORS Symposium on Identification and System Parameter Estimation, Budapest, Hungary. 878-882.

Keesman, K. J. 2011. System Identification: An Introduction. Springer UK.

Keesman, K. J., Norton, J. P., Croke, B. F. W., Newham, L. T. H. \& Jakeman, A. J. 2013. Setmembership approach for identification of parameter and prediction uncertainty in power-law relationships: The case of sediment yield. Environ Model Softw, 40, pp. 171-180.

Keesman, K. J. \& Van Straten, G. 1987. Modified set-theoretic identification of ill-defined water quality system from poor data. In: Proc. IAWPRC Symp. Systems Analysis in Water Quality Management. Pergamon Press, Oxford, 297-308.

Keesman, K. J. \& Van Straten, G. 1990. Set membership approach to identification and prediction of lake eutrophication. Water Resour Res, 26, pp. 2643-2652.

Lahanier, H., Walter, E. \& Gomeni, R. 1987. OMNE: a new robust membership-set estimator for the parameters of nonlinear models. J Pharm Biopharm, 15, pp. 203-219.

Li, H., Liang, X., Chen, Y., Tian, G. \& Zhang, Z. 2008. Ammonia volatilization from urea in rice fields with zero-drainage water management. Agric Water Manag, 95, pp. 887894.

Liang, X., Yuan, J., He, M., Li, H., Liang, L. \& Tian, G. 2014. Modeling the fate of fertilizer $\mathrm{N}$ in paddy rice systems receiving manure and urea. Geoderma, 228-229, pp. 54-61. 
Liang, X. Q., Chen, Y. X., Li, H., Tian, G. M., Ni, W. Z., He, M. M. \& Zhang, Z. J. 2007. Modelling transport and fate of nitrogen from urea applied to a near-trench paddy field. Environ Pollut, 150, pp. 313-320.

Liu, T. Q., Fan, D. J., Zhang, X. X., Chen, J., Li, C. F. \& Cao, C. G. 2015. Deep placement of nitrogen fertilizers reduces ammonia volatilization and increases nitrogen utilization efficiency in no-tillage paddy fields in central China. Field Crop Res, 184, pp. 80-90.

Makino, A. 2011. Photosynthesis, grain yield, and nitrogen utilization in rice and wheat. $A m$ Soc Plant Biol, 155, pp. 125-129.

Marsili-Libelli, S. 2016. Environmental Systems Analysis with Matlab. Taylor \& Francis.

Milanese, M., Norton, J. P., Piet-Lahanier, H. \& Walter, E. 1996. Bounding Approaches to Systems Identification. New York: Plenum Press.

Milanese, M. \& Novara, C. 2004. Nonlinear set membership prediction of river flow. Syst Control Lett, 53, pp. 31-39.

Mocenni, C. \& Vicino, A. 2006. Modelling ecological competition between seaweed and seagrass: A case study. In: Proc. IFAC SYSID 2006, Newcastle, Australia. 732-737.

Norton, J. P. 1987. Identification and application of bounded-parameter models Automatica, 23, pp. 497-507.

Norton, J. P. 1994. Bounded-error estimation: Issue 1. Int J Adapt Control Signal Process, 8, $\mathrm{pp}$.

Nurulhuda, K., Struik, P. C. \& Keesman, K. J. 2015. Set-membership identification of an agro-ecosystems from a small data set: The case of ammonia volatilisation in a flooded rice field. In: MATHMOD 2015: 8th Vienna International Conference on Mathematical Modelling, Vienna, Austria. 580-585.

Rao, P. S. C., Jessup, R. E. \& Reddy, K. R. 1984. Simulation of nitrogen dynamics in flooded soils. Soil Sci, 138, pp. 54-62.

Schweppe, F. C. 1968. Recursive state estimation: unknown but bounded errors and system inputs. IEEE Trans Autom Control, 13, pp. 22-28.

Singh, R. \& Kirk, G. J. D. 1993. A model for predicting the fate of nitrogen fertilizer in lowland ricefields. I. Theory. J Soil Sci, 44, pp. 271-283.

Stokstad, E. 2014. Ammonia pollution from farming may exact hefty health costs. Science, 343, pp. 238.

Walter, E. \& Piet-Lahanier, H. 1990. Estimation of parameter bounds from bounded-error data: A survey. Math Comput Simul, 32, pp. 449-468.

Walter, E. \& Pronzato, L. 1997. Identification of Parametric Models (sec. 5.4.2.2). Berlin: Springer.

Wang, L. \& Garnier, H. 2012. System Identification, Environmental Modelling and Control System Design. Springer Verlag, UK.

$\mathrm{Xu}$, J., Peng, S., Yang, S. \& Wang, W. 2012. Ammonia volatilization losses from a rice paddy with different irrigation and nitrogen managements. Agric Water Manag, 104, pp. 184-192.

Young, P. C., Hornberger, G. M. \& Spear, R. C. 1978. Modelling badly defined systems: Some further thoughts. In: Proceedings of SIMSIG Simulation Conference, September, Canberra, Australia. Australian National University, 24-32.

Zuberer, D. A. 2005. Biological dinitrogen fixation: Introduction and nonsymbiotic. In: Sylvia, D. M., Fuhrmann, J. J., Hartel, P. G. \& Zuberer, D. A. (eds.) Principles and Applications of Soil Microbiology. 2nd ed. New Jersey: Pearson Prentice Hall, pp. 376. 


\section{Appendix A. Model input data for Los Baños and Muñoz}

a)
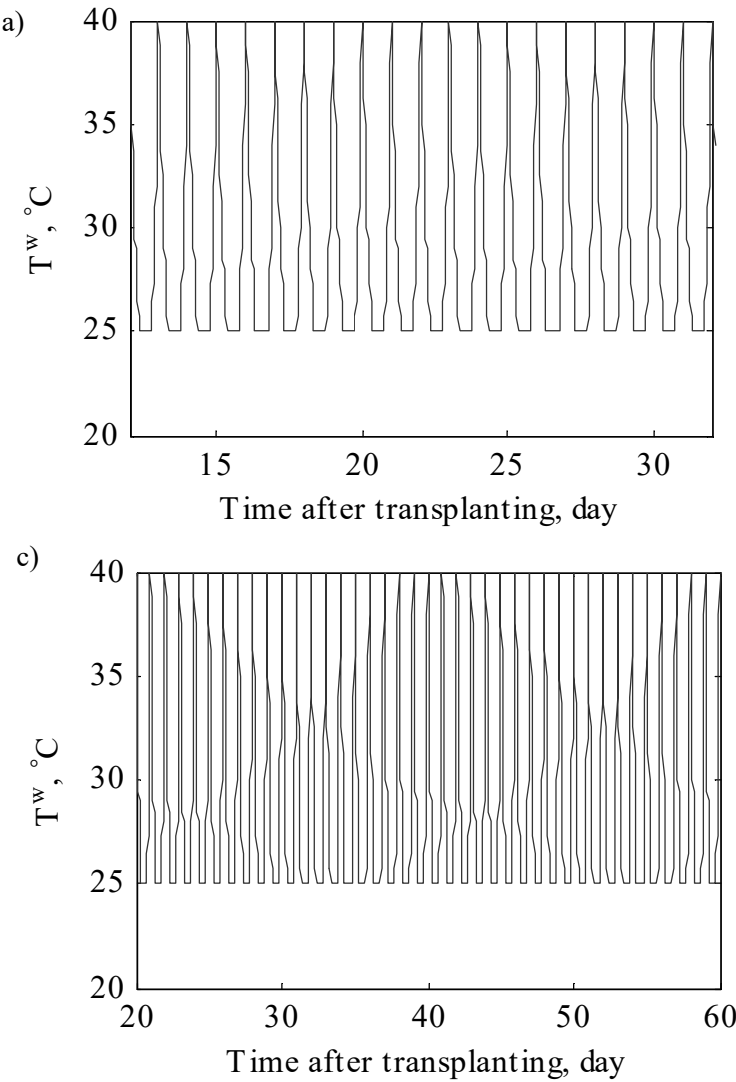

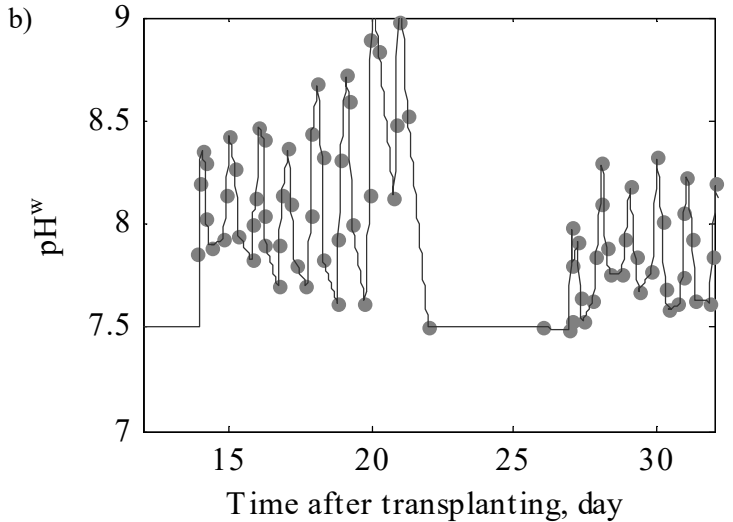

d)

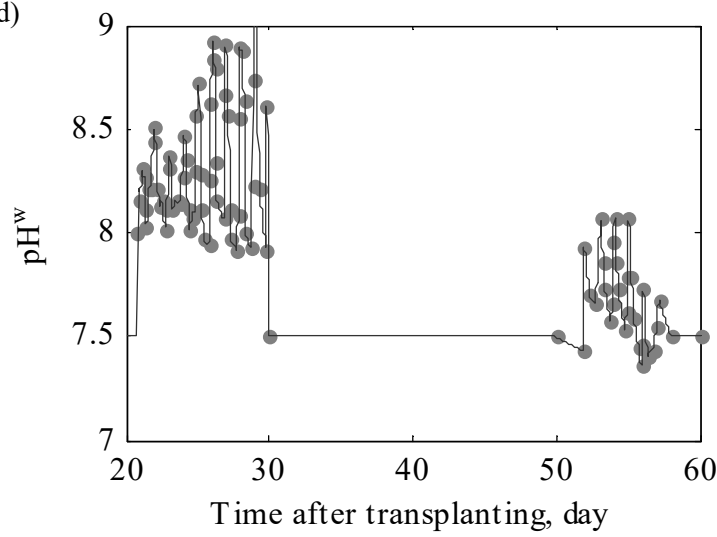

Fig. A.1 a) Synthetic floodwater temperature, and b) observed (dot) and interpolated (solid line) floodwater $\mathrm{pH}$ for Los Baños, and c) synthetic floodwater temperature that ranges from $25^{\circ} \mathrm{C}$ to $40^{\circ} \mathrm{C}$, and d) observed (dot) and interpolated (solid line) floodwater $\mathrm{pH}$ for Muñoz 


\section{Appendix B. Eigenvalue decomposition of the dispersion matrix of the feasible parameter-vectors}

\section{Los Baños}

All of the feasible parameter-vectors for Los Baños in Table 2 were combined and put into the $N_{X} \times p$ matrix $\mathbf{X}$ with corresponding $N_{X} \times p$ averaged matrix $\overline{\mathbf{X}}$ (Section 5.3.6 for details). Eigenvalue decomposition of $(\mathbf{X}-\overline{\mathbf{X}})^{\mathrm{T}}(\mathbf{X}-\overline{\mathbf{X}})$ resulted in the following eigen matrix

$$
V=\left[\begin{array}{cccccc}
-0.0136 & \mathbf{0 . 9 8 0 2} & -0.1972 & 0.0087 & 0.0011 & 0.0027 \\
\mathbf{0 . 9 9 9 4} & 0.0193 & 0.0269 & -0.0037 & -0.0007 & 0.0003 \\
0.0069 & -0.0276 & -0.0947 & \mathbf{0 . 9 7 1 0} & 0.2115 & -0.0508 \\
0.0296 & -0.1950 & -\mathbf{0 . 9 7 5 2} & -0.0943 & -0.0250 & 0.0229 \\
-0.0006 & 0.0004 & 0.0180 & 0.0472 & 0.0309 & \mathbf{0 . 9 9 8 2} \\
-0.0000 & 0.0001 & 0.0048 & 0.2142 & \mathbf{- 0 . 9 7 6 6} & 0.0200
\end{array}\right]
$$

and, the corresponding eigenvalues are given by

$\operatorname{diag}(D)=\left[\begin{array}{llllll}0.1 & 4.5 & 9.1 & 1194.8 & 2001.2 & 2476.5\end{array}\right]$

Each element in vector $\operatorname{diag}(D)$ is related to a column of matrix V. Each row in matrix V indicates a parameter weighting, in the following order from top to bottom: $K_{E}, \beta, K_{\text {sink }}, S_{0}, K_{v A T}$, and $K_{v P I}$.

\section{Muñoz}

Similary, all of the feasible parameter-vectors for Muñoz in Tables 2 and 3 were combined as above. Eigenvalue decomposition of $(\boldsymbol{X}-\overline{\boldsymbol{X}})^{\mathrm{T}}(\boldsymbol{X}-\overline{\boldsymbol{X}})$ resulted in the following eigenvectors

$$
V=\left[\begin{array}{cccccc}
0.1107 & \mathbf{- 0 . 9 9 3 3} & -0.0319 & 0.0114 & 0.0030 & 0.0037 \\
\mathbf{- 0 . 9 9 0 8} & -0.1129 & 0.0740 & -0.0056 & 0.0089 & 0.0009 \\
-0.0149 & 0.0007 & -0.0625 & 0.2828 & -\mathbf{0 . 9 5 7 0} & 0.0045 \\
-0.0764 & 0.0240 & \mathbf{- 0 . 9 9 3 4} & 0.0320 & 0.0755 & -0.0071 \\
-0.0001 & 0.0106 & 0.0507 & \mathbf{0 . 9 4 6 6} & 0.2772 & 0.1560 \\
0.0000 & 0.0023 & -0.0148 & -0.1506 & -0.0389 & \mathbf{0 . 9 8 7 7}
\end{array}\right]
$$

and, the corresponding eigenvalues are given by

$$
\operatorname{diag}(D)=\left[\begin{array}{llllll}
0.0070 & 0.0812 & 0.6038 & 27.313 & 69.880 & 179.13
\end{array}\right]
$$

Similarly, each element in vector $\operatorname{diag}(D)$ is related to a column of matrix V. Each row in matrix $\mathrm{V}$ indicates a parameter weighting, in the following order from top to bottom: $K_{E}, \beta, K_{\text {sink }}, S_{0}, K_{v A T}$, and $K_{v P I}$. 

CHAPTER 6

General discussion

K. Nurulhuda 


\subsection{Introduction}

The ammonia $\left(\mathrm{NH}_{3}\right)$ losses in fertilised and flooded rice systems range from about $2 \%$ to $60 \%$ of total $\mathrm{N}$ applied. The net $\mathrm{NH}_{3}$ loss may not be solely contributed by $\mathrm{NH}_{3}$ volatilisation from the floodwater surface, but also through a stomatal pathway. However, modelling studies of the latter pathway are hindered due to lack of studies on sinks and sources of atmospheric $\mathrm{NH}_{3}$ in fertilised and flooded rice systems. Except for Hayashi et al. (2008), researchers in general claimed that the net $\mathrm{NH}_{3}$ loss to the atmosphere was due to volatilisation from the

floodwater (Chapter 1). As a result, existing models for simulating the $\mathrm{N}$ dynamics in floodwater and soil of a rice system conceptualise $\mathrm{NH}_{3}$ volatilisation only from the floodwater surface (Chapter 2). Since models are approximations of the actual systems, not all hypotheses on $\mathrm{N}$ processes in the overall systems are conceptualised in models. Consequently, models with different underlying concepts are available to estimate $\mathrm{NH}_{3}$ volatilisation from the floodwater surface in fertilised and flooded soil systems. To the best of our knowledge, many of these models have not been co-validated with one another with respect to their performance in estimating $\mathrm{NH}_{3}$ volatilisation in fertilised and flooded rice systems.

With progress in the development of the models for simulating $\mathrm{N}$ dynamics in flooded soil systems, with and without a rice crop, the main objective of this thesis was, therefore, to determine an appropriate process-based model structure for estimating $\mathrm{NH}_{3}$ volatilisation in fertilised and flooded rice systems that were broadcast with urea.

In this thesis, evaluation of model structure adequacy is discussed under the major assumption that the net $\mathrm{NH}_{3}$ loss occurs only through $\mathrm{NH}_{3}$ volatilisation from the floodwater surface. Despite this limitation, the findings presented in this thesis are important as several models in Chapter 2 are currently being used to estimate $\mathrm{NH}_{3}$ loss in fertilised and flooded rice systems. Resistance models have been used to estimate sinks and sources of atmospheric $\mathrm{NH}_{3}$ in arable crop systems (Chapter 1), but these models were not studied in this thesis as we, and many other researchers in this field, focused on models that were able to simulate the $\mathrm{N}$ dynamics in the floodwater and soil.

\subsection{Research approach of this thesis}

In this thesis, first, a priori knowledge was evaluated in Chapter 2 where the differences and similarities of concepts and structures of 14 existing models, and the reported performances of 
the models in simulating the $\mathrm{N}$ dynamics in flooded soil systems were examined. The chapter provides a basis to assist the researcher in choosing a model based on the definition of key focal processes. Second, equifinality of the mathematical models of urea hydrolysis and $\mathrm{NH}_{3}$ volatilisation at single process level was determined for conditions observed in tropical fertilised and flooded rice systems in Chapter 3. Complex models cannot be easily evaluated for ill-defined systems. Meanwhile, simple process-based models would have fewer unknown parameters that need to be calibrated from the limited observational data sets, but the adequacy of the model structure for the estimation of $\mathrm{NH}_{3}$ volatilisation needed to be examined. Therefore, the third step was to investigate the adequacy of a simple process-based model for the estimation of $\mathrm{NH}_{3}$ volatilisation from the floodwater surface in fertilised and flooded soil systems. Several simple lumped-parameter models are described in Chapter 2, but insights from Chapter 3 indicated that the structures of the existing models were not adequate in estimating the trend of cumulative $\mathrm{NH}_{3}$ volatilisation from fertilised and flooded rice systems. Therefore, a new model was proposed in Chapter $\mathbf{4}$ as an improvement to existing lumped-parameter models. The proposed model was calibrated, and subsequently falsified by some data sets. Although typically positive outcomes in validation are sought, falsification of the model improved our understanding of the limitation of the model structure. Some of the unknown parameters in the model were gradually varied to fit the data (Chapter 4), but this calibration approach was not systematic. Meanwhile, conventional least-squares methods are not appropriate for poor data conditions, for instance, large errors in observations or small number of observations. Thus, as the fourth step, the set-membership approach was used to estimate the unknown parameters and to characterise the uncertainty in the parameter estimates in Chapter 5. As an alternative to the non-linear least-squares methods with corresponding estimate of the covariance matrix, a set-membership approach offers an efficient and transparent method in retrieving a potentially non-convex and non-connected set of feasible parameter-vectors that directly reflects the uncertainty in the estimates. The setmembership approach further allows for sensitivity analysis of parameters in a parameter region.

\subsection{Model structure adequacy for the estimation of $\mathrm{NH}_{3}$ volatilisation in fertilised and flooded rice systems}

Prior to this thesis, it was not clear whether existing models for the estimation of $\mathrm{NH}_{3}$ volatilisation significantly differ from one another, as relevant models was validated with 
independent data sets (Chapter 2). The systematic and integrated approach in this thesis revealed limitations and advantages of different modelling concepts and structures for the estimation of $\mathrm{NH}_{3}$ volatilisation in fertilised and flooded rice systems which previously may not have been discernible. In addition to Table A.7 in Chapter 2 which presented the performance of the model, the findings presented in this section can be used as criteria for stakeholders to make an informed selection of models, to modify the existing models for a specific purpose, and to interpret model-output responses critically.

Co-validation of model structures for the estimation of $\mathrm{NH}_{3}$ volatilisation from the floodwater revealed that the partitioning between $\mathrm{NH}_{3}$ and $\mathrm{NH}_{4}{ }^{+}$must be conceptualised in order to capture the diurnal trend of $\mathrm{NH}_{3}$ volatilisation observed by Fillery et al. (1984) and Fillery et al. (1986). The partitioning is regulated by floodwater $\mathrm{pH}$ and temperature. In Chapter 3, it is found that the prediction of $\mathrm{NH}_{3}$ volatilisation is sensitive to the range of floodwater $\mathrm{pH}$, but not sensitive to the range of floodwater temperature typically found in tropical flooded rice systems. Neglecting the floodwater temperature effect on the partitioning of $\mathrm{NH}_{3}$ and $\mathrm{NH}_{4}{ }^{+}$ did not result in significant differences in the estimates of $\mathrm{NH}_{3}$ volatilisation, as demonstrated in the case of the Rao et al. (1984) model.

In contrast, Jayaweera and Mikkelsen (1990a), Hayashi et al. (2008), and Chen et al. (2015) suggested that an increase in floodwater temperature has either an exponentially or a linearly increasing effect on the cumulative $\mathrm{NH}_{3}$ volatilisation. Usually, sensitivity analysis of a model is performed by varying only one process variable at a time. Consequently, in the case of analysing the sensitivity of $\mathrm{NH}_{3}$ volatilisation with respect to the floodwater temperature, the floodwater $\mathrm{pH}$ was assumed constant, which may amplify the effect of floodwater temperature on $\mathrm{NH}_{3}$ volatilisation. However, if the diurnal trends of both floodwater $\mathrm{pH}$ and temperature, which change at hourly time interval and typically peak at mid-day, are considered, the anticipated effect of increasing floodwater temperature on cumulative $\mathrm{NH}_{3}$ volatilisation was small, as shown in Chapter 3.

In Chapter 3, two models that can simulate the diurnal trends of floodwater $\mathrm{pH}$ were compared. Estimation of the floodwater $\mathrm{pH}$ using a simple model has a limited working $\mathrm{pH}$ range as the model directly assumes the floodwater $\mathrm{pH}$ would follow a sinusoidal trend, but trying to describe the underlying mechanisms resulted in highly intricate model, for instance, the model by Singh and Kirk (1993) (Chapter 3). It is concluded that the floodwater pH 
should be measured in-situ using a $\mathrm{pH}$ probe and simply treated as disturbance input in models.

In models by Chowdary et al. (2004), Liang et al. (2007), Antonopoulos (2010), and the model proposed in this thesis, the floodwater is assumed a single well-mixed compartment. In these models, the cumulative $\mathrm{NH}_{3}$ volatilisation is proportional to the mass of $\mathrm{NH}_{3}$ in a single floodwater compartment, and therefore, is irrelevant to the changes in concentrations of total ammoniacal-N. Thus, a change in the floodwater depth does not affect the rate of $\mathrm{NH}_{3}$ volatilisation (Chapter 4). This result contradicts with studies by Freney et al. (1988), Hayashi et al. (2006), Hayashi et al. (2008), and Win et al. (2009) who indicated that increasing floodwater depth would minimise the rate of $\mathrm{NH}_{3}$ volatilisation.

APSIM-Oryza and CERES-Rice also assume a single well-mixed floodwater compartment, but the rate of $\mathrm{NH}_{3}$ volatilisation is estimated using an empirical equation which is a function of floodwater properties, including floodwater depth. In the model of Jayaweera and Mikkelsen (1990a), the floodwater is also assumed to be a single well-mixed compartment, but formation of a two-film layer at the floodwater surface is conceptualised. However, the effect of floodwater depth appears twice because of the assumption made by Jayawera and Mikkelsen (1990a) in order to solve the full differential equations, which finally resulted in Eq. 7 in Chapter 3. The first effect of floodwater depth is through the concentration of the total ammoniacal $\mathrm{N}$ which is measured and then used as input to the model. The second effect is through the direct relationship between floodwater depth and rate of $\mathrm{NH}_{3}$ volatilisation as a result of the two-film theory. However, in Chapter $\mathbf{3}$ the assumption were actually removed (Eq. 9 in Chapter 3).

Simulation of the model by Jayaweera and Mikkelsen (1990a) for flooded soil systems without a rice crop showed that an increase in floodwater depth significantly minimised $\mathrm{NH}_{3}$ volatilisation (Jayaweera and Mikkelsen, 1990b). However, the decrease in cumulative $\mathrm{NH}_{3}$ volatilisation predicted by the model of Jayaweera and Mikkelsen (1990b) was larger than the field observations by Freney et al. (1988). Direct comparison is not impartial because results were simulated or measured under different environmental properties. However, what is important is that both model and data pointed out that floodwater depth would minimise the floodwater depth, but to what extent is not known.

In models by Bouwmeester and Vlek (1981), Moeller and Vlek (1982), and Singh and Kirk 
(1993) and in the model NFLOOD v.1, the floodwater compartment is divided into several vertically segmented layers, where $\mathrm{N}$ transport across the layers is assumed via molecular diffusion. Based on this concept, the floodwater depth would minimise the rate of $\mathrm{NH}_{3}$ volatilisation by increasing the time required for dissolved ammoniacal-N from the flooded soil surface to reach the floodwater surface, prior to volatilisation. This concept may hold in laboratory experiments, but under field conditions, mixing of floodwater may occur either by vertical convection due to heat from ambient temperatures (Leuning et al., 1984, Hayashi et al., 2008), or water flow through the cracks in the soil or bunds (Freney et al., 1983).

The actual state of the floodwater in flooded rice systems, thus as a well-mixed compartment or a compartment with several vertically segmented layers, is not known. This knowledge is crucial to selecting which model has adequate structure for estimating net $\mathrm{NH}_{3}$ loss, and to address if increasing floodwater depth would reduce the net $\mathrm{NH}_{3}$ loss.

Wind speed must be conceptualised in models for reliable estimate of the net $\mathrm{NH}_{3}$ loss. In models that approximated $\mathrm{NH}_{3}$ loss by first-order kinetics with a constant parameter (Rao et al., 1984, Chowdary et al., 2004, Antonopoulos, 2010), the effect of wind speed on $\mathrm{NH}_{3}$ volatilisation is implicitly captured by the calibrated constant parameter. Therefore, a timevarying rate coefficient of $\mathrm{NH}_{3}$ volatilisation is required in order to include wind speed that varies with time and locations (Chapter 3 and Chapter 4). Meanwhile, Gaydon et al. (2012a) showed that APSIM-Oryza is able to estimate total $\mathrm{N}$ loss $\left(\mathrm{NH}_{3}\right.$ volatilisation and denitrification) in fertilised and flooded rice systems fairly well in experimental plots that received different $\mathrm{N}$ treatments. Further investigation revealed that the empirical equation used to estimate the net $\mathrm{NH}_{3}$ volatilisation in APSIM-Oryza is sensitive to the time-varying pan evaporation rate. The effect of wind speed $\mathrm{NH}_{3}$ volatilisation before panicle initiation is well approximated by the pan evaporation rate. This advantage of APSIM-Oryza did not stand out in Chapter 2 and would have been revealed in the co-validation step in Chapter 3 if the pan evaporation rate was selected as one of the study variables.

In the modelling studies presented in this thesis, the net $\mathrm{NH}_{3}$ loss is assumed only through $\mathrm{NH}_{3}$ volatilisation from the floodwater surface. However, other studies have indicated that a crop can also be a sink and a source of atmospheric $\mathrm{NH}_{3}$ (Section 1.6, Chapter 1). To the best of our knowledge, there is only one study that attempted to infer the sinks and sources of $\mathrm{NH}_{3}$ in fertilised and flooded rice systems. Hayashi et al. (2008) suggested that $70 \%(3.01 \mathrm{~kg} \mathrm{~N}$ 
$\mathrm{ha}^{-1}$ ) of the net $\mathrm{NH}_{3}$ loss occurred through a stomatal pathway and only $30 \%\left(1.29 \mathrm{~kg} \mathrm{~N} \mathrm{ha}^{-1}\right)$ volatilised from the floodwater surface following application of $10 \mathrm{~kg}$ urea- $\mathrm{N} \mathrm{ha}^{-1}$ on 66 days after transplanting (DAT). However, following application of $10 \mathrm{~kg}$ urea-N ha ${ }^{-1}$ on 119 DAT, they reported that the net $\mathrm{NH}_{3}$ loss from the system was negligible and the rice leaves became a sink for $\mathrm{NH}_{3}$.

At an early rice crop growth stage, the crop canopy is sparse. Thus, $\mathrm{NH}_{3}$ in the surrounding air within the canopy may be transported by the wind to the atmospheric layer above the crop canopy. This process may prevent build-up of $\mathrm{NH}_{3}$ concentrations in the air within the canopy, and, therefore, may be conducive to $\mathrm{NH}_{3}$ emission through a stomatal pathway. At a later growth stage, the crop canopy becomes dense. Therefore, $\mathrm{NH}_{3}$ concentrations in the air within the canopy may be protected from being transported to the air. Consequently, build-up of $\mathrm{NH}_{3}$ concentration in the air within the canopy may occur, as observed by Harper et al. (2000) in a fertilised corn field. Subsequently, the $\mathrm{NH}_{3}$ concentrations within the crop canopy may exceed the concentrations of $\mathrm{NH}_{3}$ in the leaves. Under this condition, it is likely that the leaves become a sink of $\mathrm{NH}_{3}$.

However, several studies in crop systems other than rice suggested $\mathrm{NH}_{3}$ emission through non-stomatal pathways (Section 1.6, Chapter 1), and, thus, contradict with results reported by Hayashi et al. (2008). $\mathrm{NH}_{3}$ cycling within crop canopies appears to depend simultaneously on structure and density of the crop canopy (Denmead et al., 2008), opening of stomata affected by crop water status (Chaves et al., 2016), rate and timing of $\mathrm{N}$ fertiliser application (Table 2, Chapter 1), floodwater or soil properties which may affect availability of $\mathrm{NH}_{3}$ susceptible to volatilisation (Chen et al., 2015), and the whole-plant $\mathrm{N}$ dynamics, in particular rate of $\mathrm{N}$ uptake, level of glutamine synthetase activity that affects assimilation of $\mathrm{NH}_{4}{ }^{+}$by the crop that was shown to vary among cultivars, and the $\mathrm{N}$ remobilisation from senescing leaves to growing leaves or grain which may differ among plants (Kumagai et al., 2011, Yoneyama et al., 2016). All these factors may contribute to the contradicting observations in fertilised and flooded rice systems compared to the other crop systems, and may also affect the ratio between $\mathrm{NH}_{3}$ volatilisation from the floodwater and $\mathrm{NH}_{3}$ gas exchange through the stomatal pathway reported by Hayashi et al. (2008).

Models that detailed the soil $\mathrm{N}$ processes and $\mathrm{N}$ uptake by rice crop are presented in Chapter 2. However, calibration of soil $\mathrm{N}$ parameters is hindered by scarcity of soil $\mathrm{N}$ data as reported 
by Gaydon et al. (2012a), Katayanagi et al. (2013) and Liang et al. (2014). Cassman et al. (2002) have already stated that realistic prediction of soil $\mathrm{N}$ dynamics using models is difficult due to the complexity of the interactive soil $\mathrm{N}$ processes. Therefore, as an alternative to the existing concepts, a total $\mathrm{N}$ sink term was proposed as a result of iterative modelling loops in order to avoid detailed modelling of soil $\mathrm{N}$ processes for cases with scarce soil $\mathrm{N}$ data, is a simple way to approximate the effect of all $\mathrm{N}$ sink including the $\mathrm{N}$ uptake by a rice crop (Chapter 4). This simple concept can be incorporated into the model of Jayaweera and Mikkelsen (1990a) which is currently limited to application in flooded soil systems without $\mathrm{N}$ sink, except for $\mathrm{NH}_{3}$ volatilisation. One can argue that the simple concept is inadequate and each soil $\mathrm{N}$ process is indeed complex (Nieder et al., 2011, Van der Laan et al., 2014, Vereecken et al., 2016), but Cartwright et al. (2016) stated that increasing model complexity which superficially appears more credible may eventually lead to a type of black box model.

Urea hydrolysis pre-determines the amount of total ammoniacal-N that is available in the floodwater, and subsequently susceptible to $\mathrm{NH}_{3}$ volatilisation. Many modellers assume firstorder urea hydrolysis (Singh and Kirk, 1993, Chowdary et al., 2004, Gaydon et al., 2012b), but from model and data integration, we learnt that a system with low urease activity is better approximated by two first-order reactions in series. The disappearance of urea- $\mathrm{N}$ in the floodwater can be explained by the first-step first order reaction, but there appear to be several days delay in build-up of total ammoniacal-N, which can be explained by assuming the second-step first order reaction (Chapter 4). The model proposed in Chapter $\mathbf{4}$ was only tested with two observational data sets in the Philippines, and, therefore, it may be possible that the delay in urea hydrolysis is site-specific.

In Chapter 3, co-validation was performed between a first-order urea hydrolysis term with a constant rate coefficient and a time-varying rate coefficient. The time-varying rate coefficient is a function of three factors: leaf area index, organic $\mathrm{C}$ percentage, and floodwater temperature. However, in Chapter 5, the feasible parameter $K_{h}$ estimated from three sets of observational data ranged from about 0.7 to about 1.0 day $^{-1}\left(0.05\right.$ to 0.08 two-hour $\left.^{-1}\right)$. The wide range of feasible $K_{h}$ values indicates that it is not feasible to accurately estimate the $K_{h}$ per time instant due to uncertainty in the observations. Thus, first-order kinetics with a constant rate coefficient is adequate to approximate the hydrolysis of urea in the floodwater. 


\subsection{Co-validation of models}

Li et al. (2015) validated DNDC-Rice, CERES-Rice and APSIM-Oryza with respect to their common output (i.e., rice grain production) along with another 10 crop growth and development models (both generic and specific for rice crop), and found that none of these models consistently provided reliable predictions of rice grain production across four sites with different climatic conditions, management practices, rice cultivars and years. Confalonieri et al. (2016) further showed that differences in model structures could result in similar prediction, while similar structures could lead to large differences in model outputs.

This unexpected result is probably because the models are relatively complex, leading to interaction within sub-components of the models, where the output of one process may be an input to multiple process, and subsequently affect the overall model behaviours. Full model co-validation may indeed reveal the interactions of subcomponents of models each with different concepts, but the effect of different modelling concepts of a specific process can only be revealed if co-validated at single process level. This drawback of full model covalidation was already hypothesised in research question 3 in Chapter 1.

Therefore, in Chapter 3, in order to understand differences in modelling concepts for a specific process, co-validation was conducted at single process level: urea hydrolysis, $\mathrm{NH}_{3}$ volatilisation, and floodwater $\mathrm{pH}$. Chapter 3 revealed how different modelling concepts affect the trends and magnitudes of common model-outputs. Very recently, Camargo et al. (2016) presented a similar approach to study the simulation of water uptake in six crop models.

\subsection{Estimation of unknown parameters}

Uncertainty in the model structure is not the only source of prediction uncertainty, uncertainty in the parameters is another source. In a crop modelling context, Nissanka et al. (2015) state that it is still common to fit parameter against data through trial-and-error, possibly either due to the technical difficulty in coupling models to statistical software or the importance of parameter uncertainty is not generally recognised. See for instance, the supplementary materials in Li et al. (2015), where parameters in several crop models were gradually varied to fit the data sets. The trial-and-error approach only emphasises on the goodness of fit and does not characterise the uncertainty in the parameters. 
Estimation of parameters in crop models (including the $\mathrm{N}$ dynamics component) is challenging. The characterisation of parameter uncertainty using the classical methods requires assumptions on mean, variances, and/or probability density function of the model errors, which cannot be satisfactorily tested with small number of observations (Keesman and Van Straten, 1990). Furthermore, the model errors for the different model outputs may be correlated, and, thus, a method like the ordinary least-squares is not appropriate. Additionally, measurement error is also present in the observations. Thus, there is a need for a framework that simultaneously considers prediction uncertainty as a result of different sources, namely uncertainty in model structure, parameters, and observations that are used as model inputs and calibration data sets (Confalonieri et al., 2016).

In Chapter 5, the sampling-based set-membership approach with soft-bound is presented as an alternative method to estimate parameters in potentially over-parameterised model from poor quality data sets. The approach allows simultaneous consideration of the different sources of uncertainty affecting model prediction, such as uncertainty in the model structure, parameters, and observations. Wallach et al. (2016) proposed a two-step ordinary leastsquares procedure to transform the observations so that model errors become uncorrelated and homoscedastic. However, the set-membership approach offers the advantage of avoiding any assumptions beyond the model structure and the model-output-error. Confalonieri et al. (2016) generated a number of possible series of observations from the means and standard deviations of the original observations in order to account for the uncertainty in the observations. This aspect is directly considered in the set-membership approach through the pre-defined error-bounds in Chapter 5. Furthermore, in Chapter 5, it is shown that the estimation of parameters using optimisation algorithm such as the Nelder-Mead simplex and Trust-reflective region does not always converge, as demonstrated for the proposed model. The set-membership approach does not require use of built-in optimisation algorithms. See Chapter 5 for a detailed discussion on the advantages of the set-membership approach compared to the non-linear least-squares methods in estimating parameters from poor quality data sets. In summary, the sampling-based set-membership approach is a valuable method for estimating parameters from poor quality data sets.

\subsection{Research outlooks}

Models may not stay validated forever, as process-based models are derived based on 
generalised assumptions, whereas empirical models typically have a pre-determined working range. Instead of fully relying on positive outcomes from validation of models with observational data sets, understanding the limitations of the modelling concepts, as demonstrated in this thesis, is important as it is not the model that provides users the answers, but it is the modeller that implicitly dictates the outputs of the models, by defining the underlying concept and structure. The approach proposed in this thesis, from understanding models and structures of existing models, to co-validation at single process level followed by model restructuring, calibrating and validating, can also be extended to other $\mathrm{N}$ processes, such as soil organic matter dynamics, or even to other complex and ill-defined systems.

Due to lack of field observations that distinguish between $\mathrm{NH}_{3}$ volatilisation from floodwater surface and $\mathrm{NH}_{3}$ emission through a stomatal pathway (Section 1.7, Chapter 1), detailed modelling of the latter process is not yet possible. Zhou et al. (2016) reported $96 \%$ of observations in China were obtained using the chamber methods, see Table 2 in Chapter 1. The next step is to infer sinks and sources of atmospheric $\mathrm{NH}_{3}$ in fertilised and flooded rice systems by using advanced methods such as the inverse Lagrangian dispersion analysis or application of resistance models (Section 1.7, Chapter 1). Identifying sinks and sources may lead to reassessment of structure adequacy of current $\mathrm{N}$ dynamics models and methods that are recommended for $\mathrm{N}$ management in flooded rice systems.

If $\mathrm{NH}_{3}$ exchange through the stomata pathway is significant, then many existing processbased $\mathrm{N}$ dynamics model developed for flooded rice systems are wrong from the physical science perspective, but still some of these models have functional adequacy for estimating the net $\mathrm{NH}_{3}$ loss (Chapter 2). Unlike the models discussed in Section 6.3, the resistance models allow estimation of bi-directional $\mathrm{NH}_{3}$ gas exchange from multiple sinks and sources (Section 1.7, Chapter 1). The two-layer canopy compensation resistance model (foliage-litter model) presented by Nemitz et al. (2000) or Massad et al. (2010) could be adapted to simulate the $\mathrm{NH}_{3}$ cycling in the flooded rice systems. The litter or soil component in the model should be modified to approximate the $\mathrm{NH}_{3}$ volatilisation from the floodwater surface. However, the challenge lies in the calibration of the parameters in the resistance model. For instance, a constant dimensionless $\mathrm{NH}_{3}$ emission potential $\Gamma$ (Section 1.6, Chapter $\mathbf{1}$ ) is not adequate to account for the effect of diurnal floodwater $\mathrm{pH}$ on $\mathrm{NH}_{3}$ volatilisation from the floodwater surface. Therefore, future research challenges include data acquisition for insights on sinks and sources of $\mathrm{NH}_{3}$ and parameterisation of the resistance models for fertilised and flooded 
rice systems, and conceptualisation of the new insights in existing $\mathrm{N}$ dynamics models, i.e. APSIM-Oryza and CERES-Rice, which are currently used to recommend management practices.

Deep placement of urea super granules at a depth between $0.07 \mathrm{~m}$ and $0.10 \mathrm{~m}$ from the soil surface is recommended in order to reduce $\mathrm{NH}_{3}$ volatilisation from the floodwater surface, but an evaluation of this method was conducted using the chamber methods or the $15-\mathrm{N}$ tracer technique (Craswell et al., 1981, Cao et al., 1984, De Datta et al., 1988, Chien et al., 2009, Liu et al., 2015), and, therefore, is not representative of net $\mathrm{NH}_{3}$ flux in flooded rice systems (Section 1.7 in Chapter 1). If indeed the dominant pathway for atmospheric $\mathrm{NH}_{3}$ is through a stomatal pathway, deep placement may not be able to reduce the net $\mathrm{NH}_{3}$ flux, unless coated or super granule urea or slow release fertiliser is used. Photosynthetic aquatic biomass (PAB) can be a vital source of $\mathrm{C}$ and $\mathrm{N}$ for the next cropping season (Gaydon et al., 2012a). However, presence of $\mathrm{PAB}$ in the floodwater may contribute to $\mathrm{NH}_{3}$ volatilisation as the floodwater $\mathrm{pH}$ may be increased by the $\mathrm{PAB}$ activity. Therefore, a study which infers both sinks and sources of atmospheric $\mathrm{NH}_{3}$ can assess the benefits and drawbacks of PAB presence in the systems.

In Chapter 4, model simulation indicated that wind speed before panicle initiation may significantly affect the net $\mathrm{NH}_{3}$ volatilisation. Suitable hedge plants can be planted on the bund of rice systems as a barrier to wind (Nordstrom and Hotta, 2004, Cornelis and Gabriels, 2005), and hypothetically minimise $\mathrm{NH}_{3}$ volatilisation. This approach requires only a onetime establishment, and therefore, is less laborious. Modelling studies are needed to investigate effects of height and porosity of the hedge plants, and of size and orientation of the rice plot on the wind dynamics within the plot (e.g., Schwartz et al. (1995)). However, it should be noted that reducing $\mathrm{NH}_{3}$ volatilisation does not guarantee minimisation of total $\mathrm{N}$ loss from the systems, as interdependence of $\mathrm{NH}_{3}$ volatilisation and other $\mathrm{N}$ loss pathways are possible (Section 1.5, Chapter 1).

\section{References}

Antonopoulos, V. Z. 2010. Modelling of water and nitrogen balances in the ponded water and soil profile of rice fields in Northern Greece. Agric Water Manag, 98, 321-330

Bouwmeester, R. J. B. \& Vlek, P. L. G. 1981. Rate control of ammonia volatilization from rice paddies. Atmos Environ, 15, 131-140. 
Camargo, G. G. T. \& Kemanian, A. R. 2016. Six crop models differ in their simulation of water uptake. Agric For Meteorol, 220, 116-129.

Cao, Z.-H., De Datta, S. K. \& Fillery, I. R. P. 1984. Nitrogen-15 balance and residual effects of urea-N in wetland rice fields as affected by deep placement techniques. Soil Sci Soc Am J, 48, 203-208.

Cartwright, S. J., Bowgen, K. M., Collop, C., Hyder, K., Nabe-Nielsen, J., Stafford, R., Stillman, R. A., Thorpe, R. B. \& Sibly, R. M. 2016. Communicating complex ecological models to non-scientist end users. Ecol Model, 338, 51-59.

Cassman, K. G., Dobermann, A. \& Walters, D. T. 2002. Agroecosystems, nitrogen-use efficiency and nitrogen management. AMBIO: J Hum Environ, 31, 132-140.

Chaves, M. M., Costa, J. M., Zarrouk, O., Pinheiro, C., Lopes, C. M. \& Pereira, J. S. 2016. Controlling stomatal aperture in semi-arid regions-The dilemma of saving water or being cool? Plant Sci, 251, 54-64.

Chen, A., Lei, B., Hu, W., Lu, Y., Mao, Y., Duan, Z. \& Shi, Z. 2015. Characteristics of ammonia volatilization on rice grown under different nitrogen application rates and its quantitative predictions in Erhai Lake Watershed, China. Nutr Cycl Agroecosyst, 101, 139-152.

Chien, S. H., Prochnow, L. I. \& Cantarella, H. 2009. Recent developments of fertilizer production and use to improve nutrient efficiency and minimize environmental impacts. Advances in Agronomy. Academic Press.

Chowdary, V. M., Rao, N. H. \& Sarma, P. B. S. 2004. A coupled soil water and nitrogen balance model for flooded rice fields in India. Agric Ecosyst Environ, 103, 425-441.

Confalonieri, R., Bregaglio, S., Adam, M., Ruget, F., Li, T., Hasegawa, T., Yin, X., Zhu, Y., Boote, K., Buis, S., Fumoto, T., Gaydon, D., Lafarge, T., Marcaida, M., Nakagawa, H., Ruane, A. C., Singh, B., Singh, U., Tang, L., Tao, F., Fugice, J., Yoshida, H., Zhang, Z., Wilson, L. T., Baker, J., Yang, Y., Masutomi, Y., Wallach, D., Acutis, M. \& Bouman, B. 2016. A taxonomy-based approach to shed light on the babel of mathematical models for rice simulation. Environ Model Softw, 85, 332-341.

Cornelis, W. M. \& Gabriels, D. 2005. Optimal windbreak design for wind-erosion control. Journal of Arid Environments, 61, 315-332.

Craswell, E. T., De Datta, S. K., Obcemea, W. N. \& Hartantyo, M. 1981. Time and mode of nitrogen fertilizer application to tropical wetland rice. Fert Res, 2, 247-259.

De Datta, S. K., Samson, M. I., Wang, K.-R. \& Buresh, R. J. 1988. Nitrogen use efficiency and nitrogen-15 balances in broadcast-seeded flooded and transplanted rice. Soil Sci Soc Am J, 52, 849-855.

Denmead, O. T., Freney, J. R. \& Dunin, F. X. 2008. Gas exchange between plant canopies and the atmosphere: Case-studies for ammonia. Atmos Environ, 42, 3394-3406.

Fillery, I. R. P., Roger, P. A. \& De Datta, S. K. 1986. Ammonia volatilization from nitrogen sources applied to rice fields: II. Floodwater properties and submerged photosynthetic biomass. Soil Sci Soc Am J, 50, 86-91.

Fillery, I. R. P., Simpson, J. R. \& De Datta, S. K. 1984. Influence of field environment and fertilizer management on ammonia loss from flooded rice. Soil Sci Soc Am J, 48, 914920.

Freney, J. R., Simpson, J. R. \& Denmead, O. T. 1983. Volatilization of ammonia. In: Freney, J. R. \& Simpson, J. R. (eds.) Gaseous loss of nitrogen from plant-soil systems. Dordrecht, The Netherlands: Springer-Science + Business Media, B.V.

Freney, J. R., Trevitt, A. C. F., Muirhead, W. A., Denmead, O. T., Simpson, J. R. \& Obcemea, W. N. 1988. Effect of water depth on ammonia loss from lowland rice. Fert Res, 16, 97-107. 
Gaydon, D. S., Probert, M. E., Buresh, R. J., Meinke, H., Suriadi, A., Dobermann, A., Bouman, B. \& Timsina, J. 2012a. Rice in cropping systems - Modelling transition between flooded and non-flooded soil environments. Eur J Agron, 39, 9-24.

Gaydon, D. S., Probert, M. E., Buresh, R. J., Meinke, H. \& Timsina, J. 2012b. Modelling the role of algae in rice crop nutrition and soil organic carbon maintenance. Eur J Agron, $39,35-43$.

Harper, L. A., Denmead, O. T. \& Sharpe, R. R. 2000. Identifying sources and sinks of scalars in a corn canopy with inverse Lagrangian dispersion analysis: II. Ammonia. Agric For Meteorol, 104, 75-83.

Hayashi, K., Nishimura, S. \& Yagi, K. 2006. Ammonia volatilization from the surface of a Japanese paddy field during rice cultivation Soil Sci Plant Nutr, 52, 545-555.

Hayashi, K., Nishimura, S. \& Yagi, K. 2008. Ammonia volatilization from a paddy field following applications of urea: Rice plants are both an absorber and an emitter for atmospheric ammonia. Sci Total Environ, 390, 485-494.

Jayaweera, G. R. \& Mikkelsen, D. S. 1990a. Ammonia volatilization from flooded soil systems: A computer model. I. Theoretical aspects. Soil Sci Soc Am J, 54, 1447-1455.

Jayaweera, G. R. \& Mikkelsen, D. S. 1990b. Ammonia volatilization from flooded soil systems: A computer model. II. Theory and model results. Soil Sci Soc Am J, 54, 1456-1462.

Katayanagi, N., Ono, K., Fumoto, T., Mano, M., Miyata, A. \& Hayashi, K. 2013. Validation of the DNDC-Rice model to discover problems in evaluating the nitrogen balance at a paddy-field scale for single-cropping of rice. Nutr Cycl Agroecosyst, 95, 255-268.

Keesman, K. J. \& Van Straten, G. 1990. Set membership approach to identification and prediction of lake eutrophication. Water Resour Res, 26, 2643-2652.

Kumagai, E., Araki, T. \& Ueno, O. 2011. Ammonia emission from leaves of different rice (Oryza sativa L.) cultivars. Plant Prod Sci, 14, 249-253.

Leuning, R., Denmead, O. T., Simpson, J. R. \& Freney, J. R. 1984. Processes of ammonia loss from shallow floodwater. Atmos Environ (1967), 18, 1583-1592.

Li, T., Hasegawa, T., Yin, X., Zhu, Y., Boote, K., Adam, M., Bregaglio, S., Buis, S., Confalonieri, R., Fumoto, T., Gaydon, D., Marcaida, M., Nakagawa, H., Oriol, P., Ruane, A. C., Ruget, F., Singh, B., Singh, U., Tang, L., Tao, F., Wilkens, P., Yoshida, H., Zhang, Z. \& Bouman, B. 2015. Uncertainties in predicting rice yield by current crop models under a wide range of climatic conditions. Glob Change Biol, 21, 13281341.

Liang, X., Yuan, J., He, M., Li, H., Liang, L. \& Tian, G. 2014. Modeling the fate of fertilizer $\mathrm{N}$ in paddy rice systems receiving manure and urea. Geoderma, 228-229, 54-61.

Liang, X. Q., Chen, Y. X., Li, H., Tian, G. M., Ni, W. Z., He, M. M. \& Zhang, Z. J. 2007. Modelling transport and fate of nitrogen from urea applied to a near-trench paddy field. Environ Pollut, 150, 313-320.

Liu, T. Q., Fan, D. J., Zhang, X. X., Chen, J., Li, C. F. \& Cao, C. G. 2015. Deep placement of nitrogen fertilizers reduces ammonia volatilization and increases nitrogen utilization efficiency in no-tillage paddy fields in central China. Field Crop Res, 184, 80-90.

Massad, R. S., Nemitz, E. \& Sutton, M. A. 2010. Review and parameterisation of bidirectional ammonia exchange between vegetation and the atmosphere. Atmos Chem Phys, 10, 10359-10386.

Moeller, M. B. \& Vlek, P. L. G. 1982. The chemical dynamics of ammonia volatilization from aqueous solution. Atmos Environ, 16, 709-717.

Nemitz, E., Sutton, M. A., Schjoerring, J. K., Husted, S. \& Paul Wyers, G. 2000. Resistance modelling of ammonia exchange over oilseed rape. Agric For Meteorol, 105, 405-425. 
Nieder, R., Benbi, D. K. \& Scherer, H. W. 2011. Fixation and defixation of ammonium in soils: A review. Biol Fertil Soils, 47, 1-14

Nissanka, S. P., Karunaratne, A. S., Perera, R., Weerakoon, W. M. W., Thorburn, P. J. \& Wallach, D. 2015. Calibration of the phenology sub-model of APSIM-Oryza: Going beyond goodness of fit. Environ Model Softw, 70, 128-137.

Nordstrom, K. F. \& Hotta, S. 2004. Wind erosion from cropland in the USA: A review of problems, solutions and prospects. Geoderma, 121, 157-167.

Rao, P. S. C., Jessup, R. E. \& Reddy, K. R. 1984. Simulation of nitrogen dynamics in flooded soils. Soil Sci, 138, 54-62.

Schwartz, R. C., Fryrear, D. W., Harris, B. L., Bilbro, J. D. \& Juo, A. S. R. 1995. Mean flow and shear stress distributions as influenced by vegetative windbreak structure. Agric For Meteorol, 75, 1-22.

Singh, R. \& Kirk, G. J. D. 1993. A model for predicting the fate of nitrogen fertilizer in lowland ricefields. I. Theory. J Soil Sci, 44, 271-283.

Van Der Laan, M., Annandale, J. G., Bristow, K. L., Stirzaker, R. J., Preez, C. C. D. \& Thorburn, P. J. 2014. Modelling nitrogen leaching: Are we getting the right answer for the right reason? Agric Water Manag, 133, 74-80.

Vereecken, H., Schnepf, A., Hopmans, J. W., Javaux, M., Or, D., Roose, T., Vanderborght, J., Young, M. H., Amelung, W., Aitkenhead, M., Allison, S. D., Assouline, S., Baveye, P., Berli, M., Brüggemann, N., Finke, P., Flury, M., Gaiser, T., Govers, G., Ghezzehei, T., Hallett, P., Hendricks Franssen, H. J., Heppell, J., Horn, R., Huisman, J. A., Jacques, D., Jonard, F., Kollet, S., Lafolie, F., Lamorski, K., Leitner, D., Mcbratney, A., Minasny, B., Montzka, C., Nowak, W., Pachepsky, Y., Padarian, J., Romano, N., Roth, K., Rothfuss, Y., Rowe, E. C., Schwen, A., Šimůnek, J., Tiktak, A., Van Dam, J., Van Der Zee, S. E. a. T. M., Vogel, H. J., Vrugt, J. A., Wöhling, T. \& Young, I. M. 2016. Modeling soil processes: Review, key challenges, and new perspectives. Vadose Zone Journal, 15.

Wallach, D., Nissanka, S. P., Karunaratne, A. S., Weerakoon, W. M. W., Thorburn, P. J., Boote, K. J. \& Jones, J. W. 2016. Accounting for both parameter and model structure uncertainty in crop model predictions of phenology: A case study on rice. Eur $J$ Agron.

Win, K. T., Toyota, K., Motobayashi, T. \& Hosomi, M. 2009. Suppression of ammonia volatilization from a paddy soil fertilized with anaerobically digested cattle slurry by wood vinegar application and floodwater management. Soil Sci Plant Nutr, 55, 190202.

Yoneyama, T., Tanno, F., Tatsumi, J. \& Mae, T. 2016. Whole-plant dynamic system of nitrogen use for vegetative growth and grain filling in rice plants (Oryza sativa L.) as revealed through the production of 350 grains from a germinated seed over 150 days: A review and synthesis. Front Plant Sci, 7.

Zhou, F., Ciais, P., Hayashi, K., Galloway, J., Kim, D.-G., Yang, C., Li, S., Liu, B., Shang, Z. \& Gao, S. 2016. Re-estimating $\mathrm{NH}_{3}$ emissions from Chinese cropland by a new nonlinear model. Environ Sci Technol, 50, 564-572. 



\section{Summary}

In flooded rice systems that are broadcast with urea and not followed by incorporation of the urea into the soil, significant amounts of nitrogen $(\mathrm{N})$ may be lost to the atmosphere in the form of ammonia $\left(\mathrm{NH}_{3}\right)$. The $\mathrm{NH}_{3}$ loss to the atmosphere represents monetary loss and has negative effects on the environment. Currently, many mathematical models are available for predicting $\mathrm{NH}_{3}$ volatilisation from the floodwater in fertilised and flooded rice systems. These models are used to estimate the seasonal $\mathrm{N}$ balances as alternatives to tedious field and lab experiments, for scientific insights into the $\mathrm{N}$ dynamics of fertilised and flooded rice systems or for scenario studies in order to make recommendations on management practices. However, these models have varying complexities with regards to describing the process of $\mathrm{NH}_{3}$ volatilisation and the overall $\mathrm{N}$ dynamics in the systems. Therefore, the main objective of this thesis is to determine an appropriate process-based model with corresponding uncertainty characterisation for estimating $\mathrm{NH}_{3}$ volatilisation in fertilised and flooded rice systems. In this thesis, evaluation of model structure adequacy is discussed under a major assumption that the net $\mathrm{NH}_{3}$ loss occurs only from the floodwater surface.

In Chapter 2, an overview on the modelling concepts and the performance of 14 models developed to simulate $\mathrm{N}$ dynamics in flooded soil systems is given. The 14 models were NFLOOD v.1 (published by Rao et al.), NFLOOD v.2 (published by Reddy et al.), J-M's (published by Jayaweera and Mikkelsen), S-K's (published by Singh and Kirk), CERES-Rice (published by Godwin and Singh), Chowdary's (published by Chowdary et al.), Nakasone's (published by Nakasone et al.), Yoshinaga's (published by Yoshinaga et al.), DNDC-Rice (published by Li et al.), K-K's (published by Kirk and Kronzucker), Liang's (published by Liang et al.), RIWER (published by Jing et al.), RICEWNB (published by Antonopoulos), and APSIM-Oryza (published by Gaydon et al.). The overview revealed lack of co-validation among these models. Thus, it remained vague whether the differences in modelling concepts would result in substantial differences in the behaviour of the models, which led to Chapter 3 .

In Chapter 3, mathematical models of urea hydrolysis, $\mathrm{NH}_{3}$ volatilisation, and floodwater $\mathrm{pH}$ were extracted from the full models and co-validated at single process level with the aim to investigate equifinality between simple and complex process models. Equifinality is defined as the capability of mathematical models to produce similar model-output responses. Results showed that, despite detailing of the time-varying rate coefficient of urea hydrolysis in 


\section{Summary}

APSIM-Oryza, rates of urea hydrolysis can be approximated by a first-order kinetics model with constant rate coefficient. The intricate Jayaweera and Mikkelsen (1993a) model, which describes $\mathrm{NH}_{3}$ volatilisation based on the two-film theory, can be approximated by the simpler NFLOOD v.1 model, by adjusting the a priori given constant rate coefficient in NFLOOD v.1. The diurnal trend of $\mathrm{NH}_{3}$ volatilisation typically observed in fertilised and flooded rice systems, however, could not be simulated by a first-order kinetics model with a constant rate coefficient, unless the effect of $\mathrm{NH}_{4}{ }^{+}$and $\mathrm{NH}_{3}$ partitioning in the floodwater was conceptualised. The modelling concepts of floodwater $\mathrm{pH}$ in APSIM-Oryza and in the model of Singh and Kirk led to significantly different outputs.

In Chapter 4, a new process-based model for predicting the $\mathrm{NH}_{3}$ volatilisation in fertilised and flooded rice systems, and of a complexity that matches the scarcity of soil $\mathrm{N}$ data, is presented. Based on model and data integration, urea hydrolysis in the floodwater was approximated by two first-order kinetics, and the uptake of $\mathrm{N}$ by rice crop was lumped with other $\mathrm{N}$ sinks and approximated by a sigmoid curve in the proposed model. The model was falsified by some data sets, but was also in good agreement with other data sets. Inadequate model structure may have led to the falsification of the model, but uncertainty in observations and in parameters could also have led to the falsification. In this chapter, the characterisation of the uncertainty in the parameter estimates was still lacking as the parameter estimates were calibrated using a trial-and-error approach.

In Chapter 5, uncertainty in the parameter estimates in the model proposed in Chapter 4 were characterised using the set-membership parameter estimation approach with soft-errorbounds. Results showed that the set-membership approach is efficient in retrieving feasible parameter-vectors compared with non-linear least-squares methods. In fact, the non-linear least-squares methods do not always converge and often led to local minima. The set of feasible parameter-vectors allows the formation of a dispersion matrix of which the eigenvalue decomposition reflects the parameter sensitivity in a region.

In Chapter 6, perspectives of modelling to estimate $\mathrm{NH}_{3}$ volatilisation in fertilised and flooded rice systems are given. The systematic and integrated approach in this thesis revealed advantages and limitations of different modelling concepts and structures for the estimation of $\mathrm{NH}_{3}$ volatilisation in fertilised and flooded rice systems. Additionally, future research possibilities are discussed. 


\section{Glossary}

A priori knowledge

Ill-defined system

Parameter

Unidentifiable parameter
Knowledge that is gained through deduction, and not through empirical evidence (Keesman, 2011).

Size and complexity of the system prevent a full understanding a priori and when planned experimentation is difficult, if not impossible, and observational data sets are often small (Young et al., 1976).

Rate coefficient in a model that is estimated from observational data sets.

A parameter that does not have a unique value in a parameter estimation calibration step (Keesman, 2011). 



\section{Acknowledgements}

First and foremost, my heartfelt thanks go to my promotor, Prof. Paul Struik, and my copromotors, Dr. Karel Keesman and Prof. Pauzi Zakaria, whom had provided me with valuable guidance and suggestions, and at the same time allowed me to express my opinions and worked independently throughout my $\mathrm{PhD}$. As a $\mathrm{PhD}$ student enrolled in the Sandwich $\mathrm{PhD}$ programme between the Netherlands and Malaysia, communication can be a challenge due to the distance and limited time during my short stay in Wageningen. However, I am fortunate to have supervisors who were always willing to make time for me. Thank you for committing your time to all our meetings, for always responding to my e-mails promptly, and patiently and ever so willingly reviewing my thesis multiple times. To Karel, I first met you in 2006 for my MSc programme, and I am grateful that you were so patient with me despite my lack of knowledge in using Matlab at that time, and also for your kindness, for instance, when you volunteered to cycle up the 'hill' to Biotechnion when I was too tired to cycle to your office for our weekly discussion. My working experience with all of you enhanced my research skills and inspired me to be a better person overall.

I am also indebted to Dr. Donald Gaydon and Dr. Qi Jing for their valuable suggestions on Chapter 2, and Nicole Wolffensperger, the secretary of the Centre for Crop Systems Analysis, for assisting me in editing and printing my thesis.

My appreciations also go to all my colleagues at the Biobased Chemistry and Technology Group. In particular, I would like to thank Prof. Harry Bitter for allowing me to work at the department, Prof. Gerrit van Straten who was my promotor at the initial stage of my study, Hans Cappon for the suggestion he made in reference to Chapter 2 of this thesis, and Gerard van Willigenburg for assisting me with the parameter estimation toolbox. Special thanks also go to Gerda Bos and Marja Portengen for their administrative assistance. To my wonderful paranymphs, Elvira and Sanne, thank you for helping me to print the first draft of my thesis and to prepare for the thesis defence. Ellen and Farnoosh, I will miss your warm company. Piet and Daniel, I enjoyed our discussion on global subjects. Andrada, thank you for the memorable trip to your vegetable garden. Jimmy, Emmanuel, Yu Jiang, Rani, Jurjen, Luana, Cesar, Susan, and Elinor thanks for the good times.

I am also thankful to all the staff at the Department of Agriculture Malaysia and the Faculty of Agriculture, Universiti Putra Malaysia, for their technical assistance. Special thanks to Mr. 
Khairul, Dr. Husni, Prof. Zulkifli, Prof. Khanif, and Mr. Azali. My gratitude also goes to Wak Misran and his wife, the owners of Plot 3153, where I conducted my field experiments.

My appreciations also go to everyone at the Department of Biological and Agricultural Engineering, Universiti Putra Malaysia. In particular, I thank Mr. Azwan, Hafiz, Sabri, Hamid, Tajul, and the late Mr. Soaid for helping out with laborious experimental work, Dr. Rashid for introducing me the tutorship programme, and Dr. Azmi Dato' Yahya, Dr. Aimrun, Dr. Samsuzana, Dr. Khairunniza, and Dr. Hasfalina for their unwavering supports. Dyna J, Sharence, and Anas, thanks for the team work.

Rozaini, Suryani, Aizati, Naim, Fatimah, Haslinda, Melissa, Izan, Fariza, Siew Ling, Loo Wee, and Freddy, thank you for the laughters and tears that we shared together. To Huda R. and Aira, your courage in navigating through the challenges in your $\mathrm{PhD}$ journeys inspired me to keep on going, and I would like to wish both of you the same success. Nurashekin, Sahida, Amelia, Juliana, Suhani and Masitah, thank you for staying in touch through time and distance. To all Malaysians in Wageningen, Amsterdam, Groningen, Leiden, and Rotterdam, thank you for helping me with the logistics as I frequently had to travel between Wageningen and Kajang, plus for all our social gatherings. Special thanks to Kak Mai and Abang Fadzli, Khalilah and Asyraf, Nozie and Razak, Yani and Due, Tihah and Aidil, Lini and Zul, Azie, Kak Hamimah and Uncle Amin, Uncle Alan and Tony, Uncle Joe, Ching and Sabrina.

To my significant other, Asyraf, who tolerated cancellation of plans, comforted me when I felt down, and allowed me to be as ambitious as I wanted; I am grateful for your support that to this day continues exponentially! My deepest gratitude goes to my beloved parents, Zubaidah and Khairudin, for the sacrifices they made, and their unconditional love and solid supports. To my ever supportive brothers, Najmi and Mahmud, I am grateful for the honest advice and humour over the years. To all of my family members, especially Khanisah and Daud, I am thankful for the love and encouragement.

To those of you who I did not specifically named, I also give my thanks for moving me towards my goal.

Nurulhuda Khairudin

December 2016, Serdang 


\begin{abstract}
About the author
Nurulhuda Khairudin was born on September $23^{\text {rd }}$, 1982, in Kajang, Malaysia. She received her bachelor degree in Biological and Agricultural Engineering at Universiti Putra Malaysia in 2006. In January 2007, she was granted a SLAB-scholarship by the Ministry of Higher Education (MOHE), Malaysia, to pursue her MSc degree in Agricultural and Bioresource Engineering at the Systems and Control Group, Wageningen University, the Netherlands. After completion of her MSc degree, she was granted a SLAI-scholarship by MOHE to

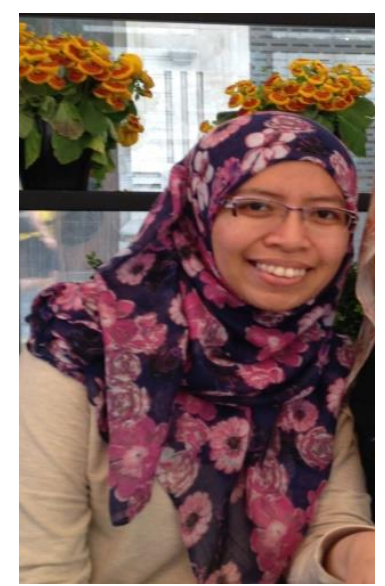
carry out her $\mathrm{PhD}$ in the same research group, which is now known as the Biobased Chemistry and Technology at Wageningen University. Since the year 2007, she works at Universiti Putra Malaysia, as a tutor, and she plans to continue research and teaching activities at the university after the completion of her $\mathrm{PhD}$.
\end{abstract}





\section{List of publications}

1. K., Nurulhuda, P.C., Struik, and K.J. Keesman (2017). Set-membership estimation from poor quality data sets: Modelling ammonia volatilisation in flooded rice systems. Environ Model Softw, 88, pp. 138-150.

2. K., Nurulhuda, P.C., Struik, and K.J. Keesman (2015). Set-membership identification of an agro-ecosystem from a small data set: The case of ammonia volatilisation in a flooded rice field. IFAC-PapersOnLine, 48 (1), pp. 580-585. (The paper was presented at 8th Vienna International Conference on Mathematical Modelling).

3. N., Khairudin, P.C., Struik, and K.J. Keesman (2014). Modelling of ammonia volatilisation in flooded rice fields: The modified Jayaweera-Mikkelsen model. In: C. M. d. S., Cordovil (Ed.). In: Proceedings of the 18th Nitrogen Workshop - The Nitrogen Challenge: Building a Blueprint for Nitrogen Use Efficiency and Food Security. 30 June - 3 July, Lisboa, pp. 447. 



\section{SENSE}

Netherlands Research School for the

Socio-Economic and Natural Sciences of the Environment

\section{I P L O M A}

For specialised PhD training

The Netherlands Research School for the Socio-Economic and Natural Sciences of the Environment (SENSE) declares that

\section{Nurulhuda Binti Khairudin}

born on 23 September 1982 in Kajang, Malaysia

has successfully fulfilled all requirements of the Educational Programme of SENSE.

Wageningen, 29 March 2016

the Chairman of the SENSE board

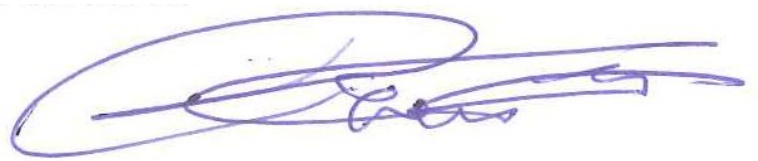

Prof. dr. Huub Rijnaarts the SENSE Director of Education

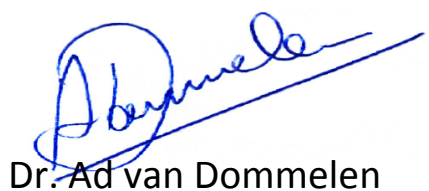

The SENSE Research School has been accredited by the Royal Netherlands Academy of Arts and Sciences (KNAW)

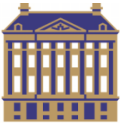

$\begin{array}{llllllllllllllllllllll}K & O & N & I & N & K & L & I & J & K & E & N & E & D & E & R & L & A & N & D & S & E\end{array}$

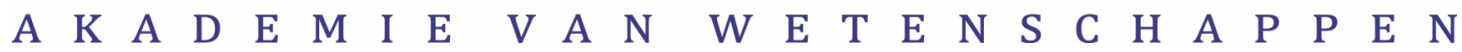




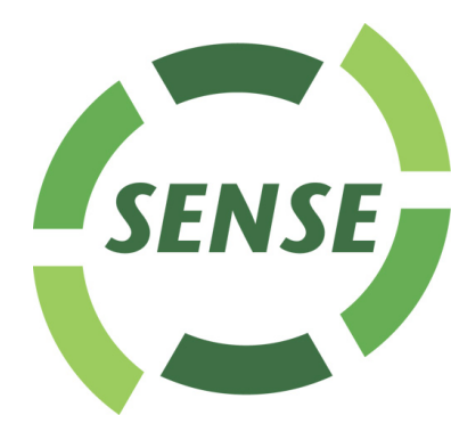

The SENSE Research School declares that Ms Nurulhuda Khairudin has successfully fulfilled all requirements of the Educational PhD Programme of SENSE with a work load of $34.1 \mathrm{EC}$, including the following activities:

\section{$\underline{\text { SENSE PhD Courses }}$}

- Environmental Research in Context (2011)

- Research in Context Activity: International collaboration for writing review paper 'Modelling nitrogen dynamics in floodwater and soil of flooded rice systems: A review' (2014)

\section{Other PhD and Advanced MSc Courses}

o Scientific Writing, Wageningen University (2011)

- Advanced Water Treatment and Re-Use, Wageningen University (2011)

- Information Literacy and EndNote for PhD, Wageningen University (2011)

o Soil-Plant-Microbe Interactions, Universiti Putra Malaysia (2012)

- Analytical Techniques in Environmental Sciences, Universiti Putra Malaysia (2012)

- Techniques for Writing and Presenting a Scientific Paper, Wageningen University (2014)

o Uncertainty Modelling and Analysis, Wageningen University (2015)

\section{Management and Didactic Skills Training}

- Supervising two BSc students with thesis entitled 'Determination of nitrate concentration in soil solution after fertilisation a in flooded rice fields' (2012) and 'Determination of ammonium in soil solution after fertilisation at Sawah Sempadan' (2012)

\section{Oral Presentations}

- Set-membership identification of an agro-ecosystem from a small data set: The case of ammonia volatilisation in a flooded rice field. $8^{\text {th }}$ Vienna International Conference on Mathematical Modelling - MATHMOD 2015, 18-20 February 2015, Vienna, Austria

\section{SENSE Coordinator PhD Education}




\section{Funding}

This research described in this thesis was financially supported by Skim Latihan Akademik IPTA (SLAI) from Ministry of Higher Education Malaysia, grant number KPT(BS)820923105374

Photo and cover design by Nurulhuda Khairudin

Printed by GVO printers \& designers B.V., Ede, the Netherlands 
